\title{
Impact of Adoption of Sustainable Supply Chain Management Practices on a Firm's Performance
}

by

\author{
Inder Jit Singh Mann
}

A thesis submitted to the Faculty of Graduate and Postdoctoral Affairs in partial fulfillment of the requirements for the degree of

Doctor of Philosophy
in

Management

Supervisor Prof. Vinod Kumar

Co-Supervisor Prof. Uma Kumar

Carleton University

Ottawa, Ontario

(C) 2018

Inder Jit Singh Mann 


\begin{abstract}
Increasing awareness of the importance of ecological and social aspects of effects of business operations has led to a growing interest in sustainability. To this end, many firms are adopting supply chain management practices that are expected to foster sustainability along their supply chains. This research studies the effect of drivers on adoption of sustainable supply chain management (SSCM) practices and impact of this adoption on the performance of a firm. Effect of size on the latter impact is also studied. For this, we follow Elkington's $(1997,1999,2006)$ triple bottom line model of a firm's sustainability comprising of economic, environmental and social aspects. After an exhaustive literature review, the hypotheses proposed in this study were tested by an empirical study. Survey data was gathered and analyzed using multiple regression analysis and structural equation modeling. The results of this study provide substantial insights into the effects of SSCM practices and their relation to firm performance.
\end{abstract}




\section{Acknowledgements}

Era. noun $\backslash$ 'er-ə, 'e-rə, 'ir-ə \a : A long and distinct period of history with a particular feature or characteristic. $\mathrm{b}$ : A stage in development (as of a person or thing).

Epoch. noun \'e-pək, 'e-, päk \An extended period of time usually characterized by a distinctive development or by a memorable series of events.

If we were to measure a lifetime in events, a significant one in my life is represented by the document that lies beneath this page. The completion of this degree has perhaps taken a bit longer than it should have. At the end of this era, I want to take this opportunity to thank the people in my life who have had patience to rival saints.

I would like to thank my supervisor, Dr. Vinod Kumar, whose constant guidance and efforts made this a reality despite his busy schedule.

I would like to extend my gratitude to a very diligent committee, Dr. Uma Kumar, Dr. David Cray and Dr. Alan Cai; a special thank you to Dr. Balbinder Deo.

With eternal gratitude to my parents, and with thanks to my daughter and son, I would like to dedicate this thesis to my wife. 


\section{Table of Contents}

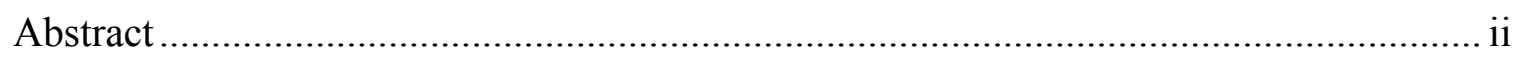

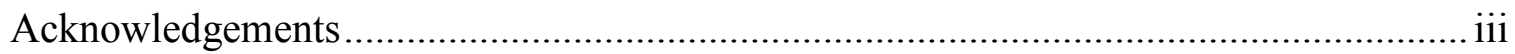

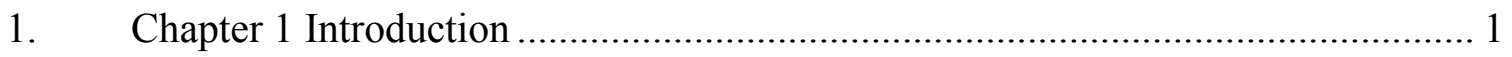

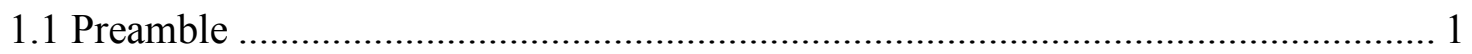

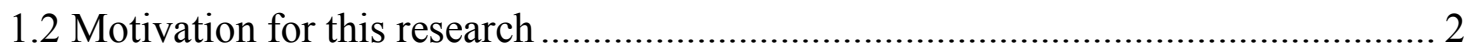

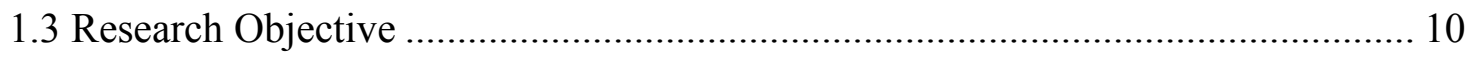

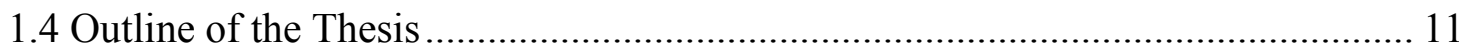

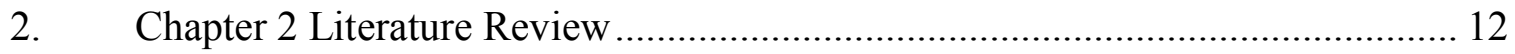

2.0 Etymology and Definition of Sustainability................................................. 12

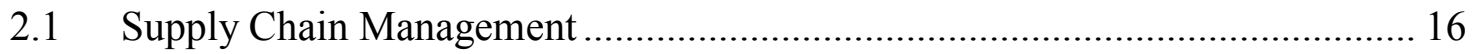

2.2 Sustainable Supply Chain Management........................................................ 18

2.3 Drivers That Move Firms to Adopt Sustainable Supply Chain Management

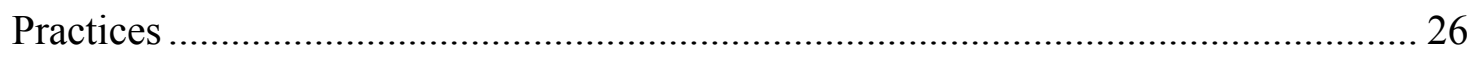

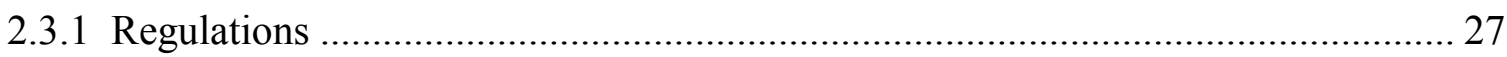

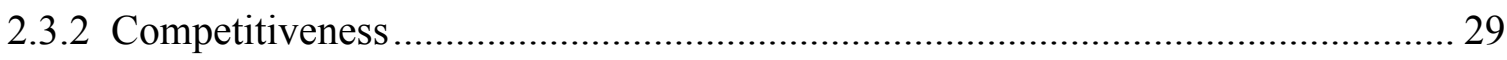


2.3.3 Stakeholder Pressures

2.4 Sustainable Supply Chain Management Practices 35

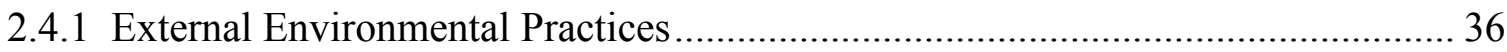

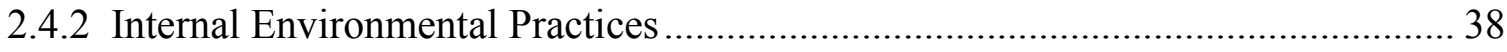

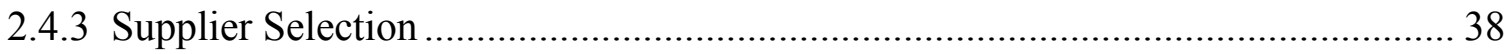

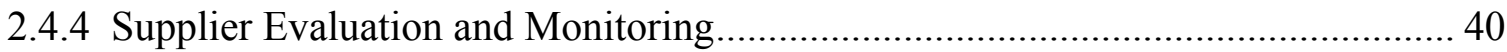

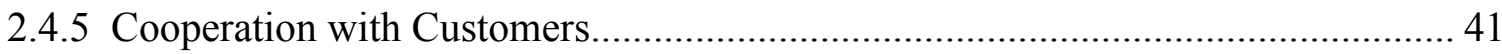

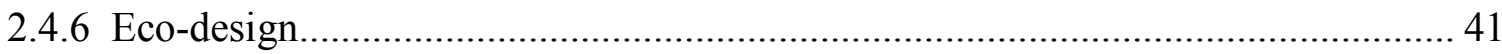

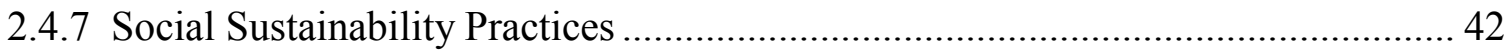

2.5 Sustainable Supply Chain Performance ………........................................... 43

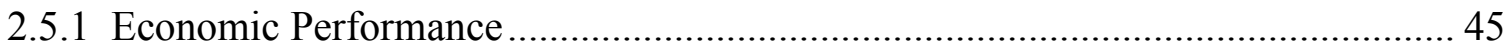

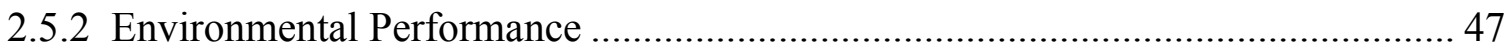

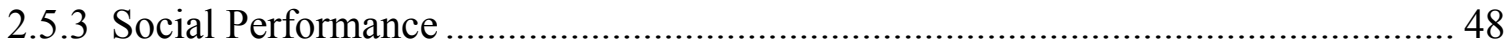

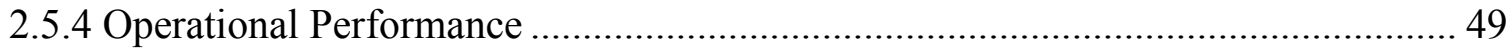

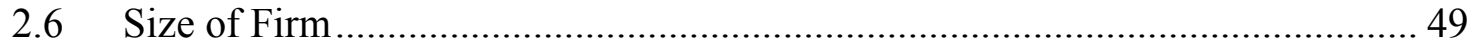

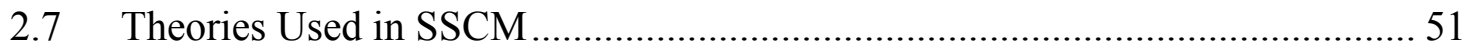


3. Chapter 3 Theoretical Framework

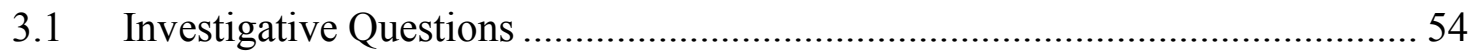

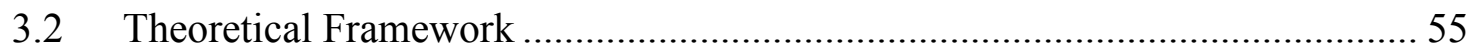

3.3 Drivers for Firms to Adopt Sustainable Supply Chain Practices ....................... 59

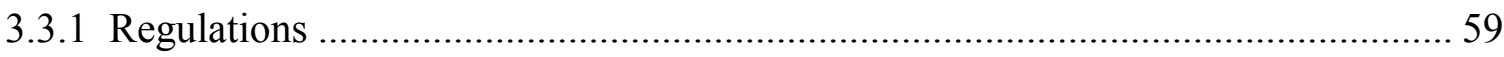

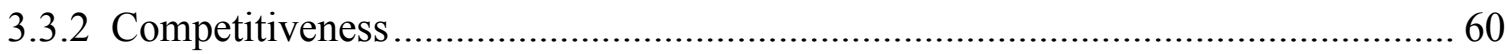

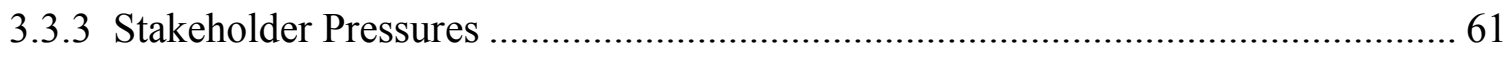

3.4 Sustainable Supply Chain Management Practices .............................................. 61

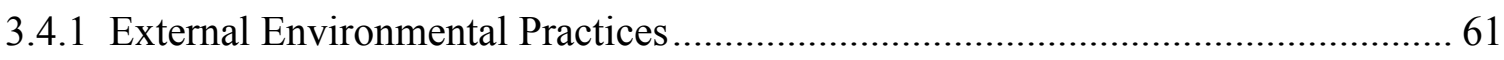

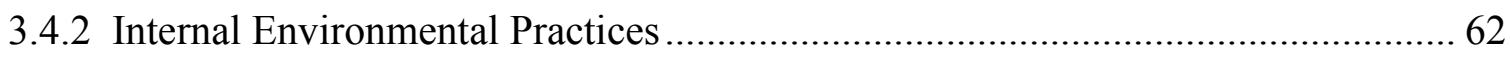

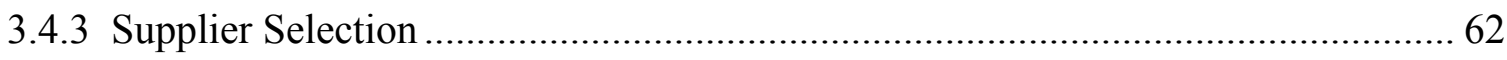

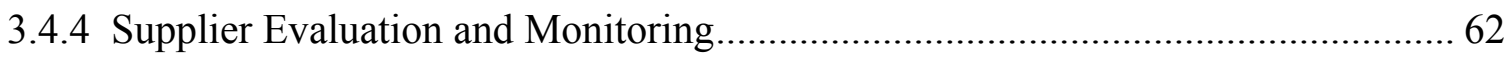

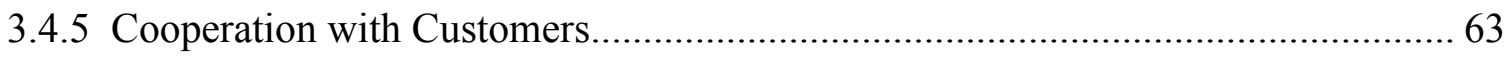

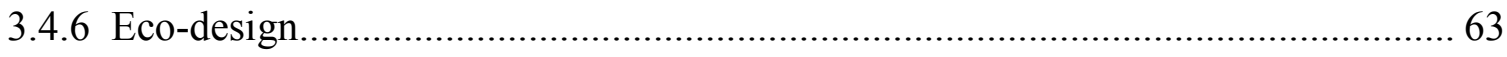

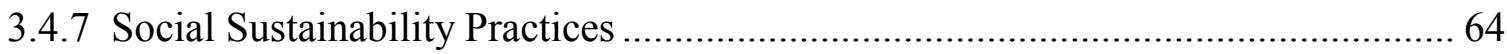

$3.5 \quad$ Firm Performance 
3.5.1 Economic Performance

3.5.2 Environmental Performance 65

3.5.3 Social Performance 65

3.5.4 Operational Performance 65

3.6 Size of Firm 65

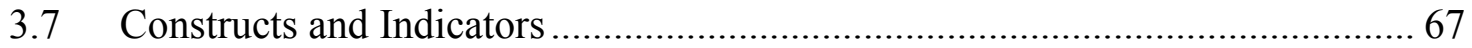

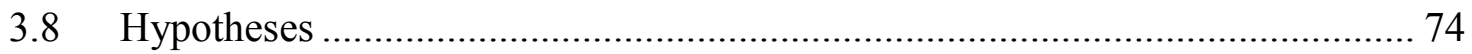

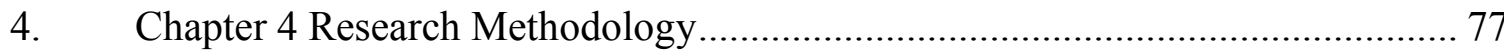

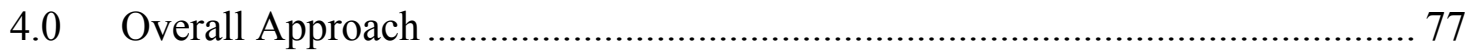

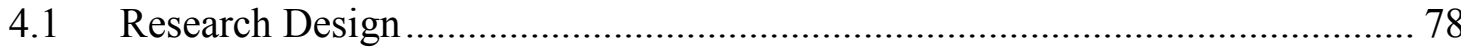

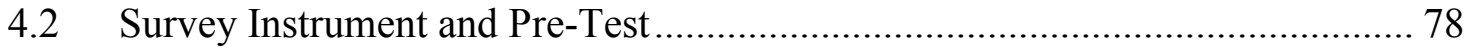

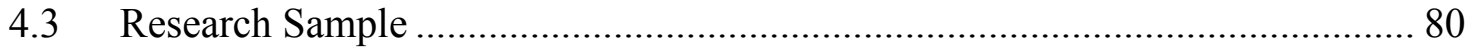

4.4 Survey Administration / Data Collection ................................................... 81

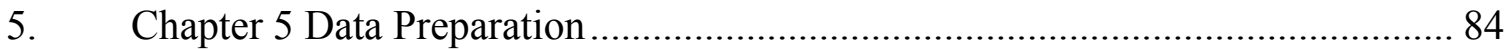

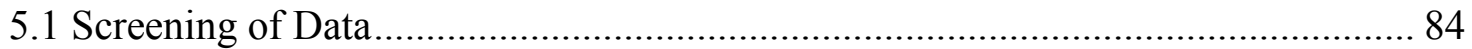

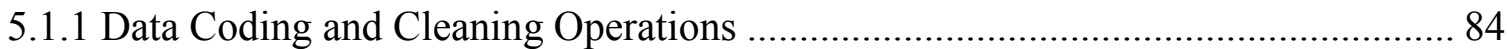




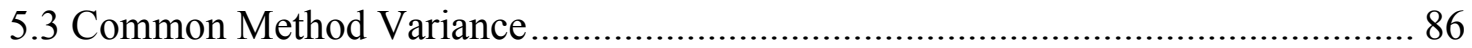

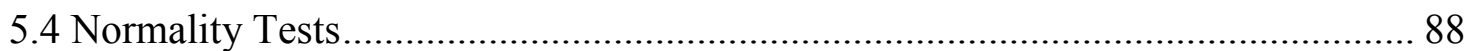

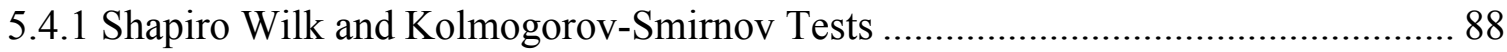

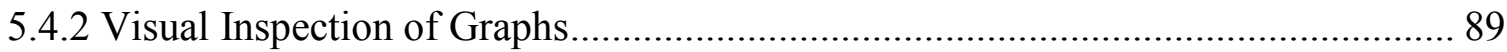

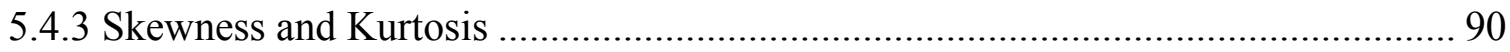

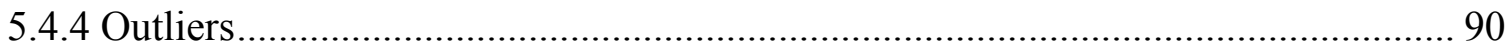

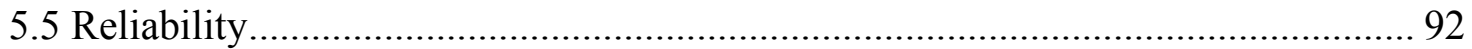

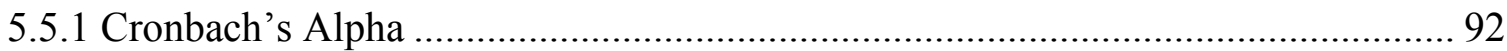

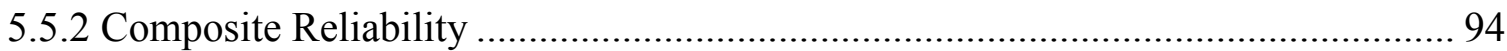

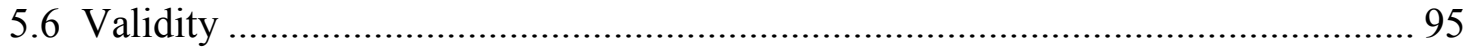

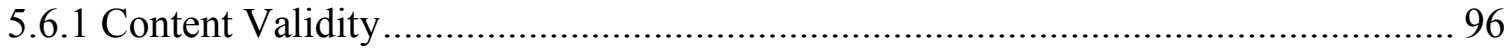

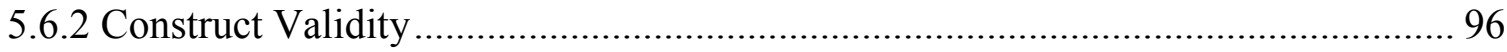

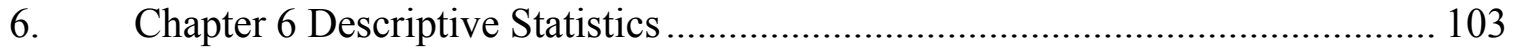

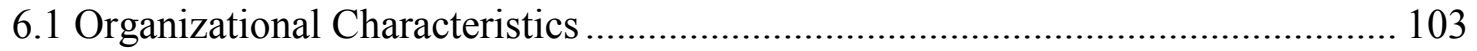


6.1.1 Location 103

6.1.2 Industry 105

6.1.3 Size 107

6.1.4 Ownership 108

6.1.5 ISO14000 Certification 109

6.1.6 ISO Certification Duration 110

6.2 Respondent Characteristics

6.2.1 Designation

6.2.2 Experience in the industry

7. Chapter 7 Data Analysis 116

7.1 Principal Component Analysis 116

7.1.1 Kaiser-Meyer-Oklin and Bartlett's Test 117

7.1.2 Grouping of constructs for analysis 118

7.1.3 Drivers 119

7.1.4 SSCM Practices Adoption 122

7.1.5 Performance 126 
7.2 Regression Analyses 130

7.2.1 Impact of Drivers on Adoption of SSCM Practices: Multiple Regression Runs 1 through 7.

7.2.2 Impact of SSCM Practices Adoption on Performance: Multiple Regression

Runs 8 through 11

7.2.3 Moderator Effect of Size on Impact of SSCM Practices Adoption on Performance: Multiple Regression Runs 12 through 15

8. Chapter 8 Analysis Using Structural Equation Modeling. 157

8.1 Introduction 157

8.2 Measurement Model Assessment 158

8.2.1 Confirmatory Factor Analysis of Constructs 158

8.2.2 Confirmatory Factor Analysis of Groups Drivers, SSCM Practices Adoption, and Performances. 189

8.3 Structural Model Assessment 207

8.3.1 Drivers, SSCM Practices Adoption and Performance 207

8.3.2 Summary of Results 
9. Chapter 9 Findings and Discussion.

9.1 Drivers, Sustainable Supply Chain Management Practices Adoption, and

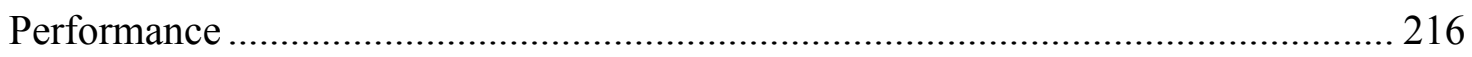

9.1.1 Drivers and SSCM Practices Adoption....................................................... 216

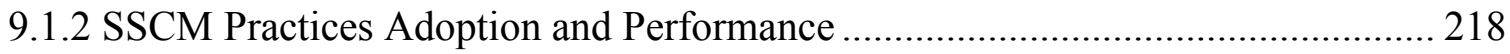

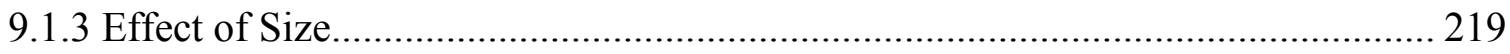

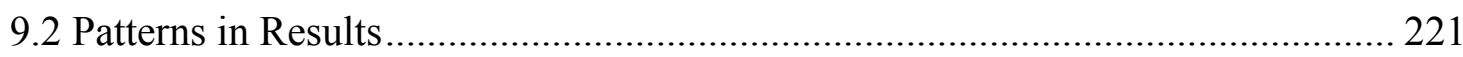

9.2.1 Different Drivers Impact Adoption of SSCM Practices Differently ................... 221

9.2.2 What connects External Environmental Practices, Internal Environmental

Practices and Supplier Evaluation and Monitoring ............................................ 221

9.2.3 What connects Supplier Selection, Cooperation with Customers and Eco-

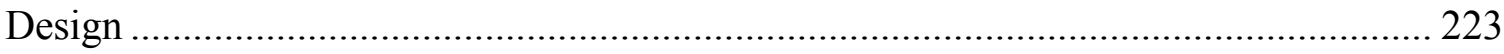

9.1.5 What makes Social Sustainability Practices stand alone ................................. 225

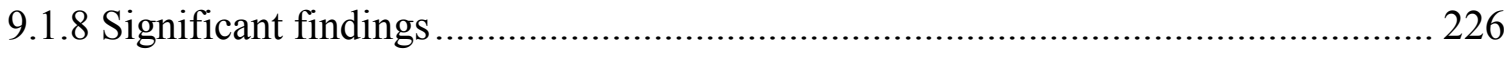

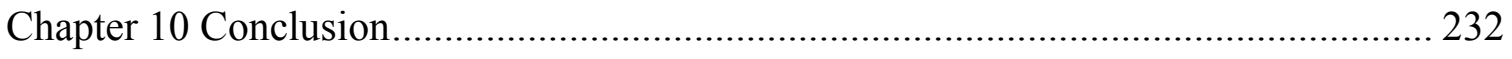

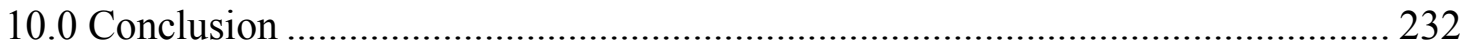

10.1 Academic Contribution of this Research ............................................... 232 
10.3 Limitations .

10.4 Future Research 238

References. 240

Appendices.. 289 


\section{List of Tables, Figures and Appendices}

\section{List of Tables}

Table 1.1 Number of Published Academic Research Papers Indicating Research Interest in Reverse logistics/ CLSCM/GSCM/SSCM ................................................................ 5

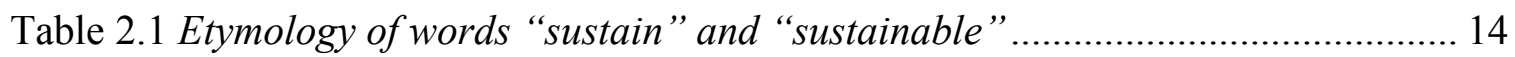

Table 2.2 Research Focus of Some Early Studies in SSCM Area .................................. 19

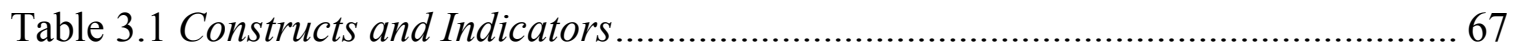

Table 3.2 Research Questions \& Hypotheses .......................................................... 75

Table 4.1 Pre-Test Feedback and Action Taken Thereon............................................ 79

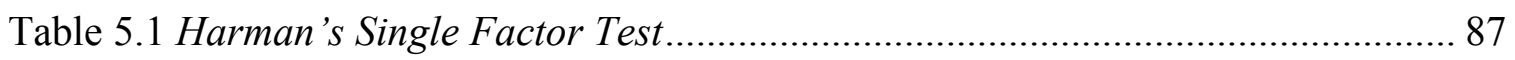

Table 5.2 Top Ten Cases with High Mahalanobis Distances with Probability Values .... 91

Table 5.3 Reliability of Constructs: Cronbach's Alpha Values..................................... 93

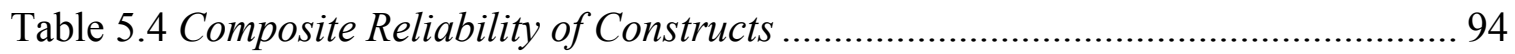

Table 5.5 Average Variance Extracted of Constructs ................................................ 98

Table 5.6 Average Variance Extracted and Maximum Shared Variance of Constructs .. 99 
Table 5.7 Discriminant Validity Check for Driver Constructs ..... 100

Table 5.8 Discriminant Validity Check for SSCM Practices Constructs. 101

Table 5.9 Discriminant Validity Check for Performance Constructs 101

Table 6.1 Location of Respondent Companies 104

Table 6.2 Industry Type 105

Table 6.3 Distribution of Respondent Companies by Size 107

Table 6.4 Distribution of Respondent Companies by Ownership Type 108

Table 6.5 Distribution of Respondent Companies by ISO14000 Certification. 110

Table 6.6 Duration of ISO14000 Certification held by Respondent Companies......

Table 6.7 Designation of Respondents.

Table 6.8 Years of Experience of Respondents 114

Table 7.1 Kaiser-Meyer-Oklin (KMO) and Bartlett's Test..... 117

Table 7.2 Variable Groups for Principal Component Analysis 118

Table 7.3 Total Variance Explained by Principal Components: Drivers 119

Table 7.4 Rotated Component Matrix: Drivers 120

Table 7.5 Principal Component Analysis of Drivers and Cronbach's Alpha. 121

xiv 
Table 7.6 Total Variance Explained by Principal Components: SSCM Practices Adoption 122

Table 7.7 Rotated Component Matrix: SSCM Practices Adoption 123

Table 7.8 Principal Component Analysis of SSCM Practices Adoption and Cronbach's Alpha

Table 7.9 Total Variance Explained by Principal Components: Performance 127

Table 7.10 Rotated Component Matrix

Table 7.11 Principal Component Analysis: Performance and Cronbach's Alpha 128

Table 7.12 Composite Constructs, Constructs and Acronym Used 132

Table 7.13 Hypothesised Effects of Variables 133

Table 7.14 Independent and Dependent Variables for Regressions 134

Table 7.15 Standardised Regression Coefficients: Regressions 1 to 7 135

Table 7.16 Inference from the Findings of Multiple Regression Analysis: Regression of Drivers on SSCM Practices 136

Table 7.17 Standardised Regression Coefficients: Regressions 8 to 11 137

Table 7.18 Findings of Multiple Regression Analyses: Regression of SSCM Practices on Performance. 139 
Table 7.19 t-Test for Equality of Means of Performance of Small and Medium+Large Firms 144

Table 7.20 Regression Runs Conducted for Testing for Moderator Effect of Size 145

Table 7.21 Results of Regression Runs Conducted for Testing Moderator Effect of Size on Impact of Adoption of SSCM Practices on Economic Performance of Firms. 146

Table 7.22 Comparison of Slopes of the Regression Lines for Small and Larger Firms for $E P$ 147

Table 7.23 Results of Regression Runs Conducted for Testing Moderator Effect of Size on the Impact of Adoption of SSCM Practices on Environmental Performance of Firms 148 Table 7.24 Comparison of Slopes of the Regression Lines for Small and Larger Firms for ENVP. 149

Table 7.25 Results of Regression Runs Conducted for Testing Moderator Effect of Size on Impact of Adoption of SSCM Practices on Social Performance of Firms..... 150

Table 7.26 Comparison of Slopes of the Regression Lines for Small and Larger Firms for $S P$ 152

Table 7.27 Results of Regression Runs Conducted for Testing Moderator Effect of Size on Impact of Adoption of SSCM Practices on Operational Performance of Firms 152

Table 7.28 Comparison of Slopes of the Regression Lines for Small and Larger Firms for $O P$ 154 
Table 7.29 Findings of Multiple Regression Analyses and t-Tests: Effect of Size as a

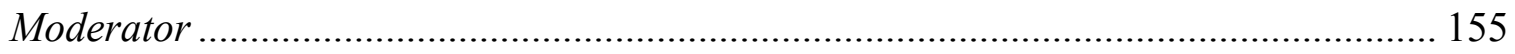

Table 8.1 Loadings on the Construct Regulations ........................................................ 159

Table 8.2 Fit Indices for the Construct Regulations .................................................. 160

Table 8.3 Loadings on the Construct Competitiveness ................................................ 162

Table 8.4 Fit Indices for the Construct Competitiveness .............................................. 162

Table 8.5 Fit Indices for the Construct Stakeholder Pressures ................................... 163

Table 8.6 Loadings on the Construct Stakeholder Pressures ....................................... 164

Table 8.7 Fit Indices for the modified Construct Stakeholder Pressures ....................... 165

Table 8.8 Fit Indices for the Construct External Environmental Practices ................... 165

Table 8.9 Loadings on the Construct External Environmental Practices ..................... 166

Table 8.10 Fit Indices for the modified Construct External Environmental Practices .. 167

Table 8.11 Fit Indices for the Construct Internal Environmental Practices .................. 168

Table 8.12 Loadings on the Construct Internal Environmental Practices ..................... 169

Table 8.13 Fit Indices for the modified Construct Internal Environmental Practices ... 169

Table 8.14 Fit Indices for the Construct Supplier Selection ......................................... 170

Table 8.15 Loadings on the Construct Supplier Selection ............................................. 171

xvii 
Table 8.16 Fit Indices for the modified Construct Supplier Selection. 171

Table 8.17 Fit Indices for the Construct Supplier Evaluation and Monitoring. 172

Table 8.18 Loadings on the Construct Supplier Evaluation and Monitoring 173

Table 8.19 Fit Indices for the Construct Cooperation with Customers. 174

Table 8.20 Loadings on the Construct Cooperation with Customers 175

Table 8.21 Fit Indices for the Construct Eco-Design 175

Table 8.22 Loadings on the Construct Eco-Design 176

Table 8.23 Fit Indices for the Construct Social Sustainability Practices 177

Table 8.24 Loadings on the Construct Social Sustainability Practices. 178

Table 8.25 Fit Indices for the modified Construct Social Sustainability Practices 179

Table 8.26 Fit Indices for the Construct Economic Performance 179

Table 8.27 Loadings on the Construct Economic Performance. 180

Table 8.28 Fit Indices for the modified Construct Economic Performance. 181

Table 8.29 Fit Indices for the Construct Environmental Performance 181

Table 8.30 Loadings on the Construct Environmental Performance 183

Table 8.31 Fit Indices for the Construct Social Performance 183

xviii 
Table 8.32 Loadings on the Construct Social Performance 184

Table 8.33 Fit Indices for the modified Construct Social Performance 185

Table 8.34 Fit Indices for the modified Model of Social Performance after removing Items SP4 and SP5 185

Table 8.35 Cronbach's Alpha if Items SP4 or SP5 are deleted. 186

Table 8.36 Fit Indices for the Construct Operational Performance 187

Table 8.37 Loadings on the Construct Operational Performance 188

Table 8.38 Fit Indices for the modified Construct Operational Performance 189

Table 8.39 Groups Used for Confirmatory Factor Analysis in AMOS 189

Table 8.40 Fit Indices for the modified Drivers Model 192

Table 8.41 Standardised Loadings on the Drivers: Regulations, Competitiveness and Stakeholder Pressures With Composite Reliability, Square Multiple Correlations and Error Variance. 192

Table 8.42 Reliability and Validity Indices of Drivers Constructs 194

Table 8.43 Fit Indices for the Modified SSCM Practices Adoption Measurement Model 198

Table 8.44 Standardised Loadings ( $\lambda$ ) on the SSCM Practices Adoption Constructs with Composite Reliability, Square Multiple Correlations and Error Variance..................... 198 xix 
Table 8.45 Reliability and Validity Indices of SSCM Practices Adoption. 200

Table 8.46 Fit Indices for the Modified Performance Measurement Model 204

Table 8.47 Standardised Loadings ( $\lambda$ ) on the Performance Constructs With Composite Reliability, Square Multiple Correlations and Error Variance .................................... 204

Table 8.48 Reliability and Validity Indices of Performance Constructs ....................... 205

Table 8.49 Fit Indices for the Structural Model ........................................................ 210

Table 9.1 Inference from the Findings of Multiple Regression Analyses: Regression of Drivers on SSCM Practices Adoption ......................................................................... 217

Table 9.2 Inference from the Findings of Multiple Regression Analyses: Regression of SSCM Practices Adoption on Performance.... 219

Table 9.3 Findings of Multiple Regression Analyses and t-Tests: Effect of Size as a Moderator 220 


\section{List of Figures}

Figure 1.1 Research Domains of RL/CLSCM/GSCM/SSCM and their overlap .............. 3

Figure 3.1 Theoretical Framework ........................................................................... 57

Figure 6.1 Location of Respondent Companies ...................................................... 104

Figure 6.2 Distribution of Respondent Companies by Industry Type......................... 106

Figure 6.3 Distribution of Respondent Companies by Size ..................................... 107

Figure 6.4 Distribution of Respondent Companies by Ownership Type ..................... 109

Figure 6.5 Distribution of Respondent Companies by ISO14000 Certification ............ 110

Figure 6.6 Duration of ISO14000 Certification Held by Respondent Companies ......... 111

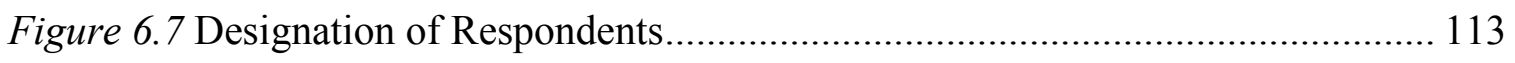

Figure 6.8 Years of Experience of Respondents ................................................... 114

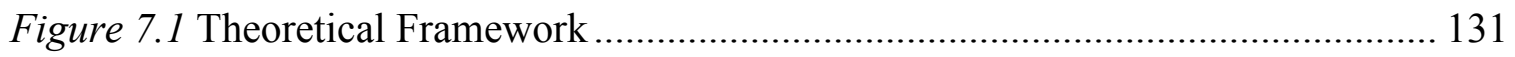

Figure 7.2 Comparison of Economic Performance of Small, Medium and Large Size

Firms 140

Figure 7.3 Comparison of Environmental Performance of Small, Medium and Large Size

Firms 141

xxi 
Figure 7.4 Comparison of Social Performance of Small, Medium and Large Size Firms 142

Figure 7.5 Comparison of Operational Performance of Small, Medium and Large Size

Firms 143

Figure 8.1 Measurement Model for the Construct Regulations 160

Figure 8.2 Measurement Model for the Construct Competitiveness. 161

Figure 8.3 Measurement Model for the Construct Stakeholder Pressures (Modified)... 164

Figure 8.4 Measurement Model for the Construct External Environmental Practices (Modified) 166

Figure 8.5 Measurement Model for the Construct Internal Environmental Practices (Modified) 168

Figure 8.6 Measurement Model for the Construct Supplier Selection (Modified) 170

Figure 8.7 Measurement Model for the Construct Supplier Evaluation and Monitoring 173

Figure 8.8 Measurement Model for the Construct Cooperation with Customers 174

Figure 8.9 Measurement Model for the Construct Eco-Design 176

Figure 8.10 Measurement Model for the Construct Social Sustainability Practices (Modified) 178 xxii 
Figure 8.11 Measurement Model for the Construct Economic Performance (Modified) 180

Figure 8.12 Measurement Model for the Construct Environmental Performance ......... 182

Figure 8.13 Measurement Model for the Construct Social Performance (Modified) .... 184

Figure 8.14 Measurement Model for the Construct Operational Performance (Modified) 188

Figure 8.15 Measurement Model for the Constructs in the group Drivers (Modified).. 191

Figure 8.16 Measurement Model for SSCM Practices Adoption (Modified) 197

Figure 8.17 Measurement Model for Performance (Modified) 203

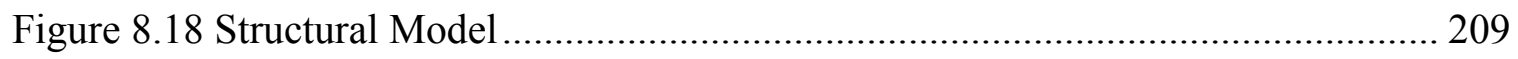

Figure 9.1 Research Framework with Standardized Regression Coefficients 215

\section{List of Equations}

Equation 5.1 Composite Reliability (Fornell \& Larcker, 1981) 94

Equation 5.2 Average Variance Extracted (Fornell \& Larcker, 1981)..... 97

Equation 7.1 General Multiple Regression. 135

xxiii 


\section{List of Appendices}

Appendix I Letter of Invitation to Participate in the Study .......................................... 289

Appendix II Copy of Online Survey Consent Form .................................................. 292

Appendix III Survey Instrument Used for Research.................................................. 295

Appendix IV Kolmogorov-Smirnova and Shapiro-Wilk Tests of Normality ................ 304

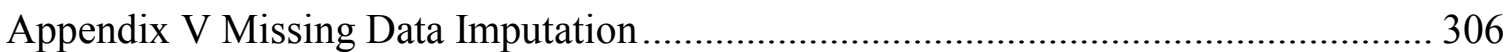

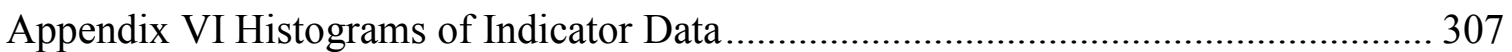

Appendix VII Levene's Test for Equality of Variances and t-Test for Equality of Means

Appendix VIII Skewness and Kurtosis of Collected Data............................................... 322

Appendix IX AMOS Output For Structural Model ………….................................... 325 


\section{Chapter 1 Introduction}

\subsection{Preamble}

This thesis deals with the study of the impact of adoption of sustainable supply chain practices on the performance of a firm. For this research, we follow Elkington's $(1997,1999,2006)$ triple bottom line model of a firm's sustainability which comprises of economic, environmental and social aspects of sustainability, and wherein all three "pillars" are assumed to be essential for a firm's long-term sustainability or success.

Various pressures, or drivers, are assumed to make a firm adopt management practices which can lead the organization to sustainable existence and survival over longterm in harmony with the ecological environment and society. These management practices are expected to have an impact on the economic, ecological and social performance of the organization. They are also expected to affect its operational performance.

For this research, we use the definition of Seuring and Muller (2008) for defining

the term sustainable supply chain management (SSCM). They define SSCM as "The management of material, information and capital flows as well as cooperation among companies along the supply chain while taking goals from all three dimensions of sustainable development, i.e., economic, environmental and social, into account which are derived from customer and stakeholder requirements" (Seuring \& Muller, 2008, p. 1700). 


\subsection{Motivation for this research}

Supply chain management and sustainability and have become important or even critical topics of research in the area of a firm's operations and its effect on ecological environment and society (Corbett \& Kleindorfer, 2003; Kleindorfer et al., 2005; Linton et al., 2007; Meixell \& Luoma, 2015;). In business practice, environmental and social issues increasingly are a part of - and are dovetailed into - a business's competitive and operational strategies (Porter \& Van der Linde, 1995; Shrivastava, 1995; Hart, 1995, 1997; Sharma \& Vredenburg, 1998; Angel \& Klassen, 1999; Hart \& Milstein, 1999; Bansal \& Roth, 2000; Matos \& Halt, 2007; Beske \& Seuring, 2014). At the same time, as supply chains expand across national boundaries, driven by the rising outsourcing and globalization requirements (Mann et al., 2008) the focus of research in sustainability shifts from firms to the supply chains in entirety (Linton et al., 2007; Seuring et al., 2008; Ortas et al., 2014). Examining the nature of historical growth trends, while the research focus has grown from that on the economic aspect to encompass environmental and social aspects, all three aspects are not yet treated equally. Environmental issues in supply chain management have been attracting a lot of interest recently. A substantial part of the previous research has focussed on environmental aspects and reverse logistics (Mann et al., 2008), but the incorporation of social issues is relatively sparse (Carter\& Easton, 2011; Seuring \& Muller, 2008).

As the field evolves, a number of names have been used to denote, what are, sometimes overlapping areas of study. Some of the areas that have attracted substantial 
attention over the past two decades are reverse logistics (RL), closed loop supply chain management (CLSCM), green supply chain management (GSCM) and sustainable supply chain management (SSCM) and corporate social responsibility (CSR).

Figure 1.1 below offers a diagrammatic representation of the inter-relationship between terms RL/CLSCM/GSCM/SSCM, as used by researchers in this field. It indicates various areas of study that are evolving and the overlap of various knowledge domains.

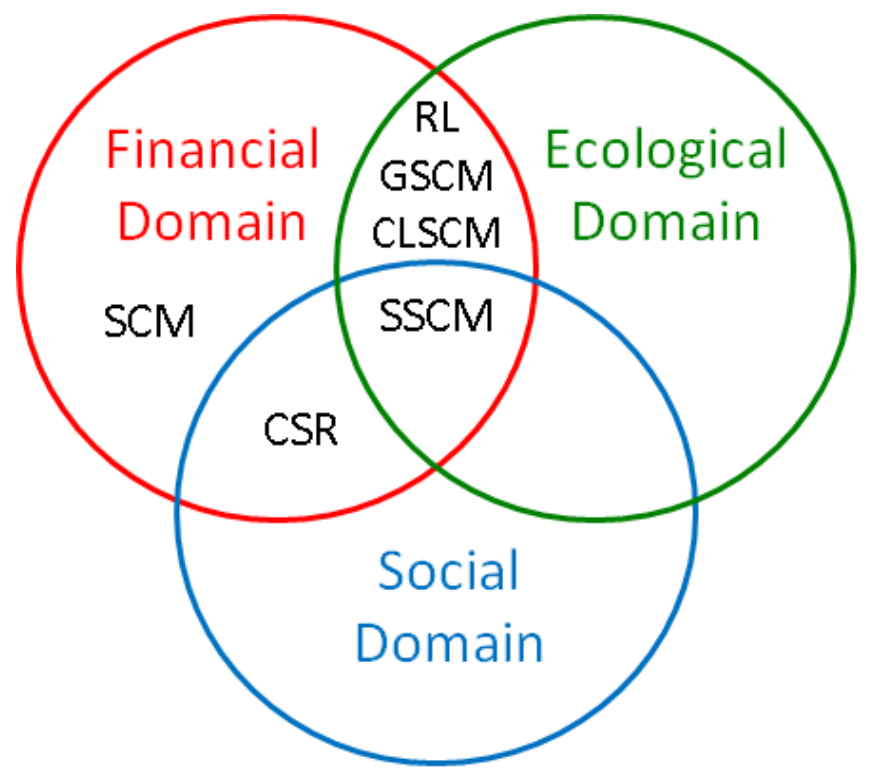

SCM: Supply Chain Management

RL: $\quad$ Reverse Logistics

CLSCM: Closed Loop Supply Chain Management

GSCM: Green Supply Chain Management

SSCM: Sustainable Supply Chain Management

CSR: Corporate Social Responsibility

Figure 1.1 Research Domains of RL/CLSCM/GSCM/SSCM and their overlap (Adapted from Xu \& Gursoy, 2015; Carter \& Rogers, 2008) 
The relative interest in some of these areas can be inferred from academic research papers published and listed by some popular electronic databases.

Table 1.1 below provides an insight into the level of research interest in these topics 
Table 1.1 Number of Published Academic Research Papers Indicating Research Interest in Reverse logistics/CLSCM/GSCM/SSCM

\begin{tabular}{|c|c|c|c|c|c|c|c|}
\hline Area of Study & Definition & $\begin{array}{l}\text { Number of } \\
\text { Scholarly } \\
\text { Articles } \\
\text { Listed on } \\
\text { Business } \\
\text { Source } \\
\text { Complete in } \\
\text { March } 2014 \\
\text { (where title } \\
\text { includes the } \\
\text { words) }\end{array}$ & $\begin{array}{l}\text { Number of } \\
\text { Scholarly } \\
\text { Articles } \\
\text { Listed on } \\
\text { Business } \\
\text { Source } \\
\text { Complete in } \\
\text { March } 2015 \\
\text { (where title } \\
\text { includes the } \\
\text { words) }\end{array}$ & $\begin{array}{l}\text { Number of } \\
\text { Scholarly } \\
\text { Articles } \\
\text { Listed on } \\
\text { Business } \\
\text { Source } \\
\text { Complete in } \\
\text { Feb. } 2018 \\
\text { (where title } \\
\text { includes the } \\
\text { words) }\end{array}$ & $\begin{array}{l}\text { Number of } \\
\text { Scholarly } \\
\text { Articles } \\
\text { Listed on } \\
\text { Scholars } \\
\text { Portal in } \\
\text { March } 2014 \\
\text { (where title } \\
\text { includes the } \\
\text { words) }\end{array}$ & $\begin{array}{c}\text { Number of } \\
\text { Scholarly } \\
\text { Articles } \\
\text { Listed on } \\
\text { Scholars } \\
\text { Portal in } \\
\text { March } 2015 \\
\text { (where title } \\
\text { includes the } \\
\text { words) }\end{array}$ & $\begin{array}{l}\text { Number of } \\
\text { Scholarly } \\
\text { Articles } \\
\text { Listed on } \\
\text { Scholars } \\
\text { Portal in } \\
\text { Feb. } 2018 \\
\text { (where title } \\
\text { includes } \\
\text { the words) }\end{array}$ \\
\hline $\begin{array}{l}\text { Supply Chain } \\
\text { Management }\end{array}$ & $\begin{array}{l}\text { SCM "encompasses the planning } \\
\text { and management of all activities } \\
\text { involved in sourcing and } \\
\text { procurement, conversion, and all } \\
\text { logistics management activities. } \\
\text { Importantly, it also } \\
\text { includes coordination and } \\
\text { collaboration with channel } \\
\text { partners, which can be suppliers, } \\
\text { intermediaries, third party service } \\
\text { providers, and customers"(Shi \& } \\
\text { Yu, 2013) }\end{array}$ & 1600 & 2095 & 2746 & 1338 & 1776 & 1929 \\
\hline
\end{tabular}




\begin{tabular}{|c|c|c|c|c|c|c|c|}
\hline $\begin{array}{c}\text { Corporate } \\
\text { Social } \\
\text { Responsibility }\end{array}$ & $\begin{array}{l}\text { CSR is defined as "the notion } \\
\text { that corporations have an } \\
\text { obligation to } \\
\text { constituent groups in society } \\
\text { other than stockholders and } \\
\text { beyond that prescribed by law } \\
\text { or union contract, indicating that } \\
\text { a stake may go beyond mere } \\
\text { ownership" (Jones, 1980). } \\
\text { However, recent definitions } \\
\text { have been trying to enlarge the } \\
\text { scope, with some } \\
\text { encompassing economic, and } \\
\text { ecological spheres as well } \\
\text { (Dahlsrud, 2008). }\end{array}$ & 1895 & 2473 & 3315 & 1113 & 1891 & 2519 \\
\hline $\begin{array}{c}\text { Reverse } \\
\text { Logistics }\end{array}$ & $\begin{array}{l}\text { that is, "Reverse logistics is a } \\
\text { process in which a manufacturer } \\
\text { systematically accepts } \\
\text { previously shipped products or } \\
\text { parts from the point of } \\
\text { consumption for possible } \\
\text { recycling, remanufacturing, or } \\
\text { disposal.", Dowlatshahi (2000) }\end{array}$ & 229 & 349 & 363 & 203 & 276 & 312 \\
\hline $\begin{array}{c}\text { Green Supply } \\
\text { Chain } \\
\text { Management }\end{array}$ & $\begin{array}{l}\text { "Integrating environmental } \\
\text { thinking into supply-chain } \\
\text { management,including product } \\
\text { design, material sourcing and } \\
\text { selection, manufacturing }\end{array}$ & 81 & 96 & 166 & 77 & 105 & 147 \\
\hline
\end{tabular}




\begin{tabular}{|c|c|c|c|c|c|c|c|}
\hline & $\begin{array}{l}\text { processes, delivery of the final } \\
\text { product to the consumers as } \\
\text { well as end-of-life management } \\
\text { of the product after its useful } \\
\text { life." (Srivastava, 2007, p 54) }\end{array}$ & & & & & & \\
\hline $\begin{array}{l}\text { Closed Loop } \\
\text { Supply Chain } \\
\text { Management }\end{array}$ & $\begin{array}{l}\text { "a closed-loop supply chain } \\
\text { includes the returns processes } \\
\text { and the manufacturer has the } \\
\text { intent of capturing additional } \\
\text { value and further integrating all } \\
\text { supply-chain activities. } \\
\text { Therefore, closed loop supply } \\
\text { chains include traditional } \\
\text { forward supply-chain activities } \\
\text { and the additional activities of } \\
\text { the reverse supply chain. These } \\
\text { additional activities include } \\
\text { product acquisition, reverse } \\
\text { logistics...testing, sorting, and } \\
\text { disposition... refurbishing to } \\
\text { enable the most economically } \\
\text { attractive of the options: direct } \\
\text { reuse, repair, remanufacture, } \\
\text { recycle, or disposal, and } \\
\text { remarketing..." } \\
\text { Guide et al., (2003b, p3) }\end{array}$ & 8 & 3 & 8 & 9 & 14 & 16 \\
\hline
\end{tabular}




\begin{tabular}{|c|c|c|c|c|c|c|c|}
\hline $\begin{array}{l}\text { Sustainable } \\
\text { Supply Chain } \\
\text { Management }\end{array}$ & $\begin{array}{l}\text { "The management of material, } \\
\text { information and capital } \\
\text { flows as well as cooperation } \\
\text { among companies along the } \\
\text { supply chain while taking goals } \\
\text { from all three dimensions of } \\
\text { sustainable development, i.e., } \\
\text { economic, environmental and } \\
\text { social, into account which are } \\
\text { derived from customer and } \\
\text { stakeholder requirements." } \\
\text { (Seuring \& Muller, 2008, p. } \\
\text { 1700) }\end{array}$ & 56 & 71 & 146 & 54 & 76 & 132 \\
\hline
\end{tabular}


In addition to overlapping research areas, sustainability research is also affected by the use of different definitions of sustainability by different researchers who often bring the construct of "sustainable development" (e.g. Seuring \& Muller, 2008) into the discussion. With environmental concerns gaining ascendance with the general populace as well as the political class, different terminology is used by them at various fora adding to the complexity. Boundaries are made further fuzzier as the field is multi-disciplinary with considerable overlaps as well as specializations. On environmental and social issues, the relative claims and pressures of various 'stakeholders' do not lend themselves to overall clarity; and verifying or validating the miscellaneous locus standi becomes a complex process with countervailing views bearing in.

All these complexities do not deter researchers, and sustainable supply chain management is gathering attention of both practitioners and researchers (Corbett \& Kleindorfer 2003; Corbett \& Klassen 2006), to the extent that the research question "whether it pays to be green" (e.g., Russo and Fouts 1997; Pagell, Yang, Krumwied and Sheu 2004) is passé and seems to have become outdated (Pagel \& Wu, 2009; Pagell \& Shevchenko, 2014). This question has now been replaced by issues beyond, and researchers increasingly assume that adoption of SSCM practices is fait accompli (Kleindorfer, et al., 2005; Corbett \& Klassen 2006). Pagell and Shevchenko (2014) go to the extent of stating that now SSCM should not be a separate research field. Instead, sustainability issues should form an integral part of every research on SCM. 
The seeming progression of the field apart, unless a clear case can be made out that it is in the long-term interest of the firm to adopt SSCM practices, the interest in SSCM may be difficult to sustain. Introducing sustainability issues into board-room discussions without a definite idea of the impacts on performance cannot create traction. Various drivers like legislation or stakeholder pressures may make firms to adopt sporadic steps to 'keep ahead of the law,' but it may not lead to a long-term attitudinal change. Strategic decision-making would need clearly-defined sustainability objectives backed by validated research on the impact of sustainable practices on performance. Specific research to cover these concerns is needed in the sustainability area, which has now become important and relevant for the long-term future of business. This insight has motivated the current research.

\subsection{Research Objective}

The objective of this research was to study the effect of drivers on adoption of sustainable supply chain management practices, and further, to study the impact of adoption of sustainable supply chain management practices on the performance of the focal firm. The moderating effect of the size of a firm on the impact of adoption of SSCM practices on performance was also studied. 


\subsection{Outline of the Thesis}

The current chapter first provides an introduction to the research topic, then briefly introduces the research objective of this study and lastly describes the organization of this document. In chapter two, recent research on the topic is discussed, which covers a review of the academic literature on sustainable supply chain management including green supply chain management. The gaps in current research in the area are also identified. In chapter three, research questions are framed, keeping in mind the identified gap in research, and a theoretical framework is developed to address the research questions. In chapter four, the research methodology adopted for the study is presented. Chapter five describes data preparation and is followed by descriptive statistics in chapter six. Data analysis using multiple regression is presented in chapter seven, while path analysis using structural equation modeling is presented in chapter eight. Chapter nine presents the research findings followed by a discussion on the findings. Chapter ten provides a conclusion to the research by summarising the salient findings of the thesis. The thesis is appended with a list of references and the survey instrument used for the research. 


\section{Chapter 2 Literature Review}

In this chapter, the relevant etymology and definition of sustainability are

discussed followed by a brief introduction to supply chain management. Extant literature on sustainable supply chain management and green supply-chain management is then reviewed to ascertain the state of research in the area and to identify the gaps therein.

\subsection{Etymology and Definition of Sustainability}

The construct 'sustainable supply chain management' raises different images in the minds of practitioners and academics alike, to a great extent, due to different meanings ascribed to the word "sustainable". Being a relatively recent construct, it would be useful to begin by examining the etymological roots of this concept. The Compact Oxford English Dictionary (Oxford, 2010) defines the word "sustainable" and "sustain" as follows:

"sustainable

- adjective 1 able to be sustained.

2 (of industry, development, or agriculture) avoiding depletion of natural resources. 
— DERIVATIVES sustainability noun sustainably adverb.

sustain

- verb 1 strengthen or support physically or

mentally.

2 bear (the weight of an object).

3 suffer (something unpleasant).

4 keep (something) going over time or

continuously.

5 confirm that (something) is just or valid.

— DERIVATIVES sustainer noun sustainment noun.

— ORIGIN Latin sustinere, from tenere 'hold'."

In a close parallel, Cambridge Advanced Learner's Dictionary (Cambridge, 2010) defines "sustainable" as follows:

"sustainable

/sə'ster.nə.bl / adj 
-adjective

1 able to continue over a period of time

2 causing little or no damage to the

environment and therefore able to

continue for a long time"

It would appear that the general public or practitioners are more attuned to the first meaning of "sustainable" and the fourth meaning of "sustain". Such an understanding might be the reason that the first five practitioners consulted about the topic "sustainable supply chain" interpreted the phrase as: a supply chain that can be sustained over the years, or where suppliers and distributors of a focal company have the capacity to sustain business fluctuations over an extended period. An inquiry into the origin of the word "sustainable" supplants the fact that this impression is not without a basis (Table 2.1):

Table 2.1 Etymology of words "sustain" and "sustainable"

\begin{tabular}{|l|l|l|l|}
\hline Sr. & \multicolumn{1}{|c|}{ Word } & \multicolumn{1}{|c|}{ Etymology } & Source \\
\hline 1 & sustain & $\begin{array}{l}\text { late 13c., from O.Fr. sustenir "hold up, endure," from L. } \\
\text { sustinere "hold up, support, endure," from sub "up from } \\
\text { below" + tenere "to hold" (see tenet). }\end{array}$ & $\begin{array}{l}\text { Harper } \\
(2010)\end{array}$ \\
\hline 2 & sustainable & $\begin{array}{l}\text { 1610s, "bearable," from sustain + -able. Attested from 1845 } \\
\text { in the sense "defensible;" } \\
\text { from 1965 with the meaning "capable of being continued at } \\
\text { a certain level." Sustainable growth is recorded from 1965. } \\
\text { Related: Sustainability (1972). }\end{array}$ & $\begin{array}{l}\text { Harper } \\
(2010)\end{array}$ \\
\hline
\end{tabular}

Note. Source: Harper (2010) 
It is observed that the second meaning of "sustainable" (in Table 2.1 above) started evolving only as recently as 1965 , and the use of "sustainability" was recorded as late as 1972. Allowing some time for diffusion of the new usage, it is understandable that managers at senior positions would still be retaining the original (or the first) meaning of "sustainable" in their mental schemas. This has important implications for the questionnaire used in this study. This change of use can be mapped in tandem with the rising prominence of environmental protection in the political agenda in the late 1960s and 1970s (Vermeulen \& Seuring, 2009) when "producers of commodities originally were addressed on the externalities connected to their products by national and local governments, with regulative approaches" (p. 269). Considering these concerns a decision was made not to use the term sustainability in the questionnaire.

The first known definition of "sustainability" (in the context of development) appeared in the Brundtland Report (WECD, 1987) also known as Our Common Future. In this report, sustainability is defined as "using resources to meet the needs of the present without compromising the ability of future generations to meet their own needs", without addressing the related questions about future needs of resources, the levels of pollutants that can be safely released, the possibilities of finding new resources, the degree of "renewability" of renewable resources, the role of market forces and technology, and the need for new policies and life styles (Linton et al., 2007). This has led to an ongoing discourse on 'sustainability' and the need for change in lifestyle and other issues (Hart, 1997; Myers; 1997; Vincent \& Panayatou, 1997; Kemp, 1994), 
sometimes without even addressing the questions relating to "future needs". This underlines the need to crystallize the domain of sustainability over time.

\subsection{Supply Chain Management}

The rise of competition in market, the need to protect margins, cross-border trade growing into globalized trade has made it imperative to focus on the supply chain phenomenon over the last four decades (Houlihan, 1985; Gunasekaran et al., 2001). Older supply chains were 'lean and mean' and effective, given the limited infrastructure and communication facilities available in those times. Using camel convoys via overland "Silk Route" from China to Europe and using "Old Spice" sea route around Cape of Good Hope, these supply chains spawned numerous business and political empires and involved hundreds of thousands of people. They sustained over a long time, braving dangers and high "taxation" en route. These supplier-manufacturer-distributor-retailercustomer chains worked in "free markets," reaching customers across national boundaries, functioning 'at arm's length,' a concept that is still in vogue.

With the rise of bigger businesses and corporations, it became expedient to take control of the entire supply chain, right from the mines to the market; US Steel and Shell are leading examples of this phenomenon. Henry Ford wrote in 1926, "Our production cycle is about eighty-one hours from the mine to the finished machine in the freight car..." (Morgan, 2004 p. 529), underlining his thinking, which was far ahead of his times. In the face of competition, and to face bigger corporations, smaller organizations were seen to forge long-term associations upstream with their suppliers and downstream with 
their distributors; on the other hand, some larger monolith organizations faced 'downsizing' in the name of 're-engineering' and took to 'outsourcing'. Focussing on their core business was cited to be the "mool mantra" or the key to success, as opposed to the monolithic business model that targeted the mopping up of all the profit margins from "mines to market." This gave rise to supply chains of "intermediate" maturity, closely knit but still rooted in paper-based manual systems. With the exchange of information becoming "real time," supported by low-priced easily-available information systems and the Internet, electronic data interchange started becoming the norm and information became actionable. This resulted in seamless inter-linkage of the members of a supply chain, which became "mature" or "advanced" with an efficient triple-flow system, that of information, goods, and finance. Acting as a 'single entity,' these supply chains can be seen competing globally (Mann et al., 2008), even though some of the dominating partners in the chain (e.g., Walmart) may have an overarching lead role to play. It cannot be ruled out that in the future, some of these chains may merge to form 'multi-national' organizations having a 'global control system' (Morgan, 2004) completing the cycle of becoming monolithic organizations once again, though with a different character and ownership structure. Also, pressures of interoperability and cooperation push members of a supply chain towards isomorphism, with the need for "synchronization and standardization of practices of business processes" (Blanc et al., 2007 p.720) catalyzing this change.

The increasing importance of supply chains has ignited research interest in supply chain management (SCM). Simchi-Levi et al. (2003, p1) define supply chain 
management as "a set of approaches utilized to efficiently integrate suppliers, manufacturers, warehouses, and stores, so that merchandise is produced and distributed at the right quantities, to the right locations, and at the right time, in order to minimize system-wide costs while satisfying service level requirements". Despite the above definition being almost all-encompassing, it stands to reason that different types of supply chains, from small triads to transnational chains, need different types of systems and management styles for efficient management. It is, however, generally assumed that the goal of SCM is to ensure that the final customer gets quality goods and services at a competitive price (Ellram \& Cooper, 2014).

In recent decades, with rising environmental awareness, supply chains have come under scrutiny for their impact on the environments and societies where they operate. Also, anecdotal news reports create a feeling that some of the supply chains that operate trans-nationally escape regulations by working their way across various jurisdictions and thus can adopt supply chain management practices that may not be sustainable. This makes research in the sustainability of supply chains much more interesting, a brief overview of which is presented in the next section.

\subsection{Sustainable Supply Chain Management}

From the mid-1990s, social and environmental impacts of supply chains started evincing the keen interest of researchers (Drumwright, 1994; Murphy et al., 1994). This interest saw a rise in research activities in a number of sub-areas. Table 2.2 below 
provides a brief list of sub-areas demarcated for study by early researchers in this field (Seuring \& Muller, 2008; Rajeev et al., 2017 ).

Table 2.2 Research Focus of Some Early Studies in SSCM Area

\begin{tabular}{|c|c|c|}
\hline Sr. & Research Focus & Authors \\
\hline 1 & $\begin{array}{l}\text { Closed Loop Supply } \\
\text { Chain }\end{array}$ & $\begin{array}{l}\text { Agrawal et al., 2015; Govindan et al. 2015a; Tao and } \\
\text { Yin, 2014; Sheriff } \text { et al., 2012; Hazen et al., 2012; } \\
\text { Hazen, 2011; Chan } \text { et al., 2010; Setaputra and } \\
\text { Mukhopadhyay, 2010; Melo et al., 2009; Pokharel and } \\
\text { Mutha, 2009; Rubio et al., 2008; Atasu et al., 2008; } \\
\text { Meade et al., 2007; Prahinski and Kocabasoglu, 2006; } \\
\text { Chu and Song, 2004. }\end{array}$ \\
\hline 2 & Cost management & Seuring, 2001 \\
\hline 3 & Decision making & Sarkis, 2003 \\
\hline 4 & Drivers & $\begin{array}{l}\text { Paulraj et al., 2017; Esfahbodi et al., 2017; Mann et } \\
\text { al., } 2010\end{array}$ \\
\hline 5 & Dyadic relationships & Carter, 2000 \\
\hline 6 & Environmental issues & Lamming \& Hampson, 1996; Preuss, 2005 \\
\hline 7 & $\begin{array}{l}\text { Environmental issues in } \\
\text { logistics }\end{array}$ & Abkhader \& Jönson, 2004 \\
\hline 8 & Ethical issues & Carter, 2000; Davies and Crane, 2003; Roberts, 2003 \\
\hline 9 & General Review & $\begin{array}{l}\text { Rajeev et al., 2017; Sambrani and Pol , 2016; } \\
\text { Fahimnia et al., 2015; Brandenburg et al., 2014; } \\
\text { Bhatia and Chand, 2014; Winter and Knemeyer, 2013; } \\
\text { Seuring, 2013; Tang and Zhou, 2012; Abbasi and } \\
\text { Nilsson, 2012; Ashby et al., 2012; Gupta and Palsule- } \\
\text { Desai, 2011; Carter and Liane Easton, 2011; Gold et } \\
\text { al., 2010; Linton } \text { et al., } 2007\end{array}$ \\
\hline 10 & Green Design & Baumann et al., 2002 \\
\hline 11 & Green Distribution & $\begin{array}{l}\text { Lin et al., 2014; Demir et al., 2014; Dekker et al., } \\
\text { 2012; Foulds and Luo, } 2006\end{array}$ \\
\hline 12 & Green Manufacturing & Paul et al., 2014; Chu et al., 2014 \\
\hline
\end{tabular}




\begin{tabular}{|c|c|c|}
\hline 13 & Green Marketing & $\begin{array}{l}\text { Kanonuhwa and Chimucheka, 2014; Chamorro et al., } \\
2009\end{array}$ \\
\hline 14 & $\begin{array}{l}\text { Green product-based } \\
\text { green supply }\end{array}$ & Handfield et al., 1997 \\
\hline 15 & Green product design & Wolters et al., 1997; Baumann et al., 2002. \\
\hline 16 & Green Purchasing & $\begin{array}{l}\text { Govindan et al., 2015b; Igarashi et al., 2013; Chun } \\
\text { and Bidanda, } 2013\end{array}$ \\
\hline 17 & Green Strategy & $\begin{array}{l}\text { Touboulic and Walker, 2015; Wong et al., 2015; } \\
\text { Patala et al., 2014; Chin et al., 2014; Gaussin et al., } \\
\text { 2013; Kronborg Jensen, 2012 }\end{array}$ \\
\hline 18 & $\begin{array}{l}\text { Greening the supply } \\
\text { process }\end{array}$ & Bowen et al., 2001 \\
\hline 19 & Governance & Bush et al., 2014; Bostrom et al., 2014 \\
\hline 20 & $\begin{array}{l}\text { Impact of cooperative } \\
\text { supply chain } \\
\text { environmental } \\
\text { management }\end{array}$ & Vachon \& Klassen, 2006; Simpson et al., 2007 \\
\hline 21 & $\begin{array}{l}\text { Integration of } \\
\text { sustainability issues } \\
\text { into supply (chain) } \\
\text { management }\end{array}$ & Koplin et al., 2007 \\
\hline 22 & Leadership & Gosling et al., 2014 \\
\hline 23 & $\begin{array}{l}\text { Life-cycle assessment } \\
\text { based criteria }\end{array}$ & $\begin{array}{l}\text { Lamming \& Hampson, 1996; Pesonen, 2001; Seuring, } \\
2004\end{array}$ \\
\hline 24 & Manufacturing Strategy & Chatha \& Butt, 2015 \\
\hline 25 & Operations & Kleindorfer et al., 2005 \\
\hline 26 & Metrics development & Das, 2017; Ahi and Searcy, 2015; Hassini et al., 2012 \\
\hline 27 & $\begin{array}{l}\text { Performance } \\
\text { management }\end{array}$ & Geng et al., 2017; Rao \& Holt, 2005; Zhu et al., 2005 \\
\hline 28 & $\begin{array}{l}\text { Performance } \\
\text { measurement }\end{array}$ & $\begin{array}{l}\text { Tseng et al., 2018; Wang and Dai, 2018; Beske- } \\
\text { Janssen et al., 2015; Taticchi et al., 2013; Pullman et } \\
\text { al., 2009; Hervani et al., } 2005\end{array}$ \\
\hline 29 & Purchasing & $\begin{array}{l}\text { Green et al., 1996; Min \& Galle, 2001; Zsidisin \& } \\
\text { Siferd, } 2001\end{array}$ \\
\hline 30 & Social issues & $\begin{array}{l}\text { Zorzini et al., 2015; Zhang et al., 2014; Carter, 2005; } \\
\text { Drumwright, } 1994\end{array}$ \\
\hline
\end{tabular}




\begin{tabular}{|l|l|l|}
\hline 31 & $\begin{array}{l}\text { Supply chain } \\
\text { management }\end{array}$ & Rao \& Holt, 2005; Zhu et al., 2005 \\
\hline 32 & Supply management & Bowen et al., 2001 \\
\hline 33 & Sustainable Strategy & $\begin{array}{l}\text { Meixell and Luoma, 2015; Beske } \text { et al., 2014; } \\
\text { Alexander } \text { et al., 2014, Tachizawa and Yew Wong, } \\
2014\end{array}$ \\
\hline 34 & $\begin{array}{l}\text { Sustainable supply } \\
\text { chain management }\end{array}$ & $\begin{array}{l}\text { Srivastava, 2007; Carter \& Rogers, 2008; Seuring \& } \\
\text { Muller, 2008. }\end{array}$ \\
\hline 35 & $\begin{array}{l}\text { Sustainable Supply } \\
\text { Chain Management } \\
\text { Practices }\end{array}$ & $\begin{array}{l}\text { Hong } \text { et al., 2018; Wang and Dai, 2018; Das, 2017; } \\
\text { Pullman } \text { et al., 2009 }\end{array}$ \\
\hline 36 & $\begin{array}{l}\text { Use of environmental } \\
\text { management systems }\end{array}$ & Darnall et al., 2008 \\
\hline
\end{tabular}

Note. Source: Seuring \& Muller (2008); Rajeev et al. (2017) \& literature under review.

As seen from the Table 2.2 above, the early research that created a seminal base, spanned over multiple disciplines. These sub-areas are coalescing under the umbrella of SSCM. This interest in sustainable supply chains is now tending to become a mainstream phenomenon (Corbett \& Kleindorfer 2003; Corbett \& Klassen 2006). While earlier, a substantial part of research was to ascertain 'whether it pays to be sustainable' (Russo \& Fouts, 1997; Pagell, et al., 2004), a number of researchers now feel that sustainability issues are fait accompli and that firms now have to come to terms to environmental and social issues (Kleindorfer et al., 2005; Corbett \& Klassen, 2006; Pagell \& Wu, 2009). Linton et al. (2007 p.1080) posit that "sustainability stretches the concept of supply chain management to look at optimizing operations from a broader perspective - the entire production system and postproduction stewardship as opposed to just the production of a specific product." In their discussion on SSCM, Krausse et al., $(2009$, p.18) underline the 
prime importance of supply chain in the overall sustainability of a firm by emphasizing that "a company is no more sustainable than its supply chain".

Kleindorfer et al. (2005) have reviewed papers published in Production and Operations Management, while Seuring and Müller (2007) analyze papers published in German to review the research therein. Webster and Mitra (2007), using mathematical modeling, try to analyse competitive strategy in remanufacturing and the impact of takeback laws, considering the environment in which the firms operate and the legislation changes. Kocabasoglu et al., (2007) consider issues involved in linking forward and reverse supply chain investment in an environment of external business uncertainty. The authors underline the need for change in existing practices in operations management to create new systems, effectively integrating reverse supply chains into forward supply chains. Using the Delphi method, Seuring \& Muller (2008) have conducted an expert survey with the aim to find issues in SSCM that impact firms and society. They posit that with the rising emphasis on the impacts of operations of firms on the environment and society, close scrutiny of operations and supply chains of organisations becomes imminent. This has created demand for increased transparency in operations and its impact, an area covered by research in corporate governance, corporate social responsibility and sustainability (Seuring \& Muller, 2008). Pullman et al., (2009) explore all three components of sustainability - social, environmental and economic - in their study using the data from the U.S. food and beverage industry. The authors use a set of performance measures (environmental, quality and cost). The authors find that managing the facets of sustainability is complex; social practices are directly linked to quality 
performance but not to environmental performance; environmental performance has only an indirect effect on cost performance which is mediated by quality performance. Their findings "highlight the complexity of sustainability impacts on performance and suggest that performance benefits from sustainability programs may be difficult to recognize" (Pullman et al., 2009 p. 38). Seuring and Müller (2008); Gold, et al. (2010); Carter and Eaton (2011); Seuring and Gold (2012); Miemczyk et al. (2012); Hassini et al. (2012); Min (2013); Taticchi et al. (2013); Tachizawa and Wong (2014); Malviya and Kant (2015); Ho et al. (2015); Touboulic (2015); Wong et al. (2015) and Meixell, and Luoma (2015) have reviewed the literature on SSCM.

The field has seen some special issues of academic journals. Linton et al. (2007), in their introduction to the special issue of Journal of Operations Management on sustainable supply chains, focus on future research and stress that "it is critical to move forward to the systemic issues that exist at the intersection of sustainability, environmental management, and supply chains" (p.1075). Reflecting a rising interest in the area, the number of articles on 'sustainability' or 'sustainable development' had reached $1.5 \%$ of the total articles published in economics, business and management journals in 2006, a substantial rise from $0.3 \%$ in 1990 when sustainability is seen to have "migrated" into management literature (Linton et al., 2007). This interest has only increased. For example, in 2013, ten percent of papers published in the Journal of Supply Chain Management and twenty percent of the papers and presentations in 2013 EUROMA conference in Dublin, were on SSCM (Pagell \& Shevchenko, 2014). 
That the research in sustainability is necessarily interdisciplinary can be seen from the publication of research papers in journals belonging to the disciplines of earth and environmental sciences; social sciences; engineering; agriculture and biological sciences; economics, business and management; energy; medicine; chemical engineering; materials science; amongst others. Further, sustainability lies at the intersection of the social sciences and the natural sciences. While social sciences are needed to analyze the interaction of sustainability issues with society, culture, individual and group behavior, the government and people; natural sciences are needed to study the interactions of sustainability issues with environment and to develop the technologies needed to make business processes sustainable.

A number of drivers have underwritten the rising interest in SSCM, both in practice and in academic research. Mounting pressures from legislation, customers, stakeholders; and environmental concerns and requirements of internal business processes, and economic needs have made firms seriously consider the issue of sustainability; that is, what are the economic, environmental and social implications of their operations (Mann et al., 2010). Accordingly, in the academic field SSCM has become an "area of significant research activity" (Pagell \& Shevchenko, 2014) and the core operational activities of procurement, production, distribution, and related logistics are now getting integrated into research on sustainable supply chain management (SSCM) (Morali \& Searcy, 2015). But with an area this wide comes the challenge how to define it. 
For the purposes of this study, we use the definition put forth by Seuring \& Muller (2008) who define SSCM as "The management of material, information and capital flows as well as cooperation among companies along the supply chain while taking goals from all three dimensions of sustainable development, i.e., economic, environmental and social, into account which are derived from customer and stakeholder requirements." (Seuring \& Muller, 2008, p. 1700)

To have a clearer distinction, in this study we adopt the approach of Pagell \& Wu (2009) and “...when we refer to a sustainable supply chain we are in essence referring to an outcome for that supply chain. When we discuss sustainable supply chain management we are referring to managerial decisions and/or behaviors" (Pagell \& Wu, 2009, p.38). Further, when building on the research on SSCM, we view the term in its broadest sense, and include all research that studies the environmental and/or social impacts of a supply chain, including research on reverse logistics, green SCM, closed-loop SCM, and ethical/responsible SCM as sources for this research, as has been suggested by Pagell and Shevchenko (2014).

Having discussed the construct of sustainability in a broader perspective and sustainability's increasing relevance in supply chain management, the drivers that move firms to adopt sustainable SC practices are considered next. 


\subsection{Drivers That Move Firms to Adopt Sustainable Supply Chain Management Practices}

With an increasing interest in the field, the emphasis on adoption of SSCM practices has increased both in practice and in academia. Seuring (2004) suggests that sustainability needs to be transformed into business practices as a guiding principle A number of studies on sustainable global supply chain management have identified motives that range from strategic to pragmatic (Hart, 1997; Gereffi et al., 2005; Runhaar et al., 2006; Vermeulen and Ras, 2006; Muller et al., 2009). The discourse on sustainability, from its origins in environmental issues (WECD, 1987; Tibbs, 1991; Socolow, 1994), has evolved to include economic and social aspects (Elkington, 1998; Cramer et al., 2004). Ras and Vermeulen (2009) posit that "profitability as part of the economic aspect is of extreme importance" (p.326). This is amply supported by common sense.

Seuring and Muller (2008) extract the core issues relating to SSCM in their Delphi study with experts (academics, practitioners and non-government organizations NGOs). The authors find that "Efforts inside of companies have to match government regulation and customer demands, while also reacting to NGO pressure. Therefore, these forces can be identified as the most important pressures and incentives for sustainable supply chain management" (p. 461). Mann et al. (2010) have presented a composite list of drivers, extracted from the literature, that motivate the adoption of SSCM practices. 
This study, for parsimony, takes up the three most important drivers for the adoption of SSCM practices, i.e., regulations, competitiveness and stakeholder pressures. Here, the construct competitiveness is assumed to envelop both the drive to meet customer demand and the drive to be economically successful (Seuring \& Muller, 2008).

\subsubsection{Regulations}

As one of the most important drivers, the legislation leaves little option for an organization but to comply or to face business-disrupting penalties and other legal action. While in some locations even the exit option may require permission from regulators, in other countries a firm may have to deal with legacy problems even after it has left the business. Regulations may be in the form of environmental laws (Fleischmann et al., 1997; van Nunen \& Zuidwijk, 2004; Georgiadis \& Vlachos, 2004; Paulraj et al., 2017; Esfahbodi et al., 2017) which are general in nature, or they may be specific to the industry, for example mandating a specified recycled content in a new product ( Krikke et $a l ., 2004)$ or fixing end-of-life (EOL) take-back responsibility ( Krikke et al., 2004). Regulatory acts in turn may be driven by concerns like a government's interest in preventing environmental degradation, public opinion, stakeholder pressure, lobbying by interest groups, scarcity of resources, preferred models of development, which in turn, may also act directly as drivers for an organization (Mann et al., 2010). Apart from environmental legislation, sustainability issues may also be activated by governmentmandated product recalls (Johnson, 1998) or as a strategic decision to reduce penalty costs by a company (Ketzenberg, 2009). 
Pointing this trend out in the context of the European Union, Linton et al., (2007 p.1077) evidence that "The European Parliament views this concept as so critical to the future of the EU that current and future legislation must integrate sustainability into implementation orders (American Chamber of Commerce of Europe, 2004).” Thus, the search and adoption of sustainable supply chain management practices can be triggered by regulations and changes in regulatory policy (Linton et al., 2007). Change in policy for electrical and electronic equipment in Europe (EU, 2003) is one such instance. Esfahbodi et al., (2017) find that governance pressures are necessary for the protection of the environment and they play an important role in the implementation of sustainable supply chain management practices.

Even in cases when these requirements are not mandatory, political or legal concerns (including existing regulations and economic requirements and any possible future regulations) (Dowlatshahi, 2005) and official campaigns for proper disposal of recycled or used products (Georgiadis \& Vlachos, 2004) can prompt organisations to adopt sustainable practices that coalesce into the firm's supply chain management. Some industries, for example, the case of rechargeable battery industry in the United States, have been active in the take-back and recycling arena to pre-empt any such regulation (Toffel, 2004). Various researchers have also discussed the role of sustainable practices in enabling the firm to satisfy its social responsibilities (Nagel \& Meyer, 1999; Presley et al., 2007) even at the stage when these initiatives are voluntary. 
There is a large number of social and ecological problems that cannot be simply legislated away. The other two drivers, i.e., competitiveness and stakeholder pressures become important in handling those scenarios. These drivers are discussed in the next two sub-sections.

\subsubsection{Competitiveness}

As brought out by literature, the drive to gain and retain competitiveness is an important consideration for the adoption of sustainable supply chain management practices. These comprise of internal and external environmental practices entailing implementation of internal business processes or operational considerations for the adoption of elements of reverse logistics, closing-the-loop, green supply chains and their integration into the forward supply chain. Issues like warranty, claims and recalls, periodical replacement of installed capacity and product lease (Krikke et al., 2004) necessitate effective and efficient reverse logistics and closed loop systems. Having a competitive reverse logistics is also essential for enhancing the following: operating level effectiveness (Richey et al., 2005a), operational performance, i.e. responsiveness (Richey et al., 2005b; Skinner et al., 2008) and service quality (Daugherty et al., 2005; Richey et al., 2005b; Skinner et al., 2008); process performance (Langer et al., 2007), processing effectiveness (Richey et al., 2005a), production rate (Spengler \& Schröter, 2003), recovery rate (Spengler \& Schröter, 2003), collection of used products/ material (Flygansvaer et al., 2008), and recycling (Johnson, 1998; Spengler \& Schröter, 2003). All these activities are also sine qua non for any remanufacturing activity (Majumder \& 
Groenevelt, 2001) or 'closing the loop.' A properly managed SSC also helps in reduction of uncertainties (Ketzenberg et al., 2006) and enables the return of unsuitable, defective or damaged merchandise to a supplier (Johnson, 1998). The strategic need to protect aftermarkets is also driving diverse companies like HP, Lexmark, Ford, and Mercedes into product recovery programs (Toffel, 2004).

Sustainable supply chain management practices also offer possibilities that lead to better financial performance (Langer et al., 2007), higher revenues (Tibben-Lembke, 2004; van Nunen \& Zuidwijk, 2004; and Miemczyk, 2008) and higher profitability (Majumder \& Groenevelt, 2001; Stock et al., 2002; Kulp et al., 2004; Fandel \& Stammen, 2004). Chan, (2007) posits that "one of the driving forces for firms to adopt the reverse logistics practice is cost saving from reverse logistics activities" (p.350). This view is supported by a number of researchers who find that properly managed reverse logistics and closing the loop can lead to cost reduction/saving/benefits/ effectiveness (Matthews, 2004; Dhanda \& Hill, 2005; Fassoula, 2005; Richey et al., 2005a; Langer et al., 2007; Efendigil, 2008; Miemczyk, 2008), energy cost reduction (Fassoula, 2005), reduction in the cost of disposal (Krikke et al., 2004; Hicks et al., 2004; Ketzenberg, 2009); reduction in the cost of quality (Fassoula, 2005); reduction in holding costs (Ketzenberg et al., 2006; Ketzenberg, 2009); reduction in waste (Goldsby \& Closs, 2000; Matthews, 2004; Fassoula, 2005); reduction in penalty costs (Ketzenberg, 2009); reduction in shortage costs (Ketzenberg et al., 2006) and reduction in redundancy in operations (Goldsby \& Closs, 2000). Dowlatshahi’s 2005 paper discusses and supports the adoption of reverse logistics and closing the loop in light of the need to reduce 
strategic costs (including life cycle and performance costs). The research of Richey et al. (2005b) has discussed the improvement of strategic performance by the adoption of the reverse logistics system. Georgiadis and Vlachos (2004) posit that "Economical...issues are the main driving forces for the development of closed-loop supply chains" (p.449). In the current literature under review, this view of the authors is supported by Nagel and Meyer, (1999); Spengler and Schröter, (2003); Matthews, (2004); Geyer and Jackson, (2004); Daugherty et al., (2005); Linton and Jayaraman, (2005); Presley et al., (2007); and Skinner et al., (2008): and this improved economic performance may arise from better acceptance by customers, lower penalty costs, better operational performance, and the recapture of value from recovered products, remanufacturing, reduction in costs, newer markets, higher revenue and improved profitability as posited by the authors listed above. Paulraj et al., (2017) sum up published literature to posit that close collaboration with supply chain partners can lead to creation of difficult to imitate dynamic capabilities which can become a source of sustained competitive advantage and, as per resource dependence theory, these capabilities can lead to improved firm performance.

\subsubsection{Stakeholder Pressures}

Wood (1991) surveys earlier (the 1980s) literature spanning the interactions of stakeholders and society vis a vis business. The traditional research areas concerning business and society covered "corporate philanthropy (Pasquero, 1990; Siegfried et al., 1983; Useem,1988); community relations (Burke et al., 1986); responses to activist pressures (Paul \& Duffy, 1988); ethical investing (Massie, 1989; Wokutch, 1982) ; 
international stakeholder management (Mahon \& Kelley, 1988; Windsor \& Preston, 1988); and business-government relations, including corporate political action (Buchholz, 1982; Epstein, 1969; Kelley \& Agle, 1990 ; Maitland, 1983; Marcus et al., 1987; Mitnick, 1980; Stevens et al., 1986; Vogel, 1978; Wood, 1986)" (Wood, 1991, p.705).

Wolf (2014) draws from Parmigiani et al. (2011) to define stakeholder pressure as the "degree of accountability an organization perceives for the actions and decisions it takes regarding product design, sourcing, production, or distribution, to stakeholders (p.319)." Firms that are highly visible are constantly under stakeholder scrutiny, and this scrutiny extends to the partners of its supply chain (Parmigiani et al., 2011) which may penetrate through to numerous tiers.

As per stakeholder theory (Freeman, 1984), stakeholder pressures can arise from consumers, activists or even other external stakeholders, and can affect various tiers of a supply chain (Parmigiani et al., 2011) to move them to adopt sustainable supply chain management practices. Pagell and Wu (2009), Reuter et al., (2010) and Parmigiani et al. (2011) discuss and underline the importance of stakeholder and sustainable supply chain interactions. Stakeholders, such as the media, activists, and consumers can raise social and ecological issues and apply significant pressure or coercion on the focal firm and its supply chain (Hendry, 2006; Phillips and Caldwell, 2005; Parmigiani et al, 2011) using boycotts or by abstaining from purchase, which can appreciably affect the profitability and reputation of the firm. Firms may adopt the strategy of developing a collaborative relationship with external stakeholders, such as non-profit organizations or non-government organisations (NGOs) (Huegens et al., 2002; Welcomer et al., 2003; 
Butterfield et al., 2004; King, 2007; Sangle, 2010) and be proactive in their approach, working towards stakeholder satisfaction, abating lenders and investors' concerns towards environmental liability, and addressing the concerns of the judiciary or media (Sangle, 2010).

Consumers may also exert significant pressure on the focal firm to adopt sustainable practices. European consumers are one of the biggest pressure groups that advocate for sustainability, and their concern about the ecological effects of products (Caniato et al., 2012) results in a significant impact on management decisions up and down the supply chain (Choi et al., 2015).

With progress in technology, better quality management, higher education in the population, a keener awareness of consumer rights, liberal return policies of businesses and increasing expectations, customers today are less ready to tolerate any defects or products that are less than perfect (Guide et al., 2003b; van Nunen \& Zuidwijk, 2004; Krikke et al., 2004 and Avitathur \& Shah, 2004). Customers tend to return products readily, leading to higher return ratios that create a direct pressure on a firm. Rising environmental awareness has led to amplified customer demand for a firm to have a "green image" (Georgiadis \& Vlachos, 2004; Krikke et al., 2004). These consumer pressures may still be evolving (Zhu et al., 2005). While Chan and Lau (2001) found that American consumers have stronger green purchasing behavior, as compared to the Chinese, Lo and Leung (2000) find that the younger Chinese consumers are picking up this trend. Along with a similar line of research, Miemczyk (2008) discusses the need for improving (or maintaining) a firm's reputation. The need to cater to product returns 
optimally translates into a need to adopt sustainable supply chain practices and create a robust SSCM system. Greater customer education regarding the potential economic and non-economic benefits of reverse logistics (Dowlatshahi, 2000), consumer rights (van Nunen \& Zuidwijk, 2004) and specific customer requirements regarding quality, reliability, delivery (Dowlatshahi, 2000) and pressures for appropriate corporate social responsibility (CSR) (Li et al. 2014a) push for a sustainable supply chain system. Higher customer service, Just-in-Time deliveries (JIT), short-notice supplies, after-sale service and repairs (Dowlatshahi, 2005) and optimal customer satisfaction (Maslennikova \& Foley, 2000; Fassoula, 2005; Langer et al., 2007; Efendigil, 2008) all call for an efficient, effective and sustainable supply chain. Dowlatshahi (2005) has discussed the adoption of reverse logistics for improvement in reliability and conformance, a fundamental customer requirement now. Another factor considered by researchers in this regard is the improvement of a firm's reputation (Miemczyk, 2008) by the adoption of sustainable practices.

Meixell and Luoma (2015) find that various pressures from stakeholders lead to an increase in a firm's awareness, its adoption of sustainability practices and their effective implementation. And even though different sets of stakeholders may have a "dissimilar influence" they do have an appreciable overall influence on key decision areas, whether environmental or social.

There is also some evidence that virtuous organizations promote ethical behavior, and that moral motives and ethical pressures can be significant drivers for firms to "do good" and adopt of sustainability practices (Sekerka et al., 2014; Paulraj et al., 
2017). Moral pressures can lead to closer adherence to corporate social responsibilities and have a high correlation with firm performance (Graafland \& Van de Ven 2006; Fernando \& Almeida 2012).

\subsection{Sustainable Supply Chain Management Practices}

Finding how to create a supply chain that is sustainable and what practices to adopt for that are important questions being raised for the past few decades (Kleindorfer et al., 2005).

Pagell \& Wu (2009) conducted case studies of ten firms to arrive at a set of coherent management practices that need to be adopted for the successful creation of a sustainable supply chain. The authors find that exemplary companies "have internalized sustainability goals in such a way that their noneconomic performance is a critical factor for growth and financial performance. In other words, financial goals and environmental goals are aligned. Sustainability is then an integral part of their business and is incorporated in every aspect of their supply chain" (p.54). Wolf (2011) also examines various SSCM practices. These practices have been researched under various heads such as external and internal environmental practices (Zhu et al., 2008a; Zhu et al., 2008b; Paulraj, 2009), supplier selection (Zhu et al., 2008a; Paulraj, 2009), supplier evaluation (Vachon \& Klassen, 2006; Vachon, 2007; Paulraj, 2009), cooperation with customers (Vachon, 2007; Zhu et al., 2007; Zhu et al., 2008a; Zhu et al., 2008b), and eco-design (Zhu et al., 2008a; Zhu et al., 2008b; Zhu \& Sarkis, 2007) to achieve environmental sustainability objectives and are studied along with social sustainability practices 
(Vachon \& Mao, 2008). Researchers stress that to achieve sustainability objectives, a business is required to adopt innovative practices (Pagell $\& \mathrm{Wu}, 2009$ ) as it is a new way to think about the business (Hart \& Milstein, 2003). Utterback (1996) feels that such "radical innovations" are more probable to come from the newer entrants in the field. This idea is supported by the rise of new types of entities like Interest Corporations or Community Interest Companies (Pagell \& Shevchenko, 2014) that are focussed more on sustainability than profits.

Working under a regulatory mechanism or stakeholder pressures, or striving to gain a sustained competitive advantage, firms have tended to develop standardized practices to meet with the laid down requirements. These have been identified as "two sets of related yet independent" (Vachon, 2007, p.4359) activities or practices, namely 'external and internal environmental practices' (Field \& Sroufe, 2007; Klassen, 1995; Logsdon, 1985). These are practices discussed in the sub-sections 2.4.1 and 2.4.2. This is followed by, in subsections 2.4.3 to 2.4.7, discussion on practices focussing on upstream, i.e. 'supplier selection' and 'supplier evaluation and monitoring,' followed by a discussion on 'cooperation with customers' on the downstream side. This is followed by a discussion on 'eco-design,' and 'social sustainability practices' that span entire supply chain activities.

\subsubsection{External Environmental Practices}

Practices that have been evolved and are being used for management of sustainability-related activities of a supply chain, which are external to an organization, 
fall into this category. Vachon and Klassen (2006) suggest that an organization can use two alternative approaches to manage or influence the practices in other organizations along the supply chain: either the organization can invest its resources, or the organization can use 'arms-length' market mechanisms to influence the supply chain partners. The authors point out that the 'internalization/ externalization' theoretical lens (Buckley \& Casson, 1976) has been beneficially used to view these practices by Krause et al. (2000) and others, even though Vachon and Klassen (2006) use terms that are different from those used by Buckley and Casson (1976). A derivative of transaction cost theory (Williamson, 1981) this internalization/externalization framework creates a distinction between activities conducted by the firm by deploying its resources (internalization) and the activities conducted by deploying market mechanisms (externalization) Krause et al., 2000). Krause et al., (2000) term "arm's length" transactions as "environmental monitoring"; while joint efforts of buyers and suppliers are termed as "environmental collaboration" (Vachon \& Klassen, 2006). In contradistinction to terms 'internalization/ externalization' used by Krause et al. (2000), we make use of the constructs external environmental practices and internal environmental practices in this research in the same way as by Paulraj (2009). While the author uses the construct internal environmental practices to include the aspects of waste reduction, reuse, and recycle (Paulraj, 2009, p.464), the external environmental practices includes cooperation with suppliers to achieve environmental objectives, to develop new source reduction strategies, to improve suppliers' waste reduction initiatives and those for cleaner production, basically focussing on "supply side of value chain" (Paulraj, 2009, 
p.457). To complement this discussion, the demand side of the value chain is discussed in sub-sections 2.4.5 under the construct 'cooperation with customers'. Before that, in the next sub section, we discuss 'internal environmental practices.'

\subsubsection{Internal Environmental Practices}

Internal environmental practices are those practices that are used for the management of sustainability-related activities of a supply chain, which are internal to an organization. These have been identified as arising from the commitment to GSCM from senior managers and mid-level managers, and involves cross-functional cooperation for environmental improvements, working towards total quality environmental management, and institutionalization of environmental compliance and auditing programs and environmental management systems (Zhu et al., 2008a; Zhu et al., 2008b). Zhu and Sarkis (2007) and Zhu et al., (2007) also take into account ISO 14001 certification and eco-labelling of products as a part of internal environmental management.

\subsubsection{Supplier Selection}

Krausse, Vachon, and Klassen (2009, p.18) posit that "The underlying premise that structures our discussion is straightforward: 'a company is no more sustainable than its supply chain"' underlining the importance of supplier selection and supplier's continuing evaluation and monitoring. While Klassen and Vachon (2003) underline the importance of certification and supplier development as key practices for "green" sourcing, Ho et al. (2010), also find that environmental or sustainability concerns are being used as supplier selection criteria. Bowersox et al. (2000) underline the importance of careful selection of 
suppliers in light of their important role in supply chain functioning and performance, which can also result in competitive advantage for the firm (Handfield et al., 2002). Walker and Philipps (2006) emphasize the use of sustainability criteria in the supplier selection process. These criteria also include whether the firm has been certified as ISO 14000 compliant.

Various practices that support the proper selection of suppliers who can meet the sustainability requirements of the organization are indicated by: selection of suppliers "based on their environmental competence; on their ability to support organisation's environmental objectives; on their environmental performance and on their ability to develop environmentally friendly goods" (Paulraj, 2009, p. 466). This appears very logical when we take a resource-based view of the supplier selection process. However, supplier selection may become more difficult when searching for an "alignment of social and environmental viewpoints" (Parmigiani et al., 2011, p. 221; Ageron et al., (2012). Maintaining an appropriate supplier portfolio is now considered a "standard tool" to meet sustainability expectations (Pagell et al., 2010). Turker and Altuntas (2014) find that the firms interested in sustainability tend to integrate those suppliers into their supply chain who are committed to achieving their sustainability goals. This focus carries within itself the risk of supply disruption when any one member of this select, but reduced, supplier base of "sustainable" suppliers fails (Das, 2017). 


\subsubsection{Supplier Evaluation and Monitoring}

Even after integration of a supplier into supply chain, regular and ongoing supplier evaluation and monitoring is an important SSCM practice. Pagell \& Wu (2009), in a case study of ten exemplar companies that had adopted SSCM practices, find that "the majority of the novel activities identified fall under the rubric of supplier management" (p.54). Supplier management also includes periodic or continuous evaluation and monitoring whether the supplier continues to meet the criteria which were set down at the time of his selection.

These supplier evaluation and monitoring practices take the form of, or are indicated by, "regular environmental audits into suppliers' internal operations; periodic evaluation of suppliers' environmentally friendly practices; site visits to suppliers' premises to help them improve their eco-performance; periodic evaluation of second-tier suppliers' environmentally friendly practices; asking suppliers to commit to waste reduction goals and sending environmental questionnaires to monitor their compliance" (Paulraj, 2009, p.466; Vachon, 2007; Vachon \& Klassen, 2006). Turker and Altuntas (2014) find that the firms set sustainability criteria for their suppliers, set a code of conduct regarding sustainability goals and tend to ensure supplier compliance through rigorous auditing, this being more so for suppliers that are working out of developing countries where the risks of non-compliance are higher. 


\subsubsection{Cooperation with Customers}

To be sustainable, cooperation with customers forms an important practice in the management of the downstream supply chain. Vachon (2007, p.4374); Zhu et al. (2007, p.1051); Zhu et al. (2008a, p.271) and Zhu et al. (2008b, p.9) highlight the importance of cooperation with customers "for cleaner production, for green packaging, for using less energy during product transportation, for developing a mutual understanding with customers of responsibilities regarding environmental performance, and to reduce the environmental impact of their activities". The aspects covering supply side have been discussed in subsection 2.4.1 and 2.4.2.

\subsubsection{Eco-design}

Considering the fact that design for ecologically optimal products is an important SSCM practice, Chen et al., (2005); Zhu et al.(2008 a, p.271 \& 2008b, p.9); Zhu \& Sarkis (2007, p.2336) and Wu et al. (2012, p.627) outline practices towards eco-design that involve designing "products for reduced consumption of material/energy, for reuse, recycle, recovery of material, component parts and to avoid or reduce use of hazardous products and/or their manufacturing process". For eco-design not only eco-friendly raw materials or inputs are to be kept in mind (Rao \& Holt, 2005), the sustainable product has to be amenable to easy disassembly, reuse, recycling, and biodegradability (Zhu et al., 2012; Carter and Easton, 2011). Eco-friendly product design needs to be complemented by eco-friendly process design. This entails the adoption of processes that aim at significant reduction in air and water emissions, reduction in solid wastes, and reduction 
in consumption of energy, materials, and resources. Achieving all this is expected to result in the improved environmental performance of the focal firm (Rao \& Holt, 2005; De Giovanni, 2012; Paulraj et al., 2017).

\subsubsection{Social Sustainability Practices}

Elkington (1997) points out that businesses have "preferred to overlook" the aspect of social justice while working for economic prosperity or even for environmental quality. Kleindorfer et al. (2005) find that sustainability research has overlooked the social component of sustainability and that this component needs further research. An important component for achieving a healthy "triple bottom line" of economic prosperity, environmental protection and social justice (Elkington, 1997, 1999 \& 2006), social sustainability practices focus on social aspects and try to ensure that impacts of the activities of an organisation on workers and society are positive or, at the very least, not negative. Corporate social responsibility is envisaged by some academics as a set of voluntary activities by a firm that span economic, social and environmental well-being of society (Blome \& Paulraj 2013; Vlachos et al., 2013). Vachon and Mao (2008) measure corporate social responsibility by measuring the organization's responsibility towards its workers and towards society, both at the level of local community and as a whole. The authors examine (p. 1556) whether the organization "frequently employs corporate codes of conduct and other aspects of corporate social responsibility, whether the organization commonly encourages workers to volunteer for social causes and has incentives that facilitate that involvement; whether the organization contributes to charitable causes; 
whether the general approach of the organization to human resources is to invest heavily to attract, train and retain employees; whether the organization employment of women is limited and usually takes place in less important jobs, or is equal to that of men; and whether in the organization, for similar work, wages for women are significantly below those of men or equal to those of men." These are posited to indicate whether the organization is implementing social sustainability practices or not. Pagell and Shevchenko (2014) trace social sustainability practices such as commitment to employees (Pullman et al., 2009) back to the work of Deming (1986). Kolk (2016) argues that firms act between two boundaries of being "economically profitable, law-abiding, ethical and socially supportive" (Carroll, 1999, p. 286), and being proactive beyond mere compliance (Portney, 2008). However, both of these boundaries face challenges when viewed in the context of a supply chain that is operating across borders (Kolk, 2016) as to what does "law abiding" mean beyond borders, and how feasible is it for a firm to be proactive across the globe. Most of the social sustainability practices that are adopted by firms focus internally, that is, at the actions being taken by the focal firm. There is sparse research on whether these criteria are used for, say, supplier selection or supplier monitoring.

\subsection{Sustainable Supply Chain Performance}

To be sustainable an organisation has to keep economic, ecological and social objectives in focus, also known as the "triple bottom line" approach (Johnson, 1991; Elkington, 1997, 1999 \& 2006; Kleindorfer et al., 2005). Accordingly, the measures of 
performance of a supply chain need to cater to its environmental and social performance in addition to economic performance (Gladwin, Kennelly \& Krause 1995; Starik \& Rands 1995; Jennings \& Zandbergen 2005). At the very least, operations of an organisation should not harm ecology or social systems, while still earning profits over a long period of time, ideally forever (Pagell \& Wu 2009). With rise of global trade, performance of supply chains, including their economic, environmental \& social aspects, is under increased focus (Schaltegger \& Burritt, 2014).

The current study adopts these three performance dimensions (economic, environmental and social) to study the impact of adoption of SSCM practices. To these three dimensions a fourth dimension, operational performance, is also added, being the area of special interest to an operations manager.

Pagell \& Wu (2009) find the empirically validated model of green supply chain management (GSCM) by Zhu and Sarkis (2004) and Zhu et al. (2008) "highly commendable" (p.38) that takes into account economic and environmental impacts of a supply chain. To 'green' research, a social dimension also needs to be added and studied. But stakeholders are not content if a firm is merely measuring or monitoring its social impact. With time, the bar is being raised for social performance as well. Now a number of researchers and stakeholders hold the opinion that zero worker accidents, or no harm (no social impact), merely forms the lower limit of expected social performance (Seuring \& Muller, 2008; OXFAM, 2013; ECCJ, 2013), and the firms are actually expected to contribute positively to a society. 
It can be argued that for long-term or 'sustainable' effect, this concern for the sustainability of supply chains has to be tied in with a firm's strategy. Li et al. (2014b) underline this and posit that even when concerned about sustainability issues, firms need to define proper strategic objectives explicitly, and then base their decision-making processes on specific performance indicators to ensure their long-term survival.

In subsections 2.5.1 to 2.5.4, which follow, we discuss economic performance, environmental performance, social performance and operational performance of focal firm (in light of its adoption of SSCM practices.)

\subsubsection{Economic Performance}

The primacy of positive economic performance is underlined by Friedman (1970) who goes to the extent of stating that being profitable is fundamental 'social responsibility' of a business. Arguably, a firm performing poorly on the economic front is very likely to be a self-limiting phenomenon and a drain on the resources of society and damaging to long-term interests of its employees and stakeholders. Carroll (1979) argues that economic performance has priority over environmental and social aspects of triple bottom line and is the "first and foremost social responsibility of business" (Carroll, 1979, p.500). This is supported by Carter and Dresner (2001) and Carter and Rogers (2008) who posit that a practice having a negative impact on economic performance is not sustainable over the long term. Carter and Rogers (2008) state that a firm should clearly recognize its economic goals and set environmental and social goals in line with them. 
On similar lines, Russo and Fouts (1997) and Klassen and Whyback (1999) and others started out on their research on sustainability trying to find out whether being green pays. In their meta-analysis of such research, Golicic and Smith (2013) find that it does pay. It runs counter to earlier assumptions/views that are trying to be green is likely to harm profits (Walley \& Whitehead, 1994). However, trade-offs exist in some instances between economic and non-economic performance (Lee, 2010; Wu \& Pagell, 2011; Kolk, 2012) where hard decisions may have to be taken by the management. But sometimes, there may be a limited degree of freedom to take those decisions. Legislative constraints may preclude a firm the luxury of choosing between the trade-offs, and the firm may have to adopt sustainable practices perforce (Pinkse \& Kolk, 2010; Hahn et al., 2010 Wu \& Pagell, 2011; Winn et al., 2012). Similarly, researchers using a stakeholder theory lens may even suggest the adoption of supply chain management practices that may not have a positive impact on the economic performance of the firm (Clarkson, 1995; Mitchell et al., 1997; Eesley \& Lenox, 2006).

In their Delphi study to discover the relative importance of the three dimensions of sustainability (economic, environmental and social), Seuring and Muller (2008) find that on a five-point Likert scale from 'not at all important' $(=1)$ to 'extremely important' $(=5)$, the "economic dimension is seen as the most important one (4.45). It can be argued that, without economic success, no supply chain can exist in the long run. The other scores are much closer together, with the environmental (4.12) and social (dimension) (3.95)" (Seuring \& Muller, 2008 p. 460). A number of researchers have focussed on the questions such as: can a sustainable management practice result in a positive economic 
outcome simultaneously along with a positive environmental impact (Zhu \& Sarkis, 2004; King \& Lenox, 2002)? Defining success in terms beyond economic performance (Wu \& Pagell, 2011), some supply chains also focus on economic and social performance. These are briefly discussed in the following sub-sections.

\subsubsection{Environmental Performance}

Environmental concern underlines the green and sustainability movement. After the economic performance, environmental performance is expected to get the most attention of a firm, given the rising awareness of people and wide media coverage the phenomenon is receiving; an expectation that is confirmed by Seuring \& Muller (2008a \& 2008b). It derives that it is important to ensure that the firm's operations create the minimal environmental effect and cause no, or minimal, pollution. This would entail the minimal use of hazardous materials; control, monitoring and reduction of emissions; processing of effluents to render them non-damaging for the environment; reduction in the use of material and energy; recovery of process materials; reduction and recycling of waste; reuse, recycling, and remanufacturing. The successful integration of these and other processes in a firm's operations; and thereby, a reduction of the impact on the environment is a desirable outcome. Some researchers underline primacy of environmental concerns in monitoring performance of a supply chain (Keating et al., 2008). Reduction in use of inputs has found support in the research that has found that

process improvement practices like TQM, JIT and Lean also improve environmental performance (e.g., Clark 1999; Curkovic et al., 2000; King \& Lenox 2001; King \& 
Lenox, 2002). Better coordination and cooperation with suppliers and customers and better environmental practices can lead to "better environmental performance" (Zhu \& Sarkis, 2004; Seuring, 2004; Vachon \& Klassen, 2006; Vachon \& Mao, 2008 p.1553). Going a step further, Pagell and Shevchenko (2014) stress that researchers should go beyond making a supply chain less unsustainable and suggest how to have positive and regenerative effects on society and ecological environment.

\subsubsection{Social Performance}

Researchers' stance on social responsibility of a firm has shifted significantly in past five decades, from that of Friedman's (1970) view that the primary social responsibility of a firm is to make profits, to one that propounds that the reduction of negative social impact forms fundamental goal of a sustainable business (Hahn \& Figgs, 2011; Figgs \& Hahn, 2012). Pagell and Shevchenko (2014) go even further to suggest that graduating from 'reduction of negative social impacts', researchers should now work on how a firm can have a positive and regenerative impact on society. Burch et al., (2013) focus their research on the rural landscape and closely look at the impact of global sourcing on rural development. Maertens and Swinnen (2009) study impact of supplier certification on remuneration in developing countries, to ascertain whether it has positive or negative social impact.

A positive social performance of the focal firm is now one of the core goals in SSCM. This may be measured in various ways, including the development of formalized relations by a firm with the community where it operates; increasing its philanthropy 
levels; increasing internships and vocational training offered by the firm for improving the lot of its employees (Muller \& Kolk, 2010).

\subsubsection{Operational Performance}

Keating et al., (2008) suggest that companies can improve their operational performance by improving sustainable supply chain performance. Pagell and $\mathrm{Wu}$ (2009) indicate a strong relationship between sustainable supply chains and operational performance. The authors posit that a "supply chain that performs well on traditional operational metrics is a foundation of a sustainable supply chain" (p.52), which seems self-evident, as any supply chain that fails to perform well operationally can hardly be expected to be sustainable over an extended period. Increased capacity utilization, ontime delivery, the decline in inventory levels, decrease in scrap rate and increase in quality and product line may be used as measures for operational performance (Zhu et al., 2008).

\subsection{Size of Firm}

Size of a firm, which may range from small to large, is an important consideration for managing its supply chain operations. A firm's size is also likely to affect the impact that firm's adoption of SSCM practices may have on its performance. Gooding and Wagner III (1985) in their meta-analytic review of thirty-one field studies on the relationship between size and performance found that while productivity in absolute 
terms increased with increased in size of the organization, the same was not true about the efficiency of organizations, which did not increase with size. Further, the subunits of organizations did not show an increase in productivity with an increase in size. The authors suggested that it could be probably due to free-rider effect. Swamidass and Kotha (1998) find that relationship between adoption of advance manufacturing technology and performance of a firm is moderated by the size the firm. This is also supported by Cagliano et al. (2001). Bowen et al. (2001) use the resource-based view (RBV) to study the relationship of a firm's resources to its triple-bottom-line performance. Drawing from the use of resource dependence theory (RDT) and resource-based view (RBV) by Svensson (2007) it follows that a large organization would have greater resources to deploy for the adoption of SSCM practices and is therefore likely to positively affect its performance. Leal-Rodríguez et al. (2015) find that firm size has a moderating effect on organizational unlearning on firm's performance. Benito-Osorio et al. (2015) analyzed the role of firm size on relationship between product diversification and performance and found that large firms can perform better with a higher level of diversification.

However, smaller firms have their advantages. Camis'on-Zornoza et al. (2004) find that number of employees, as a measure of size, do not increase innovation performance. Gong et al. (2013) in their research on the relationship between employee creativity and firm performance find that creativity is positively related to performance in smaller firms. Bourlakis et al. (2014) in their research on the relationship between firm size and performance in Greek food supply chains find small firms as "top performers." Vithessonthi and Tongurai (2015) in their research on the effect of firm size on the 
leverage-performance relationship examined 170,013 Thai firms and found that for small firms leverage is positively related to performance, while it is negative for large firms. The above literature suggests that firm size does matter and it would be interesting to study the effect of firm size on the relationship of adoption of SSCM practices by a firm and its performance. That is likely to provide an insight whether small and medium-sized firms (SMEs) are also joining this "new wave" and adopting sustainable SCM practices.

\subsection{Theories Used in SSCM}

While Cooper et al., (1997), Croxton et al., (2001), Chen and Paulraj (2004), and Carter et al., (2015) use a conceptual approach to identify constructs, processes and to develop frameworks; Lambert et al., (1998) and Mena et al., (2013) use the case study path to attempt developing theory for supply chain management, theory building for SSCM is still scarcer. Being a nascent field, SSCM is naturally dependent upon existing theories; its own theoretical underpinnings are yet to evolve (Moralli, 2015; Gold et al. 2010; Svensson 2007; Carter and Rogers 2008; Seuring and Muller 2008b). Touboulic and Walker (2015) argue that even efforts to build theories in the field of SSCM are "scarce", and most efforts revolve around importing and using some common theories; and the authors cite stakeholder theory, institutional theory and resource-based view as examples.

Bowen et al. (2001) draw from the resource-based view (RBV) to develop an SSCM framework linking triple-bottom-line performance to an organization's resources. Gold et al. (2010), use this framework to posit that SSCM provides leverage for inter- 
firm resources and inter-firm competitive advantage while confirming the positive effect of SSCM on a firm's performance. Svensson (2007) bases his conceptual framework on RDT (resource dependence theory) and RBV to present a conceptual framework taking first and second order supply chains into consideration. Font et al. (2008) state that theories of SSCM start from the fundamental that for a supply chain to be sustainable upstream and downstream, components of the chain need to be sustainable. Carter and Rogers (2008) propose a theoretical framework where, along with the entire supply chain, sustainability focussed long-term strategies are embedded to achieve a competitive advantage while integrating the three fundamentals of sustainability, i.e. economic, environmental and social. The authors derive theories from sociology/political science (Resource Dependence Theory - RDT), economics (Transaction Cost Theory), biology (Population Ecology) and strategic management (Resource-Based View of the firm RBV), which they find complementary, to posit their theoretical framework (Carter \& Rogers, 2008). The proposed theoretical framework suggests that firms that integrate all three aspects, economic, environmental \& social, will achieve better performance than those who focus on two or less. But this is yet to be tested. Paulraj et al., (2017) use utilitarianism and stakeholder theory to explain the effect of relational motives, arising from the pressures of stakeholders, on adoption of SSCM practices. The authors also posit that ethics based moral issues also serve as strong drivers in their own right, but for this research, we subsume ethical pressures into stakeholder pressures for the sake of parsimony. 
The organisational theoretic review of literature by Sarkis et al. (2011) brings out nine distinct organizational theories used in SSCM literature: "complexity theory, ecological modernization theory, information theory, institutional theory, resource-based view (RBV), resource dependence theory (RDT), social network theory, stakeholder theory, and transaction cost economics" (Sarkis et al., 2011 p.4-5). Further, the authors suggest a possibly useful adaptation of other theories like diffusion of innovation theory, path dependency theory, social embeddedness theory, structuration theory and agency theory in theoretical frameworks of SSCM. Pagell \& Wu (2009) follow a case study method towards building a theory of SSCM.

Touboulic and Walker (2015) suggest a three-pronged action plan that would help theory building: adoption of methodologies that are original, testing of frameworks that have already been developed in the SSCM field and further investigation of different aspects of SSCM where gaps exist in research. 


\section{Chapter 3 Theoretical Framework}

\subsection{Investigative Questions}

With rising interest in the field of sustainability, what to investigate in this developing field at the current stage becomes an important question. Some researchers have addressed this question. Linton et al. (p.1077) argued in 2007 that "it may be premature and/or just an academic curiosity to consider the operationalization of sustainability" and that it may be a "passing fad", but the authors then go on to confirm that "it is worthwhile for operations management researchers and practitioners to consider the implications and impacts of sustainability...". Confirming this, Seuring and Muller, (2008), in their research to extract the core issues relating to SSCM identify "four dimensions that can be used to structure the overall debate on sustainable supply chains: (1) pressures and incentives, (2) measuring impacts, (3) supplier management and (4) supply chain management" (p.464). These are very interesting dimensions for study. But for this research, it is required that the focus of the study be narrowed for parsimonious reasons.

For the current study, we decided to research Adoption of Sustainable SupplyChain Management Practices: Impact on Firm's Performance. This topic, in light of the literature reviewed in Chapter 2 above, raises the following research questions: 
1. Do the key drivers, as identified in the literature, affect the adoption of SSCM practices by a firm?

2. Does the adoption of SSCM practices impact the economic, environmental, social and operational performance of a firm?

3. Does the size of a firm have a moderating effect on the impact that a company's adoption of SSCM practices may have on the company's economic, environmental, social and operational performance?

As these questions are both important and interesting, we need to crystallize them into a research framework. In an endeavor to encompass the core dimensions identified by Seuring and Muller (2008) above, an in light of extant literature reviewed, a theoretical framework is developed, which is presented in the next section.

\subsection{Theoretical Framework}

In this section, we present the theoretical framework which would be used as a basis for this study. Paulraj (2009), Sangle (2010), Paulraj et al., (2017), and Esfahbodi et al., (2017) have studied drivers for the adoption of sustainable supply chain practices, which form the first core dimension "pressures and incentives" as researched by Seuring and Miller (2008). From the literature, it is apparent that the three most important drivers that lead to the adoption of SSCM practices by firms are (1) regulations by governments; (2) the drive to be competitive in the market, or to emulate the competitors to work 
towards sustainability; and (3) the pressures of stakeholders. These are grouped as drivers in the first group of Figure 3.1 below. 
Drivers/Motivations

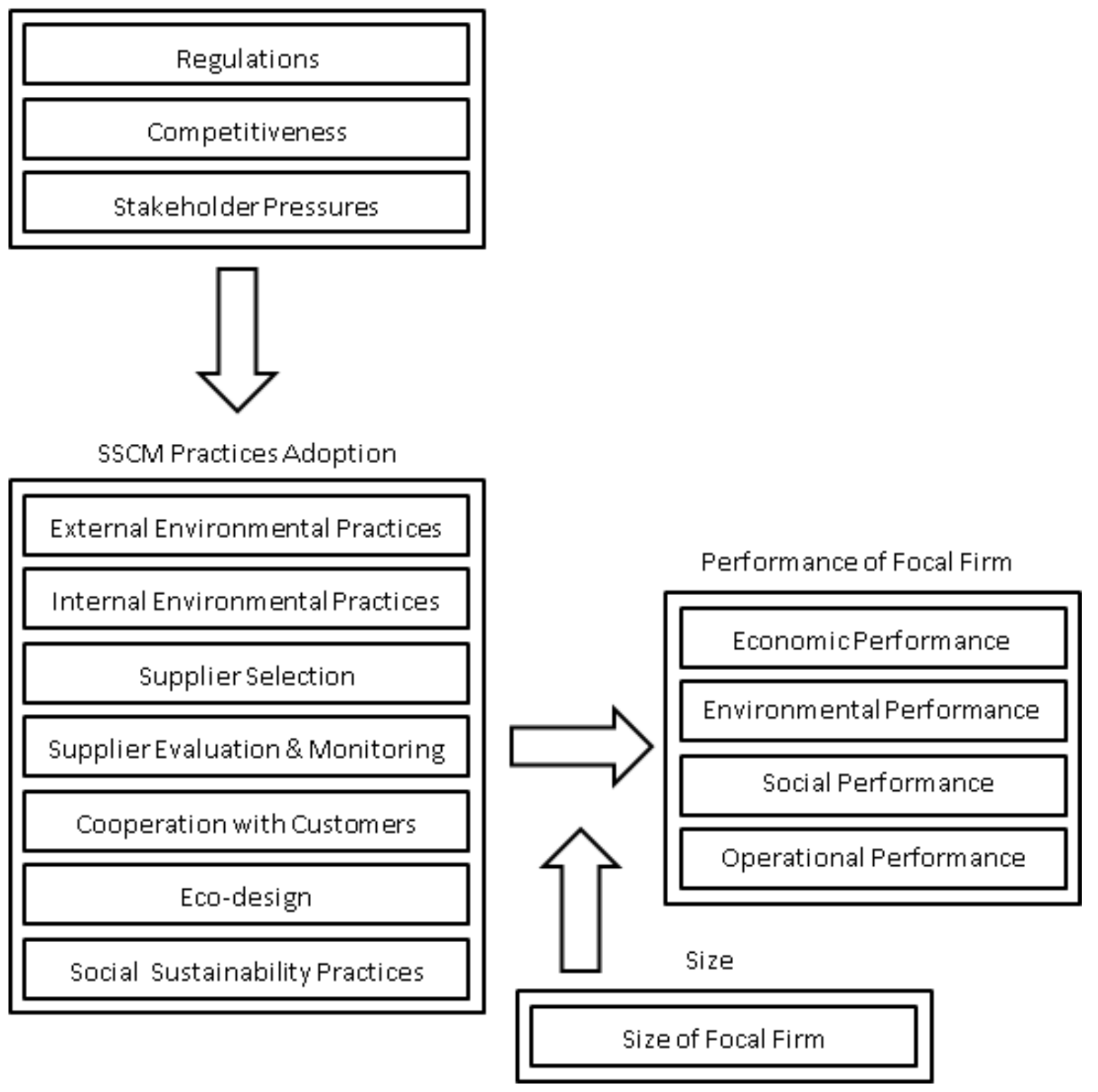

Figure 3.1 Theoretical Framework 
The second group broadly covers the important or 'core' dimensions "supplier management" and "supply chain management" identified by Seuring and Miller (2008), being SSCM practices that help "cooperation and communication between supply chain members", practices that help in "risk management", with a "proactive approach", taking into account the "total life cycle" approach (e.g. through eco-design), enabling better performance on environmental and social fronts (Seuring \& Miller, 2008, p. 461). This group covers SSCM practices adopted by the focal firm including external environmental practices, internal environmental practices, supplier selection, supplier evaluation and monitoring, cooperation with customers to build sustainable products; eco-design of products, packaging, and processes; and social practices leading to sustainability.

The third group covers the "measuring impact" dimension where the impact of SSCM practices on a firm's performance is sought to be studied. For this, we plan to find the impact on economic performance, environmental performance and social performance of the firm, as well as to find out the impact on the operational performance of the firm.

The first group, i.e., the drivers, may have some direct impact on the third group, i.e., the performance of a firm. For example, it could be argued that some regulations may impact the economic performance of a firm in a negative way, or competitiveness may impact economic performance of a firm directly. It needs to be emphasised here that these drivers are not being studied in this research as independent concepts, but within the context of their relationship with adoption of SSCM practices. Also, the possible 
direct effect is not supported or suggested by the reviewed academic literature, or by theory. The drivers have to make their impact through some action, or through some practice undertaken by the focal firm. For example, it is unconceivable how stakeholder pressures can improve performance of a firm directly, without any action by the firm. So direct effect of drivers on performance, if any, was not considered in the current research as it did not meet the contextual theoretical considerations.

The research framework is discussed in detail in the following sections.

\subsection{Drivers for Firms to Adopt Sustainable Supply Chain Practices}

The first step in this research is to understand the drivers that impel firms to adopt sustainable supply chain management practices. As discussed in Chapter 2, the extant literature suggests the existence of a number of motivators for adoption. For parsimony, the drivers/motivators are grouped into three broad categories: regulations, competitiveness, and stakeholder pressures. These are presented in the sub-sections below.

\subsubsection{Regulations}

Regulations are prime movers for a firm since these cannot be ignored without running a major risk of significant fines, penalties or disruption of business. Thus they comprise a major factor for the adoption of sustainable supply chain management practices, at least to the extent prescribed in the regulations in question. As Cosimato and Troisi (2015) state, "the respect of environmental regulations is fundamental" (p.256). 
This motivator is becoming very important in the developed countries, more so in the countries that are members of the European Union. Indicating this trend, Linton et al., (2007 p.1077) point out that "The European Parliament views this concept as so critical to the future of the EU that current and future legislation must integrate sustainability into implementation orders (American Chamber of Commerce of Europe, 2004).”

Changes in policy or regulations can trigger the search for sustainable supply chain management practices and their adoption (Linton et al., 2007). Policy on electrical and electronic equipment in Europe (EU, 2003) is one such example of a change in policy.

\subsubsection{Competitiveness}

Firms have to be competitive in their field of operation in the face of competition, or when there is more than one player in the market. The discourse on what is known to be "win-win sustainability" is increasingly making firms veer around the idea that adopting of SSCM practices is likely to make them more competitive in the market (Cucculelli \& Goffi, 2016; Tan et al., 2015; Melewar et al., 2013). This is truer in the fields where customers are more aware of sustainability issues, or where competition is bringing out increasingly sustainable products or services into the market. It could be argued that all firms want to be competitive, and how competitiveness can act a driver for some firms and not others. It is true that all firms aim for sustainable competitive advantage, not all firms focus on competitiveness to adopt such SSCM practices that lead to a better performance. Some firms merely aim to comply with the regulations and may 
adopt such SSCM practices that are barely adequate and just enough for such purposes. Hence in this research competitiveness has been selected as a distinct driver construct for study.

\subsubsection{Stakeholder Pressures}

Meixell and Luoma (2015), in their systematic review, find stakeholders pressures are very important in changing the behavior of a supply chain. They state that such pressures increase awareness about sustainability issues, the adoption of goals that are sustainable by the supply chain participants, and the adoption of practices that make the supply chain sustainable. Sangle (2010) suggests that stakeholder pressures work through stakeholder relationships, concern for stakeholder satisfaction, stakeholders' concerns for liability, customers' wishes to protect the environment, and inquiries from stakeholders about environmental and other impacts of a supply chain's operations.

\subsection{Sustainable Supply Chain Management Practices}

\subsubsection{External Environmental Practices}

External environmental practices encompass working and cooperating with suppliers on practices which are external to the firm. Even when these practices do not fall within the focal organization's operations, the firm still tries to influence its suppliers to engage in sustainable practices relating to the environment. This entails cooperating in areas of cleaner production, reduction in waste, new source reduction and achieving objectives relating to the environment (Paulraj, 2009). 


\subsubsection{Internal Environmental Practices}

Internal environmental practices relate to practices that reduce the environmental impacts of operations of the focal firm and are internal to the organization; and for that reason more in its control (Paulraj, 2009; Zhu et al., 2008a; Zhu et al., 2008b). These cover practices such as the sale of excess inventory and scrap, the use of packaging that is returnable/reusable, trying to use lesser resources for same operations, documentation practices, and the elimination of physical waste (Paulraj, 2009; Zhu et al., 2008a; Zhu et al., 2008b).

\subsubsection{Supplier Selection}

Krausse et al., (2009) stress that "the purchasing function becomes central in a company's sustainability effort" (Krausse et al., 2009, p.18). This starts with the selection of suppliers that can fit with the sustainability objectives of the focal firm. Paulraj (2009) and other authors underline that suppliers be selected on the basis of their environmental competence, their ability to support focal firm's environmental objectives, their having a performance track record in environmental practices and their following a rating system and ISO 4000 certification (Paulraj, 2009; Vachon, 2007; Zhu et al., 2008a).

\subsubsection{Supplier Evaluation and Monitoring}

Even after the selection of suppliers for the purchase of material and services, it is important that a system for regular and periodic evaluation of suppliers be put into place to monitor whether they are in continuous compliance with their commitments, and 
continue to follow the SSCM practices expected of them. This evaluation can be implemented by regular examination of their internal operations and by conducting sustainability audits; monitoring their environmentally friendly practices and ensuring that they adhere to their waste reduction goals; looking into the practices of their (second tier) suppliers - including using questionnaires and site visits to help the process (Vachon \& Klassen, 2006; Vachon, 2007; Paulraj, 2009).

\subsubsection{Cooperation with Customers}

Firms practice cooperation with customers to achieve their sustainability objectives. This includes cooperating for eco-design, for cleaner production, environmentally friendly packaging, energy saving in transportation \& distribution activities, reducing environmental impact and arriving at a mutual understanding to achieve environmental objectives (Vachon, 2007; Zhu et al., 2007; Zhu et al., 2008a; Zhu et al., 2008b).

\subsubsection{Eco-design}

Designing products for sustainability, or eco-design, involves designing the products in such a way that they consume less material and energy during manufacturing and distribution, permit the use of reusable, recycled parts, using a process that enables recovery of materials used in process, using recycled components as well as permitting avoidance or reduction of hazardous products in manufacturing and ensuring that the products are amenable to be reused, recycled or remanufactured (Zhu \& Sarkis, 2007; 
Zhu et al., 2008a; Zhu et al., 2008b). It would stand to reason that this may be best done in close cooperation with customers, as discussed in 3.4.5 above.

\subsubsection{Social Sustainability Practices}

McKone-Sweet (2004) in his research has underlined the need to practice gender equality and pay fair wages. Vachon and Mao (2008) have studied social sustainability practices of various firms. The practices in vogue are in the format of use of corporate social responsibility codes that ensure socially responsible action, encouragement of volunteer activity in firm, contribution to charitable causes, enforcement of human resource policies for training employees and managing their retention and the employment of women and paying of fair wages (Vachon \& Mao, 2008).

\subsection{Firm Performance}

\subsubsection{Economic Performance}

Firms can witness improvement in economic performance due to the adoption of SSCM practices. This can be indicated by reduction in material purchase cost, reduction in consumption of energy, savings in fees paid for waste treatment or waste discharge and reduction in fines for environmental accidents (Zhu \& Sarkis, 2007; Zhu et al., 2008a ). These economic impacts are generally measurable in money terms. 


\subsubsection{Environmental Performance}

Environmental performance is generally measured in terms of environmental impacts of the operations of the focal firm. These can be in terms of reduction in generation of waste water and solid waste, reduction in polluting air emissions, decreasing the use of materials that are environmentally harmful or toxic, improving the firm's overall position relating to the environment, and decreasing environmental accidents (Zhu et al., 2008).

\subsubsection{Social Performance}

Muller and Kolk (2010) posit that social performance of a firm can be measured by measuring the increase in vocational training and internships offered, the increase in philanthropy, and the extent of formalized relations with the community.

\subsubsection{Operational Performance}

Operational performance may be measured from on-time delivery of goods, fall in inventory levels and scrap rate, increase in the firm's product line and its quality, and increase in utilization of capacity (Zhu et al., 2008).

\subsection{Size of Firm}

Using a resource-based view (RBV) and resource dependence theory (RDT) (Svensson, 2007) it seems plausible that a large sized firm would have more resources to deploy. It follows that the size of the focal firm may affect the impact of adoption of SSCM practices on the firm's performance as, in most likelihood, a larger sized firm 
would not be constrained by the paucity of resources. This is supported by research of Swamidass and Kotha (1998) who find that association between adoption of advanced technology and performance is moderated by the size the firm. This finding is also supported by research of Cagliano et al. (2001), Gong et al. (2013), Bourlakis et al. (2014), Leal-Rodríguez et al. (2015), Benito-Osorio et al. (2015), Vithessonthi and Tongurai (2015) and others. The size of a firm may be determined by its assets (Smith et al., 2015; Brighi \& Venturelli 2014; Schaefer, 1998; Horst, 1972), revenue (Hwang, 2015; Schaefer, 1998; Cohen et al., 1987) market capitalization (Baker \& Hall, 2004), number of employees (Bolotova, 2016; Benito-Osorio et al., 2015; Elhamma, 2015; LealRodríguez, 2015; Chenhall, 2003), number of establishments (Bolotova, 2016), alliance portfolio (Lahiri \& Narayanan, 2013) and other indicators. For this research, the size classification employed by Statistics Canada is used, which classifies firms having less than 100 employees as small, with 100 to 499 employees as medium and more than 500 employees as large (Statcan, 2018).

In this research we studied the effect of size, if any, on the impact that firm's adoption of SSCM practices may have on its performance. A firm's size may also affect the impact of drivers on SSCM Practices adoption. For example, a bigger firm may have more resources to adopt suitable SSCM practices to comply with regulations, leverage its competitiveness objectives by adoption of SSCM practices, or adopt the SSCM practices that handle stakeholder pressures in a better way, and these options may not be available to a resource constrained small company. However, this possible moderating effect of size was not studied in this research for the purposes of parsimony. 


\subsection{Constructs and Indicators}

Table 3.1 below provides a list of the constructs and indicators as used in the proposed research model as well as the published academic sources they have been gleaned from.

Table 3.1 Constructs and Indicators

\begin{tabular}{|l|l|l|l|}
\hline $\begin{array}{l}\text { Composite } \\
\text { Construct }\end{array}$ & Construct & \multicolumn{1}{|c|}{ Source } & \multicolumn{1}{c|}{$\begin{array}{c}\text { Indicators } \\
\text { (adopted verbatim- please read } \\
\text { with inverted commas " })\end{array}$} \\
\hline Drivers & Regulation & Paulraj, 2009 & $\begin{array}{l}\text { Environmental regulation is the } \\
\text { primary driver for all our } \\
\text { environmental activities. } \\
\text { Our environmental activities are } \\
\text { directed towards complying with } \\
\text { institutional norms and/or } \\
\text { regulations. }\end{array}$ \\
\hline Competitiven \\
ess
\end{tabular}




\begin{tabular}{|c|c|c|c|}
\hline & & $\begin{array}{l}\text { Sangle, } 2010 \\
\text { Sangle, } 2010 \\
\text { Sangle, } 2010 \\
\text { Sangle } 2010\end{array}$ & $\begin{array}{l}\text { Improved profits is the main driver } \\
\text { for adoption of proactive } \\
\text { environmental strategies } \\
\text { Access to overseas market is the } \\
\text { main driver for adoption of } \\
\text { proactive environmental strategies } \\
\text { Improving efficiency is the main } \\
\text { driver for adoption of proactive } \\
\text { environmental strategies } \\
\text { Cost saving and risk reduction is } \\
\text { the main driver for adoption of } \\
\text { proactive environmental strategies }\end{array}$ \\
\hline & $\begin{array}{l}\text { Stakeholder } \\
\text { Pressures }\end{array}$ & $\begin{array}{l}\text { Sangle, } 2010 \\
\text { Sangle, } 2010 \\
\text { Sangle, } 2010 \\
\text { Sangle, } 2010 \\
\text { Sangle, } 2010\end{array}$ & $\begin{array}{l}\text { Stakeholder relationship is the } \\
\text { main driver for adoption of } \\
\text { proactive environmental strategies } \\
\text { Stakeholder satisfaction is the } \\
\text { main driver for adoption of } \\
\text { proactive environmental strategies } \\
\text { Lender and investors concern } \\
\text { toward environmental liability is } \\
\text { the main driver for adoption of } \\
\text { proactive environmental strategies } \\
\text { Customer desire to protect } \\
\text { environment is the main driver for } \\
\text { adoption of proactive } \\
\text { environmental strategies } \\
\text { Non Profit Organizations } \\
\text { /judiciary/media inquiries is the } \\
\text { main driver for adoption of } \\
\text { proactive environmental strategies }\end{array}$ \\
\hline $\begin{array}{l}\text { SSCM } \\
\text { Practices }\end{array}$ & $\begin{array}{l}\text { External } \\
\text { Environment }\end{array}$ & Paulraj, 2009 & $\begin{array}{l}\text { We cooperate with our suppliers to } \\
\text { achieve environmental objectives. } \\
\text { We encourage our suppliers to } \\
\text { develop new source reduction }\end{array}$ \\
\hline
\end{tabular}




\begin{tabular}{|c|c|c|c|}
\hline Adoption & al Practices & $\begin{array}{l}\text { Paulraj, } 2009 \\
\text { Paulraj, } 2009 \\
\text { Paulraj, } 2009\end{array}$ & $\begin{array}{l}\text { strategies. } \\
\text { We cooperate with our suppliers to } \\
\text { improve their waste reduction } \\
\text { initiatives. } \\
\text { We work with our suppliers for } \\
\text { cleaner production. }\end{array}$ \\
\hline & $\begin{array}{l}\text { Internal } \\
\text { Environment } \\
\text { al Practices }\end{array}$ & $\begin{array}{l}\text { Paulraj, } 2009 \\
\text { Paulraj, } 2009 \\
\text { Paulraj, } 2009 \\
\text { Paulraj, } 2009 \\
\text { Paulraj, } 2009 \\
\text { Zhu et al., } \\
\text { 2008a \& Zhu } \\
\text { et al., 2008b }\end{array}$ & $\begin{array}{l}\text { We support the inventory recovery } \\
\text { (sale) of excess } \\
\text { inventories/materials. } \\
\text { We emphasize the use of reusable } \\
\text { and returnable packaging for our } \\
\text { products. } \\
\text { We constantly strive to use lesser } \\
\text { resources in getting the tasks done. } \\
\text { We have well-documented waste } \\
\text { reduction methodologies in place. } \\
\text { We eliminate physical waste from } \\
\text { our operations. } \\
\text { We support the sale of scrap and } \\
\text { used materials }\end{array}$ \\
\hline & $\begin{array}{l}\text { Supplier } \\
\text { Selection }\end{array}$ & $\begin{array}{l}\text { Paulraj, } 2009 \\
\text { Paulraj, } 2009 \\
\text { Paulraj, } 2009 \\
\text { Paulraj, } 2009 \\
\text { Paulraj, } 2009\end{array}$ & $\begin{array}{l}\text { We select suppliers based on their } \\
\text { environmental competence. } \\
\text { Suppliers are selected based on } \\
\text { their ability to support our } \\
\text { environmental objectives. } \\
\text { We select suppliers based on their } \\
\text { environmental performance. } \\
\text { We select suppliers based on their } \\
\text { ability to develop environmentally } \\
\text { friendly goods. } \\
\text { Our organization has a thorough } \\
\text { supplier environmental rating } \\
\text { system }\end{array}$ \\
\hline
\end{tabular}




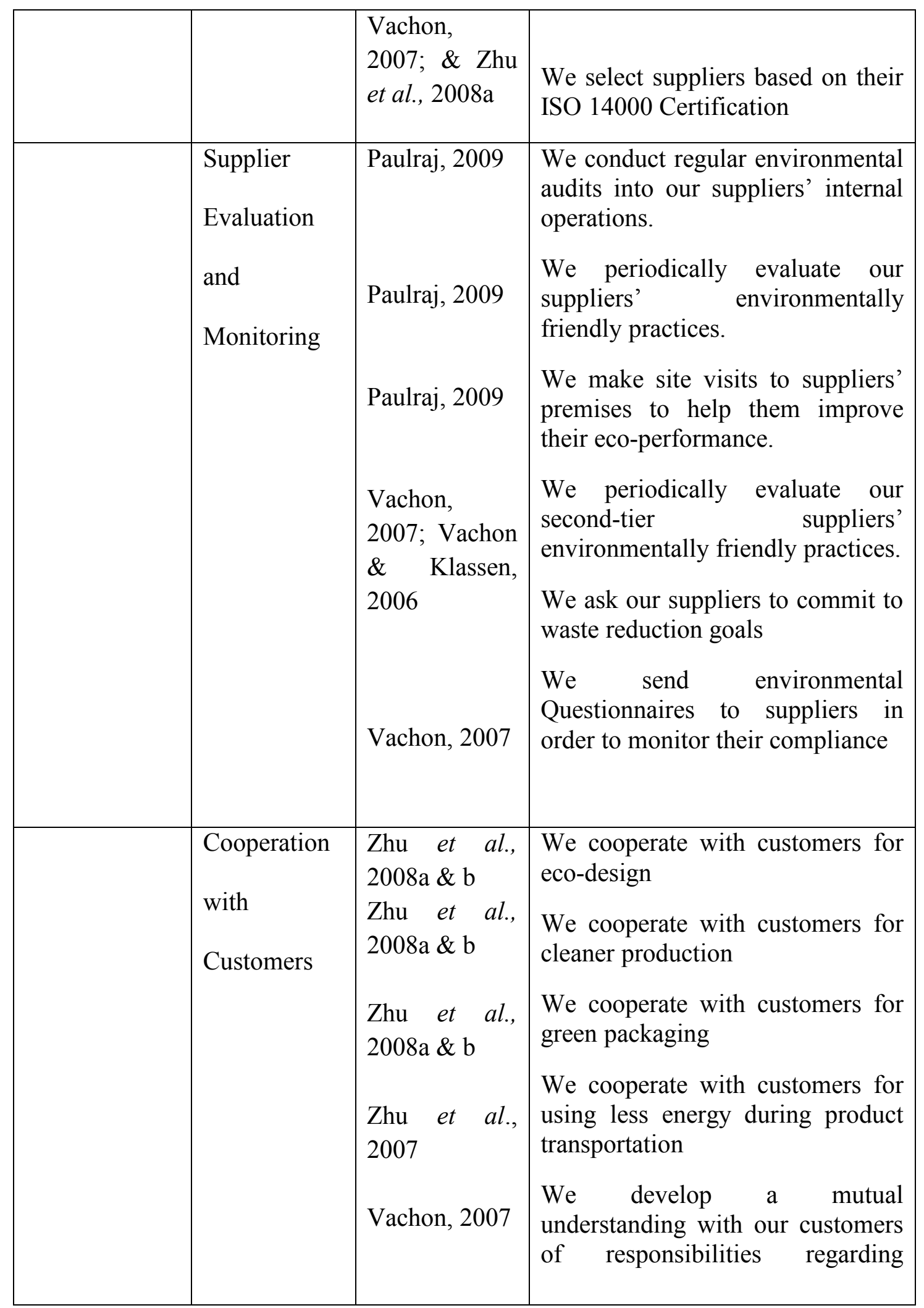




\begin{tabular}{|c|c|c|c|}
\hline & & Vachon, 2007 & $\begin{array}{l}\text { environmental performance } \\
\text { We work together with our } \\
\text { customers to reduce the } \\
\text { environmental impact of our } \\
\text { activities. }\end{array}$ \\
\hline & Eco-Design & $\begin{array}{l}\text { Zhu et al., } \\
2008 \text { a \& b; } \\
\text { Zhu \& Sarkis, } \\
\text { 2007. }\end{array}$ & $\begin{array}{l}\text { We design products for reduced } \\
\text { consumption of material/energy. } \\
\text { We design products for reuse, } \\
\text { recycle, recovery of material, } \\
\text { component parts. } \\
\text { We design products to avoid or } \\
\text { reduce the use of hazardous } \\
\text { products and/or their } \\
\text { manufacturing process. }\end{array}$ \\
\hline & $\begin{array}{l}\text { Social } \\
\text { Sustainabilit } \\
\text { y Practices }\end{array}$ & 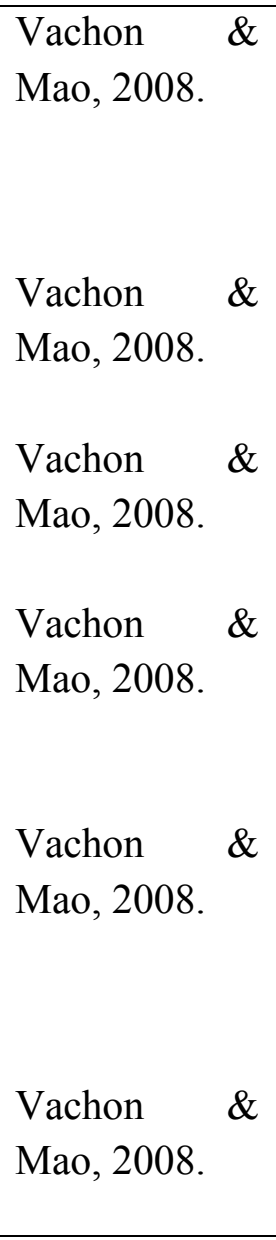 & $\begin{array}{l}\text { Our organization frequently } \\
\text { employs corporate codes of } \\
\text { conduct and other aspects of } \\
\text { corporate social responsibility. } \\
\text { Our organization commonly } \\
\text { encourages workers to volunteer } \\
\text { for social causes and has } \\
\text { incentives that facilitate that } \\
\text { involvement. } \\
\text { Our organization contributes to } \\
\text { charitable causes. } \\
\text { The general approach of our } \\
\text { organization to human resources is } \\
\text { to invest heavily to attract, train } \\
\text { and retain employees. } \\
\text { In our organization employment of } \\
\text { women is (1= limited and usually } \\
\text { takes place in less important jobs, } \\
7=\text { is equal to that of men) } \\
\text { In our organization, for similar } \\
\text { work, wages for women are } \\
\text { (1=significantly below those of }\end{array}$ \\
\hline
\end{tabular}




\begin{tabular}{|c|c|c|c|}
\hline & & & men, $7=$ equal to those of men). \\
\hline Performance & $\begin{array}{l}\text { Economic } \\
\text { Performance }\end{array}$ & $\begin{array}{l}\text { Zhu, et al., } \\
\text { 2008a. } \\
\text { Zhu \& Sarkis, } \\
\text { 2007. }\end{array}$ & $\begin{array}{l}\text { In our organization, there has been } \\
\text { a significant decrease in cost for } \\
\text { materials purchasing over the past } \\
\text { three years. } \\
\text { In our organization, there has been } \\
\text { a significant decrease in cost for } \\
\text { energy consumption over the past } \\
\text { three years. } \\
\text { In our organization, there has been } \\
\text { a significant decrease in fee for } \\
\text { waste treatment over the past three } \\
\text { years. } \\
\text { In our organization, there has been } \\
\text { a significant decrease in fee for } \\
\text { waste discharge over the past three } \\
\text { years. } \\
\text { In our organization, there has been } \\
\text { a significant decrease of fine for } \\
\text { environmental accidents over the } \\
\text { past three years. }\end{array}$ \\
\hline & $\begin{array}{l}\text { Environment } \\
\text { al } \\
\text { Performance }\end{array}$ & $\begin{array}{l}\text { Zhu et al., } \\
2008 \text {. }\end{array}$ & $\begin{array}{l}\text { In our organization, there has been } \\
\text { a significant reduction of air } \\
\text { emission over the past three years. } \\
\text { In our organization, there has been } \\
\text { a significant reduction of } \\
\text { wastewater over the past three } \\
\text { years. } \\
\text { In our organization, there has been } \\
\text { a significant reduction of solid } \\
\text { wastes over the past three years. } \\
\text { In our organization, there has been } \\
\text { a significant decrease in } \\
\text { consumption of hazardous/ } \\
\text { harmful/toxic materials over the } \\
\text { past three years. }\end{array}$ \\
\hline
\end{tabular}




\begin{tabular}{|c|c|c|c|}
\hline & & & $\begin{array}{l}\text { In our organization, there has been } \\
\text { a significant decrease in frequency } \\
\text { for environmental accidents over } \\
\text { the past three years. } \\
\text { There has been a significant } \\
\text { improvement of our organization's } \\
\text { environmental situation over the } \\
\text { past three years. }\end{array}$ \\
\hline & $\begin{array}{l}\text { Social } \\
\text { Performance }\end{array}$ & $\begin{array}{l}\text { Muller \& } \\
\text { Kolk, } 2010 .\end{array}$ & $\begin{array}{l}\text { In our organization, there has been } \\
\text { a significant increase in days of } \\
\text { vocational training over the past } \\
\text { three years. } \\
\text { In our organization, there has been } \\
\text { a significant increase in } \\
\text { philanthropy as a share of profit } \\
\text { over the past three years. } \\
\text { In our organization, there has been } \\
\text { a significant increase in the } \\
\text { formalization of community } \\
\text { relations over the past three years. } \\
\text { In our organization, there has been } \\
\text { a significant increase in a number } \\
\text { of internships offered over the past } \\
\text { three years. }\end{array}$ \\
\hline & $\begin{array}{l}\text { Operational } \\
\text { Performance }\end{array}$ & $\begin{array}{l}\text { Zhu et al., } \\
2008 \text {. }\end{array}$ & $\begin{array}{l}\text { Increase amount of goods } \\
\text { delivered on time } \\
\text { Decrease inventory levels } \\
\text { Improve capacity utilization } \\
\text { Decrease scrap rate } \\
\text { Promote products' quality } \\
\text { Increase product line }\end{array}$ \\
\hline Size & Size of Firm & $\begin{array}{l}\text { Swamidass \& } \\
\text { Kotha, } 1998 .\end{array}$ & Number of employees \\
\hline
\end{tabular}

Note. Source: Literature reviewed. 


\section{$3.8 \quad$ Hypotheses}

Based on the discussions above, the following hypotheses are put forth in this study:

H1a: Companies that face a higher level of regulations are more likely to adopt SSCM practices.

H1b: Companies that aim to achieve a higher level of competitiveness are more likely to adopt SSCM practices.

H1c: Companies that face higher pressures from stakeholders are more likely to adopt SSCM practices.

H2a: A company's economic performance is positively associated with the company's adoption of SSCM practices.

H2b: A company's environmental performance is positively associated with the company's adoption of SSCM practices.

H2c: A company's social performance is positively associated with the company's adoption of SSCM practices.

H2d: A company's operational performance is positively associated with the company's adoption of SSCM practices.

H3a: The bigger the firm size, the greater is the impact of company's adoption of SSCM practices on the company's economic performance. 
$\mathrm{H} 3 \mathrm{~b}$ : The bigger the firm size, the greater is the impact of company's adoption of SSCM practices on the company's environmental performance.

H3c: The bigger the firm size, the greater is the impact of company's adoption of SSCM practices on the company's social performance.

H3d: The bigger the firm size, the greater is the impact of company's adoption of SSCM practices on the company's operational performance.

Table 3.2 below presents the research questions discussed in section 3.1 and the hypotheses that map on to the specific research questions.

Table 3.2 Research Questions \& Hypotheses

\begin{tabular}{|l|l|}
\hline \multicolumn{1}{|c|}{ Research Question } & \multicolumn{1}{|c|}{ Hypothesis } \\
\hline $\begin{array}{l}\text { Do the key motivators, as identified in the } \\
\text { literature, affect the adoption of SSCM } \\
\text { practices by a firm? }\end{array}$ & $\begin{array}{l}\text { H1a: Companies that face a higher } \\
\text { level of regulations are more likely to } \\
\text { adopt SSCM practices. } \\
\text { H1b: Companies that aim to achieve } \\
\text { a higher level of competitiveness are } \\
\text { more likely to adopt SSCM practices. } \\
\text { H1c: Companies that face higher } \\
\text { pressures from stakeholders are more } \\
\text { likely to adopt SSCM practices. }\end{array}$ \\
\hline $\begin{array}{l}\text { Does the adoption of SSCM practices } \\
\text { impact the economic, environmental, social } \\
\text { and operational performance of a firm? }\end{array}$ & $\begin{array}{l}\text { H2a: A company's economic } \\
\text { performance is positively associated } \\
\text { with the company's adoption of } \\
\text { SSCM practices. }\end{array}$ \\
& $\begin{array}{l}\text { H2b: A company's environmental } \\
\text { performance is positively associated }\end{array}$ \\
\hline
\end{tabular}




\begin{tabular}{|c|c|}
\hline & $\begin{array}{l}\text { with the company's adoption of } \\
\text { SSCM practices. } \\
\text { H2c: A company's social } \\
\text { performance is positively associated } \\
\text { with the company's adoption of } \\
\text { SSCM practices. } \\
\text { H2d: A company's operational } \\
\text { performance is positively associated } \\
\text { with the company's adoption of } \\
\text { SSCM practices. }\end{array}$ \\
\hline $\begin{array}{l}\text { Does the size of a firm affect the impact } \\
\text { that a company's adoption of SSCM } \\
\text { practices may have on the company's } \\
\text { economic, environmental, social and } \\
\text { operational performance? }\end{array}$ & $\begin{array}{l}\text { H3a: The bigger the firm size, the } \\
\text { greater is the impact of company's } \\
\text { adoption of SSCM practices on the } \\
\text { company's economic performance. } \\
\text { H3b: The bigger the firm size, the } \\
\text { greater is the impact of company's } \\
\text { adoption of SSCM practices on the } \\
\text { company's } \\
\text { performance. } \\
\text { H3c: The bigger the firm size, the } \\
\text { greater is the impact of company's } \\
\text { adoption of SSCM practices on the } \\
\text { company's social performance. } \\
\text { H3d: The bigger the firm size, the } \\
\text { greater is the impact of company's } \\
\text { adoption of SSCM practices on the } \\
\text { company's operational performance. }\end{array}$ \\
\hline
\end{tabular}




\section{Chapter 4 Research Methodology}

\subsection{Overall Approach}

As previously discussed in Chapter 3, the objective of this study was to address the following research questions:

1. Do the key drivers, as identified in the literature, affect the adoption of SSCM practices by a firm?

2. Does the adoption of SSCM practices impact the economic, environmental, social and operational performance of a firm?

3. Does the size of a firm have a moderating effect on the impact that a company's adoption of SSCM practices may have on the company's economic, environmental, social and operational performance?

A research framework (Figure 3.1) was proposed based on an extensive review of academic literature published in this area. The measurement items for the factors being used in the framework have been taken from published research (Table 3.1). This chapter presents the research design, research sample, unit of analysis and data collection techniques used for the empirical survey. 


\subsection{Research Design}

This research examines sustainable supply chain practices and performance from the perspective of the focal firm. The 'a priori' research model (seen in Chapter 3) was developed, and measurement items and factors were determined based on the literature review in Chapter 2. The study conducted was cross-sectional in nature, for which the primary data was collected through an online survey. Since the focus and objectives of the study required responses on a large-scale with little personal variation or exception, the most amenable mode of data collection was using an empirical survey. The decision was made to utilize an online survey since most formal, and business interactions in this age are conducted via email or online. The survey instrument and data collection are presented in the next few sub-sections.

\subsection{Survey Instrument and Pre-Test}

The survey instrument or questionnaire was developed based on the research design. The survey instrument used for this study is appended to this thesis as Appendix III.

Both constructs and measurement items (or indicators) were based on previously validated and published research to ensure that they are well grounded in theory. As discussed in section 2.0, the use of concepts of "sustainable" and "sustainability" are recent (Harper, 2010), especially with reference to ecology in the context of economy, business, and development (WECD, 1987). It was, therefore, considered prudent to avoid the use of these words in the instrument. Since the mental schemas of these words and 
concepts are still evolving and diffusing through our target group, it was understood that the use of these concepts may give erroneous results.

the concept of "sustainability" (in the context of development) appeared in the Brundtland Report (WECD, 1987)

Before beginning data collection, the questionnaire was pre-tested with five practitioners and five academicians for their comments. The pre-test was conducted in person along with semi-structured conversations to collect their feedback and suggestions on (a) the instructions attached with the survey, (b) the questions themselves and (c) any other aspect of the questionnaire. This feedback was used to make the required adjustments to the survey instrument. Suggestions received, and action taken on them is presented in Table 4.1 below:

Table 4.1 Pre-Test Feedback and Action Taken Thereon

\begin{tabular}{|c|c|c|}
\hline Sr. & Feedback & Action Taken \\
\hline 1. & $\begin{array}{l}\text { Reduce the size of } \\
\text { introductory email }\end{array}$ & $\begin{array}{l}\text { The size of the email was reduced significantly to } \\
\text { minimal length, while still covering the salient } \\
\text { aspects mandated by the Carleton University } \\
\text { Research Ethics Board. }\end{array}$ \\
\hline 2. & $\begin{array}{l}\text { Add item to cover "equal } \\
\text { opportunity employment" } \\
\text { in measuring social } \\
\text { performance }\end{array}$ & Item was added to the questionnaire. \\
\hline 3. & $\begin{array}{l}\text { Make questionnaire a little } \\
\text { shorter }\end{array}$ & $\begin{array}{l}\text { In view of the research undertaken, it was not } \\
\text { possible to reduce the length of questionnaire }\end{array}$ \\
\hline
\end{tabular}


Data from pre-test surveys were not included in the final sample. The revised covering letter and questionnaire were used for final data collection.

\subsection{Research Sample}

This study investigates the impact of the adoption of sustainable supply chain management practices on a firm's performance. Hence, the unit of analysis for this research is a (for-profit) business organization. To empirically test the theoretical framework proposed, data was collected from the managers knowledgeable about supply chain activities in the organization. The population and sampling frame are presented in Section 4.4.

The information about potential respondent companies was collected from Scotts Directory of Canadian firms, Hoover's database for US firms, and similar other online sources. A snowball effect was used to enroll potential respondents. Respondents were requested to forward the questionnaire to their colleagues using the following language:

"I would greatly appreciate if you could further send this email to your colleagues at the senior manager or executive levels in other firms who are knowledgeable about supply chain processes so that they may participate as well by completing the questionnaire. Your help in this regard is highly appreciated."

To collect data on firm size, this study divided firms into three classes. The organizational size was defined as per Statistics Canada, which bases the size of a firm on 
the number of employees working in the firm. Number of employees is a generally accepted proxy for firm size in academic research. Accordingly, firms with fewer than 100 employees were classified as small, with 100 to 499 employees were classified as medium and organisations with 500 or more than 500 employees were classified as large.

Sample size is usually dictated by the level of accuracy and confidence required in the research results, but it is constrained by costs in terms of money, effort and time. While no standard guidelines for sample size for using structural equation modelling (SEM), or even multiple-regression, are available (Tanaka, 1987), it is generally accepted that sample size close to 200 may provde reasonably good estimates using Maximum Likelihood method (Boomsma, 1987; Gerbing \& Anderson, 1985). Since this research used both multiple regression and SEM methods, it was considered that the sample size should be ideally more than 200 . There were 14 constructs or variables being analysed in the study. From this it was estimated that a sample size of 210 would be adequate for the research. This was based on a heuristic of 15 respondents per construct to be analysed (Austin \& Steyerberg, 2015). This estimate also satisfied the 200 number discussed above. This estimate of sample size was validated after data collection by statistical tests like Barlett's Test and Kaiser-Meyer-Oklin Test for sampling adequacy.

\subsection{Survey Administration / Data Collection}

The data for the study was collected from managers who are knowledgeable of their organization's supply chain activities. These managers were assumed to be knowledgeable of supply chain activities such as purchasing, procurement, operations, 
logistics, and other related activities that are directly connected with internal or external supply chain management of the firm. A covering letter, containing a link to survey questionnaire was emailed to the appropriate managers of each of the firms identified for data collection.

Chandy and Tellis (1998) provide some approaches to increase response rates. These include pre-survey phone calls, hand-written and personalized cover letter /notes, professional appearance of the survey package, reminder letters with the original copy of the survey instrument. This follow-up was done in the form of sending a reminder email after three weeks. As mentioned earlier, the snow-balling technique was also used to increase response rates.

To put potential respondents' concerns about confidentiality to rest, a confidentiality statement was incorporated, as suggested by the Carleton University Research Ethics Board. This statement formed part of the covering letter:

"All information provided by you will be processed anonymously and in an aggregate manner only. It will not be identifiable and will not be attributed to your name or that of your company."

A copy of the covering letter sent by email is attached as Appendix I to the thesis.

On approval from the Carleton University Research Ethics Board, the survey was hosted on a website, along with the online consent form for participation as suggested by the board (Appendix II). A database of potential respondents was created using various 
sources including online databases, professional associations, personal sources and search engines. The instrument was administered through a Web-based survey host Survey Monkey through Blueline surveys to collect data from Supply Chain Management practitioners. This online method was found to be cost-effective and efficient. The potential respondents were sent emails soliciting their participation in the survey. A total of 2512 emails were sent over forty days. 261 emails were received back due to email addresses being inoperative. This reduced total survey communication to 2251 . Three weeks after mailing the questionnaire to the respondents, one follow-up email was sent to the potential respondents. A total of 227 responses were received after which the data collection was terminated.

Whereas the methods used to create database of potential respondents and the use of snowballing method to garner responses were successful to gather data, the data-set does not purport to be the ideal random-sample. It can also be argued that a randomsample may provide significantly different results. However, since the research area is new, and the target population is restricted to professionals that specialise in SCM field, this method of sampling was considered adequate, effective and expedient for this exploratory research.

In this chapter overall research design, survey instrument and its pre-test, research sample, administration of the survey, and data collection were discussed. This is followed by data preparation for statistical analysis which is presented in Chapter 5 . 


\section{Chapter 5 Data Preparation}

\subsection{Screening of Data}

Use of survey services available on the Web-enabled direct download of data as excel file. This prevented any errors that may arise from manual data-entry by the researcher. On receipt of an adequate number of responses (numbering 227) on the $20^{\text {th }}$ October 2017, the data was downloaded onto the researcher's computer and deleted from the web host. The data was manually screened for completeness and any apparent errors such as unengaged responses.

\subsubsection{Data Coding and Cleaning Operations}

Out of a total of 227 responses received nine were considered to be unusable. Out of these nine responses, six were substantially incomplete and had to be discarded. Three were adjudged to be unengaged responses as they contained only "strongly disagree" selection and the general questions at the end, that is questions 26 to 33 , were incomplete.

As all measurement items were worded in a unidirectional manner, there was no requirement for reverse coding before analysis.

\subsubsection{Missing Values}

A web-based survey using online questionnaire limits the control of researcher on completion of the survey by the participants. This can potentially result in incomplete surveys, loss of data, reduction of sample size, and missing values in case of marginally 
incomplete surveys. Missing values can be a result of a confusing question where the respondent is unable to select a proper answer, a partially-engaged participant, a lengthy questionnaire, an error in keying in response, a defective mouse button/touchscreen, or other reasons.

The pattern of missing data, if any, needs to be analyzed. Randomly missing data is less of a problem (Rubin, 1976). In the data collected for this research, no specific pattern in the missing data was found. One value each was missing in three cases. These missing values were small in number and seemed random. The missing data was completed by using the method of mean substitution. For this the mean of the item was used to substitute missing value, rounding it off to the nearest whole number. The missing data imputed is presented in Appendix V.

\subsection{Response Rate and Non-Response Bias}

As reported in Section 4.4 above, a total of 2512 emails were sent over a period of forty days, out of which, 261 emails rebounded due to different reasons. A total of 227 responses were received after which the data collection was terminated. The overall response rate was $227 /(2512-261)$ or $10.1 \%$. Out of 227 responses received, nine were unusable and were discarded, and only 218 were used.

Non-response can result from inaccurate, old or inoperative email addresses, nonavailability of the respondent, or his/her inability or unwillingness to respond due to 
various reasons. Non-response bias may be viewed as a continuum from early responders to late responders (Armstrong \& Overton, 1977) tailing into non-responders. Assuming that the non-responders were akin to the late responders, we compared the data collected from the late responders with the data collected from the early responders. A significant difference in these two sets of data, would lead to an inference that non-response bias existed in the collected data. Our data collection lasted for forty days. We sent one reminder email after three weeks. When the characteristics of responses of responders who responded during the first twenty days were compared with responses of those who responded in the second half of collection period, a non-significant independent t-test indicated that there was no significant difference between the two groups. This was inferred as the absence of non-response bias in the sample. Results of the independent samples t-Test for Equality of Means and Levene's Test for Equality of Variances conducted are placed as Appendix VII.

\subsection{Common Method Variance}

One of the main sources of error of measurement (Podsakoff et al., 2003) common method variances are those variances that are caused by measurement method (Bagozzi \& Yi, 1990) rather than due to the construct being measured. Such errors of measurement affect the research findings. These common method variances can arise from item characteristics, item context, common source, measurement context and other sources. 
A number of steps were taken to reduce this common method bias. A web-based survey was used, in place of face to face interviews, which tends to reduce bias (Richman et al., 1999). However, this takes away any control over the time and location of measurement. Keeping the respondents anonymous helped reduce the bias based on social desirability of responses (Podsakoff et al., 2003). Similarly, anonymity also takes away the pressure to be lenient or consistent. The survey instrument was carefully drafted and pre-tested to remove any vagueness and double-barrelled questions and to remove item characteristics bias.

Harman's single factor test was used for assessing common method bias. Using Principal Component Analysis method in SPSS only single factor was extracted, using no rotation, to ascertain if one single factor emerges that accounts for most of the variance in the variable (Verhoef \& Leeflang, 2009). If a single factor, such extracted, explains a majority of variance it may be an indication that common method may be introducing this bias. Table 5.1 provides the result of Harman's single factor test.

Table 5.1 Harman's Single Factor Test

\begin{tabular}{|c|c|c|c|c|c|c|}
\hline \multicolumn{7}{|c|}{ Total Variance Explained } \\
\hline \multirow{2}{*}{$\begin{array}{c}\text { Factor or } \\
\text { Component }\end{array}$} & \multicolumn{5}{|c|}{ Initial Eigenvalues } & \multicolumn{3}{c|}{$\begin{array}{c}\text { Extraction Sums of Squared } \\
\text { Loadings }\end{array}$} \\
\cline { 2 - 7 } & Total & $\begin{array}{c}\text { \% of } \\
\text { Variance }\end{array}$ & $\begin{array}{c}\text { Cumulative } \\
\%\end{array}$ & Total & $\begin{array}{c}\text { \% of } \\
\text { Variance }\end{array}$ & $\begin{array}{c}\text { Cumulative } \\
\%\end{array}$ \\
\hline 1 & 21.496 & 29.048 & 29.048 & 21.496 & 29.048 & 29.048 \\
\hline
\end{tabular}


Since the single factor extracted accounts for only $29.048 \%$ of the variance, out of a total of $86.547 \%$ variance explained by all the factors extracted which had eigenvalues above 1, it indicated that common method bias was probably not a significant problem in the dataset.

\subsection{Normality Tests}

A collected sample of data should ideally be distributed normally. However, that may not always be the case in real life (Stigler, 1977; Micceri, 1989). Using data that is not normally distributed and has a large number of outliers can lead to results that are not generalizable (Stevens, 1996; Tabachnick \& Fidell, 2007). Normality tests help in ascertaining whether the underlying assumption of normal data is well founded. For this, visual inspection of data spread and characteristics is very helpful. Visual inspection of graphs like histogram is a time-tested procedure to check for normal distribution and the level of its skewness and kurtosis. Other methods include statistical tests like Shapiro Wilk and Kolmogorov-Smirnov test. Comparison of means with a 5\% trimmed mean is another method used for checking if outliers are affecting an analysis or not. These analyses are dealt with in the next sub-sections.

\subsubsection{Shapiro Wilk and Kolmogorov-Smirnov Tests}

Shapiro Wilk and Kolmogorov-Smirnov tests were conducted using SPSS software. The results are placed in Appendix IV. It was found that the scores were 
significant (sig. or p-value less than 0.05 ) which indicated that the distribution of indicator data was not normally distributed. The null hypothesis that all the data was not normally distributed could not be rejected. For this research, the data was collected using a 7-point Likert scale. A perfectly normal distribution may not be possible with questions eliciting answers on a Likert scale (University of Northern Iowa, 2017).

In the book "Statistics for Management and Economics" Mendenhall et al., (1989) write: "It is important to note that the Student's $t$ and the corresponding tabulated critical values are based on the assumption that the sampled population possesses a normal probability distribution."..."Fortunately, this point is of little consequence, as it can be shown that the distribution of the $t$ statistic possesses nearly the same shape as the theoretical $t$ distribution for populations that are non-normal but possess a mound-shaped probability distribution" (University of Northern Iowa, 2017).

The distribution pattern of each indicator was scrutinized visually for this 'moundshaped' distribution before the analysis and is explained in the next sub-section.

\subsubsection{Visual Inspection of Graphs}

The data collected was analyzed by creating histograms which were visually inspected. On visual analysis of the histograms, it was found that the distribution was mound-shaped and was suitable for further analysis. The histograms generated are placed in Appendix VI. Sample data collected for the indicators presented a mound-shaped distribution in histograms with a clear indication that the data showed a tendency towards normal distribution. 


\subsubsection{Skewness and Kurtosis}

The data collected was checked for normality by testing for skewness and kurtosis. The test for skewness focuses on symmetry in the distribution of data points. A symmetric distribution indicates normality. When scores are clustered to the left and the tail extends to the right, the data is said to be positively skewed. A negatively skewed data set is mirror image of the above. Stevens (1996) and West et al. (1996) posit that when statistic values of skewness are outside the range of -2 to +2 it indicates that there is substantial departure from normality. No excessive skewness was found in the data collected. However negative skewness was seen in the data which was found to be within the acceptable range.

Kurtosis focuses on peaks in the distribution of data. The normal distribution shows a bell-shaped curve. A positive kurtosis is said to exist when an accentuated peak is there. A flat distribution is said to show a negative kurtosis (Stevens, 1996). For a normal bell-shaped curve, the kurtosis value is 0 . When the test values for kurtosis are outside the range of -7 to +7 , excessive kurtosis is said to occur (West et al.,1996). The test for kurtosis indicated that no excessive kurtosis existed in the collected data. The skewness and kurtosis statistic of the collected data are placed in Appendix VIII.

\subsubsection{Outliers}

Statistical analysis results can be affected by outliers. Outliers are those data points that are very different from the data set. In a correlation and regression, analysis outliers can affect results and its interpretation. The data set was checked for outliers. For 
this $\mathrm{F}$ scores of all the 74 observed variables were computed. The computed F scores ranged from -2.773 to 2.436 , which were well within the range of -3 to 3 , indicating that there were no univariate outliers in the collected data. Dataset was also checked for multivariate outliers. These outliers were checked by computing Mahalanobis Distance, which is the distance of the specific score from the cluster center (Stevens, 1996). Mahalanobis Distance was computed for all indicators in data, along with chi-square probability values. The dataset was found to be free from multivariate outliers. The top ten cases with high Mahalanobis distances are presented in Table 5.2 below, and none of these cases were identified as outliers, as none of them had probability values lower than 0.001 .

Table 5.2 Top Ten Cases with High Mahalanobis Distances with Probability Values

\begin{tabular}{|c|r|r|}
\hline $\begin{array}{c}\text { Case } \\
\text { ID }\end{array}$ & $\begin{array}{c}\text { Mahalanobis } \\
\text { Distance }\end{array}$ & $\begin{array}{c}\text { Chi- } \\
\text { Square } \\
\text { Probability }\end{array}$ \\
\hline $\mathbf{1 4 5}$ & 116.754 & 0.001 \\
\hline $\mathbf{5 8}$ & 112.228 & 0.003 \\
\hline $\mathbf{1 2}$ & 108.480 & 0.006 \\
\hline $\mathbf{8}$ & 105.560 & 0.009 \\
\hline $\mathbf{2 0 3}$ & 102.306 & 0.016 \\
\hline $\mathbf{1 5}$ & 101.810 & 0.018 \\
\hline $\mathbf{1 7 1}$ & 100.448 & 0.022 \\
\hline $\mathbf{6}$ & 100.252 & 0.023 \\
\hline $\mathbf{1 3 4}$ & 98.487 & 0.030 \\
\hline $\mathbf{8 2}$ & 98.191 & 0.032 \\
\hline
\end{tabular}


Each of these cases was also checked manually and was found to be a reasonable response with nothing to indicate that it was an unengaged response or in any other way not in order. The decision was made to retain all these cases in the dataset.

\subsection{Reliability}

\subsubsection{Cronbach's Alpha}

This research uses latent constructs and depends on indicators for measuring those latent constructs or variables. These indicators or items or measures must show internal consistency and homogeneity to form a reliable scale that can then be used for measurement. It is recommended to start with a well-grounded theory for the scientific development of measures. Once the scale is developed a number of methods are available to check for its reliability. Reliability of a scale may be judged by the degree of consistency in respondents' replies across the items measuring the same construct (Schwab, 1999). Verifying substantive meanings and statistical methods like finding eigenvalues and factor loadings are important and relevant criteria to check for reliability (Tabachnick \& Fidell, 2007). Finding Cronbach's Alpha coefficient statistically is a valuable and is widely used tool to test for reliability, especially for new measures (Nunnally, 1978). Cronbach's Alpha coefficient indicates the percentage of total variance that is caused by true (systematic) variance in the data used for the test. 
For testing reliability, Cronbach's Alpha coefficients were calculated for all the constructs used in the study. The value of Cronbach's Alpha calculated ranged from 0.779 to 0.986 for these constructs. As all these calculated values were found to be higher than the recommended level of 0.70 (Nunnally, 1978) it was interpreted that scale had high reliability. For newer constructs, a level of 0.60 may be considered adequate (Nunnally, 1978; Malhotra, 2004), but the constructs used in this study had been duly tested earlier in published research, so a higher cut-off of 0.70 was adopted. No Cronbach's Alpha values were found to be below 0.70 . Table 5.3 below provides Cronbach's Alpha values for all the multi-item constructs that were used in the study.

Table 5.3 Reliability of Constructs: Cronbach's Alpha Values

\begin{tabular}{|l|ll|c|c|}
\hline \multirow{3}{*}{$\begin{array}{c}\text { Composite } \\
\text { Construct }\end{array}$} & \multicolumn{1}{|c|}{ Construct } & $\begin{array}{c}\text { Cronbach's } \\
\text { Alpha }\end{array}$ & $\begin{array}{c}\text { Number } \\
\text { of } \\
\text { Indicators }\end{array}$ \\
\hline \multirow{4}{*}{ Drivers } & REG & Regulations & .910 & 3 \\
\cline { 2 - 5 } & COMP Competitiveness & .961 & 7 \\
\cline { 2 - 5 } & PRES & Stakeholder Pressures & .935 & 5 \\
\hline \multirow{2}{*}{$\begin{array}{l}\text { PSCM } \\
\text { Practices }\end{array}$} & EEP & External Environmental Practices & .897 & 4 \\
\cline { 2 - 5 } & IEP & Internal Environmental Practices & .958 & 6 \\
\cline { 2 - 5 } & SS & Supplier Selection & .940 & 6 \\
\cline { 2 - 5 } & SM & Supplier Evaluation \& Monitoring & .976 & 6 \\
\cline { 2 - 5 } & CC & Cooperation with Customers & .968 & 6 \\
\cline { 2 - 5 } & ED & Eco-Design & .767 & 3 \\
\cline { 2 - 5 } & SSP & Social Sustainability Practices & .969 & 6 \\
\hline \multirow{4}{*}{ Performance } & EP & Economic Performance & .956 & 5 \\
\cline { 2 - 5 } & ENVP & Environmental Performance & .983 & 6 \\
\cline { 2 - 5 } & SP & Social Performance & .943 & 5 \\
\cline { 2 - 5 } & OP & Operational Performance & .950 & 6 \\
\hline
\end{tabular}




\subsubsection{Composite Reliability}

While Cronbach's Alpha has been widely used in research, researchers have suggested that use of Composite Reliability, which uses both standardized loadings and measurement error for calculation, may be a preferred indicator of reliability (Ping, 2003; Wang et al., 2006). Fornell \& Larcker (1981) provide a formula to calculate CR, which is presented as Equation 5.1 below, where $\boldsymbol{\rho}_{\eta}$ represents Composite Reliability, $\lambda_{y i}$ represents standardized loading, and $\operatorname{Var}\left(\varepsilon_{i}\right)$ represents the variance of measurement error.

$$
\rho_{\eta}=\frac{\left(\sum_{i=1}^{\rho} \lambda_{y i}\right)^{2}}{\left(\sum_{i=1}^{\rho} \lambda_{y i}\right)^{2}+\left(\sum_{i=1}^{\rho} \operatorname{Var}\left(\varepsilon_{i}\right)\right)}
$$

Equation 5.1 Composite Reliability (Fornell \& Larcker, 1981)

The CR values calculated for the constructs using the above formula is presented in Table 5.4 below.

Table 5.4 Composite Reliability of Constructs

\begin{tabular}{|l|c|}
\hline Construct & $\begin{array}{c}\text { Composite } \\
\text { Reliability } \\
\text { CR }\end{array}$ \\
\hline REG & 0.914 \\
\hline
\end{tabular}




\begin{tabular}{|l|l|} 
COMP & 0.961 \\
\hline PRES & 0.929 \\
\hline EEP & 0.888 \\
\hline IEP & 0.955 \\
\hline SS & 0.934 \\
\hline SM & 0.976 \\
\hline CC & 0.969 \\
\hline ED & 0.772 \\
\hline SSP & 0.966 \\
\hline OP & 0.946 \\
\hline EP & 0.954 \\
\hline ENVP & 0.983 \\
\hline SP & 0.936 \\
\hline
\end{tabular}

It was seen that $C R$ values for all the latent constructs were above 0.70 indicating that the scales were reliable (Fornell \& Larcker, 1981).

It was seen that the above measures are reliable, and therefore it was assumed that they measure the same thing. While measures maybe reliable when they measure the same thing, but they may not measure the right thing (Cascio, 1991). Measuring the right thing is a validity issue. In the next section, we discuss tests conducted to check for validity of measures.

\subsection{Validity}

A measure should correctly represent the construct (in content), and should measure it correctly; these two aspects of validity are covered by content validity and construct validity (Nunnally, 1978). 


\subsubsection{Content Validity}

Content validity of a measure would reflect in how well it measures the dimension of the construct being measured. A traditional way has been to take help of experts in the domain, both in academia and in practice. As explained in Section 4.2 above, the survey instrument was pre-tested with five practitioners and five academicians for their comments. Feedback was solicited on the questions themselves and on any other aspect of the survey instrument that the experts may offer. This feedback was used to make adjustments to the survey. This was done in addition to the fact that all the constructs and indicators were taken from previously published research (please see Table 3.1: Constructs and Indicators) and these had been duly tested and validated by the researchers earlier.

\subsubsection{Construct Validity}

Construct validity is the degree to which a measure or a metric does its work or the extent to which it measures what it claims to measure (Davis, 2005). For this the measures of a construct should relate to one another in a theoretically sound and systematic way (Cronbach \& Meehl, 1955), that is, the measures should relate to one another both theoretically and statistically. Extending this logic, the measures that are not related theoretically should not relate statistically. This provides convergent (when similar measures relate to each other statistically) and divergent (when dissimilar measures do not relate to each other statistically) construct validity. It stands to reason 
that only by demonstrating both convergent and divergent validity one can be sure that the construct validity exists (Stevens, 1996; Trochim, 2002).

\subsubsection{Convergent Validity}

When different indicators are measuring the same construct and are in agreement, it is said that convergent validity is present. Researchers commonly report reliability measures as indicators of convergent validity (Ping, 2004). Fornell and Larcker (1981) suggest the use of average variance extracted (AVE) to test for convergent validity using the formula presented as Equation 5.2 below. In the equation $\rho_{v c(\eta)}$ is the AVE for the construct, $\lambda_{y i}$ represents standardized loading, and $\operatorname{Var}\left(\varepsilon_{i}\right)$ represents the variance of measurement error (Fornell \& Larcker, 1981).

$$
\rho_{\mathrm{vc}(\eta)}=\frac{\left(\sum_{i=1}^{\rho} \lambda^{2}\right)}{\left(\sum_{i=1}^{\rho} \lambda^{2}\right)+\left(\sum_{i=1}^{\rho} \operatorname{Var}\left(\varepsilon_{i}\right)\right)}
$$

Equation 5.2 Average Variance Extracted (Fornell \& Larcker, 1981)

Table 5.5 below presents the AVE of all the constructs calculated using the above formula. 
Table 5.5 Average Variance Extracted of Constructs

\begin{tabular}{|l|c|}
\hline & $\begin{array}{c}\text { Average Variance } \\
\text { Extracted AVE }\end{array}$ \\
\hline REG & 0.780 \\
\hline COMP & 0.778 \\
\hline PRES & 0.724 \\
\hline SSP & 0.825 \\
\hline EEP & 0.669 \\
\hline IEP & 0.781 \\
\hline SS & 0.705 \\
\hline SM & 0.872 \\
\hline CC & 0.840 \\
\hline ED & 0.548 \\
\hline OP & 0.748 \\
\hline EP & 0.806 \\
\hline ENVP & 0.906 \\
\hline SP & 0.750 \\
\hline
\end{tabular}

Ping (2004) posits that when AVE is 0.50 or higher (along with Composite Reliability of 0.80 or higher) convergent validity is said to be present. It was observed that AVE values for all the constructs were well above 0.50 (Table 5.5). We had observed in Table 5.4 above that the CR values of all these constructs were above 0.80 . Hence it was inferred that the scale had convergent validity.

\subsubsection{Discriminant Validity}

While convergent validity looks for similarity in indicators in a scale, discriminant validity searches for dissimilarity between variables. Constructs that are too similar to each other tend to overlap in the various aspects or dimensions and are said to have failed in discriminant validity. Discriminant validity examines the extent to which a variable in a model differs from the other variables in the model (Churchill, 1979). A low 
correlation with other constructs may indicate a good discriminant validity and is commonly used to indicate the same (Ping, 2004). Fornell and Larcker (1981) who arrived at the formulae to calculate CR and AVE (Equations 5.1 and 5.2) suggest that for a good discriminant validity the shared variance between any two constructs should be lower than AVE of each construct. Table 5.6 below compares these two values for the constructs under study.

Table 5.6 Average Variance Extracted and Maximum Shared Variance of Constructs

\begin{tabular}{|l|c|c|}
\hline Constructs & $\begin{array}{c}\text { Average } \\
\text { Variance } \\
\text { Extracted } \\
\text { AVE }\end{array}$ & $\begin{array}{c}\text { Maximum } \\
\text { Shared } \\
\text { Variance } \\
\text { MSV }\end{array}$ \\
\hline REG & 0.780 & 0.233 \\
\hline COMP & 0.778 & 0.094 \\
\hline PRES & 0.724 & 0.233 \\
\hline EEP & 0.669 & 0.251 \\
\hline IEP & 0.781 & 0.251 \\
\hline SS & 0.705 & 0.277 \\
\hline SM & 0.872 & 0.226 \\
\hline CC & 0.840 & 0.162 \\
\hline ED & 0.548 & 0.277 \\
\hline SSP & 0.825 & 0.162 \\
\hline OP & 0.748 & 0.699 \\
\hline EP & 0.806 & 0.699 \\
\hline ENVP & 0.906 & 0.068 \\
\hline SP & 0.750 & 0.027 \\
\hline
\end{tabular}

It was seen from the comparison between Average Variance Extracted (AVE) and Maximum Shared Variance (MSV) of the constructs that for all the constructs under review, AVE was greater than MSV indicating good discriminant validity. 
Yang et al. (2008) suggest that we should check if the correlation between any two constructs has a value lower than the square root of AVE of each of the construct to assess discriminant validity. Table 5.7 below presents the values of coefficient of correlation between the constructs, and values of the square root of AVE on the diagonals for constructs Regulations (REG), Competitiveness (COMP), and Stakeholder Pressures (PRES) for comparison.

Table 5.7 Discriminant Validity Check for Driver Constructs

\begin{tabular}{|c|c|c|c|}
\hline & REG & COMP & PRES \\
\hline REG & $0.883 * *$ & & \\
\hline COMP & $-0.273^{*}$ & $0.882 * *$ & \\
\hline PRES & $-0.483^{*}$ & $0.307 *$ & $0.851 * *$ \\
\hline
\end{tabular}

It may be seen from above that the constructs show a good discriminant validity as the coefficient of correlation between any two of them is lower than the square root of EVA of each.

Table 5.8 below presents the values of coefficient of correlation between the constructs, and the values of square root of AVE on the diagonals, for the constructs External Environmental Practices (EEP), Internal Environmental Practices (IEP), Supplier Selection (SS), Supplier Evaluation and Monitoring (SM), Cooperation with Customers (CC), Eco-Design (ED) and Social Sustainability Practices (SSP) for comparison. 
Table 5.8 Discriminant Validity Check for SSCM Practices Constructs

\begin{tabular}{|c|c|c|c|c|c|c|c|}
\hline & SSP & EEP & IEP & SS & SM & $\mathrm{CC}$ & ED \\
\hline SSP & $0.908 * *$ & & & & & & \\
\hline EEP & $0.091 *$ & $0.818 * *$ & & & & & \\
\hline IEP & $0.093^{*}$ & $0.501 *$ & $0.884 * *$ & & & & \\
\hline SS & $0.229 *$ & $0.119 *$ & $0.136^{*}$ & $0.840 * *$ & & & \\
\hline SM & $0.122 *$ & $0.444^{*}$ & $0.475^{*}$ & $0.235^{*}$ & $0.934 * *$ & & \\
\hline $\mathrm{CC}$ & $0.403 *$ & $-0.095 *$ & $-0.088^{*}$ & $0.307 *$ & $0.012 *$ & $0.917 * *$ & \\
\hline ED & $0.171 *$ & $0.054 *$ & $0.053 *$ & $0.526 *$ & $0.097 *$ & $0.220 *$ & $0.740 * *$ \\
\hline
\end{tabular}

Note. *. Correlation between constructs

**. The bold figures on the diagonals are the square roots of the respective AVE.

It was observed from Table 5.8 above that the constructs showed a good discriminant validity as the coefficient of correlation between any two was lower than the square root of EVA of each of them.

Table 5.9 below presents the values of coefficient of correlation between the constructs, and the values of the square root of AVE on the diagonals, for constructs Economic Performance (EP), Environmental Performance (ENVP), Social Performance (SP) and Operational Performance (OP) for comparison.

Table 5.9 Discriminant Validity Check for Performance Constructs

\begin{tabular}{|l|r|l|l|l|}
\hline Constructs & \multicolumn{1}{|l|}{ OP } & EP & ENVP & SP \\
\hline OP & $\mathbf{0 . 8 6 5 * *}$ & & & \\
\hline EP & $0.836 *$ & $\mathbf{0 . 8 9 8 * *}$ & & \\
\hline ENVP & $-0.189 *$ & $-0.261 *$ & $\mathbf{0 . 9 5 2} * *$ & \\
\hline SP & $0.103 *$ & $0.165 *$ & $-0.068 *$ & $\mathbf{0 . 8 6 6 * *}$ \\
\hline
\end{tabular}

Note. *. Correlation between constructs

$* *$. The bold figures on the diagonals are the square roots of the respective AVE. 
It was observed from Table 5.9 above that the constructs showed a good discriminant validity as the coefficient of correlation between any two was lower than the square root of EVA of each of them.

In summation, after considering observations elicited from all the statistical tests and calculations, all the latent variables showed a high level of construct validity.

In this chapter we presented data preparation operations and the tests conducted before data analysis, including data screening, data coding, and cleaning operations, missing value imputation, response rate and non-response bias, common method bias, normality tests, Shapiro Wilk and Kolmogorov-Smirnov Tests, use of graphs for outliers and normality, skew and kurtosis, and tests for reliability and validity. In the next chapter, descriptive statistics are presented. 


\section{Chapter 6 Descriptive Statistics}

This chapter presents descriptive statistics including organizational characteristics and respondent characteristics.

\subsection{Organizational Characteristics}

The survey instrument was sent to senior management that would be knowledgeable about supply chain management of the focal firm. Survey question number 5 asked for descriptive information about the respondent and the firm including type of industry, number of employees, ISO 14000 certification, duration of this certification, the title of the respondent, years of experience, geographical location of the firm, and whether the firm is publicly or privately owned. The data collected comprised of a sample of 218 respondents who spanned senior management of public and privatelyowned companies over different countries and industries.

\subsubsection{Location}

Out of the companies that participated in the survey $105(48.2 \%)$ were Canadian companies, while $41(19 \%)$ were from the United States; $18(8.3 \%)$ were located in Mexico; 19 (18.9\%) in Europe; 16 (7.3\%) in South America; 17 (7.8\%) in Asia; and one each in Africa and Oceania. The details by country are given in Table 6.1 and are presented in Fig. 6.1. 
Table 6.1 Location of Respondent Companies

\begin{tabular}{|l|r|r|}
\hline \multicolumn{1}{|c|}{ Country } & $\begin{array}{r}\text { Number of } \\
\text { Companies }\end{array}$ & Percent \\
\hline Canada & 105 & 48.2 \\
United States & 41 & 18.8 \\
Mexico & 18 & 8.3 \\
South America & 16 & 7.3 \\
Europe & 19 & 8.7 \\
Oceania & 1 & .5 \\
Asia & 17 & 7.8 \\
Africa & 1 & .5 \\
Total & $\mathbf{2 1 8}$ & $\mathbf{1 0 0 . 0}$ \\
\hline
\end{tabular}

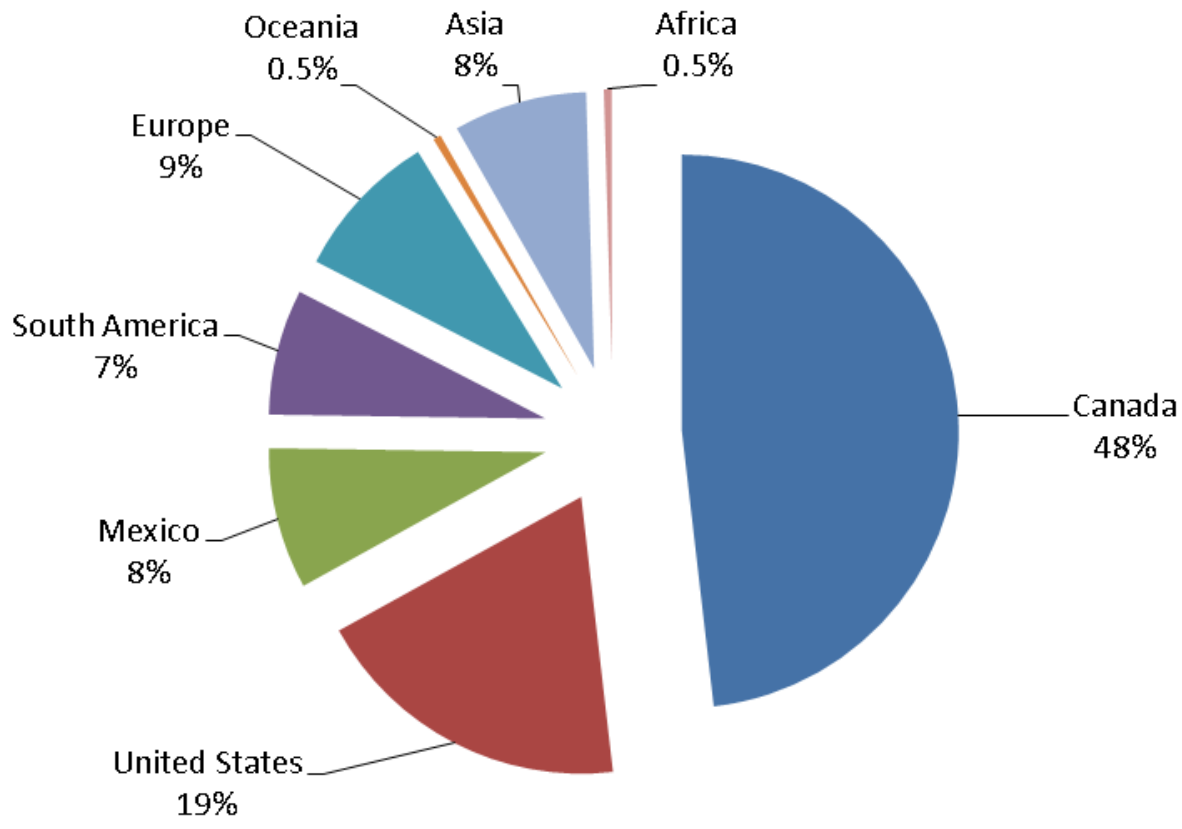

Figure 6.1 Location of Respondent Companies 
It was seen that Canada, United States of America and Mexico accounted for most of the respondents $(75.3 \%)$, there was a good representation from South America (7.3\%), Europe (8.7\%) and Asia (7.8\%). Africa and Oceania accounted for one respondent each. The distribution has implications for this research. While the results of this research are expected to hold true for Canada and USA, it would be preferable to collect data from other regions, like developing countries, Europe, and Australia for better generalizability.

\subsubsection{Industry}

Industry-wise distribution of the respondent companies is presented in Table 6.2 and Figure 6.2 below.

Table 6.2 Industry Type

\begin{tabular}{|l|r|r|}
\hline \multicolumn{1}{|c|}{ Type of Industry } & $\begin{array}{c}\text { Number of } \\
\text { Firms }\end{array}$ & Percent \\
\hline 1 General manufacturing & 58 & 26.6 \\
2 Electrical equipment, appliance, \& & 6 & 2.8 \\
component manufacturing & & \\
3 Food Industry & 28 & 12.8 \\
4 Chemical manufacturing & 12 & 5.5 \\
5 Primary metal manufacturing & 9 & 4.1 \\
6 Fabricated metal product manufacturing & 21 & 9.6 \\
7 Machinery manufacturing & 12 & 5.5 \\
8 Computer \& electronic product & 13 & 6.0 \\
manufacturing & & \\
9 Transportation equipment manufacturing & 14 & 6.4 \\
10 Other & 45 & 20.6 \\
Total & $\mathbf{2 1 8}$ & $\mathbf{1 0 0 . 0}$ \\
\hline
\end{tabular}




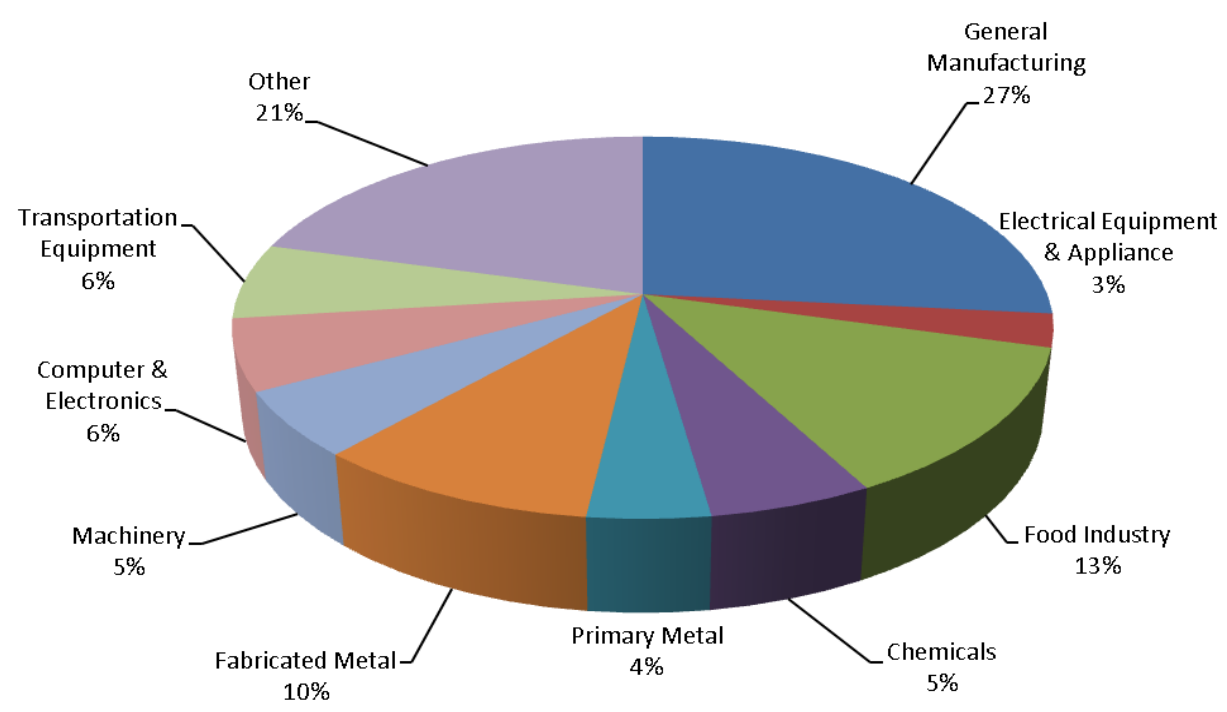

Figure 6.2 Distribution of Respondent Companies by Industry Type

The biggest participant group in the survey belonged to General manufacturing $(26.6 \%)$ followed by "Others" group of unspecified industries (20.6\%). Other big groups were Food Industry (12.8\%), Fabricated Metal Product Manufacturing (9.6\%), Transportation Equipment Manufacturing (6.4\%), Computer \& Electronic Product Manufacturing (6.0\%), Machinery Manufacturing (5.5\%), Chemical Manufacturing (5.5\%), Primary Metal Manufacturing (4.1\%), and Electrical Equipment, Appliance, \& Component Manufacturing (2.8\%). The respondents represented a wide range of industries and were fairly spread over them, indicating that there is a growing interest in sustainability issues across a large number of industries. It may be construed that given a wide representation from a number of industries the results of this research are likely to be generalizable across various industries, barring any industry-specific variations. 


\subsubsection{Size}

For this study, we adopted classification of Statistics Canada for size. Statistics Canada defines the size by number of employees as follows.

The size wise distribution of respondent companies is shown in Table 6.3 and Figure 6.3 below.

Table 6.3 Distribution of Respondent Companies by Size

\begin{tabular}{|l|r|r|}
\hline Size of Firm & Number & Percent \\
\hline 1 Small & 173 & 79.4 \\
\hline 2 Medium & 28 & 12.8 \\
\hline 3 Large & 17 & 7.8 \\
\hline Total & 218 & 100 \\
\hline
\end{tabular}

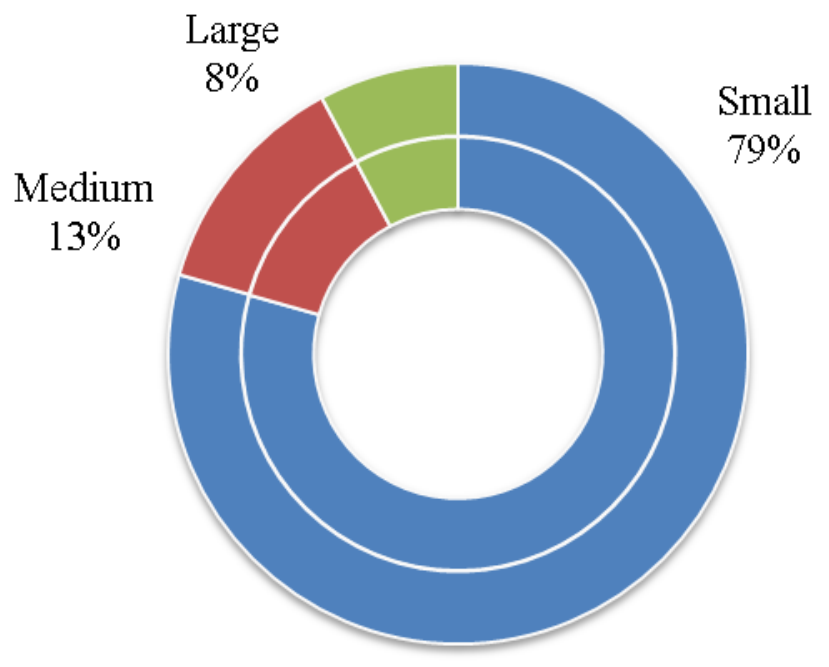

Figure 6.3 Distribution of Respondent Companies by Size 
It was seen that about $79 \%$ of respondents belonged to small-sized firms (employing under 100 employees), medium-sized firms (having between 100 and 499 employees) accounted for $12.8 \%$ of respondents, and large-sized firms (with 500 employees or more) accounted for $7.8 \%$ of respondents. This was considered a fair distribution of respondents considering that small firms account for a majority of firms in North America. However, the distribution indicated lower participation from large size firms which, to some extent, limits the generalizability of this research.

\subsubsection{Ownership}

The distribution of the companies by ownership is given in Table 6.4 and Fig. 6.4 below.

Table 6.4 Distribution of Respondent Companies by Ownership Type

\begin{tabular}{|l|c|c|}
\hline Ownership & $\begin{array}{c}\text { Number of } \\
\text { Companies }\end{array}$ & Percent \\
\hline Privately Owned & 200 & 91.7 \\
Publicly Owned & 18 & 8.3 \\
Total & $\mathbf{2 1 8}$ & $\mathbf{1 0 0 . 0}$ \\
\hline
\end{tabular}




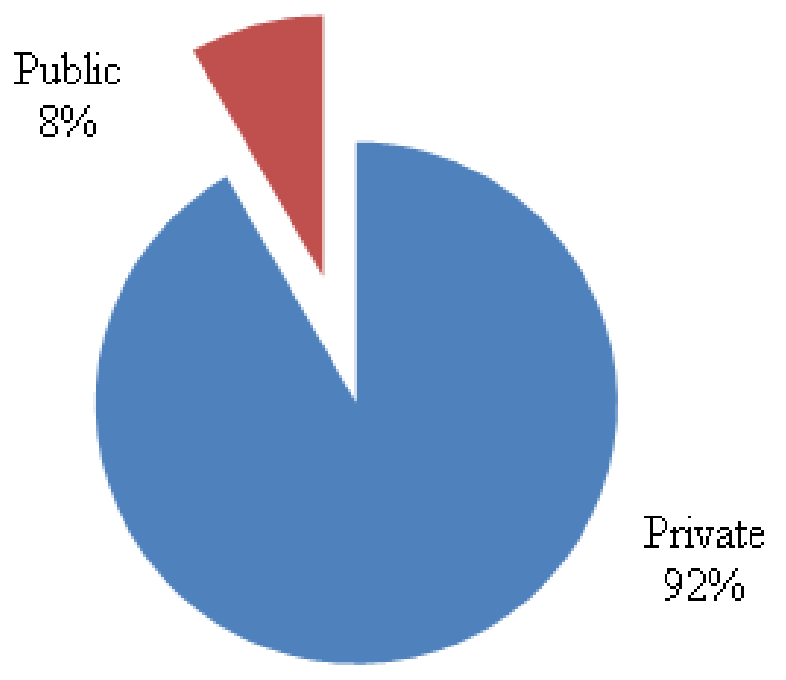

Figure 6.4 Distribution of Respondent Companies by Ownership Type

It was seen from the above distribution of ownership structure that about $8 \%$ firms belonged to the public sector, while a large majority $(92 \%)$ of firms were owned privately. It was considered a fair representation. It was heartening to note that a large number of public sector companies are actively interested in sustainability issues and spent significant time and care to respond.

\subsubsection{IS014000 Certification}

Out of total 218 companies that responded, a majority had ISO14000 Certification. The distribution of the companies by ISO14000 Certification is given in Table 6.5 and Fig. 6.5 below. 
Table 6.5 Distribution of Respondent Companies by ISO14000 Certification

\begin{tabular}{|l|c|c|}
\hline \multicolumn{1}{|c|}{ Certification Status } & $\begin{array}{c}\text { Number of } \\
\text { Companies }\end{array}$ & Percent \\
\hline ISO14000 Certified & 178 & 81.7 \\
Not Certified & 40 & 18.3 \\
Total & $\mathbf{2 1 8}$ & $\mathbf{1 0 0 . 0}$ \\
\hline
\end{tabular}

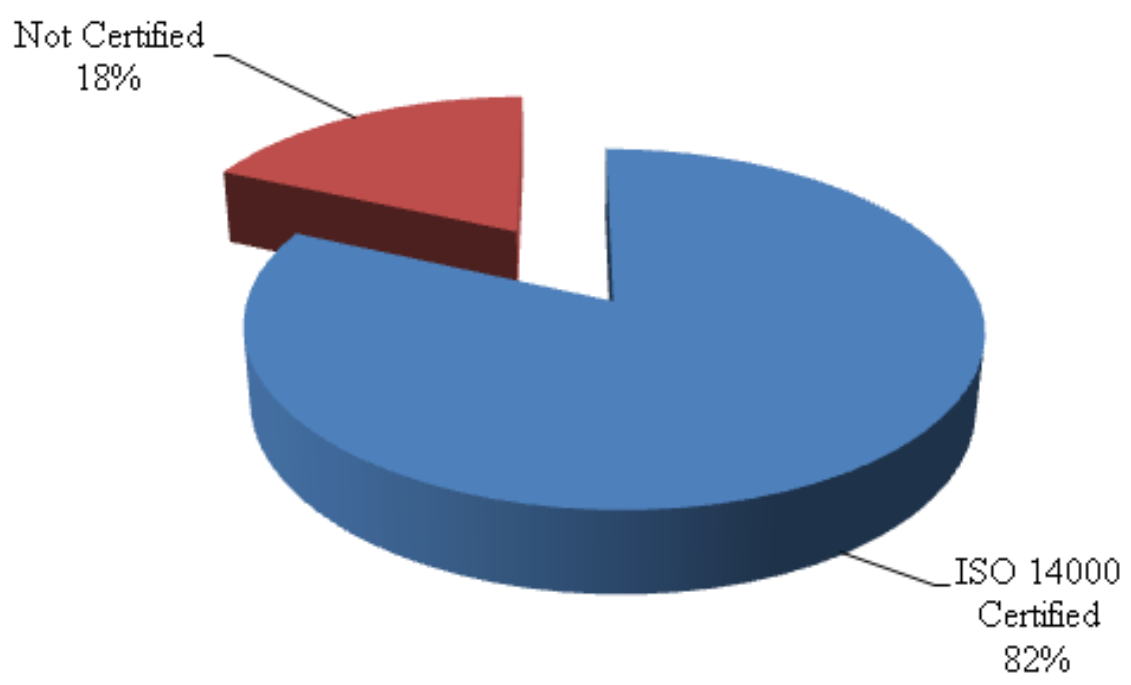

Figure 6.5 Distribution of Respondent Companies by ISO14000 Certification

It was observed that about $82 \%$ of the firms that responded are ISO14000 certified and are keenly interested in environment/sustainability issues.

\subsubsection{ISO Certification Duration}

Out of the 178 respondent companies that were ISO14000 certified, $117(53.7 \%)$ were holding ISO14000 certification for more than three years. The distribution is presented in Table 6.6 and Figure 6.6 below. 
Table 6.6 Duration of ISO14000 Certification held by Respondent Companies

\begin{tabular}{|l|c|c|}
\hline Period & $\begin{array}{c}\text { Number of } \\
\text { Companies }\end{array}$ & Percent \\
\hline Less than three yrs. & 61 & 28.0 \\
3 or more yrs. & 117 & 53.7 \\
Not applicable & 40 & 18.3 \\
Total & $\mathbf{2 1 8}$ & $\mathbf{1 0 0 . 0}$ \\
\hline
\end{tabular}

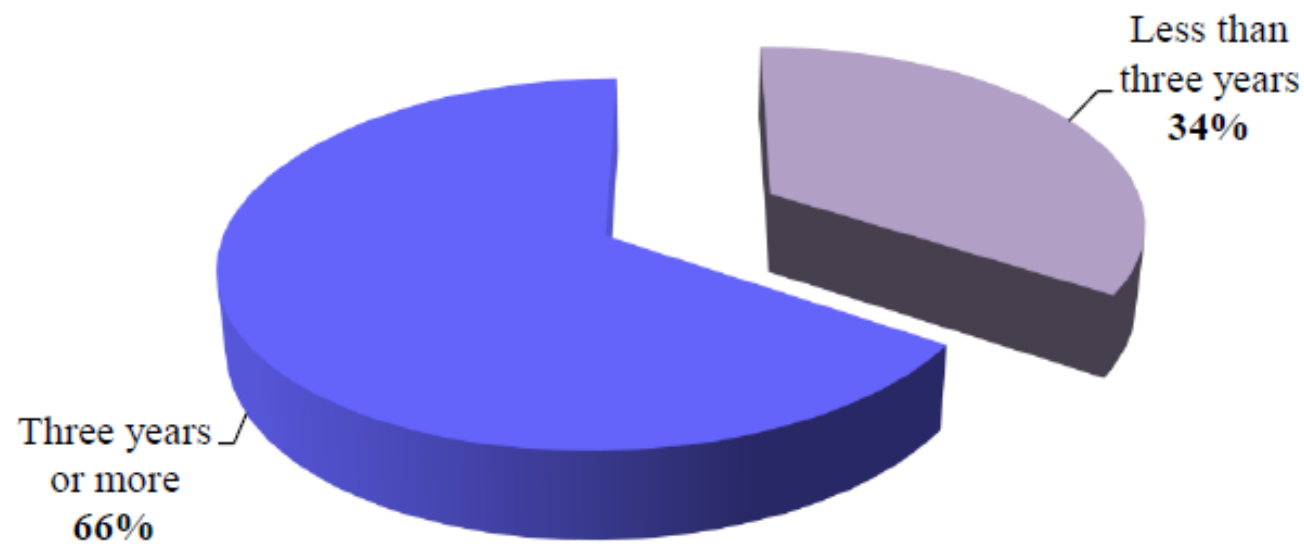

Figure 6.6 Duration of ISO14000 Certification Held by Respondent Companies

It was seen that while $66 \%$, that is two-thirds of the certified firms, have been certified for three years or longer $34 \%$ of them have been ISO14000 certified for less than three years, This indicates rising interest in ISO14000 certification and environmental/sustainability concerns. 


\subsection{Respondent Characteristics}

\subsubsection{Designation}

While the majority of the respondents (64\%) held the post of Senior Managers, 16\% were General Managers, 10\% were Vice Presidents; the respondents also included consultants, partners, owners, board members, and presidents. Table 6.7 and Figure 6.7 below presents the designation levels of respondents.

Table 6.7 Designation of Respondents

\begin{tabular}{|l|r|r|}
\hline Designation & $\begin{array}{c}\text { Number of } \\
\text { Respondents }\end{array}$ & Percent \\
\hline Senior Manager & 140 & 64.2 \\
General Manager & 35 & 16.1 \\
Vice President & 23 & 10.6 \\
President & 4 & 1.8 \\
Board Member & 2 & .9 \\
Owner & 5 & 2.3 \\
Partner & 6 & 2.8 \\
Consultant & 3 & 1.4 \\
Total & 218 & 100.0 \\
\hline
\end{tabular}




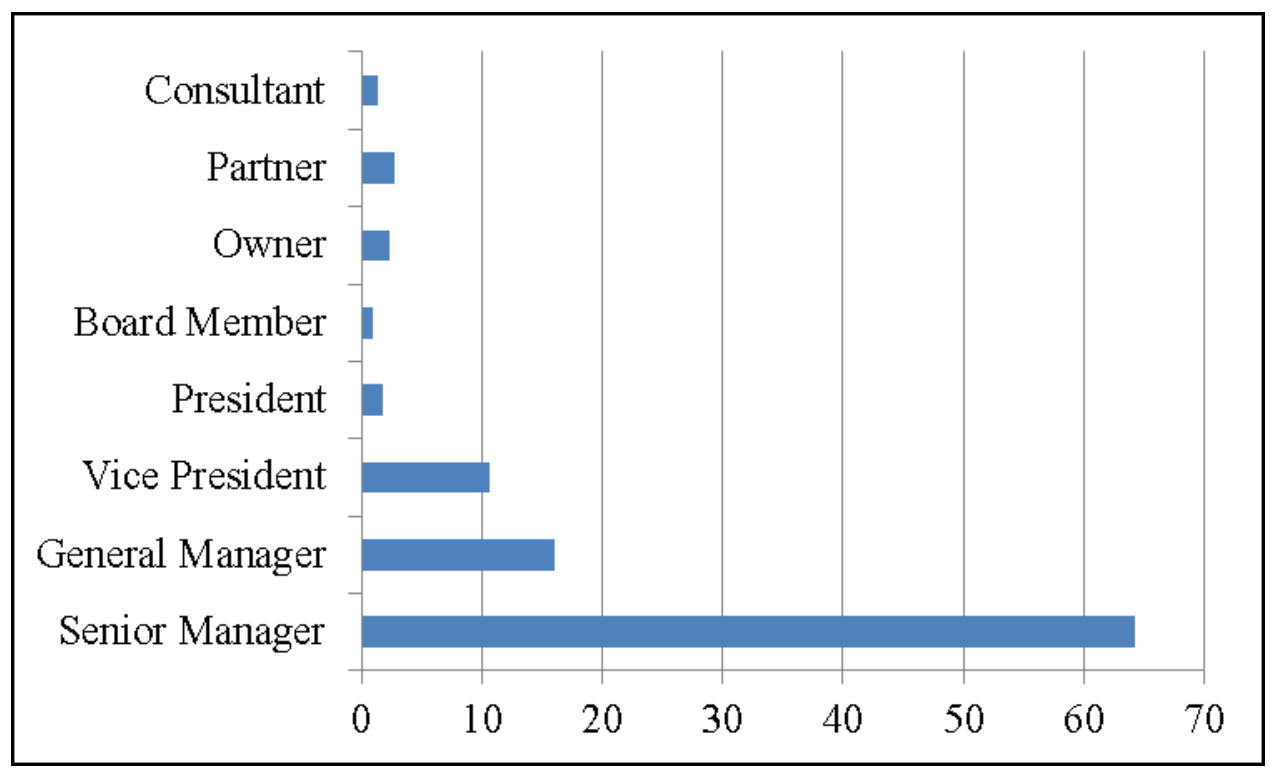

Figure 6.7 Designation of Respondents

It was seen that while Senior Managers formed the majority of respondents, who are expected to have a hands-on kind of information about sustainability issues, a large number of senior executives also responded to the survey. This made evident that there was a significant level of interest in the sustainability issues at higher echelons of the responding firms.

\subsubsection{Experience in the industry}

Duration of experience of the respondents ranged from less than one year to more than ten years. The distribution of experience is presented in Table 6.8 and Figure 6.8. 
Table 6.8 Years of Experience of Respondents

\begin{tabular}{|l|r|r|}
\hline Years of Experience & $\begin{array}{c}\text { Number of } \\
\text { Respondents }\end{array}$ & Percent \\
\hline Less than one yr. & 7 & 3.2 \\
1 to less than three & 18 & 8.3 \\
yrs. & 89 & 40.8 \\
3 to less than five & & \\
yrs. & 38 & 17.4 \\
5 to less than ten yrs. & 66 & 30.3 \\
Ten yrs. or more & 218 & 100.0 \\
Total & \\
\hline
\end{tabular}

10 yrs. Less than

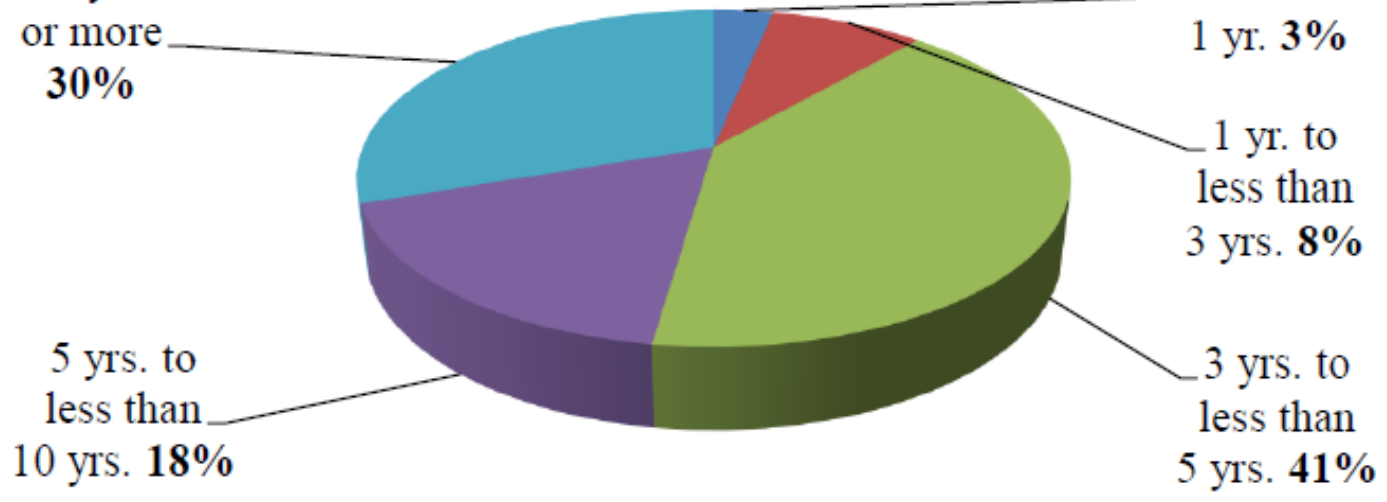

Figure 6.8 Years of Experience of Respondents

It was noticed that about $48 \%$ of the respondents had an experience of 5 years or more in their respective field, and only $11.5 \%$ had less than three years' experience. It was inferred from this that the respondents were adequately knowledgeable about their respective fields and the data collected would reflect their knowledge and experience. 
In this chapter, we dealt with the descriptive statistics of data and briefly analyzed sample characteristics, organizational characteristics including location, industry type, size of firms, firm ownership, ISO certification, and respondent characteristics including designation and experience of respondents. In the next chapter, we deal with the further analysis of data. 


\section{Chapter 7 Data Analysis}

This chapter presents further analysis of data to determine whether the hypotheses formulated in section 3.8 are supported. As a first step, a Principal Component Analysis (PCA) was conducted to extract principal components that were expected to be orthogonal variables (Abdi, 2010). As the second step multivariate regressions were conducted to examine which variables significantly contribute to the variances in the dependent variables. In each regression run, $\mathrm{R}^{2}$ (the coefficient of determination) was observed to interpret the proportion of variance that the Independent Variables (IVs) jointly account for in the Dependent Variables (DVs). Allison (1999) suggests that even

though a higher $\mathrm{R}^{2}$ is preferable, a smaller $\mathrm{R}^{2}$ should also be considered and interpreted. The overall significance of model was interpreted by the F statistic (Lewis-Beck, 1980). Section 7.1 below presents principal component analysis.

\subsection{Principal Component Analysis}

All the constructs and indicators that were used in the current exploration were taken from and validated by previously published research. However, as these constructs and indicators had not been used in the current context, Principal Component Analysis (PCA) was conducted to confirm that the principal components can be extracted from indicator data as expected. PCA analysis elicited how the indicators loaded on a reduced number of factors with which these indicators shared a correlation (Stevens, 1996). Kim and Mueller (1978a) suggest that before a PCA is conducted the matrix should be examined for correlations to see if the matrix is factorable. Tabachnick and Fidell (2007) 
also emphasize that a matrix that can be factored must include sizeable correlations (correlations $>0.30)$. Whether the variables were correlated or not was tested by using Bartlett's test which is presented in the next sub-section.

\subsubsection{Kaiser-Meyer-0klin and Bartlett's Test}

Stevens (1996) suggests that null hypothesis that the variables are not correlated may be checked by using Bartlett's Test of Sphericity. Bartlett's test assesses whether the correlation matrix created from the data collected is significantly different from zero, or whether is it an identity matrix (which forms the null hypothesis $\mathrm{H}_{0}$ here). Using SPSS, we conducted Bartlett's Test of Sphericity. The test statistic was found to be significant (sig. or p-value of .001) leading to the inference that the correlation matrix is not an identity matrix. Kaiser-Meyer-Oklin (KMO) test elicited a value of 0.957 which was higher than the cutoff of .500 . This indicated that the sample size was adequate for the analysis. Results of KMO Measure of Sampling Adequacy and Bartlett's Test of Sphericity are presented in Table 7.1 below:

Table 7.1 Kaiser-Meyer-Oklin (KMO) and Bartlett's Test

\begin{tabular}{|c|c|c|}
\hline \multicolumn{2}{|c|}{ Kaiser-Meyer-Olkin Measure of Sampling Adequacy. } & 0.929 \\
\hline \multirow[t]{3}{*}{ Bartlett's Test of Sphericity } & Approx. Chi-Square & 26525.424 \\
\hline & df & 2701 \\
\hline & Sig. & 0.001 \\
\hline
\end{tabular}


Principal Component Analysis (PCA) may provide interpretable results directly, or an oblique or orthogonal rotation may be used to improve interpretability of PCA (Rummel, 1970; Kim \& Mueller, 1978; Tabanick \& Fidell, 1989; Stevens, 1996). While oblique rotation is generally used for variables that are correlated as it allows for correlation, an orthogonal rotation is used where the variables are not expected to be correlated. An orthogonal rotation (Varimax) was used to achieve uncorrelated clusters of indicators that load on various factors.

Those indicators which had a loading of more than 0.50 were retained for further analysis. At factor level, those factors that had an eigenvalue of higher-than-one were retained after the analysis using Kaiser's criterion (Stevens, 1996). Cronbach's alpha was used to measure the reliability of each construct.

\subsubsection{Grouping of constructs for analysis}

The variables were divided into four groups for Principal Component Analysis (Table 7.2)

Table 7.2 Variable Groups for Principal Component Analysis

\begin{tabular}{|c|c|c|c|}
\hline Type of Variable & Composite Group & Construct & Acronym \\
\hline \multirow{3}{*}{$\begin{array}{l}\text { Independent } \\
\text { Variables }\end{array}$} & \multirow{3}{*}{ Drivers } & Regulations & REG \\
\hline & & Competitiveness & COMP \\
\hline & & Stakeholder Pressures & PRES \\
\hline \multirow{3}{*}{$\begin{array}{c}\text { Dependent } \\
\text { Variables for the } \\
\text { first group, and } \\
\text { Independent } \\
\text { Variables for the }\end{array}$} & \multirow{3}{*}{$\begin{array}{c}\text { SSCM Practices } \\
\text { Adoption }\end{array}$} & $\begin{array}{l}\text { External Environmental } \\
\text { Practices }\end{array}$ & EEP \\
\hline & & $\begin{array}{l}\text { Internal Environmental } \\
\text { Practices }\end{array}$ & IEP \\
\hline & & Supplier Selection & $\mathrm{SS}$ \\
\hline
\end{tabular}




\begin{tabular}{|c|c|c|c|}
\hline \multirow[t]{4}{*}{ third group } & & $\begin{array}{l}\text { Supplier Evaluation \& } \\
\text { Monitoring }\end{array}$ & SM \\
\hline & & Cooperation with Customers & $\mathrm{CC}$ \\
\hline & & Eco-Design & ED \\
\hline & & $\begin{array}{l}\text { Social Sustainability } \\
\text { Practices }\end{array}$ & SSP \\
\hline \multirow{4}{*}{$\begin{array}{c}\text { Dependant } \\
\text { Variables }\end{array}$} & \multirow{4}{*}{ Performance } & Economic Performance & EP \\
\hline & & Environmental Performance & ENVP \\
\hline & & Social Performance & SP \\
\hline & & Operational Performance & OP \\
\hline $\begin{array}{l}\text { Moderating } \\
\text { Variable }\end{array}$ & Size & Size & SIZE \\
\hline
\end{tabular}

\subsubsection{Drivers}

All indicators pertaining to the three driver constructs viz. Regulations (REG1 to REG3), Competitiveness (COMP1 to COMP7), and Stakeholder Pressures (PRES1 to PRES5) were entered into SPSS and PCA was conducted. Varimax rotation was used for Principal Component Analysis as the variables were expected to be not highly correlated. Table 7.3 below presents the total variance explained by the principal components or factors that elicited eigenvalues over 1.

Table 7.3 Total Variance Explained by Principal Components: Drivers

\begin{tabular}{|c|c|c|c|c|c|c|c|c|c|}
\hline \multirow[b]{2}{*}{$\begin{array}{l}\text { Comp } \\
\text { o-nent }\end{array}$} & \multicolumn{3}{|c|}{ Initial Eigenvalues } & \multicolumn{3}{|c|}{$\begin{array}{l}\text { Extraction Sums of } \\
\text { Squared Loadings }\end{array}$} & \multicolumn{3}{|c|}{$\begin{array}{l}\text { Rotation Sums of } \\
\text { Squared Loadings }\end{array}$} \\
\hline & $\begin{array}{c}\text { Tota } \\
1\end{array}$ & $\begin{array}{c}\text { \% of } \\
\text { Varianc } \\
\text { e }\end{array}$ & $\begin{array}{c}\text { Cumu } \\
\text {-lative } \\
\%\end{array}$ & Total & $\begin{array}{c}\text { \% of } \\
\text { Varianc } \\
\text { e }\end{array}$ & $\begin{array}{c}\text { Cumu } \\
\text {-lative } \\
\%\end{array}$ & Total & $\begin{array}{c}\text { \% of } \\
\text { Varia } \\
\text { nce }\end{array}$ & $\begin{array}{c}\text { Cumu } \\
\text {-lative } \\
\%\end{array}$ \\
\hline 1 & 6.93 & 46.201 & 46.201 & 6.930 & 46.201 & 46.201 & 5.727 & 38.183 & 38.183 \\
\hline 2 & 3.64 & 24.264 & 70.464 & 3.640 & 24.264 & 70.464 & 4.022 & 26.814 & 64.997 \\
\hline 3 & 1.97 & 13.134 & 83.599 & 1.970 & 13.134 & 83.599 & 2.790 & 18.602 & 83.599 \\
\hline
\end{tabular}


Table 7.4 below presents rotated component matrix showing the loading of indicators on the extracted principal components or factors, which were interpreted as REG, COMP, and PRES.

Table 7.4 Rotated Component Matrix: Drivers

\begin{tabular}{|l|r|r|r|}
\hline \multirow{2}{*}{ Indicators } & \multicolumn{3}{|c|}{ Component } \\
\cline { 2 - 4 } & $\begin{array}{c}\mathbf{1} \\
\text { REG }\end{array}$ & $\begin{array}{c}\mathbf{2} \\
\text { COMP }\end{array}$ & $\begin{array}{c}\mathbf{3} \\
\text { PRES }\end{array}$ \\
\hline REG1 & .902 & & \\
REG2 & .902 & & \\
REG3 & .886 & & \\
COMP1 & & .925 & \\
COMP2 & & .915 & \\
COMP3 & & .847 & \\
COMP4 & & .895 & \\
COMP5 & & .902 & \\
COMP6 & & .905 & \\
COMP7 & & .838 & \\
PRES1 & & & .920 \\
PRES2 & & & .848 \\
PRES3 & & & .881 \\
PRES4 & & & .847 \\
PRES5 & & & .832 \\
\hline
\end{tabular}

Note. Extraction Method: Principal Component Analysis.

Rotation Method: Varimax with Kaiser Normalization.

Table 7.5 presents loading of indicators of on the Driver constructs Regulations (REG), Competitiveness (COMP), and Stakeholder Pressures (PRES), and their Cronbach's Alpha. 
Table 7.5 Principal Component Analysis of Drivers and Cronbach's Alpha

\begin{tabular}{|l|r|}
\hline \multicolumn{1}{|c|}{ Principal Components and their Indicators } & Loading \\
\hline $\begin{array}{l}\text { Regulations } \\
\text { Cronbach's Alpha }=.910\end{array}$ & 0.902 \\
\hline $\begin{array}{l}\text { REG1. Environmental regulation is the primary driver for all our } \\
\text { environmental activities. }\end{array}$ & 0.902 \\
\hline $\begin{array}{l}\text { REG2. Our environmental activities are directed towards } \\
\text { complying with institutional norms and/or regulations. }\end{array}$ & 0.886 \\
\hline $\begin{array}{l}\text { REG3. Preempting future environmental legislation is the main } \\
\text { driver for adoption of proactive environmental practices. }\end{array}$ & (COMP) \\
\hline $\begin{array}{l}\text { Competitiveness } \\
\text { Cronbach's Alpha = .961 }\end{array}$ & 0.925 \\
\hline $\begin{array}{l}\text { COMP1. We believe that our environmental activities will } \\
\text { differentiate us from our competitors. }\end{array}$ & 0.915 \\
\hline $\begin{array}{l}\text { COMP2. We believe that our ecological responsiveness will lead to } \\
\text { long-term profitability. }\end{array}$ & 0.847 \\
\hline $\begin{array}{l}\text { COMP3. Protecting environment will improve long-term financial } \\
\text { performance is the main driver for adoption of proactive } \\
\text { environmental strategies }\end{array}$ & 0.895 \\
\hline $\begin{array}{l}\text { COMP4. Improved profits is the main driver for adoption of } \\
\text { environmental practices }\end{array}$ & 0.902 \\
\hline $\begin{array}{l}\text { COMP5. Access to overseas market is the main driver for adoption } \\
\text { of proactive environmental strategies }\end{array}$ & 0.905 \\
\hline $\begin{array}{l}\text { COMP6. Improving efficiency is the main driver for adoption of } \\
\text { proactive environmental strategies. }\end{array}$ & 0.838 \\
\hline $\begin{array}{l}\text { COMP7. Cost saving and risk reduction is the main driver for } \\
\text { adoption of environmental practices. }\end{array}$ & 0.832 \\
\hline $\begin{array}{l}\text { Stakeholder } \\
\text { Cronbach's Alpha = .935 }\end{array}$ & $\begin{array}{l}\text { Pressures } \\
\text { pRES1. Stakeholder relationship is the main driver for adoption of } \\
\text { PRES2. Stakeholder satisfaction is the main driver for adoption of } \\
\text { environmental practices. }\end{array}$ \\
\hline $\begin{array}{l}\text { PRES3. Lender and investors concern toward environmental } \\
\text { liability is the main driver for adoption of environmental practices. }\end{array}$ & 0.847 \\
\hline $\begin{array}{l}\text { PRES4. Customer desire to protect the environment is the main } \\
\text { driver for adoption of environmental practices. }\end{array}$ & \\
\hline $\begin{array}{l}\text { PRES5. Non Profit Organizations/judiciary/media inquiries is the } \\
\text { main driver for adoption of environmental practices }\end{array}$ & \\
\hline
\end{tabular}




\subsubsection{SSCM Practices Adoption}

All indicators pertaining to the seven SSCM Practices constructs viz. External Environmental Practices, Internal Environmental Practices, Supplier Selection, Supplier Evaluation and Monitoring, Cooperation with Customers, Eco-Design, and Social Sustainability Practices, were entered into SPSS and PCA was conducted using Varimax rotation. Table 7.6 below presents the total variance explained by the principal components or factors that elicited eigenvalues over 1.

Table 7.6 Total Variance Explained by Principal Components: SSCM Practices Adoption

\begin{tabular}{|c|c|c|l|r|l|l|l|l|l|}
\hline & \multicolumn{4}{|c|}{ Initial Eigenvalues } & \multicolumn{3}{c|}{$\begin{array}{l}\text { Extraction Sums of } \\
\text { Squared Loadings }\end{array}$} & \multicolumn{3}{|c|}{$\begin{array}{l}\text { Rotation Sums of } \\
\text { Squared Loadings }\end{array}$} \\
\hline $\begin{array}{l}\text { Com } \\
\text { pone } \\
\text { nt }\end{array}$ & Total & $\begin{array}{l}\text { \% of } \\
\text { Varian } \\
\text { ce }\end{array}$ & $\begin{array}{l}\text { Cumu- } \\
\text { lative } \\
\text { \% }\end{array}$ & Total & $\begin{array}{l}\text { \% of } \\
\text { Varia } \\
\text { nce }\end{array}$ & $\begin{array}{l}\text { Cumu } \\
\text {-lative } \\
\text { \% }\end{array}$ & Total & $\begin{array}{l}\text { \% of } \\
\text { Varia } \\
\text { nce }\end{array}$ & $\begin{array}{l}\text { Cumu } \\
\text {-lative } \\
\text { \% }\end{array}$ \\
\hline 1 & 10.638 & 28.751 & 28.751 & 10.638 & 28.751 & 28.751 & 5.813 & 15.710 & 15.710 \\
\hline 2 & 7.485 & 20.229 & 48.980 & 7.485 & 20.229 & 48.980 & 5.350 & 14.460 & 30.170 \\
\hline 3 & 3.615 & 9.770 & 58.750 & 3.615 & 9.770 & 58.750 & 5.315 & 14.366 & 44.535 \\
\hline 4 & 3.161 & 8.545 & 67.295 & 3.161 & 8.545 & 67.295 & 5.104 & 13.795 & 58.331 \\
\hline 5 & 2.713 & 7.332 & 74.627 & 2.713 & 7.332 & 74.627 & 4.809 & 12.998 & 71.328 \\
\hline 6 & 2.197 & 5.937 & 80.564 & 2.197 & 5.937 & 80.564 & 2.988 & 8.076 & 79.405 \\
\hline 7 & 1.595 & 4.310 & 84.874 & 1.595 & 4.310 & 84.874 & 2.023 & 5.469 & 84.874 \\
\hline
\end{tabular}

Table 7.7 below presents the rotated component matrix and loading of indicators on the principal components or factors extracted. These components were interpreted as EEP, IEP, SS, SM, CC, ED and SSP. 
Table 7.7 Rotated Component Matrix: SSCM Practices Adoption

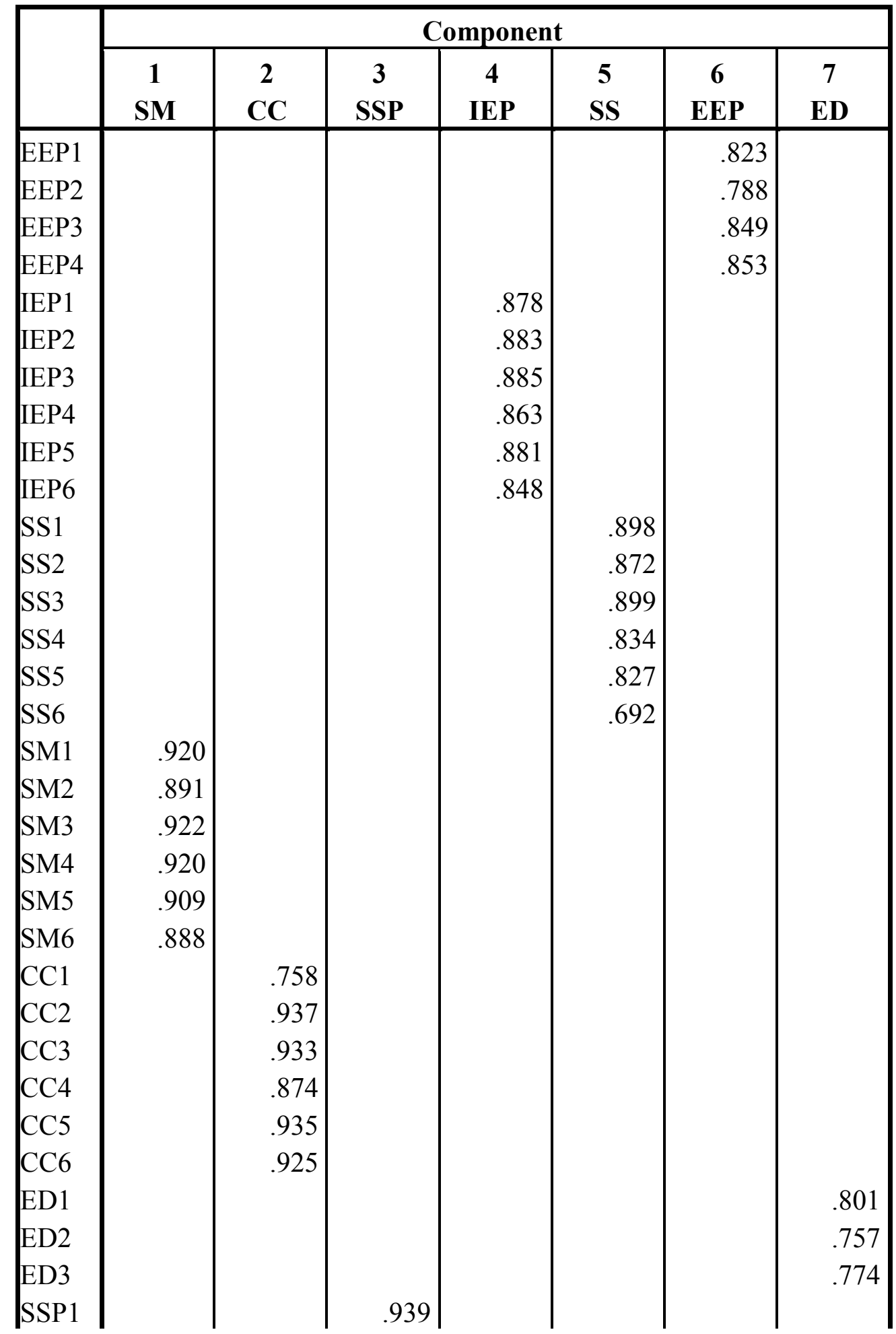




\begin{tabular}{|l|l|r|l|} 
SSP2 \\
SSP3 \\
SSP4
\end{tabular}

Note. Extraction Method: Principal Component Analysis.

Rotation Method: Varimax with Kaiser Normalization.

Rotation converged in 6 iterations.

Table 7.8 below presents loading of indicators on the SSCM Practices constructs and the calculated Cronbach's Alpha for the constructs.

Table 7.8 Principal Component Analysis of SSCM Practices Adoption and Cronbach's Alpha

\begin{tabular}{|c|c|}
\hline Principal Components and their Indicators & Loading \\
\hline $\begin{array}{l}\text { External Environmental Practices (EEP) Cronbach's Alpha }=\mathbf{. 8 9 7} \\
\text { EEP1. We cooperate with our suppliers to achieve environmental } \\
\text { objectives. } \\
\text { EEP2. We encourage our suppliers to develop new source reduction } \\
\text { strategies. } \\
\text { EEP3. We cooperate with our suppliers to improve their waste reduction } \\
\text { initiatives. } \\
\text { EEP4. We work with our suppliers for cleaner production. }\end{array}$ & $\begin{array}{l}.823 \\
.788 \\
.849 \\
.853\end{array}$ \\
\hline $\begin{array}{l}\text { Internal Environmental Practices (IEP) Cronbach's Alpha }=\mathbf{. 9 5 8} \\
\text { IEP1. We support the inventory recovery (sale) of excess } \\
\text { inventories/materials. } \\
\text { IEP2. We emphasize the use of reusable and returnable packaging for } \\
\text { our products. } \\
\text { IEP3. We constantly strive to use lesser resources in getting the tasks } \\
\text { done. } \\
\text { IEP4. We have well-documented waste reduction methodologies in }\end{array}$ & $\begin{array}{l}.878 \\
.883 \\
.885 \\
.863 \\
.881 \\
.848\end{array}$ \\
\hline
\end{tabular}


place.

IEP5. We eliminate physical waste from our operations.

IEP6. We support the sale of scrap and used materials.

Supplier Selection (SS) Cronbach's Alpha $=\mathbf{. 9 4 0}$

SS1. We select suppliers based on their environmental competence.

.898

SS2. Suppliers are selected based on their ability to support our

.872

environmental objectives.

SS3. We select suppliers based on their environmental performance.

.899

SS4. We select suppliers based on their ability to develop

.834 environmentally friendly goods.

SS5. Our organization has a thorough supplier environmental rating system.

.692

SS6. We select suppliers based on their ISO 14000 Certification.

\section{Supplier Evaluation \& Monitoring (SM) Cronbach's Alpha = .976}

SM1. We conduct regular environmental audits into our suppliers'

internal operations.

SM2. We periodically evaluate our suppliers' environmentally friendly

SM3. We make site visits to suppliers' premises to help them improve their eco-performance.

SM4. We periodically evaluate our second-tier suppliers' environmentally friendly practices.

SM5. We ask our suppliers to commit to waste reduction goals.

SM6. We send environmental questionnaires to suppliers in order to monitor their compliance.

\section{Cooperation with Customers (CC) Cronbach's Alpha $=.968$}

$\mathrm{CC} 1$. We co-operate with customers for eco-design.

$\mathrm{CC} 2$. We co-operate with customers for cleaner production.

CC3. We co-operate with customers for green packaging.

CC4. We co-operate with customers using less energy during product

CC5. We develop a mutual understanding with our customers of responsibilities regarding environmental performance.

CC6. We work together with our customers to reduce the environmental impact of our activities.

\section{Eco-Design (ED)}

Cronbach's Alpha $=.767$

ED1. We design products for reduced consumption of material/energy.

ED2. We design products for reuse, recycle, recovery of material, 


\begin{tabular}{|l|c|}
\hline $\begin{array}{l}\text { component parts. } \\
\text { ED3. We design products to avoid or reduce use of hazardous products } \\
\text { and/or their manufacturing process. }\end{array}$ & .774 \\
\hline $\begin{array}{l}\text { Social Sustainability Practices (SSP) Cronbach's Alpha =.969 } \\
\text { SSP1. Our organization frequently employs corporate codes of conduct } \\
\text { and other aspects of corporate social responsibility. }\end{array}$ & .939 \\
SSP2. Our organization commonly encourages workers to volunteer for & .933 \\
social causes and has incentives that facilitate that involvement. & \\
SSP3. Our organization contributes to charitable causes. & .946 \\
SSP4. The general approach of our organization to human resources is to & .935 \\
invest heavily to attract, train and retain employees. & \\
SSP5. In our organization employment of women is (1= limited and & .787 \\
usually takes place in less important jobs, 7=is equal to that of men) \\
SSP6. In our organization, for similar work, wages for women are \\
(1=significantly below those of men, 7=equal to those of men).
\end{tabular}

\subsubsection{Performance}

All indicators pertaining to the four performance constructs viz. Economic Performance, Environmental Performance, Social Performance, and Operational Performance were entered into SPSS and PCA was conducted using Varimax rotation Table 7.9 below presents the total variance explained by the principal components or factors that elicited eigenvalues above 1. 
Table 7.9 Total Variance Explained by Principal Components: Performance

\begin{tabular}{|c|c|c|c|c|c|c|c|c|c|}
\hline \multirow{2}{*}{$\begin{array}{l}\text { Co } \\
\text { mp } \\
\text { one } \\
\text { nt }\end{array}$} & \multicolumn{3}{|c|}{ Initial Eigenvalues } & \multicolumn{3}{|c|}{$\begin{array}{l}\text { Extraction Sums of } \\
\text { Squared Loadings }\end{array}$} & \multicolumn{3}{|c|}{$\begin{array}{l}\text { Rotation Sums of } \\
\text { Squared Loadings }\end{array}$} \\
\hline & Total & $\begin{array}{c}\% \text { of } \\
\text { Varia } \\
\text { nce } \\
\end{array}$ & $\begin{array}{c}\text { Cumu } \\
\text { lative } \\
\% \\
\end{array}$ & otal & $\begin{array}{c}\text { \% of } \\
\text { Varia } \\
\text { nce } \\
\end{array}$ & $\begin{array}{l}\mathrm{Cu} \\
\text { ativ }\end{array}$ & Total & $\begin{array}{c}\% \text { of } \\
\text { Varia } \\
\text { nce }\end{array}$ & $\begin{array}{c}\text { Cumulati } \\
\text { ve } \%\end{array}$ \\
\hline 1 & 9.135 & 41.523 & 41.523 & 9.135 & 41.523 & 41.523 & 8.526 & 38.755 & 38.755 \\
\hline 2 & 52 & 24.784 & 66.307 & 5.452 & 24.784 & 66.307 & 5.774 & 26.245 & 65.000 \\
\hline 3 & 4.005 & 18.203 & 84.509 & 4.005 & 18.203 & 84.509 & 4.149 & 18.860 & 83.861 \\
\hline
\end{tabular}

Table 7.10 below presents rotated component matrix and the loading of indicators on respective principal component or factors.

Table 7.10 Rotated Component Matrix

\begin{tabular}{|l|r|r|r|}
\hline & \multicolumn{3}{|c|}{ Components } \\
\hline Indicators & \multicolumn{1}{|c|}{$\mathbf{1}$} & \multicolumn{1}{|c|}{$\mathbf{3}$} & \multicolumn{1}{|c|}{} \\
\hline EP1 & .887 & & \\
EP2 & .883 & & \\
EP3 & .898 & & \\
EP4 & .890 & & \\
EP5 & .874 & & \\
ENVP1 & & .878 & \\
ENVP2 & & .879 & \\
ENVP3 & & .879 & \\
ENVP4 & & .867 & \\
ENVP5 & & .895 & \\
ENVP6 & & .872 & \\
SP1 & & & .908 \\
SP2 & & & .914 \\
SP3 & & & .919 \\
SP4 & & & .762 \\
SP5 & & & .803 \\
OP1 & .826 & & \\
OP2 & .804 & &
\end{tabular}




\begin{tabular}{|l|l|l|} 
OP3 & .875 & \\
OP4 & .724 & \\
OP5 & .906 & \\
OP6 & .902
\end{tabular} \mid

Table 7.11 below presents loading of indicators of Performances, i.e., Economic Performance (EP), Environmental Performance (ENVP), Social Performance (SP), and Operational Performance (OP) and their Cronbach's Alpha for the factors.

Table 7.11 Principal Component Analysis: Performance and Cronbach's Alpha

\begin{tabular}{|c|c|}
\hline Component/Indicators & Loading \\
\hline Economic Performance (EP) & \\
\hline $\begin{array}{l}\text { EP1. In our organization, there has been significant decrease in } \\
\text { cost for materials purchasing over the past three years. }\end{array}$ & .887 \\
\hline $\begin{array}{l}\text { EP2. In our organization, there has been significant decrease in } \\
\text { cost of energy consumption over the past three years. }\end{array}$ & .883 \\
\hline $\begin{array}{l}\text { EP3. In our organization, there has been a significant decrease in } \\
\text { fee for waste treatment over the past three years. }\end{array}$ & .898 \\
\hline $\begin{array}{l}\text { EP4. In our organization, there has been a significant decrease in } \\
\text { fee for waste discharge over the past three years. }\end{array}$ & .890 \\
\hline $\begin{array}{l}\text { EP5. In our organization, there has been a significant decrease of } \\
\text { fine for environmental accidents over the past three years. }\end{array}$ & .874 \\
\hline Environmental Performance (ENVP) Cronbach's Alpha $=.983$ & \\
\hline $\begin{array}{l}\text { ENVP1. In our organization, there has been a significant } \\
\text { reduction of air emission over the past three years. }\end{array}$ & .878 \\
\hline $\begin{array}{l}\text { ENVP2. In our organization, there has been a significant } \\
\text { reduction of wastewater over the past three years. }\end{array}$ & .879 \\
\hline $\begin{array}{l}\text { ENVP3. In our organization, there has been a significant } \\
\text { reduction of solid wastes over the past three years. }\end{array}$ & .879 \\
\hline ENVP4. In our organization, there has been a significant decrease & .867 \\
\hline $\begin{array}{l}\text { in consumption of hazardous/harmful/toxic materials over the past } \\
\text { three years. }\end{array}$ & .895 \\
\hline
\end{tabular}




\begin{tabular}{|l|c|}
\hline ENVP5. In our organization, there has been significant decrease & \\
in frequency for environmental accidents over the past three years. & .872 \\
ENVP6. There has been a significant improvement of our & \\
organization's environmental situation over the past three years. & \\
\hline $\begin{array}{l}\text { Social Performance (SP) } \\
\text { SP1. In our organization, there has been a significant increase in } \\
\text { days of vocational training over the past three years. }\end{array}$ & .908 \\
SP2. In our organization, there has been a significant increase in \\
philanthropy as a share of profit over the past three years.
\end{tabular}

\subsubsection{Summary of Principal Component Analysis}

The principal component analysis is a psychometrically sound technique (Stevens, 1996) to reduce the number of variables for parsimony and to keep the model compact. It is expected that logical and small number of components would help in running a 
regression in a meaningful way and would have enough power to detect significant relationships. These components have to both make practical sense and be grounded in theory as well. The data was analyzed to identify these components by conducting PCA as a dimension reduction process using Varimax rotation in SPSS. The aim was to identify principal components, which have little or no correlations between themselves to minimize the problem of multicollinearity in multiple regression analysis.

All the items or indicators loaded well on components and elicited loading values of above 0.70 , which was commendable when compared to the benchmark of 0.50 (Fornell \& Larcker, 1981). None of the items was removed from the scale after PCA. Values for constructs were computed by calculating the mean of all the items indicating a single construct, ignoring their relative weights, or their level of loading on the components. These computed construct values were then used for conducting multiple regression analyses.

\subsection{Regression Analyses}

Figure 7.1 below reproduces the a-priori theoretical framework and the relationships hypothesized between the variables for ready reference. 
Drivers/Motivations
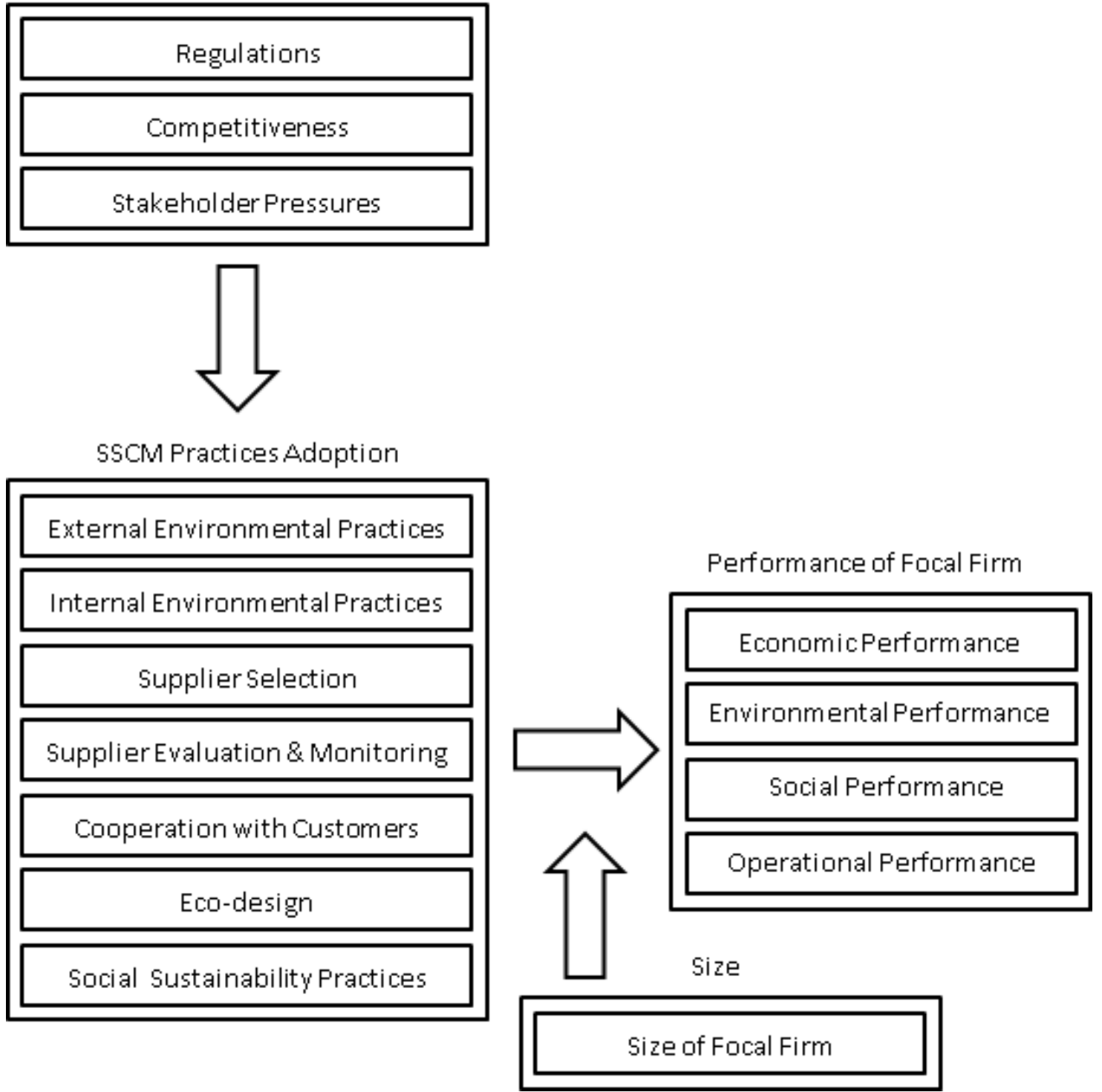

Figure 7.1 Theoretical Framework

The conceptual framework is formed of three distinct groups or composite constructs, theoretically. These constructs are Drivers, SSCM Practices Adoption, and Performance of focal firm. These groups form a logical basis for analysis and discussion. 
Accordingly, the relationships between these groups, which were derived from literature review, and were used for planning regressions, are summarised in Table 7.12 below.

Table 7.12 Composite Constructs, Constructs and Acronym Used

\begin{tabular}{|l|l|c|}
\hline $\begin{array}{c}\text { Composite } \\
\text { Construct or } \\
\text { Group }\end{array}$ & \multicolumn{1}{|c|}{ Constructs } & $\begin{array}{c}\text { Acronym } \\
\text { Used in } \\
\text { Analysis }\end{array}$ \\
\hline Drivers & Regulations & REG \\
\cline { 2 - 3 } & Competitiveness & COMP \\
\cline { 2 - 3 } $\begin{array}{l}\text { SSCM } \\
\text { Adoption }\end{array}$ & Stakeholder Pressures & PRES \\
\cline { 2 - 3 } & External Environmental Practices & EEP \\
\cline { 2 - 3 } & Internal Environmental Practices & IEP \\
\cline { 2 - 3 } & Supplier Selection & SS \\
\cline { 2 - 3 } & Supplier Evaluation \& Monitoring & SM \\
\cline { 2 - 3 } & Cooperation with Customers & CC \\
\cline { 2 - 3 } & Eco-Design & SSP \\
\cline { 2 - 3 } & Social Sustainability Practices & EP \\
\hline \multirow{4}{*}{ Performance } & Economic Performance & ENVP \\
\cline { 2 - 3 } & Environmental Performance & OP \\
\cline { 2 - 3 } & Social Performance & SP \\
\cline { 2 - 3 } & Operational Performance & SPan \\
\hline
\end{tabular}

Note. Source: Literature review

Keeping these groups in view, the effects hypothesized were classified as given in Table 7.13 below. 
Table 7.13 Hypothesised Effects of Variables

\begin{tabular}{|c|c|c|}
\hline Independent & Dependent & Hypotheses \\
\hline Drivers & $\begin{array}{l}\text { SSCM } \\
\text { Practices } \\
\text { Adoption }\end{array}$ & $\begin{array}{l}\text { H1a: Companies that face a higher level of } \\
\text { regulations are more likely to adopt SSCM practices. } \\
\text { H1b: Companies that aim to achieve a higher level of } \\
\text { competitiveness are more likely to adopt SSCM } \\
\text { practices. } \\
\text { H1c: Companies that face higher pressures from } \\
\text { stakeholders are more likely to adopt SSCM } \\
\text { practices. }\end{array}$ \\
\hline $\begin{array}{l}\text { SSCM } \\
\text { Practices } \\
\text { Adoption }\end{array}$ & Performance & $\begin{array}{l}\text { H2a: A company's economic performance is } \\
\text { positively associated with the company's adoption of } \\
\text { SSCM practices. } \\
\text { H2b: A company's environmental performance is } \\
\text { positively associated with the company's adoption of } \\
\text { SSCM practices. } \\
\text { H2c: A company's social performance is positively } \\
\text { associated with the company's adoption of SSCM } \\
\text { practices. } \\
\text { H2d: A company's operational performance is } \\
\text { positively associated with the company's adoption of } \\
\text { SSCM practices. }\end{array}$ \\
\hline Size & $\begin{array}{l}\text { Posited to } \\
\text { Moderate } \\
\text { Impact of } \\
\text { SSCM } \\
\text { Practices } \\
\text { Adoption on } \\
\text { Performance. }\end{array}$ & $\begin{array}{l}\text { H3a: The bigger the firm size, the greater is the } \\
\text { impact of company's adoption of SSCM practices on } \\
\text { the company's economic performance. } \\
\text { H3b: The bigger the firm size, the greater is the } \\
\text { impact of company's adoption of SSCM practices on } \\
\text { the company's environmental performance. } \\
\text { H3c: The bigger the firm size, the greater is the } \\
\text { impact of company's adoption of SSCM practices on } \\
\text { the company's social performance. } \\
\text { H3d: The bigger the firm size, the greater is the } \\
\text { impact of company's adoption of SSCM practices on } \\
\text { the company's operational performance. }\end{array}$ \\
\hline
\end{tabular}

Note. Source: Literature review

To examine these effects, various runs of multiple regressions were planned in three sets for analysis. These three sets are summarised in Table 7.14 below. 
Table 7.14 Independent and Dependent Variables for Regressions

\begin{tabular}{|c|c|c|c|c|}
\hline Set & Regression & Independent Variables & $\begin{array}{c}\text { Dependent } \\
\text { Variables }\end{array}$ & Hypothesis \\
\hline \multirow[t]{7}{*}{1} & 1 & REG, COMP, PRES & EEP & H1a, H1b, H1c \\
\hline & 2 & REG, COMP, PRES & IEP & H1a, H1b, H1c \\
\hline & 3 & REG, COMP, PRES & SS & H1a, H1b, H1c \\
\hline & 4 & REG, COMP, PRES & SM & H1a, H1b, H1c \\
\hline & 5 & REG, COMP, PRES & $\mathrm{CC}$ & H1a, H1b, H1c \\
\hline & 6 & REG, COMP, PRES & ED & H1a, H1b, H1c \\
\hline & 7 & REG, COMP, PRES & SSP & H1a, H1b, H1c \\
\hline \multirow[t]{4}{*}{2} & 8 & $\begin{array}{l}\text { EEP, IEP, SS, SM, CC, } \\
\text { ED,SSP }\end{array}$ & EP & $\mathrm{H} 2 \mathrm{a}$ \\
\hline & 9 & $\begin{array}{l}\text { EEP, IEP, SS, SM, CC, } \\
\text { ED,SSP }\end{array}$ & ENVP & $\mathrm{H} 2 \mathrm{~b}$ \\
\hline & 10 & $\begin{array}{l}\text { EEP, IEP, SS, SM, CC, } \\
\text { ED,SSP }\end{array}$ & SP & $\mathrm{H} 2 \mathrm{c}$ \\
\hline & 11 & $\begin{array}{l}\text { EEP, IEP, SS, SM, CC, } \\
\text { ED,SSP }\end{array}$ & $\mathrm{OP}$ & $\mathrm{H} 2 \mathrm{~d}$ \\
\hline \multirow[t]{4}{*}{3} & 12 & $\begin{array}{l}\text { Moderator variable SIZE, } \\
\text { Independent variables EEP, } \\
\text { IEP, SS, SM, CC, ED,SSP }\end{array}$ & $\mathrm{EP}$ & $\mathrm{H} 3 \mathrm{a}$ \\
\hline & 13 & $\begin{array}{l}\text { Moderator variable SIZE, } \\
\text { Independent variables EEP, } \\
\text { IEP, SS, SM, CC, ED,SSP }\end{array}$ & ENVP & $\mathrm{H} 3 \mathrm{~b}$ \\
\hline & 14 & $\begin{array}{l}\text { Moderator variable SIZE, } \\
\text { Independent variables EEP, } \\
\text { IEP, SS, SM, CC, ED,SSP }\end{array}$ & SP & $\mathrm{H} 3 \mathrm{c}$ \\
\hline & 15 & $\begin{array}{l}\text { Moderator variable SIZE, } \\
\text { Independent variables EEP, } \\
\text { IEP, SS, SM, CC, ED,SSP }\end{array}$ & OP & H3d \\
\hline
\end{tabular}


A general regression equation representing these regressions is

$$
\hat{Y}=b_{0}+b_{1}(x 1)+b_{2}(x 2)+b_{3}(x 3)+\ldots+b_{K}(x K)
$$

Equation 7.1 General Multiple Regression

\subsubsection{Impact of Drivers on Adoption of SSCM Practices: Multiple Regression Runs 1 through 7}

In literature, a positive relationship has been posited between drivers and adoption of SSCM practices. First set of multivariate regressions numbered 1 through 7 (please see Table 7.14) were run to test for this relationship. That is, REG, COMP, PRES were regressed on variable EEP as the first regression, then the same independent variables were regressed on variable IEP, and so on. The results of these regressions are detailed in Table 7.15 below.

Table 7.15 Standardised Regression Coefficients: Regressions 1 to 7

\begin{tabular}{|c|c|c|c|c|c|c|c|c|}
\hline \multicolumn{2}{|c|}{ Regression No. } & \multirow{2}{*}{$\begin{array}{c}1 \\
\text { EEP }\end{array}$} & \multirow{2}{*}{$\begin{array}{c}2 \\
\text { IEP }\end{array}$} & \multirow{2}{*}{\begin{tabular}{|c|}
3 \\
$S S$
\end{tabular}} & \multirow{2}{*}{$\begin{array}{c}4 \\
S M\end{array}$} & \multirow{2}{*}{$\begin{array}{c}5 \\
C C\end{array}$} & \multirow{2}{*}{\begin{tabular}{|c|}
6 \\
$E D$
\end{tabular}} & \multirow{2}{*}{$\begin{array}{c}7 \\
\text { SSP }\end{array}$} \\
\hline $\begin{array}{l}\text { Ind. } \\
\text { Var. }\end{array}$ & $\begin{array}{l}\text { Dependent } \\
\text { Variables }>\end{array}$ & & & & & & & \\
\hline \multirow{2}{*}{ REG } & Std. Beta & $.654 * * *$ & $.732 * * *$ & $.400 * * *$ & $.729 * * *$ & $.178 * * *$ & $.380 * * *$ & $.310 * * *$ \\
\hline & Partial & .599 & .668 & .446 & .662 & .211 & .421 & .586 \\
\hline \multirow[t]{2}{*}{ COMP } & Std. Beta & & & $.590 * * *$ & & $.506^{* * *}$ & $.591 * * *$ & \\
\hline & Partial & & & .612 & & .542 & .606 & \\
\hline \multirow[t]{2}{*}{ PRES } & Std. Beta & $.129 * *$ & $.202 * * *$ & $.298 * * *$ & $.250 * * *$ & $.397 * * *$ & $.270 * * *$ & $.999 * * *$ \\
\hline & Partial & .146 & .242 & .350 & .291 & .435 & .315 & .920 \\
\hline \multicolumn{2}{|l|}{$\mathrm{R}^{2}$} & .369 & .452 & .468 & .439 & .437 & .448 & .848 \\
\hline \multicolumn{2}{|c|}{ Adjusted $\mathrm{R}^{2}$} & .360 & .444 & .460 & .431 & .429 & .440 & .846 \\
\hline \multicolumn{2}{|c|}{ F Statistics } & 41.67 & 58.79 & 62.68 & 55.85 & 55.29 & 57.85 & 398.95 \\
\hline \multicolumn{2}{|l|}{ F sig. } & .001 & .001 & .001 & .001 & .001 & .001 & .001 \\
\hline
\end{tabular}


Note. 1.This table only shows significant Betas.

2. Standardised regression coefficients are shown: ${ }^{*} \mathrm{p}<.10 ; * * \mathrm{p}<.05 ; * * * \mathrm{p}<.01$

It was observed from the above results that the driver Regulations displayed a statistically significant positive impact on adoption of all the seven SSCM Practices; the driver Competitiveness showed a statistically significant positive impact on adoption of supplier selection practices, cooperation with customer practices and eco-design practices; and the driver Stakeholder Pressures showed a statistically significant positive impact on adoption of all seven SSCM Practices.

Table 7.16 below summarises the inference from the above findings concerning the support they lend to hypotheses H1a to H1c.

Table 7.16 Inference from the Findings of Multiple Regression Analysis: Regression of

Drivers on SSCM Practices

\begin{tabular}{|c|c|l|c|}
\hline $\begin{array}{c}\text { Independe } \\
\text { nt } \\
\text { Variables }\end{array}$ & $\begin{array}{c}\text { Dependent } \\
\text { Variables }\end{array}$ & \multicolumn{1}{|c|}{ Hypotheses } & Inference \\
\hline \multirow{2}{*}{ Drivers } & $\begin{array}{c}\text { SSCM } \\
\text { Practices } \\
\text { Adoption }\end{array}$ & $\begin{array}{l}\text { H1a: Companies that face a higher level of } \\
\text { regulations are more likely to adopt SSCM } \\
\text { practices. }\end{array}$ & Supported \\
\cline { 3 - 5 } REG, & EEP, IEP, & $\begin{array}{l}\text { H1b: Companies that aim to achieve a higher } \\
\text { level of competitiveness are more likely to } \\
\text { adopt SSCM practices. }\end{array}$ & $\begin{array}{c}\text { Partially } \\
\text { Supported }\end{array}$ \\
\cline { 3 - 3 }, & SS, SM, & $\begin{array}{l}\text { H1c: Companies that face higher pressures } \\
\text { from stakeholders are more likely to adopt }\end{array}$ & Supported \\
PRES & CC, ED, & SSCM practices. & \\
& SSP & &
\end{tabular}


The results of regressions 8 through 11 are detailed in the next sub-section.

\subsubsection{Impact of SSCM Practices Adoption on Performance: Multiple Regression Runs 8 through 11}

In literature, a positive relationship has been posited between adoption of SSCM practices and performance of a firm. The second set of regressions numbered 8 through 11 (please see Table 7.14) were run to test for this relationship. That is, variables EEP, IEP, SS, SM, CC, ED, and SSP were regressed first on variable EP as the first regression, and then the same independent variables were regressed on variable ENVP, and so on. The results of these regressions are detailed in Table 7.17 below.

Table 7.17 Standardised Regression Coefficients: Regressions 8 to 11

\begin{tabular}{|c|c|c|c|c|c|}
\hline \multicolumn{2}{|c|}{ Regression } & \multirow{2}{*}{$\begin{array}{c}8 \\
E P\end{array}$} & \multirow{2}{*}{$\begin{array}{c}9 \\
\text { ENVP }\end{array}$} & \multirow{2}{*}{$\begin{array}{l}10 \\
\text { SP }\end{array}$} & \multirow{2}{*}{$\begin{array}{c}11 \\
\text { OP }\end{array}$} \\
\hline $\begin{array}{l}\text { Ind. } \\
\text { Var. }\end{array}$ & $\begin{array}{l}\text { Dependent } \\
\text { Variables-> }\end{array}$ & & & & \\
\hline \multirow[t]{2}{*}{ EEP } & Std. Beta & & $.256 * * *$ & & \\
\hline & Partial & & .411 & & \\
\hline \multirow[t]{2}{*}{ IEP } & Std. Beta & & $.388 * * *$ & & \\
\hline & Partial & & .552 & & \\
\hline \multirow[t]{2}{*}{ SS } & Std. Beta & $.355 * * *$ & & & $.444 * * *$ \\
\hline & Partial & .488 & & & .557 \\
\hline \multirow[t]{2}{*}{ SM } & Std. Beta & $-.102 * *$ & $.481 * * *$ & & $-.101 * *$ \\
\hline & Partial & -.161 & .634 & & -.152 \\
\hline \multirow[t]{2}{*}{$\mathbf{C C}$} & Std. Beta & $.509 * * *$ & & & $.362 * * *$ \\
\hline & Partial & .630 & & & .484 \\
\hline \multirow[t]{2}{*}{ ED } & Std. Beta & $.377 * * *$ & & & $.419 * * *$ \\
\hline & Partial & .533 & & & .556 \\
\hline SSP & Std. Beta & $-.269 * * *$ & $-.152 * * *$ & $.963 * * *$ & $-.285 * * *$ \\
\hline
\end{tabular}




\begin{tabular}{|c|c|c|c|c|}
\hline Partial & -.400 & -.255 & .962 & -.405 \\
\hline $\mathrm{R}^{2}$ & .711 & .746 & .943 & .684 \\
\hline Adjusted $\mathrm{R}^{2}$ & .701 & .738 & .941 & .674 \\
\hline F Statistics & 73.67 & 88.22 & 492.39 & 65.08 \\
\hline F sig. & .001 & .001 & .001 & .001 \\
\hline
\end{tabular}

Note. 1.This table only shows significant Betas.

2. Standardised regression coefficients are shown: ${ }^{*} \mathrm{p}<.10 ; * * \mathrm{p}<.05 ; * * * \mathrm{p}<.01$

From the above results, we observe that adoption of Supplier Selection Practices, Cooperation with Customer Practices and Eco-Design Practices have a high and statistically significant positive impact on Economic Performance and Operational Performance. On the other hand, adoption of Social Sustainability Practices and Supplier Evaluation and Monitoring practices has a statistically significant negative impact on Economic Performance and Operational Performance. External Environmental Practices and Internal Environmental Practices do not show any statistically significant impact on Economic Performance or Operational Performance.

Adoption of External Environmental Practices, Internal Environmental Practices and Supplier Evaluation and Monitoring practices have a high and statistically significant positive impact on Environmental Performance. Adoption of the other four SSCM Practices does not have any statistically significant impact on Environmental Performance.

Adoption of Social Sustainability Practices has a high and statistically significant positive impact on Social Performance. Adoption of other six SSCM Practices does not have any statistically significant impact on Social Performance. 
Table 7.18 below summarises the inference from the above findings concerning the support they lend to hypotheses $\mathrm{H} 2 \mathrm{a}$ to $\mathrm{H} 2 \mathrm{~d}$.

Table 7.18 Findings of Multiple Regression Analyses: Regression of SSCM Practices on Performance

\begin{tabular}{|c|c|c|c|}
\hline $\begin{array}{l}\text { Independ } \\
\text { ent } \\
\text { Variable }\end{array}$ & $\begin{array}{c}\text { Dependent } \\
\text { Variables }\end{array}$ & Hypotheses & Findings \\
\hline \multirow{4}{*}{$\begin{array}{c}\text { SSCM } \\
\text { Practices } \\
\text { Adoption } \\
\text { EEP, IEP, } \\
\text { SS, SM, } \\
\text { CC, ED, } \\
\text { SSP }\end{array}$} & $\begin{array}{c}\text { Economic } \\
\text { Performance } \\
\text { EP }\end{array}$ & $\begin{array}{l}\text { H2a: A company's economic } \\
\text { performance is positively associated } \\
\text { with the company's adoption of SSCM } \\
\text { practices. }\end{array}$ & $\begin{array}{l}\text { Partially } \\
\text { Supported }\end{array}$ \\
\hline & $\begin{array}{l}\text { Environment } \\
\text { al } \\
\text { Performance } \\
\text { ENVP }\end{array}$ & $\begin{array}{l}\text { H2b: A company's environmental } \\
\text { performance is positively associated } \\
\text { with the company's adoption of SSCM } \\
\text { practices. }\end{array}$ & $\begin{array}{c}\text { Partially } \\
\text { Supported }\end{array}$ \\
\hline & $\begin{array}{c}\text { Social } \\
\text { Performance } \\
\text { SP }\end{array}$ & $\begin{array}{l}\text { H2c: A company's social performance } \\
\text { is positively associated with the } \\
\text { company's adoption of SSCM } \\
\text { practices. }\end{array}$ & $\begin{array}{c}\text { Partially } \\
\text { Supported }\end{array}$ \\
\hline & $\begin{array}{l}\text { Operational } \\
\text { Performance } \\
\text { OP }\end{array}$ & $\begin{array}{l}\text { H2d: A company's operational } \\
\text { performance is positively associated } \\
\text { with the company's adoption of SSCM } \\
\text { practices. }\end{array}$ & $\begin{array}{l}\text { Partially } \\
\text { Supported }\end{array}$ \\
\hline
\end{tabular}

\subsubsection{Moderator Effect of Size on Impact of SSCM Practices Adoption on}

\section{Performance: Multiple Regression Runs 12 through 15}

In literature, it is posited that size of a firm may significantly moderate the impact of different factors on the performance of a firm (Swamidass \& Kotha, 1998). In subsection 6.1.3 we noticed that the respondents in data collected represented firms which were of three sizes: small, medium and large, classified on the basis of the number of 
their employees. As a first step, we tested whether there was indeed a difference between performances of firms of different sizes. Checking for differences in means is a valid way to determine whether there is a difference in performance of the firms belonging to different sizes. From graphical comparison, it was seen that the means of performance of firms from the three sizes differed from one another. Figures 7.2 to 7.5 below present a visual representation of this comparison.

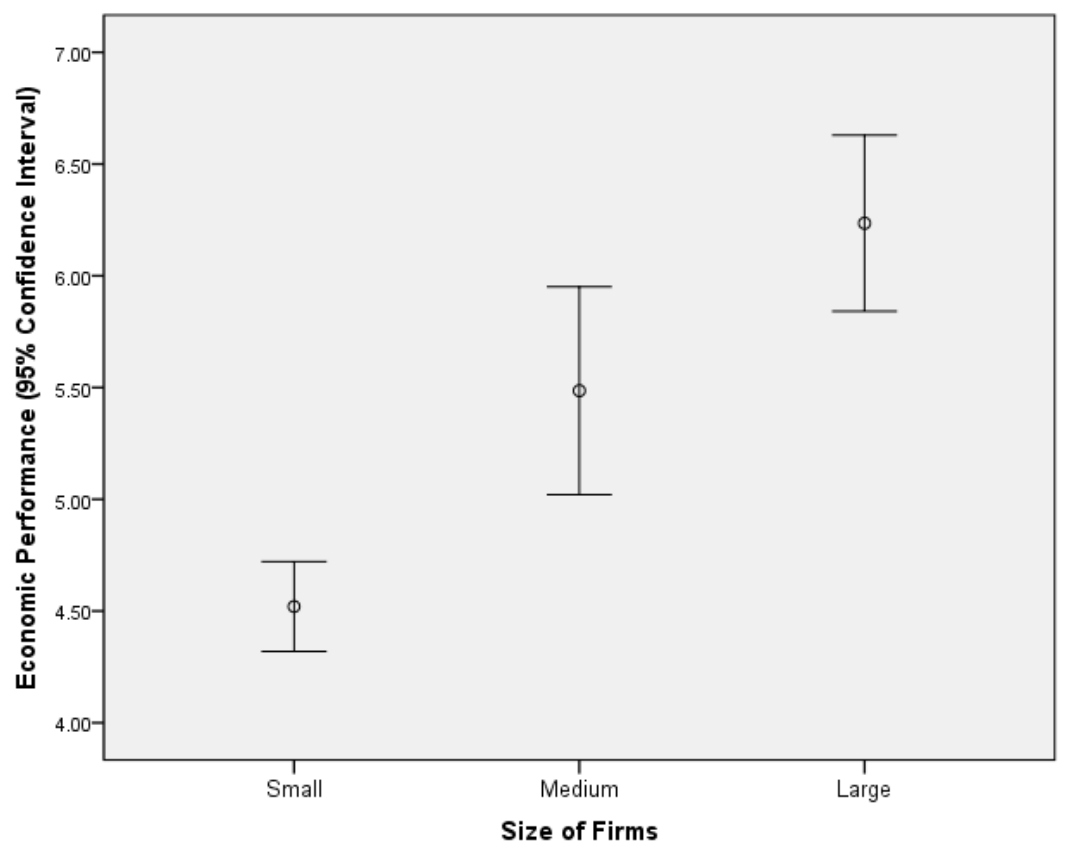

Figure 7.2 Comparison of Economic Performance of Small, Medium and Large Size Firms

It was observed from the Figure 7.2 that the mean economic performance of medium size firms was higher than that of small firms, and the mean economic performance of large size firms was higher than that of medium firms. 


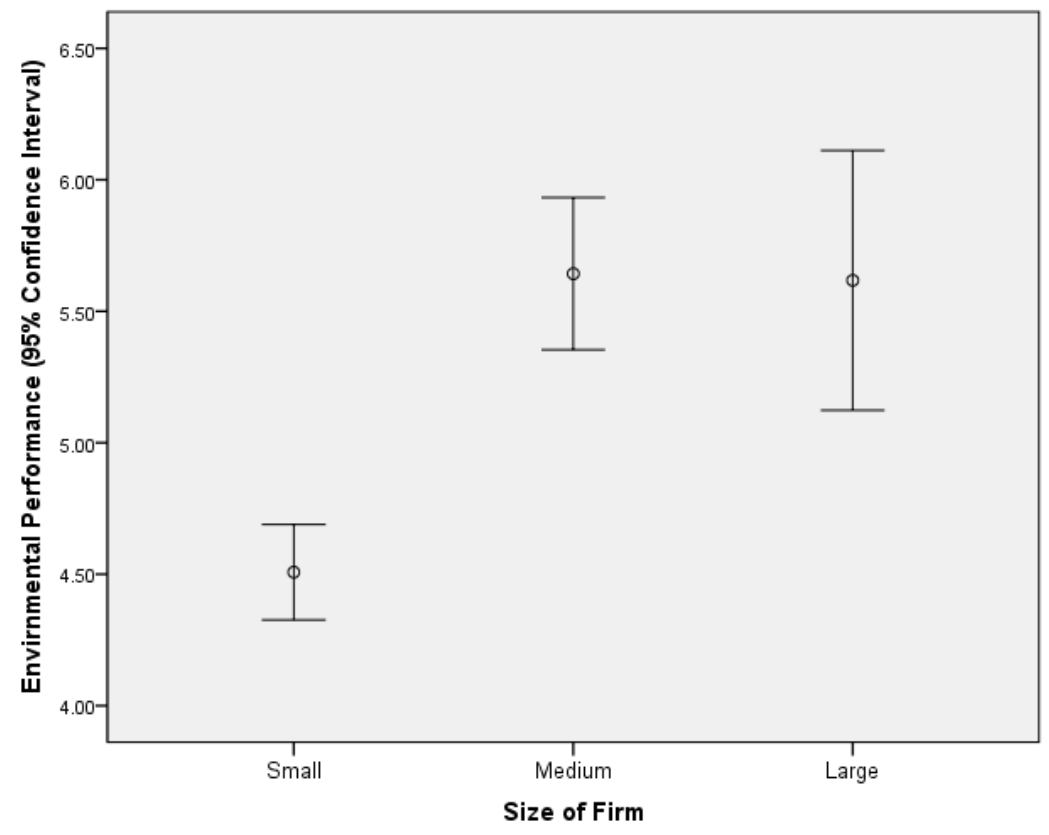

Figure 7.3 Comparison of Environmental Performance of Small, Medium and Large Size Firms

The Figure 7.3 above displayed that the mean environmental performance of medium size firms was higher than that of small firms and the mean environmental performance of large size firms was roughly about same as that of medium firms. Figure 7.4 below shows the mean social performance of small, medium and large size firms. 


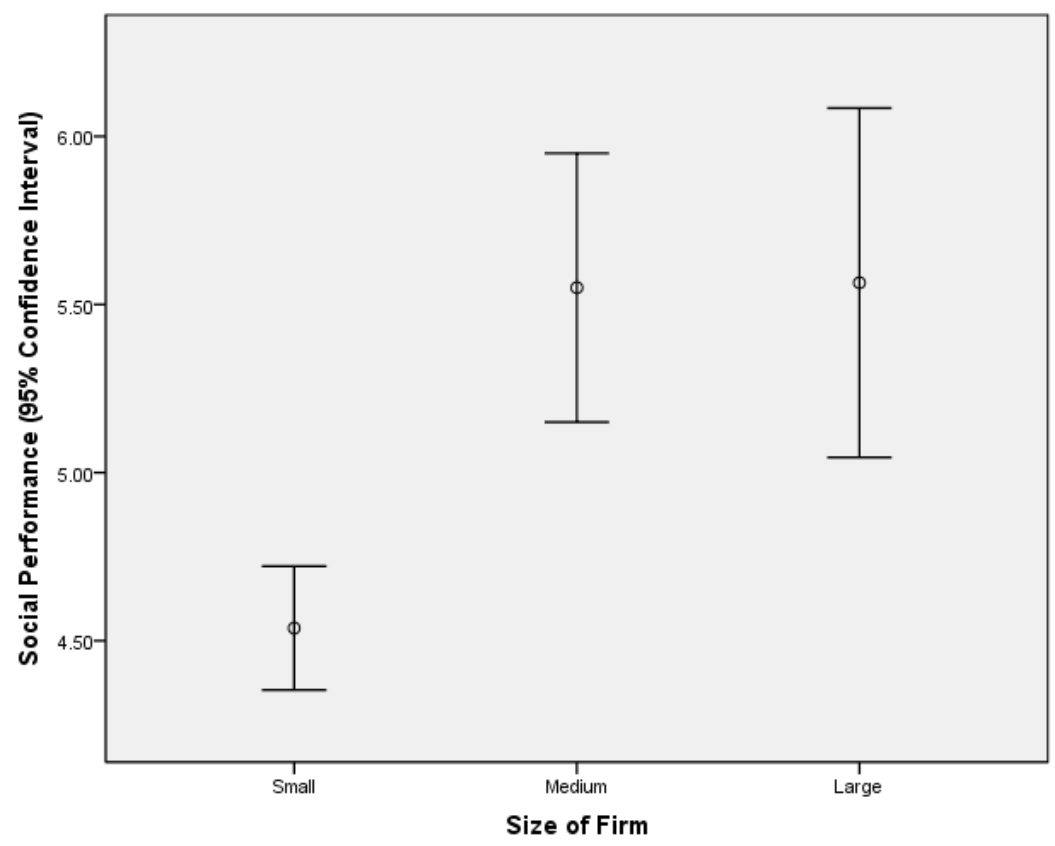

Figure 7.4 Comparison of Social Performance of Small, Medium and Large Size Firms

It was observed from the Figure 7.4 that the mean social performance of medium size firms was higher than that of small firms, and the mean social performance of large size firms was roughly about same as that of medium firms. Figure 7.5 below shows the operational performance of small, medium and large size firms. 


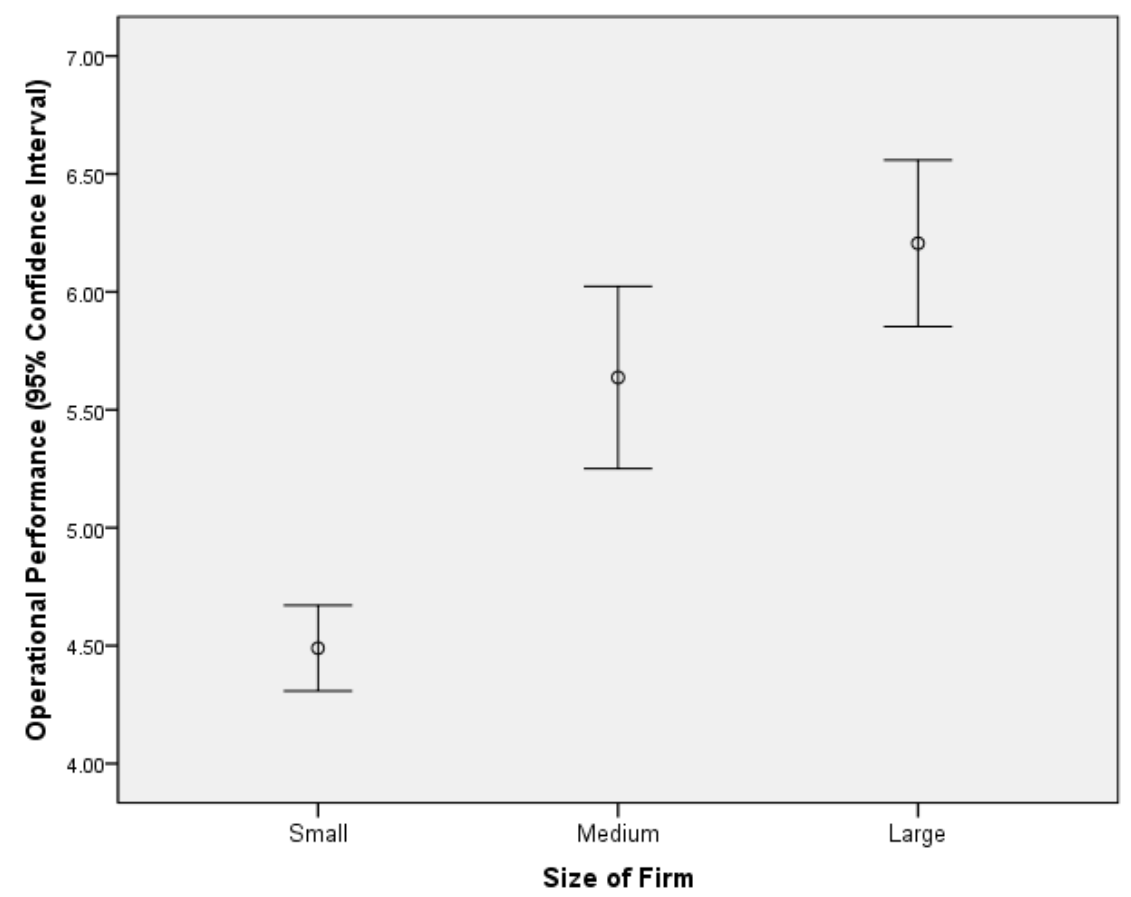

Figure 7.5 Comparison of Operational Performance of Small, Medium and Large Size Firms

It was seen from the Figure 7.5 above that the mean operational performance of medium size firms was higher than that of small firms, and the mean operational performance of large size firms was higher than that of medium firms.

It was inferred from the above graphical analyses that there was a difference in the means of economic, environmental, social and operational performance of the firms belonging to the three size groups. The next step was to determine whether this difference was statistically significant. For this, we conducted t-test for equality of means. As the sample consisted of 173 small size firms, 28 medium-size firms, and 17 large size firms, 
the decision was made to combine both medium and large firms (for a better $\mathrm{N}$ ) and compare them with small firms.

The result of t-Test performed is presented in Table 7.19 below.

Table 7.19 t-Test for Equality of Means of Performance of Small and Medium+Large

Firms

Independent Samples Test

\begin{tabular}{|c|c|c|c|c|c|c|c|c|c|}
\hline & \multicolumn{2}{|c|}{$\begin{array}{l}\text { Levene's } \\
\text { Test for } \\
\text { Equality of } \\
\text { Variances }\end{array}$} & \multicolumn{7}{|c|}{ t-test for Equality of Means } \\
\hline & \multirow[t]{2}{*}{$\mathbf{F}$} & \multirow[t]{2}{*}{ Sig. } & \multirow[t]{2}{*}{$\mathbf{t}$} & \multirow[t]{2}{*}{ df } & \multirow[t]{2}{*}{$\begin{array}{l}\text { Sig. } \\
(2- \\
\text { taile } \\
\text { d) }\end{array}$} & \multirow[t]{2}{*}{$\begin{array}{c}\text { Mean } \\
\text { Differ } \\
\text { ence }\end{array}$} & \multirow[t]{2}{*}{$\begin{array}{l}\text { Std. } \\
\text { Error } \\
\text { Differ } \\
\text { ence }\end{array}$} & \multicolumn{2}{|c|}{\begin{tabular}{|c|}
$95 \%$ \\
Confidence \\
Interval of the \\
Difference
\end{tabular}} \\
\hline & & & & & & & & Lower & Upper \\
\hline EP EVA* & 4.247 & .04 & -5.762 & 216 & .000 & -1.248 & .216 & -1.675 & -.821 \\
\hline $\mathrm{EVNA}^{* *}$ & & & -6.427 & 80.589 & .000 & -1.248 & .194 & -1.635 & -.862 \\
\hline ENVP EVA* & 11.567 & .00 & -5.895 & 216 & .000 & -1.125 & .190 & -1.501 & -.749 \\
\hline $\mathrm{EVNA}^{* *}$ & & & -7.342 & 99.250 & .000 & -1.125 & .153 & -1.429 & -.821 \\
\hline SP EVA* & 5.490 & .02 & -5.126 & 216 & .000 & -1.017 & .198 & -1.409 & -.626 \\
\hline $\mathrm{EVNA}^{* *}$ & & & -5.740 & 81.111 & .000 & -1.017 & .177 & -1.370 & -.665 \\
\hline OP EVA* & 3.852 & .05 & -7.041 & 216 & .000 & -1.362 & .193 & -1.743 & -.981 \\
\hline $\mathrm{EVNA}^{* *}$ & & & -8.213 & 87.135 & .000 & -1.362 & .165 & -1.692 & -1.032 \\
\hline
\end{tabular}

Note. *. EVA Equal Variances Assumed

**. EVNA: Equal Variances Not Assumed

$\mathrm{N}$ : Small $=173$, Medium + Large $=45$

Levene's Test for Equality of Variances and t-test for Equality of Means elicited a p-value of less than 0.05 for all the four types of performance. It was inferred from test results 
above that there was a significant difference between all four types of performance of small firms and of the firms that are larger (medium+large firms).

This difference in performance could be through the direct effect of the size of a firm or due to size acting as a moderator on the impact of SSCM Practices Adoption on performance. In this research, we were only testing for moderator effect of the size of the focal firm (Table 3.2). To test for this relationship, the third set of multivariate regressions were conducted which were numbered 12 through 15 in accordance with Table 7.14 above. Separate multiple regressions were run for small firms and larger firms, with each of the performance types as the dependent variable and the seven SSCM Practices as predictor variables. For example, the seven SSCM Practices EEP, IEP, SS, SM, CC, ED and SSP were regressed on EP, first for small firms $(\mathrm{N}=173)$ and then for larger firms (Medium + Large, $\mathrm{N}=45$ ) and so on. In total eight regression runs were conducted for this test, which are presented in Table 7.20 below.

Table 7.20 Regression Runs Conducted for Testing for Moderator Effect of Size

\begin{tabular}{|c|l|l|l|c|}
\hline No. & $\begin{array}{c}\text { Dependent } \\
\text { Variable }\end{array}$ & \multicolumn{1}{|c|}{ Predictor Variables } & \multicolumn{1}{|c|}{ Size of Firm } & N \\
\hline 12a & EP & EEP, IEP, SS, SM, CC, ED, SSP & Small & 173 \\
\hline $12 \mathrm{~b}$ & EP & EEP, IEP, SS, SM, CC, ED, SSP & Medium + Large & 45 \\
\hline $13 \mathrm{a}$ & ENVP & EEP, IEP, SS, SM, CC, ED, SSP & Small & 173 \\
\hline $13 \mathrm{~b}$ & ENVP & EEP, IEP, SS, SM, CC, ED, SSP & Medium + Large & 45 \\
\hline $14 \mathrm{a}$ & SP & EEP, IEP, SS, SM, CC, ED, SSP & Small & 173 \\
\hline $14 \mathrm{~b}$ & SP & EEP, IEP, SS, SM, CC, ED, SSP & Medium + Large & 45 \\
\hline $15 \mathrm{a}$ & OP & EEP, IEP, SS, SM, CC, ED, SSP & Small & 173 \\
\hline 15b & OP & EEP, IEP, SS, SM, CC, ED, SSP & Medium + Large & 45 \\
\hline
\end{tabular}


The results from regression runs $12 \mathrm{a}$ and $12 \mathrm{~b}$ are placed in Table 7.21 and are discussed below.

Table 7.21 Results of Regression Runs Conducted for Testing Moderator Effect of Size on Impact of Adoption of SSCM Practices on Economic Performance of Firms

\begin{tabular}{|c|c|c|c|c|c|}
\hline \multicolumn{6}{|c|}{ Coefficients } \\
\hline \multirow{2}{*}{$\begin{array}{c}\text { Dependent } \\
\text { Variable=EP } \\
\text { Size Small } \\
\mathbf{N}=\mathbf{1 7 3}\end{array}$} & \multicolumn{2}{|c|}{$\begin{array}{c}\text { Unstandardized } \\
\text { Coefficients }\end{array}$} & \multirow{2}{*}{$\begin{array}{c}\text { Standardized } \\
\text { Coefficients } \\
\text { Beta }\end{array}$} & \multirow{2}{*}{$\mathbf{t}$} & \multirow{2}{*}{ Sig. } \\
\hline & B & $\begin{array}{c}\text { Std. } \\
\text { Error }\end{array}$ & & & \\
\hline (Constant) & 1.404 & 0.434 & & 3.235 & 0.001 \\
\hline EEP & -0.183 & 0.055 & -0.133 & -3.321 & 0.001 \\
\hline IEP & -0.024 & 0.06 & -0.016 & -0.402 & 0.688 \\
\hline SS & 0.367 & 0.054 & 0.267 & 6.730 & 0.000 \\
\hline SM & -0.198 & 0.059 & -0.136 & -3.363 & 0.001 \\
\hline $\mathrm{CC}$ & 0.648 & 0.046 & 0.567 & 14.026 & 0.000 \\
\hline ED & 0.484 & 0.052 & 0.356 & 9.355 & 0.000 \\
\hline SSP & -0.302 & 0.038 & -0.306 & -7.983 & 0.000 \\
\hline
\end{tabular}

\begin{tabular}{|l|r|r|r|r|r|}
\hline $\begin{array}{c}\text { Dependent } \\
\text { Variable=EP }\end{array}$ & \multicolumn{2}{|c|}{$\begin{array}{c}\text { Unstandardized } \\
\text { Coefficients }\end{array}$} & $\begin{array}{c}\text { Standardized } \\
\text { Coefficients }\end{array}$ & & \\
\cline { 1 - 3 } $\begin{array}{c}\text { Size } \\
\text { Medium }+ \\
\text { Large } \\
\text { N=45 }\end{array}$ & B & $\begin{array}{c}\text { Std. } \\
\text { Error }\end{array}$ & Beta & \multirow{2}{*}{ t } & Sig. \\
\cline { 1 - 3 } (Constant) & 0.031 & 1.495 & & 0.021 & 0.984 \\
\hline EEP & 0.445 & 0.163 & 0.366 & 2.722 & $\mathbf{0 . 0 1 0}$ \\
\hline IEP & -0.092 & 0.155 & -0.076 & -0.596 & 0.555 \\
\hline SS & 0.349 & 0.119 & 0.380 & 2.932 & $\mathbf{0 . 0 0 6}$ \\
\hline SM & 0.097 & 0.15 & 0.083 & 0.644 & 0.524 \\
\hline CC & 0.157 & 0.143 & 0.161 & 1.095 & 0.281 \\
\hline ED & 0.401 & 0.131 & 0.428 & 3.052 & $\mathbf{0 . 0 0 4}$ \\
\hline SSP & -0.214 & 0.179 & -0.21 & -1.193 & 0.240 \\
\hline
\end{tabular}


It was seen from the above regression results that while the impact of adoption of six SSCM Practices (EEP, SS, SE, CC, ED, and SSP) on EP was significant in small firms, for larger firms this impact was significant only for EEP, SS, and ED.

It can be argued that if size acts as a moderator, for a larger sized firm the slope of regression line representing the impact of SSCM Practices Adoption on Performance would be significantly different than the slope of regression line representing the corresponding impact in case of small firms. For testing this, we compared the slopes of the regression lines for small and larger firms for the impacts of adoption of EEP, SS and ED practices on EP, because they were found to have a significant impact both in small firms and in larger firms. The results are presented in Table 7.22 below.

Table 7.22 Comparison of Slopes of the Regression Lines for Small and Larger Firms for

$E P$

\begin{tabular}{|l|c|c|c|c|c|c|c|c|c|}
\hline & \multicolumn{2}{|c|}{ N } & \multicolumn{2}{c|}{ B } & \multicolumn{2}{c|}{$\begin{array}{c}\text { Standard } \\
\text { Error }\end{array}$} & \multirow{2}{*}{ t } & \multirow{2}{*}{ Df } & \multirow{2}{*}{$\begin{array}{c}\text { Probabilit } \\
\mathbf{y}\end{array}$} \\
& $\begin{array}{c}\text { Line } \\
\mathbf{1}\end{array}$ & $\begin{array}{c}\text { Line } \\
\mathbf{2}\end{array}$ & Line 1 & Line 2 & $\begin{array}{c}\text { Line } \\
\mathbf{1}\end{array}$ & $\begin{array}{c}\text { Line } \\
\mathbf{2}\end{array}$ & & & \\
\hline EEP & 173 & 45 & -0.183 & 0.445 & 0.055 & 0.163 & 3.651 & 214 & 0.000 \\
\hline SS & 173 & 45 & 0.367 & 0.349 & 0.054 & 0.119 & 0.138 & 214 & 0.890 \\
\hline ED & 173 & 45 & 0.484 & 0.401 & 0.052 & 0.131 & 0.589 & 214 & 0.557 \\
\hline
\end{tabular}

Note. Dependent Variable $=\mathrm{EP}$

Line $1=$ Small Size Firms Line $2=$ Medium + Large Firms

From the above results, it was found that only for EEP the difference in slopes was significant $(t=3.651, \mathrm{Df}=214$, Probability $=$ less than 0.001$)$. A probability value of less than 0.05 indicated that the two slopes significantly differed from each other. We inferred 
from the above results that for EEP's impact on EP, a firm's size acted as a significant moderator and this effect was positive.

Next, we examined the impact on Environmental Performance. Table 7.23 presents results of regression runs $13 \mathrm{a}$ and $13 \mathrm{~b}$ for identifying the impact of adoption of SSCM Practices on Environmental Performance of small firms and larger firms.

Table 7.23 Results of Regression Runs Conducted for Testing Moderator Effect of Size on the Impact of Adoption of SSCM Practices on Environmental Performance of Firms

\begin{tabular}{|l|r|r|r|r|r|}
\hline \multicolumn{7}{|c|}{ Coefficients } \\
\cline { 1 - 4 } $\begin{array}{c}\text { Dependent } \\
\text { Variable } \\
\text { =ENVP }\end{array}$ & \multicolumn{2}{|c|}{$\begin{array}{c}\text { Unstandardized } \\
\text { Coefficients }\end{array}$} & $\begin{array}{c}\text { Standardized } \\
\text { Coefficients }\end{array}$ & \multirow{2}{*}{$\mathbf{t}$} & \multirow{2}{*}{ Sig. } \\
\cline { 1 - 4 } $\begin{array}{c}\text { Size Small } \\
\text { N=173 }\end{array}$ & $\mathbf{B}$ & $\begin{array}{c}\text { Std. } \\
\text { Error }\end{array}$ & Beta & & \\
\hline (Constant) & -0.710 & 0.401 & & -1.772 & 0.078 \\
\hline EEP & 0.408 & 0.051 & 0.328 & 8.011 & $\mathbf{0 . 0 0 0}$ \\
\hline IEP & 0.487 & 0.055 & 0.370 & 8.832 & $\mathbf{0 . 0 0 0}$ \\
\hline SS & 0.025 & 0.050 & 0.020 & 0.492 & 0.623 \\
\hline SM & 0.554 & 0.054 & 0.423 & 10.203 & $\mathbf{0 . 0 0 0}$ \\
\hline CC & -0.068 & 0.043 & -0.066 & -1.602 & 0.111 \\
\hline ED & -0.047 & 0.048 & -0.039 & -0.991 & 0.323 \\
\hline SSP & -0.104 & 0.035 & -0.117 & -2.986 & $\mathbf{0 . 0 0 3}$ \\
\hline
\end{tabular}

\begin{tabular}{|l|r|r|r|r|r|}
\hline $\begin{array}{c}\text { Dependent } \\
\text { Variable= } \\
\text { ENVP }\end{array}$ & \multicolumn{2}{|c|}{$\begin{array}{c}\text { Unstandardized } \\
\text { Coefficients }\end{array}$} & $\begin{array}{c}\text { Standardized } \\
\text { Coefficients }\end{array}$ & & \\
\cline { 1 - 5 } $\begin{array}{c}\text { Size } \\
\text { Medium + } \\
\text { Large } \\
\mathbf{N = 4 5}\end{array}$ & B & $\begin{array}{c}\text { Std. } \\
\text { Error }\end{array}$ & Beta & \multirow{2}{*}{ Sig. } \\
\cline { 1 - 4 } (Constant) & 2.042 & 1.214 & & 1.682 & 0.101 \\
\hline EEP & -0.030 & 0.133 & -0.033 & -0.223 & 0.824 \\
\hline IEP & 0.370 & 0.126 & 0.412 & 2.940 & $\mathbf{0 . 0 0 6}$ \\
\hline SS & 0.070 & 0.097 & 0.103 & 0.729 & 0.471 \\
\hline
\end{tabular}




\begin{tabular}{|l|r|r|r|r|r|} 
SM & 0.399 & 0.122 & 0.460 & 3.273 & $\mathbf{0 . 0 0 2}$ \\
\hline CC & 0.038 & 0.116 & 0.053 & 0.327 & 0.745 \\
\hline ED & 0.077 & 0.107 & 0.111 & 0.721 & 0.475 \\
\hline SSP & -0.238 & 0.146 & -0.315 & -1.634 & 0.111 \\
\hline
\end{tabular}

It was seen from the above regression results that while the impact of adoption of four SSCM Practices (EEP, IEP, SM, and SSP) on ENVP was significant in small firms, for larger firms this impact was significant only for adoption of IEP and SM practices.

If size acted as a moderator on the impact of adoption of the above SSCM Practices on ENVP, the slope of regression line representing the impact of SSCM Practices Adoption on Environmental Performance for a larger sized firm would be significantly different from the slope of the corresponding impact in case of small firms. For testing this, we compared the slopes of the above regression lines for small and larger firms for the impact of IEP and SM practices adoption as they were found to have a significant impact on ENVP both in small firms and in larger firms. The results are presented in Table 7.24 below.

Table 7.24 Comparison of Slopes of the Regression Lines for Small and Larger Firms for

ENVP

\begin{tabular}{|l|c|c|c|c|c|c|c|r|r|}
\hline & \multicolumn{2}{|c|}{ N } & \multicolumn{2}{c|}{ B } & \multicolumn{2}{c|}{$\begin{array}{c}\text { Standard } \\
\text { Error }\end{array}$} & \multirow{2}{*}{ t } & \multirow{2}{*}{ Df } & \multirow{2}{*}{ Probability } \\
& $\begin{array}{c}\text { Line } \\
\mathbf{1}\end{array}$ & $\begin{array}{c}\text { Line } \\
\mathbf{2}\end{array}$ & $\begin{array}{c}\text { Line } \\
\mathbf{1}\end{array}$ & $\begin{array}{c}\text { Line } \\
\mathbf{2}\end{array}$ & $\begin{array}{c}\text { Line } \\
\mathbf{1}\end{array}$ & $\begin{array}{c}\text { Line } \\
\mathbf{2}\end{array}$ & & & \\
\hline IEP & 173 & 45 & 0.487 & 0.370 & 0.055 & 0.126 & 3.273 & 214 & 0.001 \\
\hline SM & 173 & 45 & 0.554 & 0.399 & 0.054 & 0.122 & 1.162 & 214 & 0.247 \\
\hline
\end{tabular}

Note. Dependent Variable $=$ ENVP

Line $1=$ Small Size Firms Line $2=$ Medium + Large Firms 
From the results above it was found that only for IEP the difference in slopes of regression lines was significant $(t=3.273, \mathrm{Df}=214$, Probability $=0.001)$. A probability value of less than 0.05 indicated that the two slopes significantly differed from each other. We inferred from this that for IEP's impact on ENVP, a firm's size acted as a significant moderator and this effect was positive.

Next, we examined the impact on Social Performance. Table 7.25 presents the results of regression runs $14 \mathrm{a}$ and $14 \mathrm{~b}$ for identifying the impact of adoption of SSCM Practices on Social Performance of small firms and larger firms.

Table 7.25 Results of Regression Runs Conducted for Testing Moderator Effect of Size on Impact of Adoption of SSCM Practices on Social Performance of Firms

\begin{tabular}{|c|c|c|c|c|c|}
\hline \multicolumn{6}{|c|}{ Coefficients } \\
\hline $\begin{array}{c}\text { Dependent } \\
\text { Variable } \\
=\text { SP }\end{array}$ & \multicolumn{2}{|c|}{$\begin{array}{c}\text { Unstandardized } \\
\text { Coefficients }\end{array}$} & $\begin{array}{l}\text { Standardized } \\
\text { Coefficients }\end{array}$ & \multirow{2}{*}{$\mathbf{t}$} & \multirow{2}{*}{ Sig. } \\
\hline $\begin{array}{c}\text { Size Small } \\
\mathbf{N}=173\end{array}$ & B & $\begin{array}{l}\text { Std. } \\
\text { Error }\end{array}$ & Beta & & \\
\hline (Constant) & 0.939 & 0.209 & & 4.502 & 0.000 \\
\hline EEP & -0.009 & 0.027 & -0.007 & -0.355 & 0.723 \\
\hline IEP & -0.029 & 0.029 & -0.022 & -1.02 & 0.309 \\
\hline $\mathrm{SS}$ & 0.011 & 0.026 & 0.009 & 0.411 & 0.682 \\
\hline SM & 0.008 & 0.028 & 0.006 & 0.289 & 0.773 \\
\hline $\mathrm{CC}$ & -0.010 & 0.022 & -0.009 & -0.429 & 0.668 \\
\hline ED & -0.061 & 0.025 & -0.049 & -2.439 & 0.016 \\
\hline SSP & 0.881 & 0.018 & 0.976 & 48.536 & 0.000 \\
\hline
\end{tabular}

\begin{tabular}{|c|c|c|c|c|c|}
\hline $\begin{array}{c}\text { Dependent } \\
\text { Variable }= \\
\text { SP }\end{array}$ & \multicolumn{2}{|c|}{$\begin{array}{c}\text { Unstandardized } \\
\text { Coefficients }\end{array}$} & $\begin{array}{c}\text { Standardized } \\
\text { Coefficients }\end{array}$ & t & Sig. \\
\cline { 1 - 3 } $\begin{array}{c}\text { Size } \\
\text { Medium }+\end{array}$ & B & $\begin{array}{c}\text { Std. } \\
\text { Error }\end{array}$ & Beta & & \\
\hline
\end{tabular}




\begin{tabular}{|c|c|c|c|c|c|}
\hline $\begin{array}{l}\text { Large } \\
N=45\end{array}$ & & & & & \\
\hline (Constant) & -0.187 & 0.523 & & -0.357 & 0.723 \\
\hline EEP & 0.020 & 0.057 & 0.018 & 0.343 & 0.734 \\
\hline IEP & 0.081 & 0.054 & 0.074 & 1.502 & 0.141 \\
\hline SS & -0.028 & 0.042 & -0.034 & -0.681 & 0.500 \\
\hline SM & 0.091 & 0.053 & 0.085 & 1.732 & 0.092 \\
\hline $\mathrm{CC}$ & 0.071 & 0.050 & 0.080 & 1.414 & 0.166 \\
\hline ED & -0.016 & 0.046 & -0.018 & -0.342 & 0.735 \\
\hline SSP & 0.833 & 0.063 & 0.897 & 13.289 & 0.000 \\
\hline
\end{tabular}

From the above regression results, it was elicited that while the impact of adoption of two SSCM Practices (ED and SSP) on SP was significant in small firms, for larger firms this impact was significant only for SSP.

In case firm size acted as a moderator on this impact of adoption of the above SSCM Practices on SP, for a larger sized firm the slope of the regression line representing the impact of SSCM Practices Adoption on Social Performance would be significantly different than the slope the regression line representing the corresponding impact in case of small firms. For testing this, we compared the slopes of the two regression lines for small and larger firms for the impact of SSP adoption on SP as these practices were found to have a significant impact both in small firms and in larger firms. Table 7.26 presents the results of this comparison. 
Table 7.26 Comparison of Slopes of the Regression Lines for Small and Larger Firms for $S P$

\begin{tabular}{|l|c|c|c|c|c|c|c|r|r|}
\hline & \multicolumn{2}{|c|}{ N } & \multicolumn{2}{c|}{ B } & \multicolumn{2}{c|}{$\begin{array}{c}\text { Standard } \\
\text { Error }\end{array}$} & \multirow{2}{*}{ t } & \multirow{2}{*}{ Df } & \multirow{2}{*}{ Probability } \\
\hline & $\begin{array}{c}\text { Lin } \\
\text { e 1 }\end{array}$ & $\begin{array}{c}\text { Line } \\
\mathbf{2}\end{array}$ & $\begin{array}{c}\text { Line } \\
\mathbf{1}\end{array}$ & $\begin{array}{c}\text { Line } \\
\mathbf{2}\end{array}$ & $\begin{array}{c}\text { Line } \\
\mathbf{1}\end{array}$ & $\begin{array}{c}\text { Line } \\
\mathbf{2}\end{array}$ & & & \\
\hline SSP & 173 & 45 & 0.881 & 0.833 & 0.018 & 0.063 & 0.733 & 214 & 0.465 \\
\hline
\end{tabular}

Note. Dependent Variable $=\mathrm{SP}$ Line $1=$ Small Size Firms Line $2=$ Medium + Large Firms

It was found that for SSP the difference in slopes was not significant $(\mathrm{t}=0.733, \mathrm{Df}=214$, Probability $=0.465)$. A probability value of more than 0.05 indicated that the two slopes did not significantly differ from each other. We inferred from this that for SSP's impact on SP, a firm's size did not act as a significant moderator.

Next, we examined the impact on Operating Performance. Table 7.27 presents results of regression runs $15 \mathrm{a}$ and $15 \mathrm{~b}$ for identifying the impact of adoption of SSCM Practices on Operational Performance of small firms and larger firms.

Table 7.27 Results of Regression Runs Conducted for Testing Moderator Effect of Size on Impact of Adoption of SSCM Practices on Operational Performance of Firms

\begin{tabular}{|c|c|c|c|c|c|}
\hline \multicolumn{7}{|c|}{ Coefficients } & \\
\hline $\begin{array}{c}\text { Dependent } \\
\text { Variable } \\
=\text { SP }\end{array}$ & $\begin{array}{c}\text { Unstandardized } \\
\text { Coefficients }\end{array}$ & $\begin{array}{c}\text { Standardized } \\
\text { Coefficients }\end{array}$ & t & Sig. \\
\cline { 1 - 4 } $\begin{array}{c}\text { Size Small } \\
\text { N=173 }\end{array}$ & B & $\begin{array}{c}\text { Std. } \\
\text { Error }\end{array}$ & Beta & & \\
\cline { 1 - 3 } (Constant) & 1.427 & 0.460 & & 3.105 & 0.002 \\
\hline
\end{tabular}




\begin{tabular}{|l|r|r|r|r|r|} 
EEP & -0.146 & 0.058 & -0.117 & -2.500 & $\mathbf{0 . 0 1 3}$ \\
\hline IEP & 0.059 & 0.063 & 0.045 & 0.932 & 0.353 \\
\hline SS & 0.447 & 0.058 & 0.361 & 7.755 & $\mathbf{0 . 0 0 0}$ \\
\hline SM & -0.209 & 0.062 & -0.160 & -3.353 & $\mathbf{0 . 0 0 1}$ \\
\hline CC & 0.417 & 0.049 & 0.405 & 8.530 & $\mathbf{0 . 0 0 0}$ \\
\hline ED & 0.490 & 0.055 & 0.399 & 8.946 & $\mathbf{0 . 0 0 0}$ \\
\hline SSP & -0.277 & 0.040 & -0.312 & -6.937 & $\mathbf{0 . 0 0 0}$ \\
\hline
\end{tabular}

\begin{tabular}{|l|r|r|r|r|r|}
\hline $\begin{array}{c}\text { Dependent } \\
\text { Variable= } \\
\text { SP }\end{array}$ & \multicolumn{2}{|c|}{$\begin{array}{c}\text { Unstandardized } \\
\text { Coefficients }\end{array}$} & $\begin{array}{c}\text { Standardized } \\
\text { Coefficients }\end{array}$ & & \\
$\begin{array}{c}\text { Size } \\
\text { Medium }+ \\
\text { Large } \\
\text { N=45 }\end{array}$ & B & $\begin{array}{c}\text { Std. } \\
\text { Error }\end{array}$ & Beta & Sig. & \\
\hline (Constant) & 0.880 & 1.213 & & & \\
\hline EEP & 0.328 & 0.133 & 0.323 & 2.470 & $\mathbf{0 . 0 1 8}$ \\
\hline IEP & 0.035 & 0.126 & 0.034 & 0.276 & 0.784 \\
\hline SS & 0.348 & 0.097 & 0.454 & 3.605 & $\mathbf{0 . 0 0 1}$ \\
\hline SM & 0.093 & 0.122 & 0.096 & 0.766 & 0.449 \\
\hline CC & 0.100 & 0.116 & 0.122 & 0.857 & 0.397 \\
\hline ED & 0.403 & 0.107 & 0.516 & 3.781 & $\mathbf{0 . 0 0 1}$ \\
\hline SSP & -0.315 & 0.145 & -0.370 & -2.164 & $\mathbf{0 . 0 3 7}$ \\
\hline
\end{tabular}

It was seen from the above regression results that while the impact of adoption of six SSCM Practices (EEP, SS, SE, CC, ED, and SSP) on OP was significant in small firms, for larger firms this impact was significant only for EEP, SS, ED, and SSP.

If size acts as a moderator on the impact of adoption of SSCM Practices on OP, for a larger sized firm, the slope of regression line representing the impact would be significantly different from the slope of regression line representing the corresponding impact in case of small firms. For testing this, we compared the slopes of the above 
regression lines for small and larger firms for the impacts of adoption of EEP, SS, ED, and SSP on OP, because these four practices were found to have a significant impact both in small firms and in larger firms. The results are presented in Table 7.28 below.

Table 7.28 Comparison of Slopes of the Regression Lines for Small and Larger Firms for

$O P$

\begin{tabular}{|l|c|c|c|c|c|c|c|r|r|}
\hline & \multicolumn{2}{|c|}{ N } & \multicolumn{2}{c|}{ B } & \multicolumn{2}{c|}{$\begin{array}{c}\text { Standard } \\
\text { Error }\end{array}$} & \multirow{2}{*}{ t } & \multirow{2}{*}{ Df } & \multirow{2}{*}{ Probability } \\
& $\begin{array}{c}\text { Line } \\
\mathbf{1}\end{array}$ & $\begin{array}{c}\text { Line } \\
\mathbf{2}\end{array}$ & $\begin{array}{c}\text { Line } \\
\mathbf{1}\end{array}$ & Line 2 & $\begin{array}{c}\text { Line } \\
\mathbf{1}\end{array}$ & $\begin{array}{c}\text { Line } \\
\mathbf{2}\end{array}$ & & & \\
\hline EEP & 173 & 45 & -0.146 & 0.328 & 0.058 & 0.133 & 3.267 & 214 & 0.001 \\
\hline SS & 173 & 45 & 0.447 & 0.348 & 0.058 & 0.097 & 0.876 & 214 & 0.382 \\
\hline ED & 173 & 45 & 0.490 & 0.403 & 0.055 & 0.107 & 0.723 & 214 & 0.470 \\
\hline SSP & 173 & 45 & -0.277 & -0.315 & 0.040 & 0.145 & 0.253 & 214 & 0.801 \\
\hline
\end{tabular}

Note. Dependent Variable $=\mathrm{OP}$

Line 1 = Small Size Firms Line $2=$ Medium + Large Firms

It was found that only for EEP the difference in slopes was significant $(t=3.267$, $\mathrm{Df}=214$, Probability $=0.001)$. A probability value of less than 0.05 indicated that the two slopes significantly differed from each other. We inferred from the above tests that for EEP's impact on OP, a firm's size acted as a significant moderator and this effect was positive.

In summary, from the results of regression runs $12 \mathrm{a}$ through $15 \mathrm{~b}$, and the subsequent t-tests, it was inferred that size had a significant and positive moderator effect on the impact of adoption of EEP on EP and OP. Size also had a significant and positive moderator effect on the impact of adoption of IEP on ENVP. In all other cases, the effects were found to be not significant. 
Table 7.29 below summarises the support these test results lend to the hypotheses H3a to H3d.

Table 7.29 Findings of Multiple Regression Analyses and t-Tests: Effect of Size as a Moderator

\begin{tabular}{|c|c|c|c|}
\hline $\begin{array}{l}\text { Independ } \\
\text { ent } \\
\text { Variable }\end{array}$ & Effect & Hypotheses & Inference \\
\hline \multirow{4}{*}{ Size } & \multirow{4}{*}{$\begin{array}{l}\text { Posited to } \\
\text { Moderate } \\
\text { Impact of } \\
\text { SSCM } \\
\text { Practices } \\
\text { Adoption on } \\
\text { Performanc } \\
\text { e }\end{array}$} & $\begin{array}{l}\text { H3a: The bigger the firm size, the } \\
\text { greater is the impact of company's } \\
\text { adoption of SSCM practices on the } \\
\text { company's economic performance. }\end{array}$ & $\begin{array}{l}\text { Partially } \\
\text { Supported }\end{array}$ \\
\hline & & $\begin{array}{l}\text { H3b: The bigger the firm size, the } \\
\text { greater is the impact of company's } \\
\text { adoption of SSCM practices on the } \\
\text { company's environmental performance. }\end{array}$ & $\begin{array}{l}\text { Partially } \\
\text { Supported }\end{array}$ \\
\hline & & $\begin{array}{l}\text { H3c: The bigger the firm size, the } \\
\text { greater is the impact of company's } \\
\text { adoption of SSCM practices on the } \\
\text { company's social performance. }\end{array}$ & $\begin{array}{c}\text { Not } \\
\text { Supported }\end{array}$ \\
\hline & & $\begin{array}{l}\text { H3d: The bigger the firm size, the } \\
\text { greater is the impact of company's } \\
\text { adoption of SSCM practices on the } \\
\text { company's operational performance. }\end{array}$ & $\begin{array}{l}\text { Partially } \\
\text { Supported }\end{array}$ \\
\hline
\end{tabular}

In this chapter, we analyzed data using principal component analysis. We then conducted multiple regression analysis to test the impact of Drivers on SSCM Practices Adoption and presented their results. We further examined the impact of SSCM Practices Adoption on Performance of a firm, and we also analyzed the moderation effect of size on this impact.

While the regression analyses, which were conducted to test for the impact of the Drivers on SSCM Practices Adoption and to test for the impact of adoption on 
Performance, have confirmed these impacts, their strength, and their direction. To get a better insight into these relationships a decision was made to conduct path analysis and also to test whether the structure of the a priori theoretical framework was supported by the structural model using structural equation modeling as suggested by Das (2017). This is presented in the next chapter. 


\section{Chapter 8 Analysis Using Structural Equation Modeling}

In this chapter, we introduce structural equation modeling (SEM), test for validation of measures and present the results of these tests. It is followed by testing of measurement models and structural model and a discussion on the test results.

\subsection{Introduction}

A multivariate analysis technique, structural equation modeling (SEM) is used to test the relationship between independent variables and dependent variables. SEM can assess measurement (i.e., the relationship between indicators or observed variables and the construct they purport to measure) and the model structure (i.e., how the constructs are related, or the "paths" among them). As a result, SEM may be used to test both measurement models and structural models. It allows the researcher to develop measurement models which relate the measures to a construct that is latent and cannot be measured directly, providing an alternate analytical technique to multiple regression analysis and factor analysis to estimate coefficients within the structural model along with error terms.

Anderson and Gerbing (1988) and Ping (2004) recommend that measurement model be properly specified before the structural model can be inferred to be meaningful. Once the measurement model is specified, the constructs are tested for their relationship with other constructs. In this research, the same sequence is followed. First measurement models are specified, and then the structural models are tested using SEM techniques. 
Previously, LISREL has been extensively used for SEM analysis by researchers (Joreskog, 1973, 1996, 2001; Chin et al., 1997; Agarwal \& Karahanna, 2000; Sabherwal \& Fernandez, 2003). For this research, IBM AMOS software version 25 was used.

\subsection{Measurement Model Assessment}

Ping (2004) stresses the importance of "demonstrating the adequacy of the study measures" (p.126) before proceeding to data analysis. Accordingly, in the following subsections, we present the results of Confirmatory Factor Analysis (CFA) conducted using SEM to assess the measurement models of all our constructs. These measurement models of the constructs are created as reflective models, and this includes both independent and dependent variables. This is followed by CFA for the three groups of constructs, which are: the Drivers, SSCM Practices Adoption, and Performance. We also assess and discuss uni-dimensionality, reliability, and validity of different measures and constructs.

\subsubsection{Confirmatory Factor Analysis of Constructs}

To test if the proposed measurement model derived from literature fits the sample data we conducted CFA of the constructs. For a measurement model fit that is acceptable usual norms indicate that the tests should ideally generate scores of CMIN/Df (minimum discrepancy divided by the degrees of freedom) of 5 or less, comparative fit index (CFI) and other goodness of fit indices, like normed fit index (NFI), values of 0.9 or more, and root mean square error of approximation (RMSEA) value less than 0.08 (Baldwin, 1989). Each of these indices has limitations and are affected by a number of factors including 
sample size, degrees of freedom and model characteristics. For example, while CMIN is affected by sample size and Df is affected by model characteristics, the CFI and RMSEA "relatively independent of sample size" (Bagozzi, 2012, p.29). For structural equation modeling (SEM) the index Root mean square error of approximation (RMSEA) is "currently one of the most popular measures of goodness-of-model fit" (Kenny et al., 2014, p.486). For models with small degrees of freedom, fit indices may be problematic and may not be computed (Kenny et al., 2014). For purposes of parsimony, we use CMIN/Df, RMSEA and the CFI for reporting the model fit.

\subsubsection{Regulations}

Regulations (REG) was posited as a latent construct measured by three indicators (REG1 to REG3, please see Table 3.1). On testing with the data collected the measurement model elicited the standardized loadings of indicators and their Squared Multiple Correlation R2 as presented in Table 8.1 below.

Table 8.1 Loadings on the Construct Regulations

\begin{tabular}{|c|r|r|}
\hline Item & $\begin{array}{c}\text { Standardised } \\
\text { Loading } \\
\boldsymbol{\lambda}\end{array}$ & $\begin{array}{c}\text { Squared Multiple } \\
\text { Correlations } \\
\mathbf{R}^{\mathbf{2}}\end{array}$ \\
\hline REG1 & .881 & .776 \\
\hline REG2 & .868 & .754 \\
\hline REG3 & .799 & .639 \\
\hline
\end{tabular}

The measurement model for the construct Regulations is presented in Figure 8.1. 


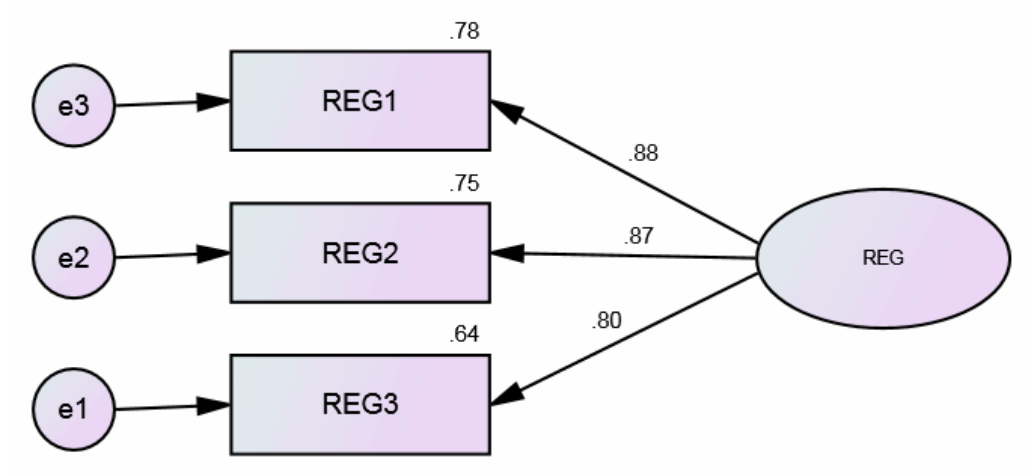

Figure 8.1 Measurement Model for the Construct Regulations

When tested, the measurement model for Regulations generated the following values of model fit indices.

Table 8.2 Fit Indices for the Construct Regulations

\begin{tabular}{|l|r|}
\hline \multicolumn{1}{|c|}{ Index } & \multicolumn{2}{c|}{ Value } \\
\hline CMIN/Df & 10.870 \\
\hline CFI & .978 \\
\hline RMSEA & .213 \\
\hline NFI Delta1 & .976 \\
\hline IFI Delta2 & .978 \\
\hline Cronbach's Alpha & .910 \\
\hline
\end{tabular}

It was observed that fit indices CFI, NFI and IFI were good (above 0.9), while CMIN/Df and RMSEA were high. On inspection of modification indices in AMOS results, it was observed that no modifications to the model were recommended. This measurement model was considered parsimonious and was theoretically supported in published literature; hence a decision was made to retain it for further analysis. 


\subsubsection{Competitiveness}

Competitiveness (COMP) was posited as a latent construct measured by seven items (COMP1 to COMP7, please see Table 3.1). The measurement model is presented in Figure 8.2 below.

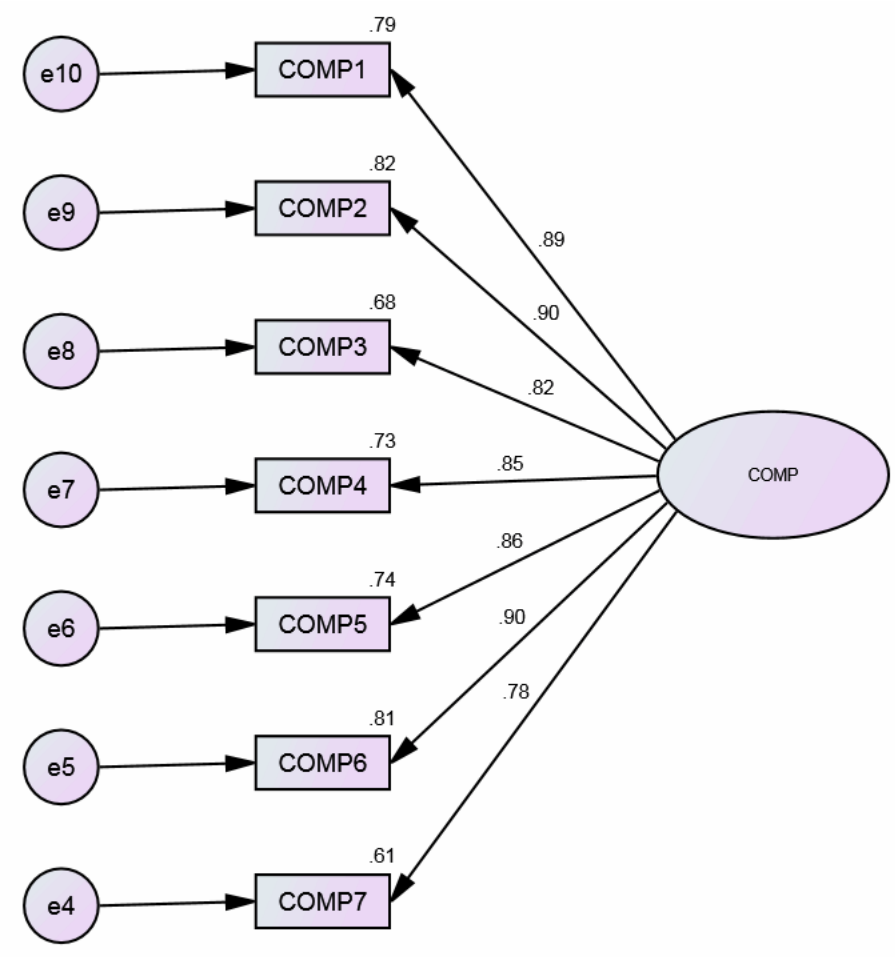

Figure 8.2 Measurement Model for the Construct Competitiveness

.When tested using the collected data it elicited the following standardized loadings of indicators on the construct and their Squared Multiple Correlation $\mathrm{R}^{2}$ (Table 8.3). 
Table 8.3 Loadings on the Construct Competitiveness

\begin{tabular}{|c|r|r|}
\hline Item & $\begin{array}{c}\text { Standardised } \\
\text { Loading } \\
\boldsymbol{\lambda}\end{array}$ & $\begin{array}{c}\text { Squared Multiple } \\
\text { Correlations } \\
\mathbf{R}^{\mathbf{2}}\end{array}$ \\
\hline COMP1 & 0.887 & 0.787 \\
\hline COMP2 & 0.905 & 0.819 \\
\hline COMP3 & 0.824 & 0.680 \\
\hline COMP4 & 0.855 & 0.731 \\
\hline COMP5 & 0.862 & 0.743 \\
\hline COMP6 & 0.899 & 0.808 \\
\hline COMP7 & 0.780 & 0.608 \\
\hline
\end{tabular}

The measurement model for Competitiveness generated the following values of model fit indices:

Table 8.4 Fit Indices for the Construct Competitiveness

\begin{tabular}{|l|r|}
\hline \multicolumn{1}{|c|}{ Index } & Value \\
\hline CMIN/Df & 3.678 \\
\hline CFI & 0.976 \\
\hline RMSEA & 0.111 \\
\hline NFI Delta1 & 0.967 \\
\hline IFI Deta2 & 0.976 \\
\hline Cronbach's Alpha & 0.961 \\
\hline
\end{tabular}

It was observed that fit indices CFI, NFI and IFI were good, being higher than 0.9, CMIN/Df was below 5, but RMSEA was a bit higher than 0.08. On inspection of modification indices in AMOS results, it was observed that no modifications to the model were recommended. This measurement model was considered parsimonious and was theoretically supported in published literature; hence a decision was made to retain it for further analysis. 


\subsubsection{Stakeholder Pressures}

Stakeholder Pressures (PRES) was posited as a latent construct measured by five items (PRES1 to PRES5, please see Table 3.1). When tested, the measurement model for Stakeholder Pressures provided the following values of model fit indices (Table 8.5).

Table 8.5 Fit Indices for the Construct Stakeholder Pressures

\begin{tabular}{|l|r|}
\hline \multicolumn{1}{|c|}{ Index } & Value \\
\hline CMIN/Df & 15.534 \\
\hline CFI & 0.910 \\
\hline RMSEA & 0.259 \\
\hline NFI Delta1 & 0.904 \\
\hline IFI Deta2 & 0.910 \\
\hline Cronbach's Alpha & 0.935 \\
\hline
\end{tabular}

On further analysis, it was observed that modification indices in AMOS results indicated that introducing covariance arrows between the error terms e13 and e15 may improve model fit. The modified model is presented in Figure 8.3 below. 


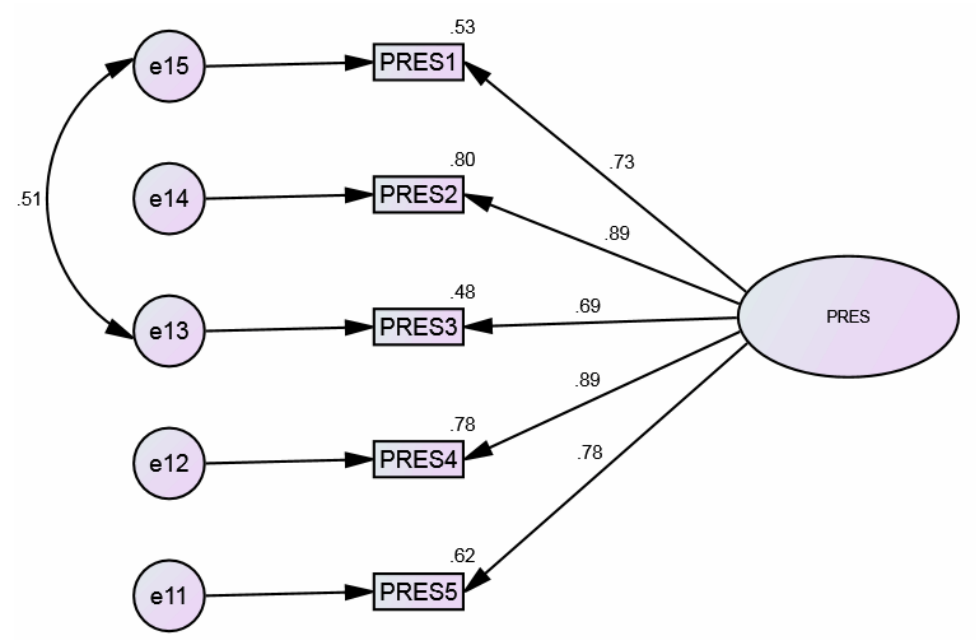

Figure 8.3 Measurement Model for the Construct Stakeholder Pressures (Modified)

Table 8.6 below presents the standardized loadings of indicators on the construct stakeholder pressures (PRES) and their Squared Multiple Correlation $\mathrm{R}^{2}$.

Table 8.6 Loadings on the Construct Stakeholder Pressures

\begin{tabular}{|c|r|r|}
\hline Item & $\begin{array}{c}\text { Standardised } \\
\text { Loading } \\
\boldsymbol{\lambda}\end{array}$ & $\begin{array}{c}\text { Squared Multiple } \\
\text { Correlations } \\
\mathbf{R}^{\mathbf{2}}\end{array}$ \\
\hline PRES1 & 0.731 & 0.534 \\
\hline PRES2 & 0.894 & 0.799 \\
\hline PRES3 & 0.691 & 0.478 \\
\hline PRES4 & 0.885 & 0.784 \\
\hline PRES5 & 0.784 & 0.615 \\
\hline
\end{tabular}

The fit indices for a modified model of the construct improved to those as under (Table 8.7). 
Table 8.7 Fit Indices for the modified Construct Stakeholder Pressures

\begin{tabular}{|l|r|}
\hline \multicolumn{1}{|c|}{ Index } & Value \\
\hline CMIN/Df & 7.680 \\
\hline CFI & 0.965 \\
\hline RMSEA & 0.175 \\
\hline NFI Delta1 & 0.961 \\
\hline IFI Deta2 & 0.966 \\
\hline
\end{tabular}

It was observed that fit indices CFI, NFI and IFI were good, being higher than 0.9 , CMIN/Df was higher than 5, and RMSEA was higher than 0.08. However, This measurement model is theoretically supported in the published literature and being parsimonious; a decision was made to retain it for further analysis without any further modifications.

\subsubsection{External Environmental Practices}

External Environmental Practices (EEP) was posited as a latent construct measured by four items (EEP1 to EEP4, please see Table 3.1). When tested, the measurement model for External Environmental Practices elicited the following values of model fit indices:

Table 8.8 Fit Indices for the Construct External Environmental Practices

\begin{tabular}{|l|r|}
\hline \multicolumn{1}{|c|}{ Index } & Value \\
\hline CMIN/Df & 6.453 \\
\hline CFI & 0.971 \\
\hline RMSEA & 0.159 \\
\hline NFI Delta1 & 0.966 \\
\hline IFI Delta2 & 0.971 \\
\hline Cronbach's Alpha & 0.897 \\
\hline
\end{tabular}


On further analysis, modification indices suggested introducing covariance arrows between the error terms e18 and e19. The modified model is presented in Figure 8.4 below.

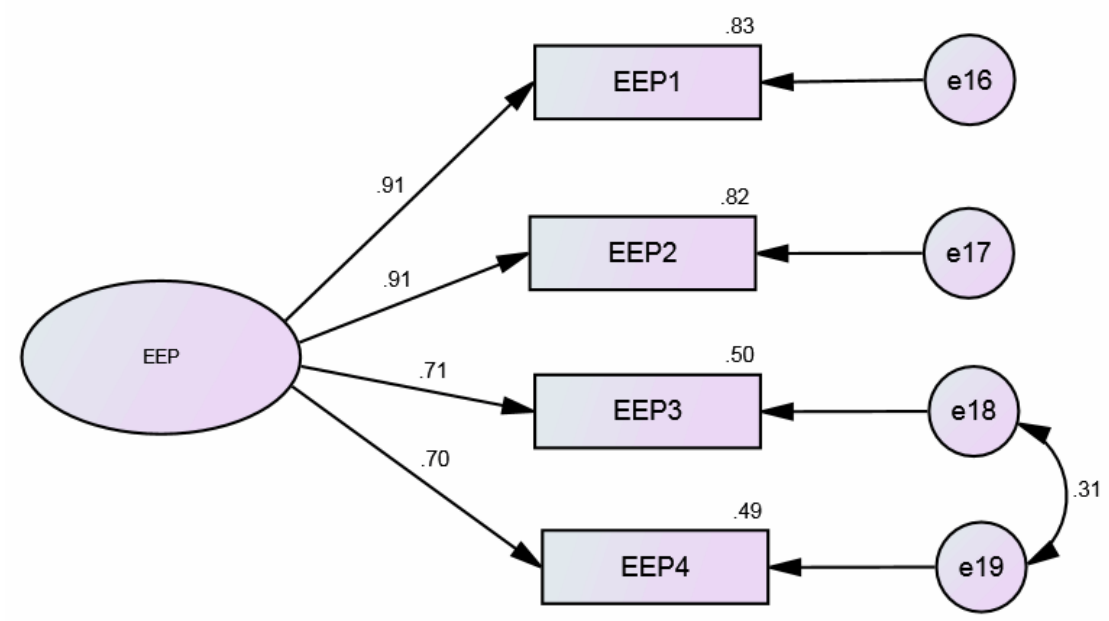

Figure 8.4 Measurement Model for the Construct External Environmental Practices (Modified)

Table 8.9 below shows the standardized loadings of indicators on the construct External Environmental Practices (EEP) and their Squared Multiple Correlations $\mathrm{R}^{2}$.

Table 8.9 Loadings on the Construct External Environmental Practices

\begin{tabular}{|c|c|r|}
\hline Item & $\begin{array}{c}\text { Standardised } \\
\text { Loading } \\
\boldsymbol{\lambda}\end{array}$ & $\begin{array}{c}\text { Squared Multiple } \\
\text { Correlations } \\
\mathbf{R}^{\mathbf{2}}\end{array}$ \\
\hline EEP1 & 0.913 & 0.833 \\
\hline EEP2 & 0.908 & 0.824 \\
\hline EEP3 & 0.709 & 0.500 \\
\hline EEP4 & 0.702 & 0.492 \\
\hline
\end{tabular}


The goodness of fit indices for modified measurement model of the construct were as under (Table 8.10).

Table 8.10 Fit Indices for the modified Construct External Environmental Practices

\begin{tabular}{|l|r|}
\hline \multicolumn{1}{|c|}{ Index } & Value \\
\hline CMIN/Df & 0.440 \\
\hline CFI & 1.000 \\
\hline RMSEA & 0.000 \\
\hline NFI Delta1 & 0.998 \\
\hline IFI Delta2 & 1.000 \\
\hline
\end{tabular}

It was observed that fit indices CFI, NFI and IFI were good, being higher than 0.9, CMIN/Df was below 5, and RMSEA was a bit lower than 0.08. This measurement model was considered parsimonious and was theoretically supported in published literature; hence a decision was made to retain it for further analysis.

\subsubsection{Internal Environmental Practices}

Internal Environmental Practices (IEP) was posited as a latent construct measured by six items (IEP1 to IEP6, please see Table 3.1). When tested, the measurement model for Internal Environmental Practices elicited the following values of model fit indices (Table 8.11). 
Table 8.11 Fit Indices for the Construct Internal Environmental Practices

\begin{tabular}{|l|r|}
\hline \multicolumn{1}{|c|}{ Index } & \multicolumn{1}{c|}{ Value } \\
\hline CMIN/Df & 20.615 \\
\hline CFI & 0.892 \\
\hline RMSEA & 0.301 \\
\hline NFI Delta1 & 0.887 \\
\hline IFI Delta2 & 0.892 \\
\hline Cronbach's Alpha & 0.958 \\
\hline
\end{tabular}

On further analysis, modification indices suggested introducing covariance arrows between e23 and e25 to improve the fit. The measurement model was modified accordingly and is presented in Figure 8.5 below.

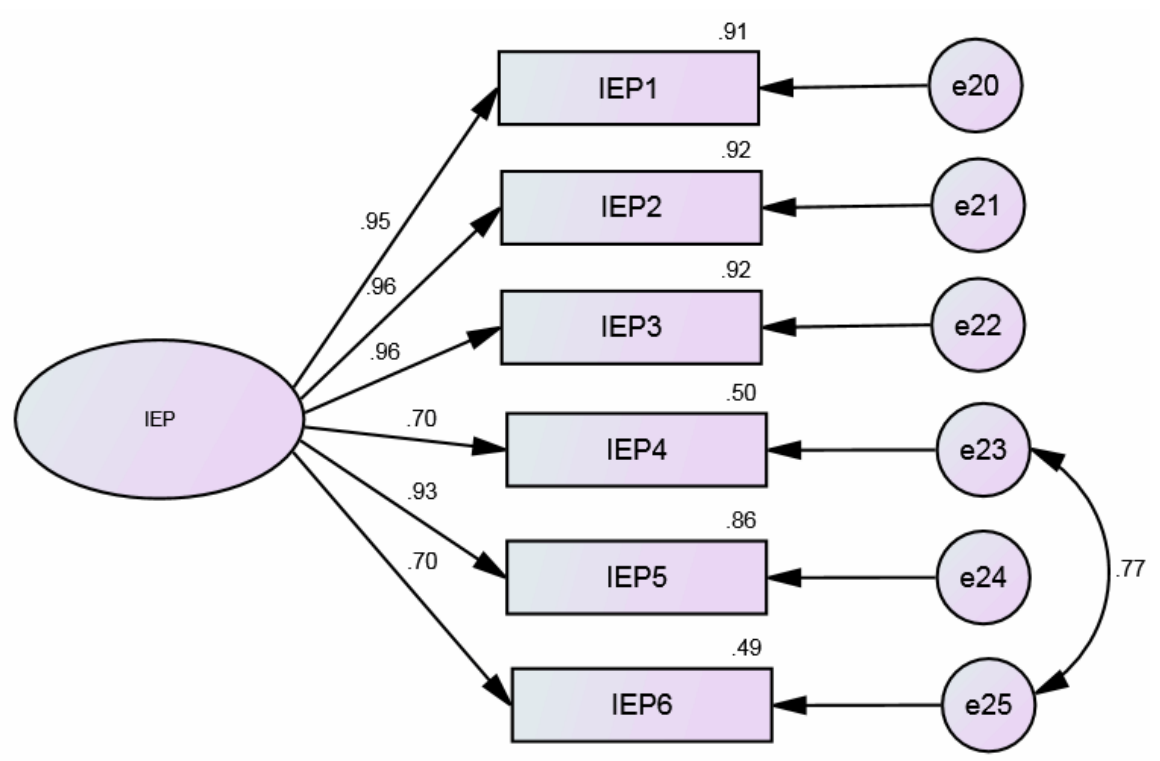

Figure 8.5 Measurement Model for the Construct Internal Environmental Practices (Modified)

Table 8.12 below presents the standardized loadings of indicators on the construct Internal Environmental Practices (IEP) and their Squared Multiple Correlations $\mathrm{R}^{2}$. 
Table 8.12 Loadings on the Construct Internal Environmental Practices

\begin{tabular}{|c|r|r|}
\hline Item & $\begin{array}{c}\text { Standardised } \\
\text { Loading } \\
\lambda\end{array}$ & $\begin{array}{c}\text { Squared Multiple } \\
\text { Correlations } \\
\mathbf{R}^{2}\end{array}$ \\
\hline IEP1 & 0.953 & 0.908 \\
\hline IEP2 & 0.960 & 0.922 \\
\hline IEP3 & 0.958 & 0.918 \\
\hline IEP4 & 0.704 & 0.496 \\
\hline IEP5 & 0.929 & 0.863 \\
\hline IEP6 & 0.698 & 0.487 \\
\hline
\end{tabular}

The fit indices for the modified model of the construct were as under (Table 8.13).

Table 8.13 Fit Indices for the modified Construct Internal Environmental Practices

\begin{tabular}{|l|r|}
\hline \multicolumn{1}{|c|}{ Index } & \multicolumn{1}{c|}{ Value } \\
\hline CMIN/Df & 1.343 \\
\hline CFI & 0.998 \\
\hline RMSEA & 0.040 \\
\hline NFI Delta1 & 0.993 \\
\hline IFI Delta2 & 0.998 \\
\hline
\end{tabular}

It was observed that fit indices CFI, NFI and IFI were good, being higher than 0.9 , CMIN/Df was below 5, and RMSEA was lower than 0.08. This measurement model was considered parsimonious and was theoretically supported in published literature; hence a decision was made to retain it for further analysis. 


\subsubsection{Supplier Selection}

Supplier Selection (SS) was posited as a latent construct measured by six items (SS1 to SS6), please see Table 3.1). When tested, the measurement model for Supplier Selection elicited the following values of model fit indices (Table 8.14).

Table 8.14 Fit Indices for the Construct Supplier Selection

\begin{tabular}{|l|r|}
\hline \multicolumn{1}{|c|}{ Index } & \multicolumn{1}{c|}{ Value } \\
\hline CMIN/Df & 26.067 \\
\hline CFI & 0.824 \\
\hline RMSEA & 0.340 \\
\hline NFI Delta1 & 0.819 \\
\hline IFI Delta2 & 0.825 \\
\hline Cronbach's Alpha & 0.940 \\
\hline
\end{tabular}

On further analysis, modification indices suggested introducing covariance arrows between the error terms e29 and e30 to improve the fit. The measurement model was modified accordingly and is presented in Figure 8.6 below.

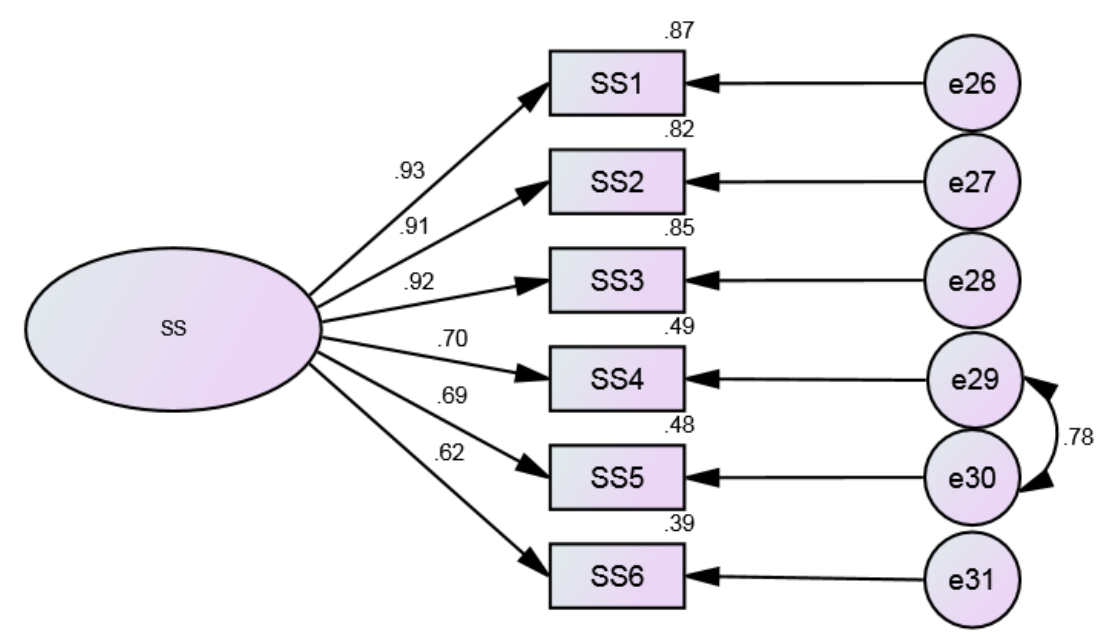

Figure 8.6 Measurement Model for the Construct Supplier Selection (Modified) 
Table 8.15 below presents the standardized loadings of indicators on the construct Supplier Selection (SS) and their Squared Multiple Correlations $\mathrm{R}^{2}$.

Table 8.15 Loadings on the Construct Supplier Selection

\begin{tabular}{|c|r|c|}
\hline & $\begin{array}{c}\text { Standardised } \\
\text { Loading } \\
\lambda\end{array}$ & $\begin{array}{c}\text { Squared } \\
\text { Multiple } \\
\text { Correlations } \\
\mathbf{R}^{\mathbf{2}}\end{array}$ \\
\hline SS1 & 0.931 & 0.867 \\
\hline SS2 & 0.906 & 0.820 \\
\hline SS3 & 0.921 & 0.848 \\
\hline SS4 & 0.699 & 0.489 \\
\hline SS5 & 0.693 & 0.481 \\
\hline SS6 & 0.621 & 0.386 \\
\hline
\end{tabular}

The fit indices for modified measurement model of the construct were as under (Table 8.16).

Table 8.16 Fit Indices for the modified Construct Supplier Selection

\begin{tabular}{|l|r|}
\hline \multicolumn{1}{|c|}{ Index } & Value \\
\hline CMIN/Df & 7.234 \\
\hline CFI & 0.961 \\
\hline RMSEA & 0.169 \\
\hline NFI Delta1 & 0.955 \\
\hline IFI Delta2 & 0.961 \\
\hline
\end{tabular}

It was observed that fit indices CFI, NFI and IFI were good, being higher than 0.9, CMIN/Df was a little higher than 5, and RMSEA was higher than 0.08. This measurement model was considered parsimonious and was theoretically supported in 
published literature; hence a decision was made to retain the modified measurement model for further analysis.

\subsubsection{Supplier Evaluation and Monitoring}

Supplier Evaluation and Monitoring (SM) was posited as a latent construct measured by six items (SM1 to SM6, please see Table 3.1). When tested, the measurement model for Supplier Evaluation and Monitoring elicited the following values of model fit indices (Table 8.17).

Table 8.17 Fit Indices for the Construct Supplier Evaluation and Monitoring

\begin{tabular}{|l|r|}
\hline \multicolumn{1}{|c|}{ Index } & Value \\
\hline CMIN/Df & 2.853 \\
\hline CFI & 0.990 \\
\hline RMSEA & 0.092 \\
\hline NFI Delta1 & 0.985 \\
\hline IFI Delta2 & 0.990 \\
\hline Cronbach's Alpha & 0.976 \\
\hline
\end{tabular}

It was observed that fit indices CFI, NFI and IFI were good, being higher than 0.9, CMIN/Df was below 5, but RMSEA was a little higher than 0.08. On inspection of modification indices in AMOS results, it was observed that no modifications to the model were recommended. This measurement model was considered parsimonious and was theoretically supported in published literature; hence a decision was made to retain it without any modifications for further analysis.

The measurement model is presented in Figure 8.7 below. 


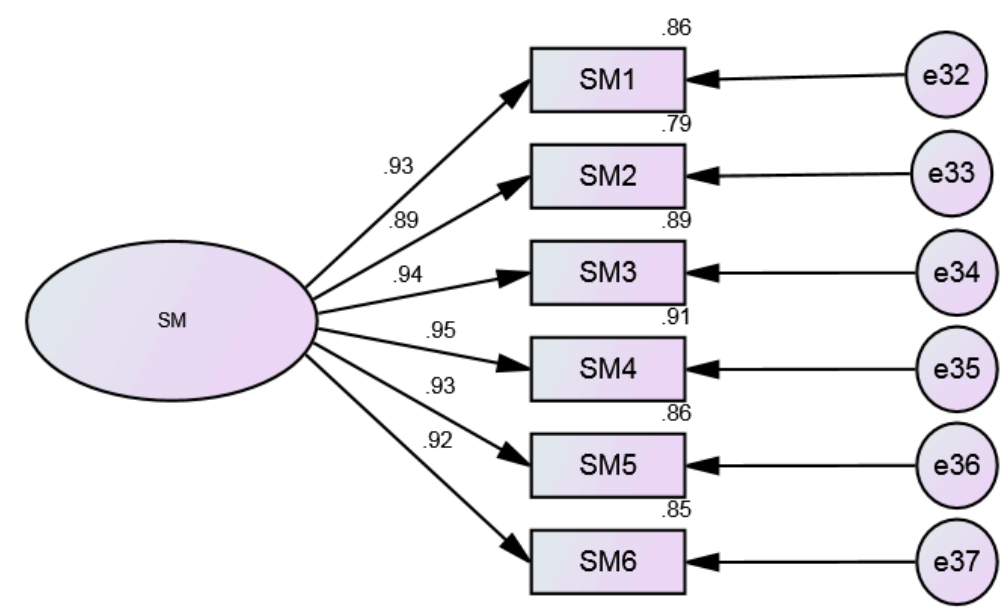

Figure 8.7 Measurement Model for the Construct Supplier Evaluation and Monitoring

Table 8.18 below presents the standardized loadings of indicators on the construct Supplier Evaluation and Monitoring (SM) and their Squared Multiple Correlations ${ }^{2}$.

Table 8.18 Loadings on the Construct Supplier Evaluation and Monitoring

\begin{tabular}{|c|r|r|}
\hline Item & $\begin{array}{c}\text { Standardised } \\
\text { Loading } \\
\lambda\end{array}$ & $\begin{array}{c}\text { Squared Multiple } \\
\text { Correlations } \\
\mathbf{R}^{2}\end{array}$ \\
\hline SM1 & 0.929 & 0.862 \\
\hline SM2 & 0.888 & 0.789 \\
\hline SM3 & 0.942 & 0.887 \\
\hline SM4 & 0.951 & 0.905 \\
\hline SM5 & 0.930 & 0.864 \\
\hline SM6 & 0.924 & 0.854 \\
\hline
\end{tabular}

\subsubsection{Cooperation with Customers}

Cooperation with Customers (CC) was posited as a latent construct measured by six items (CC1 to CC6, please see Table 3.1). When tested, the measurement model for 
Cooperation with Customers generated the following values of model fit indices (Table 8.19).

Table 8.19 Fit Indices for the Construct Cooperation with Customers

\begin{tabular}{|l|r|}
\hline \multicolumn{1}{|c|}{ Index } & \multicolumn{2}{c|}{ Value } \\
\hline CMIN/Df & 1.313 \\
\hline CFI & 0.998 \\
\hline RMSEA & 0.038 \\
\hline NFI Delta1 & 0.993 \\
\hline IFI Delta2 & 0.998 \\
\hline Cronbach's Alpha & 0.968 \\
\hline
\end{tabular}

It was observed that fit indices CMIN/Df was lower than 5, and RMSEA was lower than 0.08. CFI, NFI, and IFI were above 0.9. This measurement model fitted the data well and was considered parsimonious, was theoretically supported in published literature; hence a decision was made to retain it for further analysis. The measurement model is presented in Figure 8.8 below.

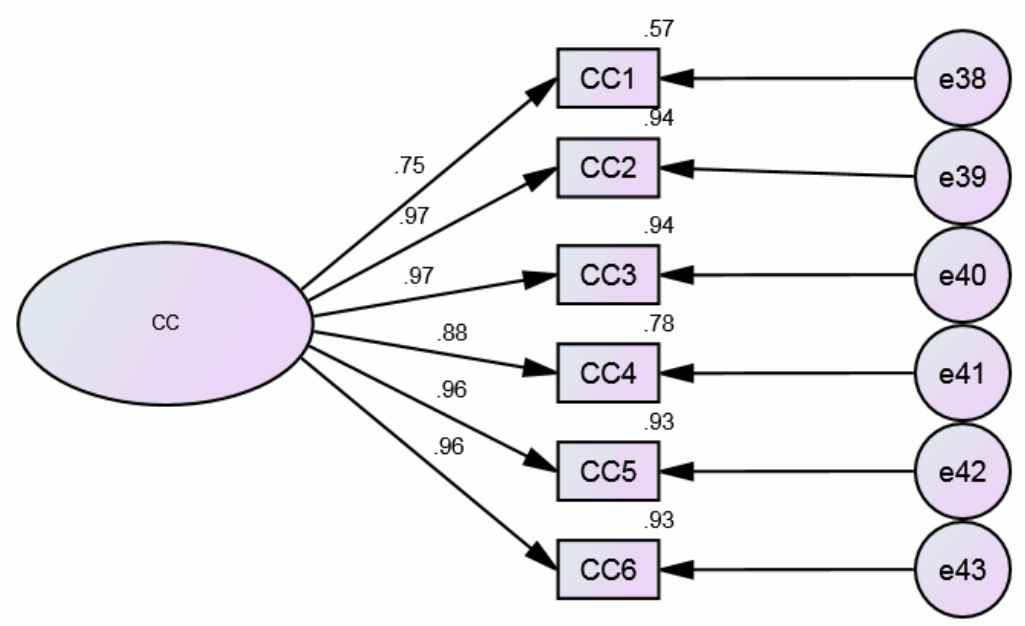

Figure 8.8 Measurement Model for the Construct Cooperation with Customers 
Table 8.20 below presents standardized loadings of indicators on the construct Cooperation with Customers (CC) and their Squared Multiple Correlations $\mathrm{R}^{2}$.

Table 8.20 Loadings on the Construct Cooperation with Customers

\begin{tabular}{|c|r|r|}
\hline Item & $\begin{array}{c}\text { Standardised } \\
\text { Loading } \\
\boldsymbol{\lambda}\end{array}$ & $\begin{array}{c}\text { Squared Multiple } \\
\text { Correlations } \\
\mathbf{R}^{\mathbf{2}}\end{array}$ \\
\hline $\mathrm{CC} 1$ & 0.754 & 0.569 \\
\hline $\mathrm{CC} 2$ & 0.968 & 0.937 \\
\hline $\mathrm{CC} 3$ & 0.969 & 0.939 \\
\hline $\mathrm{CC} 4$ & 0.880 & 0.775 \\
\hline $\mathrm{CC} 5$ & 0.964 & 0.930 \\
\hline $\mathrm{CC} 6$ & 0.964 & 0.930 \\
\hline
\end{tabular}

\subsubsection{Eco-Design}

Eco-Design (ED) was posited as a latent construct measured by three items (ED1 to ED3, please see Table 3.1). When tested, the measurement model for Eco-Design elicited the following values of model fit indices (Table 8.21).

Table 8.21 Fit Indices for the Construct Eco-Design

\begin{tabular}{|l|r|}
\hline \multicolumn{1}{|c|}{ Index } & Value \\
\hline CMIN/Df & 0.699 \\
\hline CFI & 1.000 \\
\hline RMSEA & 0.000 \\
\hline NFI Delta1 & 0.996 \\
\hline IFI Delta2 & 1.002 \\
\hline Cronbach's Alpha & 0.767 \\
\hline
\end{tabular}


It was observed that fit indices CFI, NFI and IFI were good, being higher than 0.9, CMIN/Df was below 5, and RMSEA was lower than 0.08 indicating a good fit. This measurement model was considered parsimonious and was theoretically supported in published literature; hence a decision was made to retain it for further analysis.

The measurement model is presented in Figure 8.9 below.

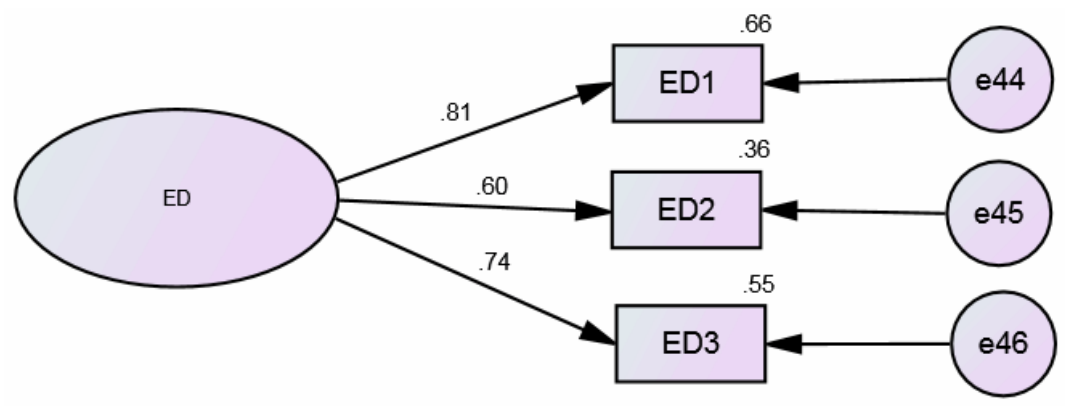

Figure 8.9 Measurement Model for the Construct Eco-Design

Table 8.22 below presents the standardized loadings of indicators on the construct EcoDesign (ED) and their Squared Multiple Correlations $\mathrm{R}^{2}$.

Table 8.22 Loadings on the Construct Eco-Design

\begin{tabular}{|c|r|r|}
\hline Item & $\begin{array}{c}\text { Standardised } \\
\text { Loading } \\
\lambda\end{array}$ & $\begin{array}{c}\text { Squared Multiple } \\
\text { Correlations } \\
\mathbf{R}^{\mathbf{2}}\end{array}$ \\
\hline ED1 & 0.813 & 0.661 \\
\hline ED2 & 0.600 & 0.360 \\
\hline ED3 & 0.744 & 0.553 \\
\hline
\end{tabular}




\subsubsection{Social Sustainability Practices}

Social Sustainability Practices (SSP) was posited as a latent construct measured by six items (SSP1 to SSP6, please see Table 3.1). When tested, the measurement model for Social Sustainability Practices elicited the following values of model fit indices (Table 8.23).

Table 8.23 Fit Indices for the Construct Social Sustainability Practices

\begin{tabular}{|l|r|}
\hline \multicolumn{1}{|c|}{ Index } & \multicolumn{1}{c|}{ Value } \\
\hline CMIN/Df & 33.519 \\
\hline CFI & 0.856 \\
\hline RMSEA & 0.387 \\
\hline NFI Delta1 & 0.853 \\
\hline IFI Delta2 & 0.857 \\
\hline Cronbach's Alpha & 0.969 \\
\hline
\end{tabular}

On further analysis, modification indices suggested introducing covariance arrows between the error terms e51 and e52 to improve the fit. The modified measurement model is presented in Figure 8.10 below. 


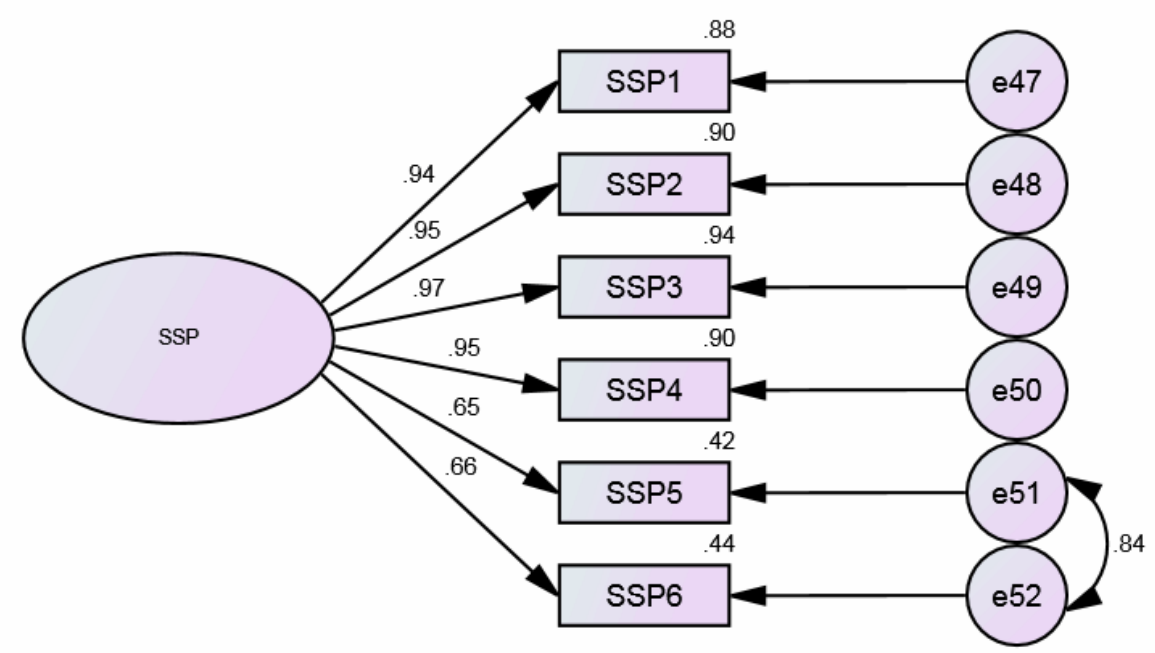

Figure 8.10 Measurement Model for the Construct Social Sustainability Practices (Modified)

Table 8.24 below presents the standardized loadings of indicators on the construct Social Sustainability Practices (SSP) and their Squared Multiple Correlations $\mathrm{R}^{2}$.

Table 8.24 Loadings on the Construct Social Sustainability Practices

\begin{tabular}{|c|r|r|}
\hline Item & $\begin{array}{c}\text { Standardised } \\
\text { Loading } \\
\lambda\end{array}$ & $\begin{array}{c}\text { Squared Multiple } \\
\text { Correlations } \\
\mathbf{R}^{2}\end{array}$ \\
\hline SSP1 & 0.936 & 0.876 \\
\hline SSP2 & 0.946 & 0.896 \\
\hline SSP3 & 0.970 & 0.941 \\
\hline SSP4 & 0.947 & 0.896 \\
\hline SSP5 & 0.649 & 0.421 \\
\hline SSP6 & 0.664 & 0.441 \\
\hline
\end{tabular}

The fit indices for modified model of the construct were as under: 
Table 8.25 Fit Indices for the modified Construct Social Sustainability Practices

\begin{tabular}{|l|r|}
\hline \multicolumn{1}{|c|}{ Index } & \multicolumn{1}{c|}{ Value } \\
\hline CMIN/Df & 7.554 \\
\hline CFI & 0.974 \\
\hline RMSEA & 0.174 \\
\hline NFI Delta1 & 0.970 \\
\hline IFI Delta2 & 0.974 \\
\hline
\end{tabular}

It was observed that fit indices CFI, NFI and IFI were good, being higher than 0.9, CMIN/Df was a little higher than 5, and RMSEA was higher than 0.08. This measurement model was considered parsimonious and was theoretically supported in published literature; hence a decision was made to retain it for further analysis.

\subsubsection{Economic Performance}

Economic Performance (EP) was posited as a latent construct measured by five items (EP1 to EP5, please see Table 3.1). When tested, the measurement model for Economic Performance elicited the following values of model fit indices (Table 8.26).

Table 8.26 Fit Indices for the Construct Economic Performance

\begin{tabular}{|l|r|}
\hline \multicolumn{1}{|c|}{ Index } & \multicolumn{1}{c|}{ Value } \\
\hline CMIN/Df & 15.788 \\
\hline CFI & 0.937 \\
\hline RMSEA & 0.261 \\
\hline NFI Delta1 & 0.933 \\
\hline IFI Delta2 & 0.937 \\
\hline Cronbach's Alpha & 0.956 \\
\hline
\end{tabular}


On further analysis, modification indices suggested introducing covariance arrows between the error terms e53 and e57 to improve the fit. The measurement model was modified accordingly and is presented in Figure 8.11 below.

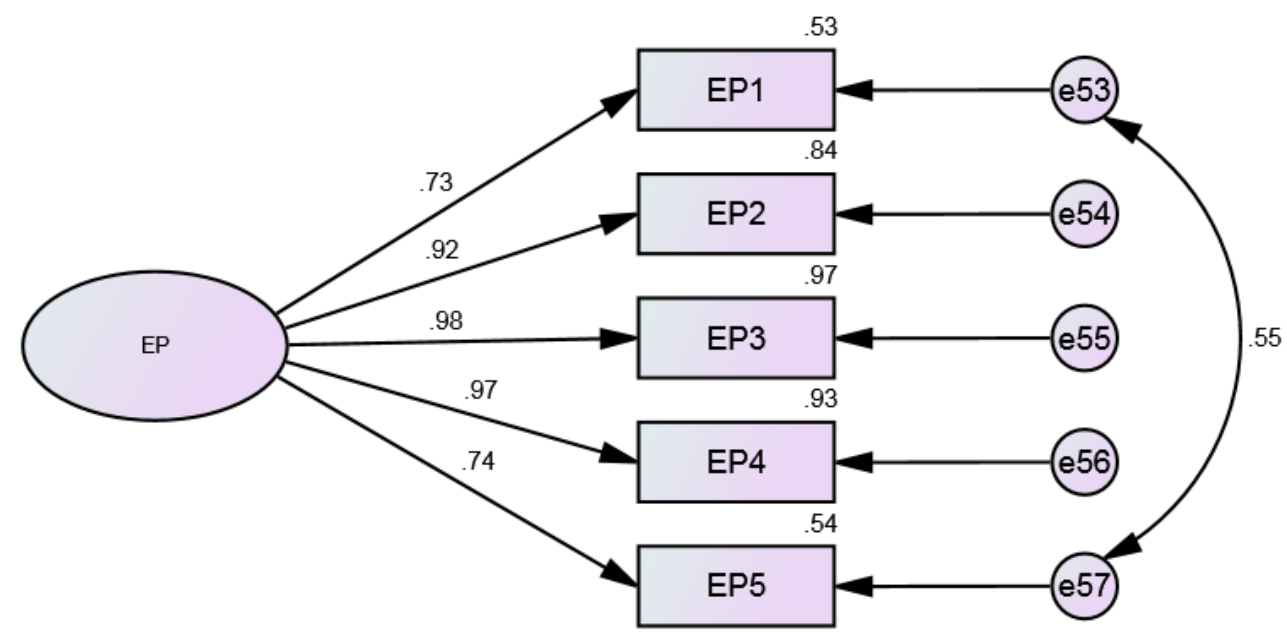

Figure 8.11 Measurement Model for the Construct Economic Performance (Modified)

Table 8.27 below presents the standardized loadings of indicators on the construct Economic Performance (EP) and their Squared Multiple Correlations $\mathrm{R}^{2}$.

Table 8.27 Loadings on the Construct Economic Performance

\begin{tabular}{|c|c|r|}
\hline Item & $\begin{array}{c}\text { Standardised } \\
\text { Loading } \\
\lambda\end{array}$ & $\begin{array}{c}\text { Squared Multiple } \\
\text { Correlations } \\
\mathbf{R}^{2}\end{array}$ \\
\hline EP1 & 0.729 & 0.531 \\
\hline EP2 & 0.917 & 0.840 \\
\hline EP3 & 0.982 & 0.965 \\
\hline EP4 & 0.965 & 0.932 \\
\hline EP5 & 0.735 & 0.541 \\
\hline
\end{tabular}


The fit indices for the modified model of the construct were as under (Table 8.28).

Table 8.28 Fit Indices for the modified Construct Economic Performance

\begin{tabular}{|l|r|}
\hline \multicolumn{1}{|c|}{ Index } & Value \\
\hline CMIN/Df & 3.880 \\
\hline CFI & 0.990 \\
\hline RMSEA & 0.115 \\
\hline NFI Delta1 & 0.986 \\
\hline IFI Delta2 & 0.990 \\
\hline
\end{tabular}

It was observed that for the modified model the fit indices CFI, NFI and IFI were good, being higher than 0.9, CMIN/Df was below 5, but RMSEA was a little higher than 0.08 . This measurement model was considered parsimonious and was theoretically supported in published literature; hence a decision was made to retain it for further analysis.

\subsubsection{Environmental Performance}

Environmental Performance (ENVP) was posited as a latent construct measured by six items (ENVP1 to ENVP6, please see Table 3.1). The initial measurement model for Environmental Performance, when tested, elicited the following values of model fit indices (Table 8.29).

Table 8.29 Fit Indices for the Construct Environmental Performance

\begin{tabular}{|l|r|}
\hline \multicolumn{1}{|c|}{ Index } & Value \\
\hline CMIN/Df & 2.889 \\
\hline CFI & 0.992 \\
\hline RMSEA & 0.093 \\
\hline NFI Delta1 & 0.987 \\
\hline IFI Delta2 & 0.992 \\
\hline Cronbach's Alpha & 0.983 \\
\hline
\end{tabular}


It was observed that fit indices CFI, NFI and IFI were good, being higher than 0.9, CMIN/Df was below 5, but RMSEA was a little higher than 0.08. This model fitted well with data. This measurement model was considered parsimonious and was theoretically supported in published literature; hence a decision was made to retain it for further analysis without any modification. This measurement model is presented in Figure 8.12 below.

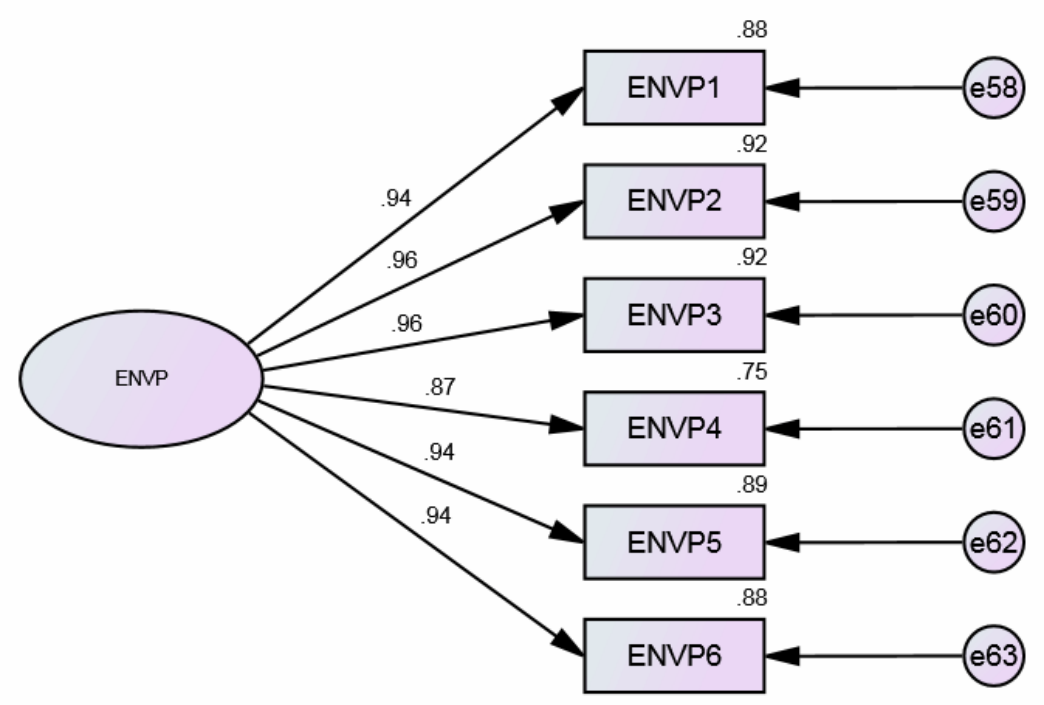

Figure 8.12 Measurement Model for the Construct Environmental Performance

Table 8.30 below shows standardized loadings of indicators on the construct Environmental Performance (ENVP) and their Squared Multiple Correlations $\mathrm{R}^{2}$. 
Table 8.30 Loadings on the Construct Environmental Performance

\begin{tabular}{|c|r|r|}
\hline Item & $\begin{array}{c}\text { Standardised } \\
\text { Loading } \\
\lambda\end{array}$ & $\begin{array}{c}\text { Squared Multiple } \\
\text { Correlations } \\
\mathbf{R}^{\mathbf{2}}\end{array}$ \\
\hline ENVP1 & 0.937 & 0.878 \\
\hline ENVP2 & 0.959 & 0.921 \\
\hline ENVP3 & 0.957 & 0.916 \\
\hline ENVP4 & 0.865 & 0.748 \\
\hline ENVP5 & 0.941 & 0.885 \\
\hline ENVP6 & 0.936 & 0.876 \\
\hline
\end{tabular}

\subsubsection{Social Performance}

Social Performance (SP) was posited as a latent construct measured by five items (SP1 to SP5, please see Table 3.1). When tested, the measurement model for Social Performance elicited the following values of model fit indices (Table 8.31).

Table 8.31 Fit Indices for the Construct Social Performance

\begin{tabular}{|l|r|}
\hline \multicolumn{1}{|c|}{ Index } & \multicolumn{1}{c|}{ Value } \\
\hline CMIN/Df & 35.008 \\
\hline CFI & 0.838 \\
\hline RMSEA & 0.396 \\
\hline NFI Delta1 & 0.835 \\
\hline IFI Delta2 & 0.838 \\
\hline Cronbach's Alpha & 0.943 \\
\hline
\end{tabular}

On further analysis, modification indices suggested introducing covariance arrows between the error terms e67 and e68 to improve fit. The measurement model was modified accordingly and is presented in Figure 8.13 below. 


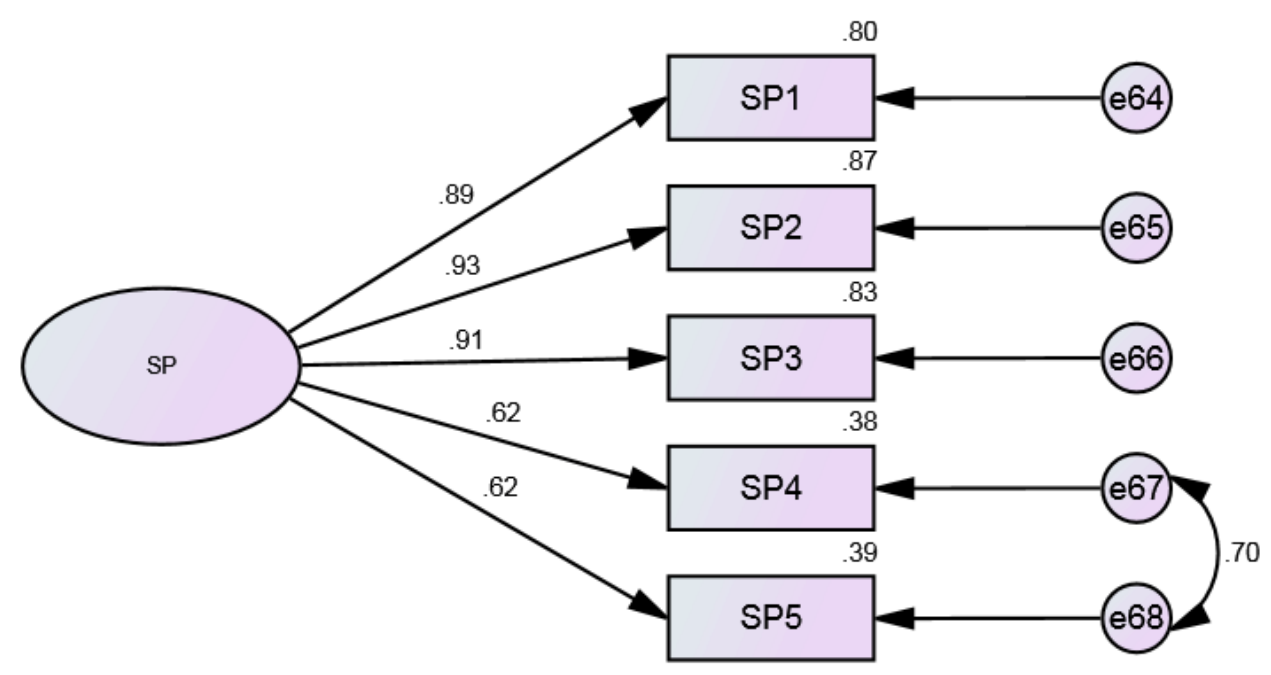

Figure 8.13 Measurement Model for the Construct Social Performance (Modified)

Table 8.32 below presents standardized loadings of indicators on the construct Social Performance (SP) and their Squared Multiple Correlations $\mathrm{R}^{2}$.

Table 8.32 Loadings on the Construct Social Performance

\begin{tabular}{|c|r|r|}
\hline Item & $\begin{array}{c}\text { Standardised } \\
\text { Loading } \\
\lambda\end{array}$ & $\begin{array}{c}\text { Squared Multiple } \\
\text { Correlations } \\
\mathbf{R}^{2}\end{array}$ \\
\hline SP1 & 0.892 & 0.796 \\
\hline SP2 & 0.934 & 0.872 \\
\hline SP3 & 0.912 & 0.833 \\
\hline SP4 & 0.619 & 0.383 \\
\hline SP5 & 0.625 & 0.390 \\
\hline
\end{tabular}

The fit indices for the modified model of the construct were as under (Table 8.33). 
Table 8.33 Fit Indices for the modified Construct Social Performance

\begin{tabular}{|l|r|}
\hline \multicolumn{1}{|c|}{ Index } & \multicolumn{1}{c|}{ Value } \\
\hline CMIN/Df & 13.541 \\
\hline CFI & 0.950 \\
\hline RMSEA & 0.240 \\
\hline NFI Delta1 & 0.947 \\
\hline IFI Delta2 & 0.950 \\
\hline
\end{tabular}

It was observed that fit indices CFI, NFI and IFI were good, being higher than 0.9, CMIN/Df was above 5, and RMSEA was higher than 0.08. It was further observed that after modification of the measurement model the strength of loading of items SP4 and SP5 reduced from 0.644 and 0.651 to 0.619 and 0.625 respectively. It could be argued that the items SP5 and SP6 could be removed for a better model fit and a parsimonious model. However, on testing the measurement model with items SP4 and SP5 removed the fit indices deteriorated, as presented in Table 8.34 below.

Table 8.34 Fit Indices for the modified Model of Social Performance after removing Items SP4 and SP5

\begin{tabular}{|l|r|r|}
\hline \multicolumn{1}{|c|}{ Index } & Value with five indicators & \multicolumn{1}{c|}{$\begin{array}{c}\text { Value after removing } \\
\text { SP4 and SP5 }\end{array}$} \\
\hline CMIN/Df & 13.541 & 52.042 \\
\hline CFI & 0.950 & 0.936 \\
\hline RMSEA & 0.240 & 0.485 \\
\hline NFI Delta1 & 0.947 & 0.935 \\
\hline IFI Delta2 & 0.950 & 0.936 \\
\hline
\end{tabular}

When we conducted analyses using SPSS to determine whether the removal of the items SP4 and SP5 would add to reliability of the construct we got the following result (Table 8.35): 
Table 8.35 Cronbach's Alpha if Items SP4 or SP5 are deleted

\begin{tabular}{|l|r|r|r|r|}
\hline & $\begin{array}{c}\text { Scale Mean } \\
\text { if Item } \\
\text { Deleted }\end{array}$ & $\begin{array}{c}\text { Scale } \\
\text { Variance if } \\
\text { Item Deleted }\end{array}$ & $\begin{array}{c}\text { Corrected } \\
\text { Item-Total } \\
\text { Correlation }\end{array}$ & $\begin{array}{c}\text { Cronbach's } \\
\text { Alpha if Item } \\
\text { Deleted }\end{array}$ \\
\hline SP1 & 18.96 & 23.741 & .899 & .920 \\
SP2 & 18.90 & 24.696 & .884 & .922 \\
SP3 & 18.94 & 24.034 & .891 & .921 \\
SP4 & 19.09 & 27.724 & .778 & .941 \\
SP5 & 19.05 & 27.394 & .786 & .940 \\
\hline
\end{tabular}

It was interpreted from the above results that deleting item SP5 from scale would reduce the Cronbach's Alpha's current value of 0.943 to 0.941 ; similarly deleting item SP6 from scale would reduce Cronbach's Alpha's current value of 0.943 to 0.940 . Thus deletion of these items would not add to Cronbach's Alpha's current value of 0.943 , i.e. it would not increase the reliability of the construct.

So, a decision was made to retain the items SP5 and SP6 in the measurement model because firstly they provide a richer insight into the construct and secondly, removing them does not improve its fit or add to the reliability of the model. Rather, the measurement model fit deteriorates, indicating that the measurement model as presented in Figure 8.13 is better supported. Therefore, this modified model (Figure 8.13) was considered appropriate, and the decision was made retain it for further analysis. 


\subsubsection{Operational Performance}

Operational Performance (OP) was posited as a latent construct measured by six items (OP1 to OP6, please see Table 3.1). When tested, the measurement model for Operational Performance elicited the following values of model fit indices (Table 8.36).

Table 8.36 Fit Indices for the Construct Operational Performance

\begin{tabular}{|l|r|}
\hline \multicolumn{1}{|c|}{ Index } & Value \\
\hline CMIN/Df & 19.118 \\
\hline CFI & 0.882 \\
\hline RMSEA & 0.289 \\
\hline NFI Delta1 & 0.877 \\
\hline IFI Delta2 & 0.882 \\
\hline Cronbach's Alpha & 0.950 \\
\hline
\end{tabular}

On further analysis, modification indices suggested introducing covariance arrows between the error terms e69 and e70 to improve the fit. The measurement model was modified accordingly and is presented in Figure 8.14 below. 


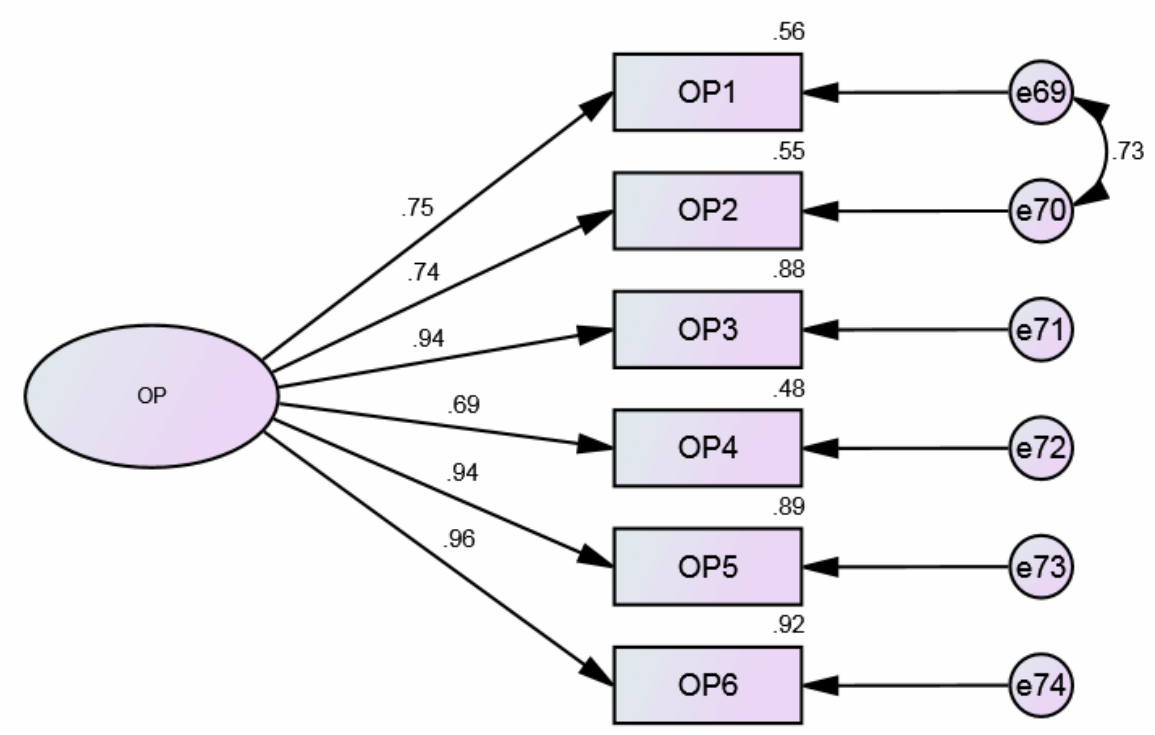

Figure 8.14 Measurement Model for the Construct Operational Performance (Modified)

Table 8.37 below presents the standardized loading of indicators on the construct Operational Performance (OP), and their Squared Multiple Correlations $\mathrm{R}^{2}$.

Table 8.37 Loadings on the Construct Operational Performance

\begin{tabular}{|c|c|r|}
\hline Item & $\begin{array}{c}\text { Standardised } \\
\text { Loading } \\
\lambda\end{array}$ & $\begin{array}{c}\text { Squared Multiple } \\
\text { Correlations } \\
\mathbf{R}^{\mathbf{2}}\end{array}$ \\
\hline OP1 & 0.748 & 0.559 \\
\hline OP2 & 0.740 & 0.547 \\
\hline OP3 & 0.939 & 0.881 \\
\hline OP4 & 0.695 & 0.483 \\
\hline OP5 & 0.943 & 0.889 \\
\hline OP6 & 0.960 & 0.922 \\
\hline
\end{tabular}

The fit indices for the modified model of the construct improved and are placed as under (Table 8.38). 
Table 8.38 Fit Indices for the modified Construct Operational Performance

\begin{tabular}{|l|r|}
\hline \multicolumn{1}{|c|}{ Index } & Value \\
\hline CMIN/Df & 4.099 \\
\hline CFI & 0.982 \\
\hline RMSEA & 0.119 \\
\hline NFI Delta1 & 0.976 \\
\hline IFI Delta2 & 0.982 \\
\hline
\end{tabular}

It was observed that fit indices CFI, NFI and IFI were good, being higher than 0.9, CMIN/Df was below 5, though RMSEA was a little higher than 0.08. It is seen that the modified model now fits the data well hence a decision was made to retain the modified model for further analysis.

\subsubsection{Confirmatory Factor Analysis of Groups Drivers, SSCM Practices}

\section{Adoption, and Performances}

As the second step, groupings of constructs were analyzed using CFA. As discussed in sub-section 7.1.2 earlier, the following groups were formed for analysis (Table 8.39).

Table 8.39 Groups Used for Confirmatory Factor Analysis in AMOS

\begin{tabular}{|l|l|c|}
\hline $\begin{array}{c}\text { Group or } \\
\text { Composite } \\
\text { Construct }\end{array}$ & \multicolumn{1}{|c|}{ Constructs } & $\begin{array}{c}\text { Acronym } \\
\text { Used in } \\
\text { Analysis }\end{array}$ \\
\hline \multirow{2}{*}{ Drivers } & Regulations & REG \\
\cline { 2 - 3 } & Competitiveness & COMP \\
\cline { 2 - 3 } & Stakeholder Pressures & PRES \\
\hline SSCM & External Environmental Practices & EEP \\
\hline
\end{tabular}




\begin{tabular}{|l|l|c|}
\hline \multirow{4}{*}{ Practices } & Internal Environmental Practices & IEP \\
\cline { 2 - 3 } & Supplier Selection & SS \\
\cline { 2 - 3 } & Supplier Evaluation \& Monitoring & SM \\
\cline { 2 - 3 } & Cooperation with Customers & CC \\
\cline { 2 - 3 } & Eco-Design & ED \\
\cline { 2 - 3 } & Social Sustainability Practices & SSP \\
\hline \multirow{4}{*}{ Performance } & Economic Performance & EP \\
\cline { 2 - 3 } & Environmental Performance & ENVP \\
\cline { 2 - 3 } & Social Performance & SP \\
\cline { 2 - 3 } & Operational Performance & OP \\
\hline
\end{tabular}

These groups of constructs were used for testing the measurement model, which is discussed in the next sub-section.

\subsubsection{Drivers}

\section{Measurement Model}

Drivers Regulations (REG), Competitiveness (COMP), and Stakeholder Pressures (PRES) which have been posited as latent constructs were measured using a set of indicators (please see Table 3.1). When tested by conducting CFA using AMOS, the modification indices suggested introduction of covariance arrows between the error terms e4 and e8; e13 and e15 to improve the fit. The measurement model was modified accordingly and is presented in Figure 8.15. 


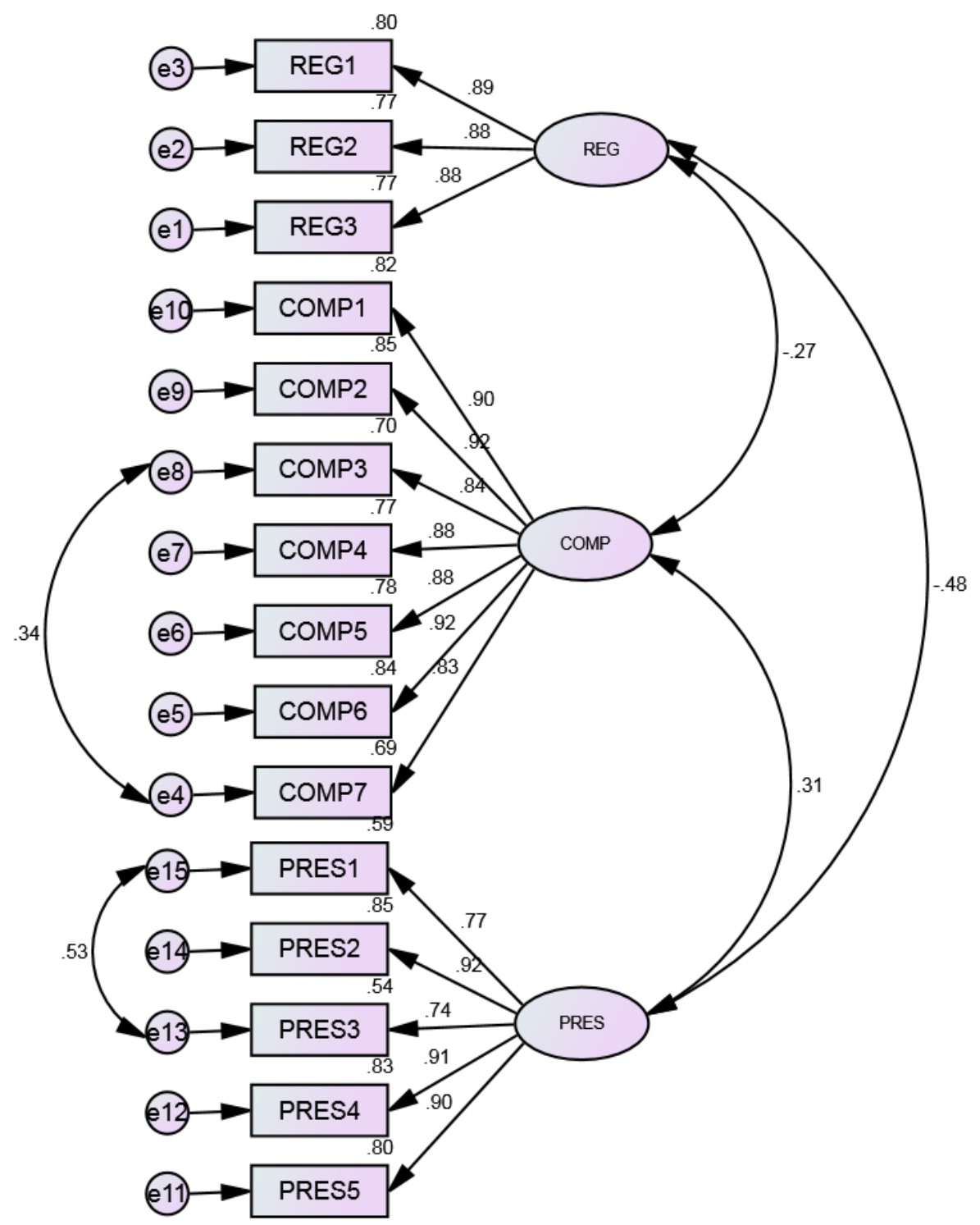

Figure 8.15 Measurement Model for the Constructs in the group Drivers (Modified)

The fit indices for the modified model for the Drivers improved as under (Table 8.40). 
Table 8.40 Fit Indices for the modified Drivers Model

\begin{tabular}{|l|r|}
\hline \multicolumn{1}{|c|}{ Index } & Value \\
\hline CMIN/Df & 3.688 \\
\hline CFI & 0.932 \\
\hline RMSEA & 0.111 \\
\hline NFI Delta1 & 0.909 \\
\hline IFI Delta2 & 0.932 \\
\hline
\end{tabular}

It was observed that fit indices CFI, NFI and IFI were good, being higher than 0.9 , CMIN/Df was below 5, but RMSEA was a little higher than 0.08. It was seen that the modified model fitted the data better than before and the latter model was retained for analysis of results.

Table 8.41 below presents the standardized loadings of indicators on the constructs and their Squared Multiple Correlations $\mathrm{R}^{2}$.

Table 8.41 Standardised Loadings on the Drivers: Regulations, Competitiveness and Stakeholder Pressures With Composite Reliability, Square Multiple Correlations and Error Variance

\begin{tabular}{|c|c|c|c|c|c|}
\hline $\begin{array}{c}\text { ITEMS } \\
\text { CR }\end{array}$ & $\begin{array}{c}\text { REG } \\
0.914\end{array}$ & $\begin{array}{c}\text { COMP } \\
0.961\end{array}$ & $\begin{array}{c}\text { PRES } \\
\mathbf{0 . 9 2 9}\end{array}$ & $\begin{array}{c}\text { SQUARED } \\
\text { MULTIPLE } \\
\text { CORRELATIONS }\end{array}$ & $\begin{array}{c}\text { ERROR } \\
\text { VARIANCE }\end{array}$ \\
\hline & $\lambda$ & $\lambda$ & $\lambda$ & $\mathbf{R}^{2}$ & $\varepsilon$ \\
\hline REG1 & 0.894 & & & 0.799 & 0.201 \\
\hline REG2 & 0.877 & & & 0.769 & 0.231 \\
\hline REG3 & 0.879 & & & 0.772 & 0.228 \\
\hline COMP1 & & 0.904 & & 0.817 & 0.183 \\
\hline COMP2 & & 0.920 & & 0.847 & 0.153 \\
\hline COMP3 & & 0.839 & & 0.704 & 0.296 \\
\hline COMP4 & & 0.876 & & 0.767 & 0.233 \\
\hline COMP5 & & 0.881 & & 0.776 & 0.224 \\
\hline COMP6 & & 0.917 & & 0.841 & 0.159 \\
\hline COMP7 & & 0.833 & & 0.693 & 0.307 \\
\hline
\end{tabular}




\begin{tabular}{|l|l|l|l|l|l|}
\hline PRES1 & & 0.771 & 0.594 & 0.406 \\
\hline PRES2 & & & 0.921 & 0.848 & 0.152 \\
\hline PRES3 & & & 0.736 & 0.542 & 0.458 \\
\hline PRES4 & & & 0.912 & 0.832 & 0.168 \\
\hline PRES5 & & 0.897 & 0.805 & 0.195 \\
\hline
\end{tabular}

Assessing Reliability, and Convergent and Discriminant Validity

\section{Reliability}

Reliability may be assessed using Cronbach's Alpha, which was calculated in sub-section 5.5.1 and presented in Table 5.3. It was found that Cronbach's Alpha of each of the constructs in Drivers group was higher than 0.9 which showed high reliability of the scale being used.

Composite Reliability is also used for assessing reliability, and it can be calculated from CFA outputs. CR values of higher than 0.8 (Raykov, 1997) or 0.7 (Hair et al., 2010) are considered good to indicate the high reliability of a scale.

\section{Validity}

Convergent validity of the scale may be ascertained by inspecting the standardized loadings of items on the respective constructs. Table 8.42 shows that these loadings are robust and are all above 0.7 , the lowest being 0.736 for PRES3 and can be interpreted to indicate a high convergent validity (Tabachnick \& Fidell, 2007).

Another index used for convergent validity is Average Variance Extracted (AVE). AVE ranges from 0 to 1 , and any value above 0.5 is considered to be good 
indicator of convergent validity (Dillon \& Goldstein, 1984; Fornell \& Larcker, 1981). Malhotra and Dash (2011) state that "AVE is a more conservative measure than CR. On the basis of CR alone, the researcher may conclude that the convergent validity of the construct is adequate, even though more than $50 \%$ of the variance is due to error." (Malhotra \& Dash, 2011, p.702).

Discriminant validity between constructs may be established by comparing the square root of AVE of each construct with its correlation with other constructs under analysis. The square root of AVE should be higher than the correlation values for good discriminant validity (Fornell \& Larcker, 1981). Values for AVE may be compared with Maximum Shared Variance (MSV). AVE should be greater than MSV for good discriminant validity (Hair et al., 2010).

Composite Reliability (CR), Average Variance Extracted (AVE), Maximum Shared Variance (MSV), and the square root of AVE were calculated from the regression and correlation tables in the output of the CFA conducted on the Drivers constructs. Table 8.42 presents these indices.

Table 8.42 Reliability and Validity Indices of Drivers Constructs

\begin{tabular}{|l|c|c|c|c|c|c|}
\hline & $\begin{array}{c}\text { Composite } \\
\text { Reliability } \\
\text { CR }\end{array}$ & $\begin{array}{c}\text { Average } \\
\text { Variance } \\
\text { Extracted } \\
\text { AVE }\end{array}$ & $\begin{array}{c}\text { Maximum } \\
\text { Shared } \\
\text { Variance } \\
\text { MSV }\end{array}$ & REG & COMP & PRES \\
\hline REG & 0.914 & 0.780 & 0.233 & $\mathbf{0 . 8 8 3 * *}$ & & \\
\hline COMP & 0.961 & 0.778 & 0.094 & $-0.273 *$ & $\mathbf{0 . 8 8 2 * *}$ & \\
\hline PRES & 0.929 & 0.724 & 0.233 & $-0.483 *$ & $0.307 *$ & $\mathbf{0 . 8 5 1 * *}$ \\
\hline
\end{tabular}


Note. **. The bold figures on the diagonal are the square roots of the respective AVE.

* . The values in italics are coefficients of correlation.

The three constructs in the Drivers model displayed high Composite Reliability, i.e., Regulations (0.914), Competitiveness (0.961), and Stakeholder Pressures (0.929), which was much higher than the cut-off of 0.800 (Raykov, 1997), this indicated high reliability of the constructs.

The absolute values of AVE for the constructs REG (0.780), COMP (0.778), and PRES (0.724) were much higher than the recommended value of 0.500 (Fornell \& Larcker, 1981) indicating the high convergent validity of the constructs. CR of each construct was higher than AVE indicating the high discriminant validity of the constructs.

Maximum Shared Variance MSV for the constructs was low: REG (0.233), COMP (0.094), and PRESS (0.233) and was lower than the corresponding AVE, thus indicating high discriminant validity (Hair et al., 2010).

Discriminant validity between constructs may be established by comparing the square root of AVE of each construct with its correlation with other constructs under analysis. The square root of AVE should be higher than the correlation values for good discriminant validity (Fornell \& Larcker, 1981).

When the square root of the AVE of each construct (the bold figures placed on the diagonal in the Table above) was compared with its correlation with other constructs 
under analysis, it was observed that the square root of AVE was higher than the correlation values, indicating good discriminant validity (Fornell \& Larcker, 1981).

\subsubsection{SSCM Practices Adoption}

\section{Measurement Model}

The seven SSCM Practices Adoption constructs, viz. EEP, IEP, SS, SM, CC, ED SSP were posited as latent constructs measured by their indicators (please see Table 3.1). When tested by conducting CFA using AMOS, the modification indices suggested changes i.e., introduction of covariance arrows between the error terms e18 and e19; e23 and e25; e29 and e30; and e51 and e52. The measurement model was modified accordingly and is presented in Figure 8.16 below. 


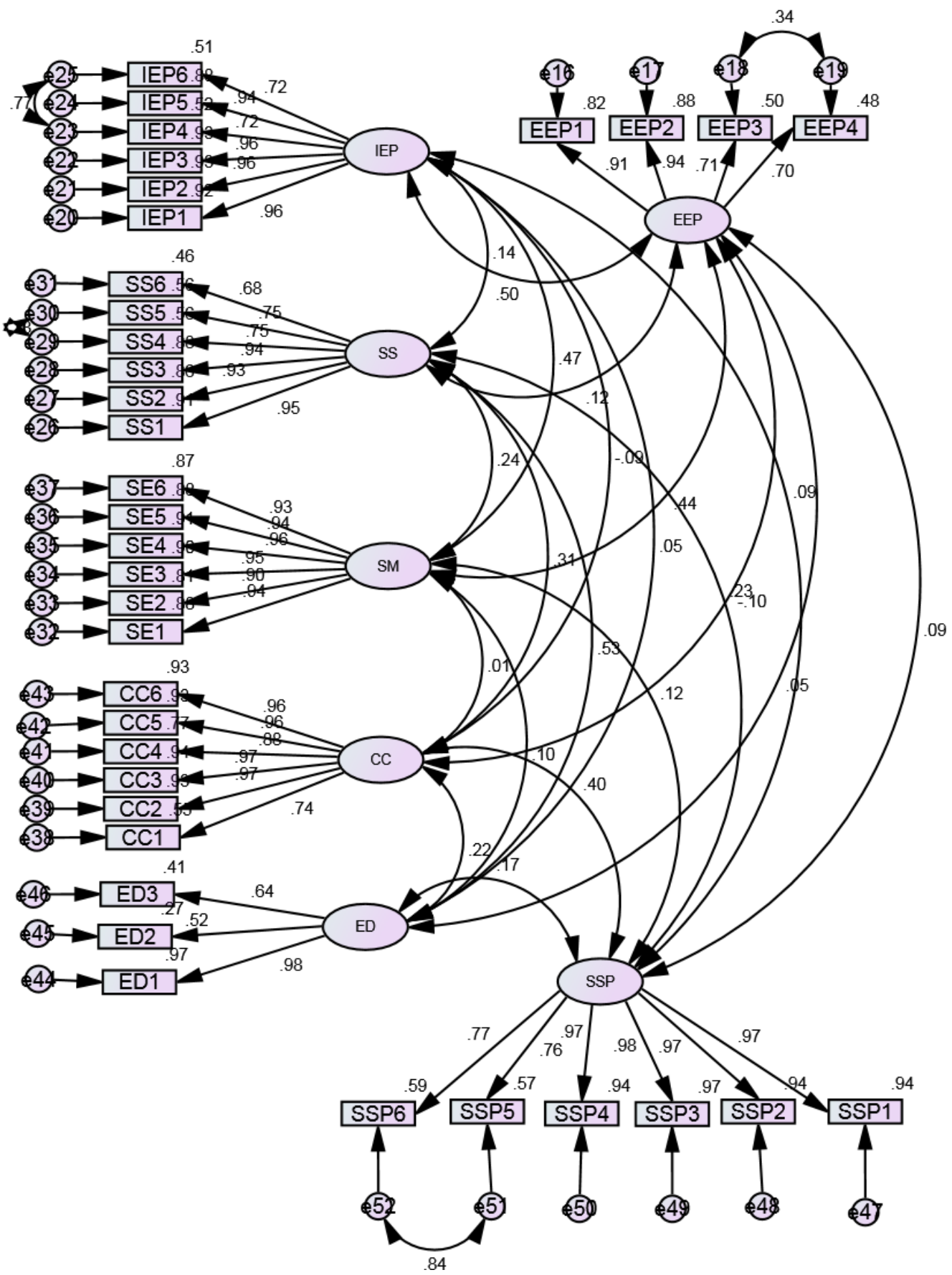

Figure 8.16 Measurement Model for SSCM Practices Adoption (Modified)

The fit indices for the modified measurement model for the SSCM Practices Adoption were as under (Table 8.46). 
Table 8.43 Fit Indices for the Modified SSCM Practices Adoption Measurement Model

\begin{tabular}{|l|r|}
\hline \multicolumn{1}{|c|}{ Index } & Value \\
\hline CMIN/Df & 2.425 \\
\hline CFI & 0.923 \\
\hline RMSEA & 0.081 \\
\hline NFI Delta1 & 0.876 \\
\hline IFI Delta2 & 0.923 \\
\hline
\end{tabular}

It was observed that CMIN/Df was below 5, and RMSEA was at 0.081, CFI and IFI were above 0.9 while NFI was a bit below 0.9. It is seen that the modified model (Figure 8.16) fitted the data well and was retained for analysis of results.

Table 8.44 below presents the standardized loadings $(\lambda)$ of indicators on the constructs and their Squared Multiple Correlations $\mathrm{R}^{2}$ and error variance $\varepsilon$.

Table 8.44 Standardised Loadings ( $\lambda$ ) on the SSCM Practices Adoption Constructs with Composite Reliability, Square Multiple Correlations and Error Variance

\begin{tabular}{|c|c|c|c|c|c|c|c|c|c|}
\hline & EEP & IEP & SS & SM & $\mathrm{CC}$ & ED & SSP & \multirow{2}{*}{$\begin{array}{c}\text { Squared } \\
\text { Multiple } \\
\text { Correlations }\end{array}$} & \multirow[t]{2}{*}{$\begin{array}{c}\text { Error } \\
\text { Variance }\end{array}$} \\
\hline CR & 0.888 & 0.955 & 0.934 & 0.976 & 0.969 & 0.772 & 0.966 & & \\
\hline & $\lambda$ & $\lambda$ & $\lambda$ & $\lambda$ & $\lambda$ & $\lambda$ & $\lambda$ & $\mathbf{R}^{2}$ & $\varepsilon$ \\
\hline EEP1 & 0.905 & & & & & & & 0.819 & 0.181 \\
\hline EEP2 & 0.936 & & & & & & & 0.877 & 0.123 \\
\hline EEP3 & 0.705 & & & & & & & 0.498 & 0.502 \\
\hline EEP4 & 0.696 & & & & & & & 0.485 & 0.515 \\
\hline IEP1 & & 0.959 & & & & & & 0.919 & 0.081 \\
\hline IEP2 & & 0.964 & & & & & & 0.928 & 0.072 \\
\hline IEP3 & & 0.963 & & & & & & 0.926 & 0.074 \\
\hline IEP4 & & 0.721 & & & & & & 0.520 & 0.480 \\
\hline IEP5 & & 0.936 & & & & & & 0.876 & 0.124 \\
\hline IEP6 & & 0.715 & & & & & & 0.511 & 0.489 \\
\hline
\end{tabular}




\begin{tabular}{|c|c|c|c|c|c|c|c|}
\hline SS1 & 0.954 & & & & & 0.911 & 0.089 \\
\hline SS2 & 0.930 & & & & & 0.864 & 0.136 \\
\hline SS3 & 0.936 & & & & & 0.877 & 0.123 \\
\hline SS4 & 0.751 & & & & & 0.564 & 0.436 \\
\hline SS5 & 0.745 & & & & & 0.555 & 0.445 \\
\hline SS6 & 0.679 & & & & & 0.461 & 0.539 \\
\hline SM1 & & 0.936 & & & & 0.875 & 0.125 \\
\hline SM2 & & 0.897 & & & & 0.805 & 0.195 \\
\hline SM3 & & 0.946 & & & & 0.895 & 0.105 \\
\hline SM4 & & 0.955 & & & & 0.913 & 0.087 \\
\hline SM5 & & 0.935 & & & & 0.875 & 0.125 \\
\hline SM6 & & 0.932 & & & & 0.869 & 0.131 \\
\hline CC1 & & & 0.739 & & & 0.546 & 0.454 \\
\hline $\mathrm{CC} 2$ & & & 0.967 & & & 0.935 & 0.065 \\
\hline CC3 & & & 0.968 & & & 0.937 & 0.063 \\
\hline $\mathrm{CC} 4$ & & & 0.877 & & & 0.769 & 0.231 \\
\hline CC5 & & & 0.963 & & & 0.927 & 0.073 \\
\hline CC6 & & & 0.963 & & & 0.928 & 0.072 \\
\hline ED1 & & & & 0.983 & & 0.966 & 0.034 \\
\hline ED2 & & & & 0.522 & & 0.272 & 0.728 \\
\hline ED3 & & & & 0.637 & & 0.406 & 0.594 \\
\hline SSP1 & & & & & 0.971 & 0.943 & 0.057 \\
\hline SSP2 & & & & & 0.969 & 0.939 & 0.061 \\
\hline SSP3 & & & & & 0.982 & 0.965 & 0.035 \\
\hline SSP4 & & & & & 0.970 & 0.941 & 0.059 \\
\hline SSP5 & & & & & 0.756 & 0.572 & 0.428 \\
\hline SSP6 & & & & & 0.770 & 0.593 & 0.407 \\
\hline
\end{tabular}

\section{Assessing Reliability, and Convergent and Discriminant Validity}

Composite Reliability (CR), Average Variance Extracted (AVE), Maximum Shared Variance (MSV), and the square root of AVE were calculated from the regression and 
correlation tables in the output of the CFA conducted on the SSCM Practices adoption.

Table 8.45 presents these indices.

Table 8.45 Reliability and Validity Indices of SSCM Practices Adoption

\begin{tabular}{|l|l|l|l|l|r|r|r|l|l|l|}
\hline & CR & AVE & MSV & SSP & EEP & IEP & SS & SM & CC & ED \\
\hline SSP & 0.966 & 0.825 & 0.162 & $\mathbf{0 . 9 0 8 * *}$ & & & & & & \\
\hline EEP & 0.888 & 0.669 & 0.251 & $0.091^{*}$ & $\mathbf{0 . 8 1 8 * *}$ & & & & & \\
\hline IEP & 0.955 & 0.781 & 0.251 & $0.093^{*}$ & $0.501 *$ & $\mathbf{0 . 8 8 4 * *}$ & & & & \\
\hline SS & 0.934 & 0.705 & 0.277 & $0.229^{*}$ & $0.119^{*}$ & $0.136^{*}$ & $\mathbf{0 . 8 4 0 * *}$ & & & \\
\hline SM & 0.976 & 0.872 & 0.226 & $0.122^{*}$ & $0.444^{*}$ & $0.475^{*}$ & $0.235^{*}$ & $\mathbf{0 . 9 3 4 * *}$ & & \\
\hline CC & 0.969 & 0.840 & 0.162 & $0.403^{*}$ & $-0.095^{*}$ & $-0.088^{*}$ & $0.307^{*}$ & $0.012^{*}$ & $\mathbf{0 . 9 1 7 * *}$ & \\
\hline ED & 0.772 & 0.548 & 0.277 & $0.171^{*}$ & $0.054^{*}$ & $0.053^{*}$ & $0.526^{*}$ & $0.097 *$ & $0.220^{*}$ & $\mathbf{0 . 7 4 0 * *}$ \\
\hline
\end{tabular}

Note. $* *$. The bold figures on the diagonal are the square roots of the respective AVE.

* The values in italics are coefficients of correlation.

\section{Reliability}

Reliability maybe assessed by Cronbach's Alpha, which was calculated in subsection 5.5.1 and presented in Table 5.3. It was found that Cronbach's Alpha of each of the constructs in SSCM Practices Adoption group was higher than 0.9, except EEP (0.897) and ED (0.767). This represents high reliability of the scale being used.

As observed from Table 8.45 above, the seven constructs of the SSCM Practices Adoption displayed a high Composite Reliability. While six constructs elicited a CR of higher than the cut-off value of 0.800 and indicated high reliability of the constructs, ED had a CR of 0.772 , which was slightly lower than the 0.8 cut off suggested by Raykov (1997) but was higher than 0.7, the cutoff suggested by Hair et al. (2010), and thus was not considered to be a cause of concern. 


\section{Validity}

Convergent validity of the scale may be ascertained by inspecting the standardized loadings of items on the constructs. Table 8.44 exhibits that these loadings were robust and were all above 0.7, except in four cases (EEP4, 0.696; SS6, 0.679; ED2, 0.572; ED3, 0.637). All the loadings above 0.7 were interpreted to be excellent, while others ranged from very good to good (Tabachnick \& Fidell, 2007) indicating convergent validity.

The absolute values of AVE of all the seven constructs were observed to be higher than the recommended value of 0.500 indicating the high convergent validity of the constructs (Fornell \& Larcker, 1981).

Maximum Shared Variance values for the seven constructs were low and ranged from a low of 0.162 to a high of 0.277 and were lower than the corresponding AVE, again indicating the high discriminant validity of the constructs (Hair et al., 2010).

When the square root of the AVE of each construct (the bold figures placed on the diagonal in the Table above) was compared with its correlation with other constructs under analysis, it was observed that the square root of AVE was higher than the correlation values, indicating good discriminant validity (Fornell \& Larcker, 1981). Also, CR of each construct was higher than AVE indicating the high discriminant validity of the constructs. 


\subsubsection{Performance}

\section{Measurement Model}

The constructs relating to Performance types, i.e., EP, ENVP, SP, and OP were posited as latent constructs that were measured by their indicators (please see Table 3.1). When the measurement model for these four constructs was tested using AMOS, the modification indices suggested introduction of covariance arrows between the error terms e53 and e57; e67 and e68; and e69 and e70. The measurement model was modified accordingly and is presented in Figure 8.17 below. 


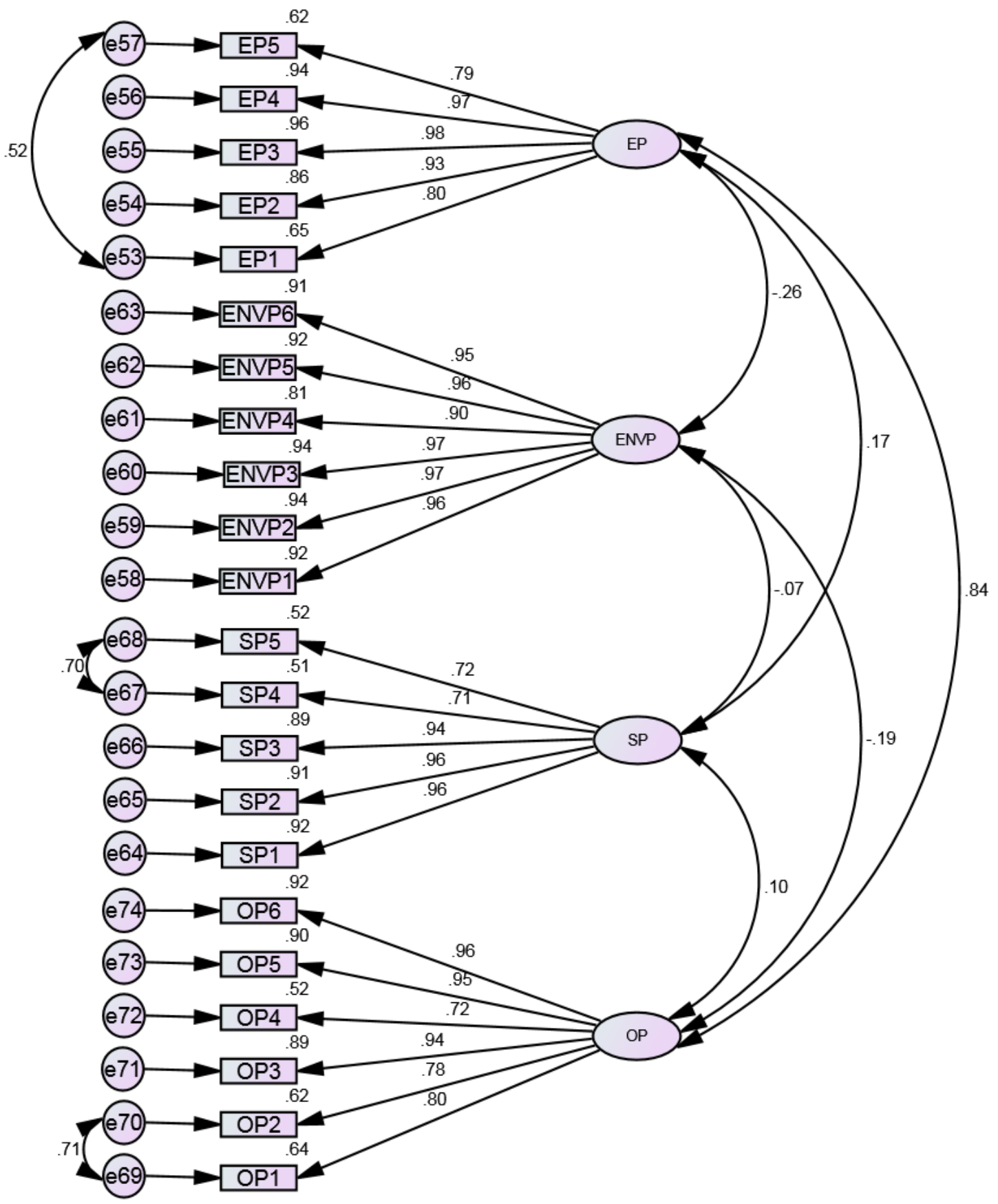

Figure 8.17 Measurement Model for Performance (Modified) 
The fit indices for the modified Performance measurement model were elicited as under (Table 8.46).

Table 8.46 Fit Indices for the Modified Performance Measurement Model

\begin{tabular}{|l|r|}
\hline \multicolumn{1}{|c|}{ Index } & \multicolumn{1}{c|}{ Value } \\
\hline CMIN/Df & 3.845 \\
\hline CFI & 0.921 \\
\hline RMSEA & 0.115 \\
\hline NFI Delta1 & 0.897 \\
\hline IFI Delta2 & 0.922 \\
\hline
\end{tabular}

It was seen that the CMIN/Df was below 5, RMSEA was a little higher than 0.08, the CFI and IFI were above 0.9 and NFI were a bit lower than 0.9 , but now the modified measurement model fitted the data better. This measurement model was parsimonious and theoretically supported by published literature; hence a decision was made to retain it for further runs and analysis of results.

Table 8.47 below presents the standardized loadings $(\lambda)$ of indicators on the Performance constructs EP, ENVP, SP and OP, their Squared Multiple Correlations $\mathrm{R}^{2}$ and error variance $\varepsilon$.

Table 8.47 Standardised Loadings ( $\lambda$ ) on the Performance Constructs With Composite Reliability, Square Multiple Correlations and Error Variance

\begin{tabular}{|c|c|c|c|c|c|c|}
\hline & SP & ENVP & EP & OP & \multirow{2}{*}{$\begin{array}{c}\text { Squared } \\
\text { Multiple } \\
\text { Correlations }\end{array}$} & \multirow[t]{2}{*}{$\begin{array}{c}\text { Error } \\
\text { Variance }\end{array}$} \\
\hline CR & 0.936 & 0.983 & 0.954 & 0.946 & & \\
\hline & $\lambda$ & $\lambda$ & $\lambda$ & $\lambda$ & $\mathbf{R}^{2}$ & $\varepsilon$ \\
\hline EP1 & & & 0.803 & & 0.645 & 0.355 \\
\hline EP2 & & & 0.930 & & 0.865 & 0.135 \\
\hline
\end{tabular}




\begin{tabular}{|c|l|l|l|l|l|l|}
\hline EP3 & & & 0.979 & & 0.959 & 0.041 \\
\hline EP4 & & & 0.969 & & 0.939 & 0.061 \\
\hline EP5 & & & 0.790 & & 0.625 & 0.375 \\
\hline ENVP1 & & 0.959 & & & 0.921 & 0.079 \\
\hline ENVP2 & & 0.971 & & & 0.943 & 0.057 \\
\hline ENVP3 & & 0.969 & & & 0.939 & 0.061 \\
\hline ENVP4 & & 0.899 & & & 0.808 & 0.192 \\
\hline ENVP5 & & 0.957 & & & 0.915 & 0.085 \\
\hline ENVP6 & & 0.954 & & & 0.910 & 0.090 \\
\hline SP1 & 0.957 & & & & 0.916 & 0.084 \\
\hline SP2 & 0.956 & & & & 0.914 & 0.086 \\
\hline SP3 & 0.942 & & & & 0.887 & 0.113 \\
\hline SP4 & 0.715 & & & & 0.511 & 0.489 \\
\hline SP5 & 0.722 & & & & 0.521 & 0.479 \\
\hline OP1 & & & & 0.800 & 0.640 & 0.360 \\
\hline OP2 & & & & 0.785 & 0.616 & 0.384 \\
\hline OP3 & & & & 0.941 & 0.885 & 0.115 \\
\hline OP4 & & & & 0.724 & 0.524 & 0.476 \\
\hline OP5 & & & & 0.949 & 0.900 & 0.100 \\
\hline OP6 & & & & 0.961 & 0.924 & 0.076 \\
\hline
\end{tabular}

\section{Assessing Reliability, and Convergent and Discriminant Validity}

Composite Reliability (CR), Average Variance Extracted (AVE), Maximum Shared Variance (MSV), and the square root of AVE were calculated from the regression and correlation tables in the output of the CFA conducted on the Performance constructs. Table 8.48 below presents these indices.

Table 8.48 Reliability and Validity Indices of Performance Constructs

\begin{tabular}{|l|r|r|r|r|l|l|l|}
\hline & \multicolumn{1}{l|}{ CR } & \multicolumn{1}{|l|}{ AVE } & \multicolumn{1}{l|}{ MSV } & OP & EP & ENVP & SP \\
\hline OP & 0.946 & 0.748 & 0.699 & $\mathbf{0 . 8 6 5} * *$ & & & \\
\hline EP & 0.954 & 0.806 & 0.699 & $0.836^{*}$ & $\mathbf{0 . 8 9 8}^{* *}$ & & \\
\hline
\end{tabular}




\begin{tabular}{|l|r|r|r|r|r|r|l|} 
ENVP & 0.983 & 0.906 & 0.068 & $-0.189 *$ & $-0.261 *$ & $\mathbf{0 . 9 5 2 * *}$ & \\
\hline SP & 0.936 & 0.750 & 0.027 & $0.103 *$ & $0.165 *$ & $-0.068 *$ & $\mathbf{0 . 8 6 6 * *}$ \\
\hline
\end{tabular}

Note. *. The values in italics are correlation between constructs.

$* *$. The bold figures on the diagonal are the square roots of the respective AVE.

\section{Reliability}

Reliability maybe assessed by interpreting Cronbach's Alpha, which was calculated in sub-section 5.5.1 above and presented in Table 5.3. It was found that Cronbach's Alpha of each of the four constructs in Performance group (EP, ENVP, SP, and OP) was higher than 0.9 . This represented high reliability of the scale being used.

These constructs also displayed robust CR values of over 0.93 , which were well above the cut-off value of 0.8 , and indicated a high reliability of the constructs (Raykov, 1997).

\section{Validity}

Convergent validity of the scale may be ascertained by inspecting the standardized loadings of items on the constructs. It was observed from Table 8.47 that these loadings were all well above 0.7 and were interpreted to be excellent (Tabachnick \& Fidell, 2007) indicating high convergent validity.

The absolute values of AVE, of all the constructs, were higher than the recommended value of 0.500 indicating the high validity of the constructs.

Maximum Shared Variance MSV values for the four constructs were low and ranged from a low of 0.027 to a high of 0.699 and were lower than the corresponding 
AVE indicating good discriminant validity between the constructs. Also, CR values of each construct were higher than AVE values, indicating high discriminant validity.

\subsection{Structural Model Assessment}

\subsubsection{Drivers, SSCM Practices Adoption and Performance}

After the establishment of measurement models, statistical tests were conducted for assessing relationships between independent and dependent variables by running structural model in AMOS. The structural model was created on the basis of a priori theoretical framework which was presented as Figure 7.1.

In the left half of structural model, the Drivers are treated as independent variables, and SSCM Practices are treated as dependent variables (Figure 8.18). All the dependent variables carry an error term as mandated by AMOS software. AMOS treats all indicators as observed endogenous variables, and all of them carry an error term. The SSCM Practices constructs, i.e. EEP, IEP, SS, SM, CC, ED and SSP are treated as unobserved endogenous variables, as they are dependent variables for analyzing this relationship. The three Driver constructs, i.e., REG, COMP, and PRES are treated as unobserved, exogenous variables.

In the right half of the structural model the adoption of SSCM Practices adoption EEP, IEP, SS, SM, CC, ED and SSP act as independent variables; whereas Performance constructs, i.e., EP, ENVP, SP and OP act as the dependent variables. The four dependent 
variables are treated as unobserved endogenous variables by AMOS and carry error terms.

This makes a total or 173 variables in the model: 74 observed variables (consisting of the indicators), and 99 unobserved variables (consisting of the 14 latent constructs and 85 error terms that are connected to the indicators and the latent constructs).

The structural model constructed on the basis of the a priori theoretical framework was run in AMOS using Maximum Likelihood Estimation (MLE) method using the sample data collected in the survey. Figure 8.18 presents the structural model. 


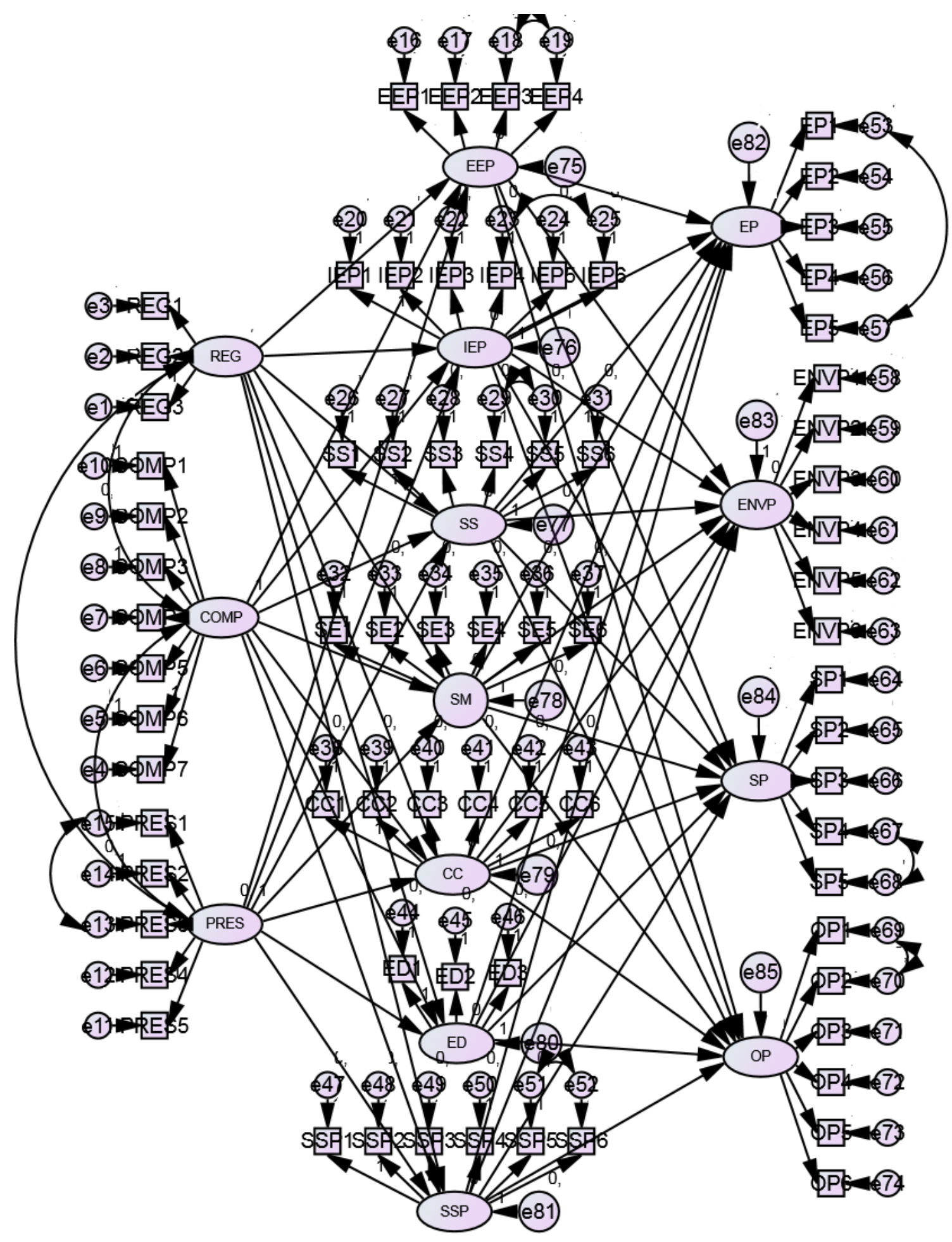

Figure 8.18 Structural Model 
The structural model fit indices are presented in the Table 8.55, and they indicate a good overall fit to the data.

Table 8.49 Fit Indices for the Structural Model

\begin{tabular}{|l|c|}
\hline \multicolumn{1}{|c|}{ Index } & \multicolumn{2}{c|}{ Value } \\
\hline CMIN/Df & 1.378 \\
\hline RMSEA & 0.042 \\
\hline CFI & 0.936 \\
\hline
\end{tabular}

The hypotheses $\boldsymbol{H 1 a}$ through $\boldsymbol{H} \mathbf{2 d}$ were examined in the light of the output from the run of the Structural Model in AMOS (attached as Appendix IX). It yielded the following findings.

H1a: Companies that face a higher level of regulations are more likely to adopt SSCM practices.

A statistically significant positive effect of Regulations on adoption of all seven SSCM Practices provided support for the hypothesis H1a. The statistically significant ( $p$ values $\geq 0.05)$ standardised coefficients of the paths that link Regulations to SSCM Practices were: EEP (0.711), IEP (0.766), SS (0.388), SM (0.812), CC (0.131), ED (0.234), and SSP (0.281).

H1b: Companies that aim to achieve a higher level of competitiveness are more likely to adopt SSCM practices. 
A statistically significant positive effect of competitiveness of a firm on adoption of four out of seven SSCM Practices provided partial support for the hypothesis H1b. The statistically significant ( $\mathrm{p}$ values $\geq 0.05$ ) standardised coefficients of the paths that link firm competitiveness to SSCM Practices were: SS (0.554), SM (0.146), CC (0.433), and ED (0.704). Firm competitiveness had a statistically significant negative effect on adoption of social sustainability practices (SSP, -0.125 ), and the impact on the adoption of EEP and IEP were observed to be not statistically significant.

H1c: Companies that face higher pressures from stakeholders are more likely to adopt SSCM practices.

A statistically significant positive effect of stakeholder pressures on adoption of six out of seven SSCM Practices was observed which provided partial support for the hypothesis H1c. The statistically significant ( $\mathrm{p}$ values $\geq 0.05$ ) standardised coefficients of the paths that link firm stakeholder pressures to adoption of SSCM Practices were: IEP (0.133), SS (0.162), SM (0.166), CC (0.334), ED (0.142), and SSP (0.909). The impact of stakeholder pressures on adoption of EEP was observed to be not statistically significant.

H2a: A company's economic performance is positively associated with the company's adoption of SSCM practices.

A statistically significant positive effect on a firm's economic performance was shown by the adoption of two SSCM Practices, which provided partial support for the hypothesis H2a. The statistically significant ( $p$ values $\geq 0.05$ ) standardized coefficients of the paths that link adoption of the two SSCM Practices to Economic Performance were 
ED (0.674), and CC (0.422) and they displayed a positive impact on EP. Adoption of SSP $(-0.147)$ elicited a statistically significant negative impact on economic performance. The other four SSCM practices, i.e., EEP, IEP, SS, and SM did not display any statistically significant impact on economic performance.

H2b: A company's environmental performance is positively associated with the company's adoption of SSCM practices.

A statistically significant positive effect on a firm's Environmental Performance was shown by the adoption of four SSCM Practices, which provided partial support for the hypothesis H2b. These were: SM (0.414), IEP (0.343), EEP (0.321), and SS (0.119), and they elicited statistically significant ( $\mathrm{p}$ values $\geq 0.05$ ) positive standardised coefficients. Adoption of SSP (-0.119) and ED (-0.214) showed a statistically significant negative impact on Environmental Performance. Adoption of CC practices did not elicit any statistically significant impact on the environmental performance.

H2c: A company's social performance is positively associated with the company's adoption of SSCM practices.

A statistically significant positive effect on a firm's Social Performance was shown by the adoption of SSP, which provided partial support for the hypothesis H2c. The path from SSP to Social Performance showed a statistically significant standardized coefficient ( $p$-value $\geq 0.05$ ) with a beta value of 0.754 . Adoption of the rest of the six SSCM practices, i.e., EEP, IEP, SS, SM, CC, and ED, did not show any statistically significant impact on the Social Performance. 
H2d: A company's operational performance is positively associated with the company's adoption of SSCM practices.

A statistically significant positive effect on a firm's operational performance was shown by the adoption of three SSCM Practices, which provided partial support for the hypothesis H2d. Adoption of ED (0.915), CC (0.151), and SS (0.078) showed a statistically significant ( $\mathrm{p}$ values $\geq 0.05$ ) positive impact on the Operational Performance of a firm. Figures in parenthesis are standardized coefficients of the paths that link adoption of the three SSCM Practices to Operational Performance. Adoption of EEP (0.081), SM (-0.124), and SSP (-0.150) showed a statistically significant negative impact on Operational Performance of a firm. Adoption of the seventh SSCM practice, i.e., IEP (0.025), did not show any statistically significant impact on the Operational Performance.

\subsubsection{Summary of Results}

It was observed that while H1a was supported by the SEM results, H1b, H1c, $\mathrm{H} 2 \mathrm{a}, \mathrm{H} 2 \mathrm{~b}, \mathrm{H} 2 \mathrm{c}$, and $\mathrm{H} 2 \mathrm{~d}$ were partially supported. The lack of full support was due to the findings that some factors had statistically insignificant impacts, and some others had a negative impact on dependent variables.

In the next chapter we discuss the results and implications of the research findings. 


\section{Chapter 9 Findings and Discussion}

The objective of this research was to study the effect of drivers on adoption of sustainable supply chain management practices, and further, the impact of adoption of sustainable supply chain management practices on the performance of the focal firm. The moderating effect of the size of a firm on the impact of adoption of SSCM practices on performance was also studied.

The following research questions were addressed in the research:

1. Do the key drivers, as identified in the literature, affect the adoption of SSCM practices by a firm?

2. Does the adoption of SSCM practices impact the economic, environmental, social and operational performance of a firm?

3. Does the size of a firm have a moderating effect on the impact that a company's adoption of SSCM practices may have on the company's economic, environmental, social and operational performance?

The conceptual framework was formed based on an extensive literature review.

The framework comprised of three distinct groups of theory-based constructs, which are: (1) Drivers, (2) SSCM Practices Adoption, and (3) Performance of the focal firm. In this chapter, first each sub-framework is discussed separately, and then their relationship with each other is discussed while interpreting the findings from the analyses presented in the previous chapters. The research framework with standardized regression coefficients is presented in Figure 9.1. 


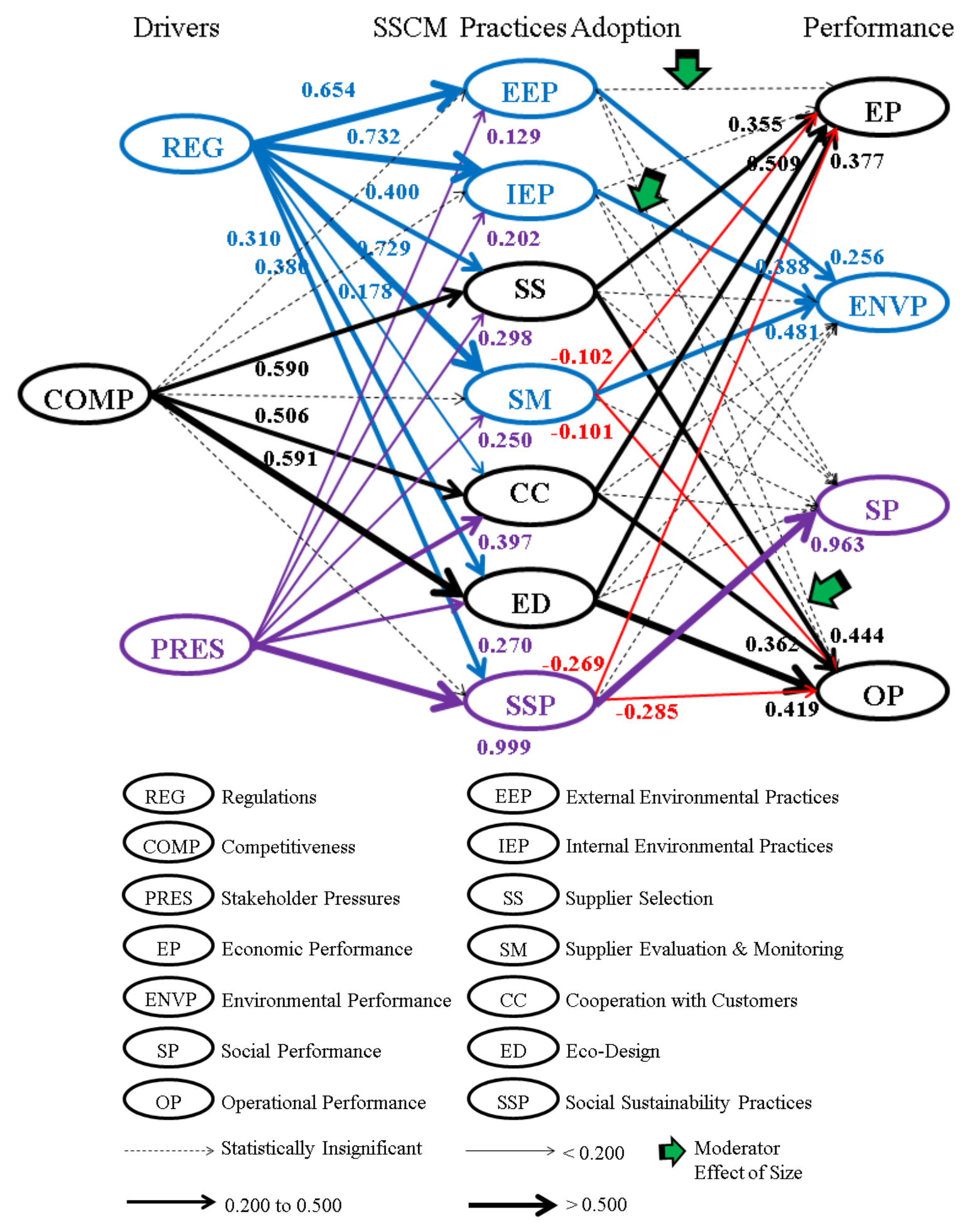

Figure 9.1 Research Framework with Standardized Regression Coefficients 


\subsection{Drivers, Sustainable Supply Chain Management Practices Adoption, and Performance}

This research is one of the early works that study the impact of these drivers on SSCM practices adoption and the effect of adoption of such practices on the performance of the focal firm, while the firm is considered as a unit of analysis. Published research has not studied the specific impact issues that were explored in this research in a composite manner (Wang \& Dai, 2018; Rajeev et al., 2017; Paulraj et al., 2017). Drivers that motivate the adoption of SSCM practices have been discussed in Section 3.3. It was seen that the influence of these drivers on SSCM practices adoption had not been empirically tested yet in the literature in the current context. Impact of size as a moderator on the impact of adoption of SSCM practices on the performance of the focal firm has also not been studied earlier.

\subsubsection{Drivers and SSCM Practices Adoption}

All the three drivers dealt with by this study - that is Regulations, Competitiveness and Stakeholder Pressures - have been posited to influence SSCM practice adoption in theory. Essentially, each one of these three represents a group of drivers (Mann et al., 2010), but based on underlying conceptual similarities; these multiple drivers have been grouped as three logical categories of drivers for parsimony, i.e., REG, COMP, and PRES. These driver constructs were regressed on SSCM practices adoption (section 7.2). 
Regression analyses indicated that the driver Regulations displayed a statistically significant positive impact on all the seven SSCM Practices, with standardized Betas ranging from to 0.178 to 0.732 (please see Figure 9.1 / Table 7.15). Competitiveness displayed a statistically significant positive impact on supplier selection practices, cooperation with customer practices and eco-design practices with standardized Betas ranging from to 0.506 to 0.591 . Stakeholder Pressure displayed a statistically significant positive impact on all the seven SSCM Practices, with the highest Beta for social sustainability practices. This was in line with findings Tate et al., (2010) and Carter and Easton (2011) who find that firms are under significant pressure from their stakeholders to adopt sustainable practices and reduce the environmental impact of their supply chains. Table 9.1 below presents the inference of the findings of the regression analyses referred above.

Table 9.1 Inference from the Findings of Multiple Regression Analyses: Regression of Drivers on SSCM Practices Adoption

\begin{tabular}{|c|c|c|c|}
\hline $\begin{array}{c}\text { Independent } \\
\text { Variables }\end{array}$ & $\begin{array}{c}\text { Dependent } \\
\text { Variables }\end{array}$ & Hypotheses & Inference \\
\hline Drivers: & \multirow{3}{*}{$\begin{array}{c}\text { SSCM } \\
\text { Practices } \\
\text { Adoption: } \\
\text { EEP, IEP, } \\
\text { SS, SM, } \\
\text { CC, ED, } \\
\text { SSP }\end{array}$} & $\begin{array}{l}\text { H1a: Companies that face a higher } \\
\text { level of regulations are more likely to } \\
\text { adopt SSCM practices. }\end{array}$ & Supported \\
\hline \multirow{2}{*}{$\begin{array}{l}\text { REG } \\
\text { COMP } \\
\text { PRES }\end{array}$} & & $\begin{array}{l}\text { H1b: Companies that aim to achieve a } \\
\text { higher level of competitiveness are } \\
\text { more likely to adopt SSCM practices. }\end{array}$ & $\begin{array}{l}\text { Partially } \\
\text { Supported }\end{array}$ \\
\hline & & $\begin{array}{l}\text { H1c: Companies that face higher } \\
\text { pressures from stakeholders are more } \\
\text { likely to adopt SSCM practices. }\end{array}$ & Supported \\
\hline
\end{tabular}




\subsubsection{SSCM Practices Adoption and Performance}

Adoption of all the seven SSCM practices taken up for the study, that is, EEP, IEP, SS, SM, CC, ED, and SSP have been posited to influence a firm's performance in theory. We had taken four types of performances for the research model: EP, ENVP, and SP (these three make the "Triple Bottom Line" of sustainability) and OP. The second set of regressions numbered 8 through 11 (please see Table 7.14) were run to test for the posited relationship between SSCM Practices Adoption and firm performance. That is, the seven independent variables EEP, IEP, SS, SM, CC, ED, and SSP were regressed first on variable EP as the first regression, and then the same independent variables were regressed on variable ENVP, and so on (please see Figure 9.1 / Table 7.17).

From the regression results, we observed that adoption of three types of SSCM Practices, i.e., SS, CC, and ED had a statistically significant positive impact on EP and OP. On the other hand, adoption of SSP and SM practices had a statistically significant negative impact on EP and OP. EEP and IEP do not show any statistically significant impact on these two performance types.

Adoption of EEP, IEP and SM had a statistically significant positive impact on Environmental Performance. Adoption of the other four SSCM Practices did not display any statistically significant impact on the Environmental Performance.

Adoption of Social Sustainability Practices displayed a high and statistically significant positive impact on Social Performance. Adoption of other six SSCM 
Practices did not have any statistically significant impact on Social Performance. Table 9.6 below presents the inference from the findings of the regression analyses referred above.

Table 9.2 Inference from the Findings of Multiple Regression Analyses: Regression of SSCM Practices Adoption on Performance

\begin{tabular}{|c|c|c|c|}
\hline $\begin{array}{c}\text { Independ } \\
\text { ent } \\
\text { Variable }\end{array}$ & $\begin{array}{l}\text { Dependent } \\
\text { Variables }\end{array}$ & Hypotheses & Inference \\
\hline \multirow{4}{*}{$\begin{array}{c}\text { SSCM } \\
\text { Practices } \\
\text { Adoption: } \\
\text { EEP, IEP, } \\
\text { SS, SM, } \\
\text { CC, ED, } \\
\text { SSP }\end{array}$} & $\begin{array}{c}\text { Economic } \\
\text { Performance: } \\
\text { EP }\end{array}$ & $\begin{array}{l}\text { H2a: A company's economic } \\
\text { performance is positively associated } \\
\text { with the company's adoption of SSCM } \\
\text { practices. }\end{array}$ & $\begin{array}{l}\text { Partially } \\
\text { Supported }\end{array}$ \\
\hline & $\begin{array}{l}\text { Environmental } \\
\text { Performance: } \\
\text { ENVP }\end{array}$ & $\begin{array}{l}\text { H2b: A company's environmental } \\
\text { performance is positively associated } \\
\text { with the company's adoption of SSCM } \\
\text { practices. }\end{array}$ & $\begin{array}{l}\text { Partially } \\
\text { Supported }\end{array}$ \\
\hline & $\begin{array}{c}\text { Social } \\
\text { Performance: } \\
\text { SP }\end{array}$ & $\begin{array}{l}\text { H2c: } \text { A company's social performance } \\
\text { is positively associated with the } \\
\text { company's adoption of SSCM } \\
\text { practices. }\end{array}$ & $\begin{array}{l}\text { Partially } \\
\text { Supported }\end{array}$ \\
\hline & $\begin{array}{c}\text { Operational } \\
\text { Performance: } \\
\text { OP }\end{array}$ & $\begin{array}{l}\text { H2d: A company's operational } \\
\text { performance is positively associated } \\
\text { with the company's adoption of SSCM } \\
\text { practices. }\end{array}$ & $\begin{array}{l}\text { Partially } \\
\text { Supported }\end{array}$ \\
\hline
\end{tabular}

\subsubsection{Effect of Size}

From the results of separate multiple regressions for small firms and larger firms, and from the subsequent t-tests conducted to detect whether the slopes of these regression lines were statistically different, it was inferred that size had a statistically significant and positive moderator effect on the impact of adoption of EEP on EP and OP. This indicated that for the larger firms the adoption of External Environmental Practices had a 
significant and positive impact on economic and operational performance, while this impact was significant but negative in case of small firms. This moderator effect of size is supported by Resource-Based View according to which larger firms have greater resources and therefore can leverage these resources for better performance. Size also elicited a statistically significant and positive moderator effect on the impact of adoption of IEP on ENVP. In all the other cases the effects of size were found to be statistically not significant.

Table 9.3 below summarises the findings of the test results and the support they lend to the hypotheses H3a to H3d.

Table 9.3 Findings of Multiple Regression Analyses and t-Tests: Effect of Size as a Moderator

\begin{tabular}{|c|c|c|c|}
\hline $\begin{array}{c}\text { Independe } \\
\text { nt } \\
\text { Variable }\end{array}$ & Effect & Hypotheses & $\begin{array}{c}\text { Inferenc } \\
\text { e }\end{array}$ \\
\hline \multirow{4}{*}{ Size } & \multirow{4}{*}{$\begin{array}{l}\text { Posited to } \\
\text { Moderate } \\
\text { Impact of } \\
\text { SSCM } \\
\text { Practices } \\
\text { Adoption on } \\
\text { Performance }\end{array}$} & $\begin{array}{l}\text { H3a: The bigger the firm size, the } \\
\text { greater is the impact of company's } \\
\text { adoption of SSCM practices on the } \\
\text { company's economic performance. }\end{array}$ & $\begin{array}{c}\text { Partially } \\
\text { Supporte } \\
\text { d }\end{array}$ \\
\hline & & $\begin{array}{l}\text { H3b: The bigger the firm size, the } \\
\text { greater is the impact of company's } \\
\text { adoption of SSCM practices on the } \\
\text { company's environmental performance. }\end{array}$ & $\begin{array}{l}\text { Partially } \\
\text { Supporte } \\
\text { d }\end{array}$ \\
\hline & & $\begin{array}{l}\text { H3c: The bigger the firm size, the } \\
\text { greater is the impact of company's } \\
\text { adoption of SSCM practices on the } \\
\text { company's social performance. }\end{array}$ & $\begin{array}{c}\text { Not } \\
\text { Supporte } \\
d\end{array}$ \\
\hline & & $\begin{array}{l}\text { H3d: The bigger the firm size, the } \\
\text { greater is the impact of company's } \\
\text { adoption of SSCM practices on the } \\
\text { company's operational performance. }\end{array}$ & $\begin{array}{c}\text { Partially } \\
\text { Supporte } \\
\text { d }\end{array}$ \\
\hline
\end{tabular}




\subsection{Patterns in Results}

A number of interesting insights were gained from the results discussed above. On viewing the results from a broader perspective, they seemed to present a specific pattern of relationships. The following subsections discuss the possible reasons and logic for the existence, strength, and direction of these relationships.

\subsubsection{Different Drivers Impact Adoption of SSCM Practices Differently}

It was observed from the results that different drivers impact the adoption of SSCM Practices differently. Regulations influence adoption of EEP, IEP, and SM positively to a greater extent; Competitiveness had a greater influence on adoption of SS, CC, and ED; and Stakeholder Pressures show the greatest influence on SSP. So while the SSCM Practices EEP, IEP and SM 'went together,' and such was again the case with SS, CC, and ED, while SSP was observed to be distinctly separate from these two groups.

\subsubsection{What connects External Environmental Practices, Internal \\ Environmental Practices and Supplier Evaluation and Monitoring}

The dividing line between External Environmental Practices and Internal Environmental Practices is basically there for the purposes of classification. These two types of practices are complementary to each other, both being organizational environmental practices. The close association of Supplier Evaluation and Monitoring with these two constructs, EEP and IEP, observed in the results are easier to interpret when we view Supplier Evaluation and Monitoring in the context of being an ongoing 
environmental practice. From that standpoint, SM spans both EEP and IEP and is expected to have a high level of association with them as seen in the results. Adoption of these three SSCM Practices is positively impacted by the driver Regulations, and these three practices, in turn, produce a significant positive impact on the environmental performance of the focal firm.

It is observed that with a rise in awareness of environmental degradation worldwide, firms are faced with an increasing number of regulations in the environmental domain. To ensure compliance with regulations, firms adopt a set of SSCM Practices that enable them to meet with the requisite norms because supply chain management plays a pivotal role in determining what impact a firm has on the environment (Handfield et al., 2005; Isaksson et al., 2010). The environmental norms, for example, may be a required percentage of recycled content in the paper, or it may be maximum emission or effluent level permitted for chemical industry. These are specific targets that have to be achieved by the firms in cooperation with their supply chains. The findings from this research indicate that in the face of regulations firms adopt a specific set of external environmental practices, and a set of internal environmental practices, along with close evaluation and monitoring of their suppliers. Adoption of these practices results in a better environmental performance which helps these firms in meeting the norms prescribed by those regulations. These results are in line with the findings of Esfahbodi et al., (2017) who found that adoption of SSCM Practices leads to improved environmental performance. 


\subsubsection{What connects Supplier Selection, Cooperation with Customers and Eco-Design}

The dividing line between Supplier Selection and Cooperation with Customers is normally thought to be distinct. One is related to the selection of suppliers and other to the diametrically opposite end-of-supply-chain, which is a customer. But when considering the objective of these two practices, they may be viewed as being closely related. For example, if a firm selects a supplier based on their environmental competence and performance, for supplier's ability to develop environmentally friendly products, to achieve its environmental objectives, and uses the ISO14000 documentation process and rating systems to achieve those objectives, the entire protocol is very akin to what the firm is conducting with its customers to attain its sustainability goals. In cooperation with its customers, the focal firm works to achieve cleaner production, ecodesigns its products and processes to attain that, uses green packaging and transportation and creates a formally-articulated mutual understanding with its customers to accomplish its environmental objectives with the clear aim to reduce environmental impact. These two activities with both suppliers and customers are closely related, or even mirror image of each other, and aim to achieve the same sustainability objectives, especially from the point of view of a supply chain expert, who is trained to perceive every supply chain activity as an operationally connected un-broken chain. Eco-design weaves into this seamlessly as it requires close interaction with, and cooperation of, both the suppliers and the customers of the focal firm. From this standpoint, it is not surprising that these three constructs (SS, CC, and ED) are seen to be 'going together' in research findings. 
A significant number of firms are oriented towards attaining a sustained competitive advantage for better economic performance. To gain this advantage, these firms are prone to adopt a set of SSCM Practices that enable them to have close cooperation with their suppliers and customers and to design their products and processes to meet with higher environmental standards. With the systematic adoption of SSCM Practices, the focal firm develops the embedded sustainable supplier management capabilities; and these path dependent dynamic capabilities of the focal firm are a critical source of sustained competitive advantage and superior firm performance (Reuter et al., 2010). The findings from this research support this theory and indicate that competitiveness has a positive impact on the adoption of SSCM Practices and that adoption of SSCM Practices like supplier selection practices, cooperation with customers and eco-design of products and processes results in better economic performance. These findings are further supported by Resource-Based View; as by adopting these SSCM practices firm can attain a positive reputation which can lead to sustained competitive advantage and improved firm performance (McWilliams \& Siegel 2011; Barney, 2012). These research findings are also supported by the theory of ethical egoism, which assumes that competitive firms are more likely to adopt suitable SSCM Practices if the adoption profits the focal firm (Paulraj et al., 2017).

These research findings find an echo in the words of Montabon et al., (2016) who note that, "the vast majority of research and practice regarding sustainable supply chains has followed an instrumental logic, which has led firms and supply chain managers to place economic interests ahead of environmental and social interests" (p.11). But we 
would not view these findings in a pessimistic way. We would argue that these competitive firms embrace a positive perspective and that this perspective is supported by the theory of utilitarianism (Bentham, 1789). The firms that are driven by competitiveness, adopt SSCM Practices, and perform economically better are not only maximizing utility for the highest number of people, but they may also be found to be the 'last firms standing' when all others close their shop for being economically unviable. Being competitive and endeavoring to make healthy profits is a drive that powers businesses. Taking sustainability concerns in the stride is what we are aiming at. The research findings underscore the same very holistic perspective as we were hoping for. If carried on in the right earnest the drive to be competitive through adopting SSCM practices may be the 'light at the end of the tunnel' of ongoing sustainability discourse in finding the answer to the question: does it pay to be green? (Golicic \& Smith 2013).

\subsubsection{What makes Social Sustainability Practices stand alone}

Social Sustainability Practices are not traditionally seen as related to hard-core supply chain management activities. SSP constitute preferred practices in the context of codes of conduct, corporate social responsibility, voluntary or charitable activities, staff welfare, and may sometimes also relate to regulations, institutional norms or stakeholder expectations. For example, in the sphere of equal opportunity, employment regulations play an important role, and in the sphere of social responsibility, CSR regulations play a key role. So, it is not expected that these practices have a high association with other SSCM practices, which is supported by our research findings. In our results, we found 
that the SSP was seen to be not highly correlated with EEP, IEP, SS, SM, CC, or ED in the analyzed results. It was also observed that stakeholder pressures emerged to be the most important driver for SSP. This observation is supported by the research findings of Tate et al., (2010) and Carter \& Easton (2011) that firms are under significant pressure from their stakeholders to adopt sustainable practices.

At the same time, while SSP was observed to be positively and statistically significantly affecting social performance, regression analyses results showed that it negatively impacted the operational and economic performance of a firm. A logical explanation for this is, considering other relationships materializing from the results, that firms incur additional costs for adopting SSP, and the operational processes that are needed to implement SSP are not perfectly aligned with operational and economic objectives of the firm, causing this negative impact on operational and economic performance. This negative impact is in line with the research of Hahn et al., (2010) and Winn et al., (2012) who find that adoption of SSCM practices may have negative impacts on economic performance.

\subsubsection{Significant findings}

A number of interesting findings come to light on analysis of the data collected based on the theoretical model posited by this study. The most significant are enumerated and discussed below.

First, it may be noted that presently most manufacturing firms are significantly impacted by sustainability regulations to some extent at this point. The firms are seen to 
select and implement those set of practices that best enable them to comply with the above-mentioned regulations. Since most sustainability regulations relate to the environment, firms tend to adopt external and internal environmental practices and closely evaluate and monitor the performance of their suppliers. As seen from the results of this study the adoption of these SSCM practices helps firms achieve their environmental performance objectives, as these three SSCM practices have highly positive and statistically significant impact on the environmental performance of the firm.

Second, we find that there are some important and significant regulations that cover the domain of corporate social responsibility and equal opportunity employment. The results of this study highlight the fact that regulations do have a positive and statistically significant impact on the adoption of social sustainability practices, with a high partial effect of 0.586 . Adoption of these social sustainability practices has a positive and statistically significant impact on the social performance of the focal firm. Thus, it is seen that regulations play an important role in this arena.

Third, the driver Regulations drives firms to adopt those SSCM Practices (EEP, IEP, and SM) which help them to be compliant, but adoption of those practices has no significant impact on the economic and operational performance of the focal firm. This is in line with research findings of Esfahbodi et al., (2017) and Wang and Dai (2018) who observe that while adoption of environmental management practices has a positive impact on environmental performance, they do not have any significant effect on economic performance. 
Fourth, the strategic emphasis on the competitiveness of a firm drives it to focus on the economic performance, while taking the concerns of sustainability in its stride as a given. Such a firm leverages suitable SSCM practices as tools that will enable it to meaningfully exploit newer opportunities. They try to out-perform the competitors who are 'stuck in regulatory quagmire' by attaining dynamic capabilities that set them apart and bestow upon them the sustained competitive advantage arising from these dynamic capabilities (Reuter et al., 2010). Thus, it is seen that indicators such as "we believe that our environmental activities will differentiate us from our competitors"; "we believe that our ecological responsiveness will lead to long-term profitability"; and "access to overseas market is the main driver for adoption of proactive environmental strategies" load well on the construct Competitiveness and show the orientation of the firm towards achieving better economic performance while, at the very same time, aligning the sustainability practices to achieve their sustainability goals. For this, the firms focus on SSCM practices encompassing the entire supply chain. These practices start right from those specific to suppliers, such as selecting suppliers based on their ability to support the firm's environmental objectives or their ability to develop environmentally friendly goods, to those that entail close cooperation with customers. These practices also cover eco-design which entails working closely with suppliers and customers alike for designing environmentally friendly products and processes. This holistic approach in adopting SSCM practices with the aim of achieving superior economic performance sets these firms apart from those that are focussed on merely complying with the regulations. These firms seem to follow the advice of Carter and Rogers (2008) to adopt those 
environmental practices that are suited to superior economic performance. Such strategic positioning regarding competitiveness is expected to positively and statistically significantly affect the adoption of suitable SSCM practices, which in turn have a positive and significant impact on economic and operational performance; and this is supported by the results of this study. This is in line with the research findings of Paulraj et al. (2017) that those firms that go beyond mere compliance and are pro-active, and adopt SSCM practices like eco-design of products and processes, collaboration with suppliers and customers are likely to show a better financial performance.

Fifth, Stakeholder pressures on a firm arise from its customers, investors, lenders, employees, the social milieu it is embedded in, the media, lawmakers, judiciary, nonprofit organizations and academia. These expectations channel firm activities toward a committed and responsible course of action, i.e., to "do the right thing" (Bronn \& Vidaver-Cohen, 2009, p.87). Our study finds support for this argument. Stakeholder pressures motivate a firm to adopt various combinations of SSCM practices. The strongest effect of this pressure is seen to urge adoption of social sustainability practices (Beta $=0.9)$. This result is supported by the research of Bronn and Vidaver-Cohen (2009) who found that a high majority (92\%) of the respondents agreed that fulfilling stakeholder expectations was an important motive to undertake social initiatives.

But that is not the sole focus of such pressures. Stakeholder pressures impact positively and statistically significantly the adoption of the other six SSCM practices as well, right from supplier selection, supplier evaluation, and monitoring, through to 
external and internal environmental practices, eco-design, and cooperation with customers. This impact of stakeholder pressures on adoption of SSCM Practices may be interpreted as the impact of a wide spectrum of stakeholders when viewed with an Organization-Stakeholder Fit (O-S fit) lens proposed by Bundy et al. (2018). Bundy et al., (2018) build upon stakeholder theory to posit the existence of an OrganizationStakeholder Fit ( $O-S$ fit) to emphasize the importance of "the supplementary fit of organizational and stakeholder values, and...the complementary fit of strategic needs and resources" (p.476). This is supported by the findings of our research where stakeholder pressures on a firm to act on values which the stakeholders hold dear (in this case, sustainability) are seen to positively influence the adoption of SSCM Practices by the focal firm, which in turn significantly impacts the firm performance. This is in line with the observations of Graafland and Van de Ven (2006) and Fernando and Almeida (2012) that moral pressures can lead to closer adherence to corporate social responsibilities and have a high correlation with the firm's performance.

Sixth, the impact of social sustainability practices is greatest on the social performance of the focal firm, borne out by the fact that this study has found a high positive and statistically significant relationship with the social performance of the firm. A significant but negative impact of SSP is seen on economic performance and operational performance. This may be interpreted as the cost of those practices, and that these social sustainability practices take attention away from the core operational functions. There is no significant impact of the adoption of social sustainability practices 
on the environmental performance, and rightly so, because the social sustainability practices focus on social domain.

Seventh, the size of the focal firm acts as a moderator on the impact that adoption of SSCM practices has on performance. While this moderator effect has been found to be not significant on the impact of the other SSCM practices, this moderator effect has been found to be significant and positive on the impact of adoption of the External Environmental Practices on Economic Performance and Operational Performance, and also on the impact of adoption of IEP on Environmental Performance. It may be logical to conclude that larger firms have greater resources to leverage the adoption of these practices into dynamic capabilities for a sustainable competitive advantage for a better economic, operational, and environmental performance, while the small firms with the adoption of the same practices are not able to do as much. These findings are strongly supported by the Resource-Based View and Resource Dependence Theory (Barney, 2012; McWilliams \& Siegel 2011; Reuter et al., 2010). This moderator effect was not significant in the case of social performance. Drawing from the embeddedness theory (Granovetter, 1985) it may be argued that small firms seem to be equally effective in achieving its social performance goals, because the small firms are strongly embedded in the social milieu, and they gain an advantage out of this embeddedness which seems to offset the advantages of greater resources of larger firms. 


\section{Chapter 10 Conclusion}

\subsection{Conclusion}

In this research, we examined the impact of various factors that motivate firms to adopt SSCM practices. Furthermore, we also studied whether adoption of these SSCM practices has an impact on the "triple bottom line" and operational performance of a firm. We also factored in the effect of the size of the firm within this context.

This chapter summarises the salient findings of the thesis by providing a conclusion to the research. We conclude this document by discussing academic contributions of this research, implications for practitioners, limitations of this study, and possible directions of future research.

\subsection{Academic Contribution of this Research}

We investigated the relationship between motivating factors and adoption of SSCM practices, first through an expansive literature review of the related areas and then through validation via an empirical study. Further, we studied the impact of the adoption of SSCM practices on the economic, environmental, social and operational performance of the firm. This empirical study fills the gap in the literature in this research area by demonstrating and elucidating nuanced paths of causality between the drivers and adoption of the practices of SSCM as well as the adoption of the practices and performances of the firm. This exploratory research has supported theory development in the area of adoption of different sustainable supply chain management practices. The 
premise put forth consolidates and logically links some loosely connected theoretical aspects that were generated from the literature review, and tests them using empirical research. This data analysis and the results generated from this research enable an indepth understanding of what drives the adoption of SSCM practices and what impact these practices have on the performance of firms. This research also studies the effect of the size of the focal firm as it relates to the relationship between the adoption of SSCM practices and firm performance.

This research presents a robust research framework which has been developed using the multiple needs theory (Maslow, 1954; Alderfer, 1969), which underlines that at any given time, multiple needs may be driving any actor (firm) at that point of time. The study explores these multiple needs in the form of main drivers of SSCM Practices Adoption, i.e., Regulations, Competitiveness, and Stakeholder Pressures, all of which drive or motivate the adoption of these practices to various extents. Though the impact of various drivers had been studied earlier, it had not been done in a comprehensive manner. Earlier researches have dealt with only select drivers individually and have lacked a comprehensive approach (Mann et al., 2010). In contrast, each of the drivers considered in this research in effect represents a composite group of drivers, and this method covers the drivers, and their impacts, comprehensively and not in piecemeal manner. This overarching view was missing in the existing literature.

The majority of existing research on sustainability focuses on consequences rather than precursors of the sustainable practices, (Aguilera et al., 2007; Bronn \& Vidaver- 
Cohen, 2009; Paulraj et al., 2017) and research on drivers and their effect on a firm's performance has been sparse (Fresner,1998; Kjaerheim, 2005) in the area of cleaner production. Bronn and Vidaver-Cohen (2009, p.92) emphasize that "studying antecedents can make a particularly useful contribution to the literature." By incorporating the drivers of SSCM Practices Adoption into this research and by exploring these precursors or drivers in a comprehensive way, this study bridges this gap substantially and contributes to the existing literature in the sustainability field.

This study also adds significantly to quantitative SSCM research, as most researchers have studied these relationships using qualitative methods "and large-scale quantitative analyses remain very limited" (Paulraj et al., 2017, p.252).

Academically this research provides a tested framework for developing a theory on what drives firms to adopt SSCM practices, and what impact adoption of these practices has on the economic, environmental, social, and operational performance of the focal firm. Development of theory is the sine qua non for bringing the academics and practitioners on the same page about the theoretical connections between drivers, SSCM practices adoption, and performance. The contribution of this study is especially significant when viewed in light of the observations of Markman and Krause (2014) who explicitly state in their editorial on a special issue of Journal of Supply Chain Management on theory building in SSCM, "our own research of the 500 most cited studies on sustainability shows that scholars and managers often struggle with the concept and applications of sustainability." Thus, substantiating theoretical underpinnings 
of what is happening in the field is what validates this research and its importance. This research framework presented here comprehensively incorporates the main drivers, practices, and performances, and their inter-relationships, which enables simultaneous and multi-level exploration of a complex network of factors (Aguilera et al., 2007, Paulraj et al., 2017) and academics will be able to use this model for future research.

\subsection{Implications for Regulators and Managers}

The results of this research have significant implications for practitioners, both within the government and industry.

This study will help regulators to gain a deeper insight into the impact of regulations in prompting firms to adopt sustainable supply chain management practices. It would also help them to understand what impact the adoption of these practices has in turn on the performance of those firms. That the regulations play an important role in "encouraging" firms to adopt SSCM practices has been confirmed by this study. The finding that the impact of adoption of some SSCM practices has a negative impact on the economic and operational performance of small firms, while at the same time the impact is positive for the larger firms, provides valuable insights. It strongly suggests that the regulators need to keep the impact of regulations in mind, especially for small firms. In light of the negative impact of adoption of some SSCM practices, regulators may need to look at a judicious mix of penalties and subsidies so that firms, particularly the small ones, do not go out of business. It is also important to note that firms are in the active 
process of adopting these SSCM practices, as evident from the fact that ISO14000 certification is still growing, the regulations need to be actively and periodically reviewed to cater to the dynamically changing needs. Also required is close coordination with regulators in other countries, as while the sustainability concerns are being increasingly shared by a larger number of states as shown by the data, differential regulations may tend to shift supply chain operations to areas with softer regulations defeating the overall global objective. This research would thus help regulators to adapt regulations to real-life situations.

Business managers would be able to understand the different impacts of the drivers and the impact of adoption of SSCM practices on performance and tailor their long-term strategy and plans in light of this research. This study brings out that while focussing on competitiveness, adoption of suitable SSCM practices creates a positive impact on economic and operational performance. For attaining these performance objectives cooperation with customers, selection of appropriate suppliers, and eco-design of products and processes may be good SSCM practices to adopt. The focus on competitiveness stands out in contrast with solely aiming at complying with the regulations, where the adoption of SSCM practices leads to better environmental performance, but it has no significant impact on economic or operational performance. In the geek parlance, 'what you aim is what you get,' so firms should seek out and adopt those practices that, while meticulously meeting the sustainability requirements, also focus on a better economic and operational performance. The practitioners will also benefit from the findings that underline the importance of creating dynamic capabilities 
that help in better management of a suitable supplier base and create a sustained competitive advantage for the focal firm. The appointment of sustainability officers in firms, responsible for monitoring sustainability issues, may be an idea worth considering; till such time that the firm's culture can truly absorb the resultant changes. The small firms will find it interesting to study what other things the larger firms are doing while adopting the same SSCM practices that make them perform better, their greater resources notwithstanding.

\subsection{Limitations}

The research is limited by the fact that the data sample has been obtained mainly from developed countries (specifically North America) which would imply that further research would be required in order to generalize the results to firms operating in EU or developing countries which have different socio-economic parameters due to vastly different market and growth trajectories as well as different set of driving motivations and restrictions that are tied to their specific contexts. Also, as sustainability is still an evolving field, there may be a possibility that the data that may initially be perceived as statistical outliers may actually be a useful source of different insight for evolving newer and innovative practices (Singhal \& Singhal, 2012) rather than just statistical 'noise.' So, while studying a large number of "relatively unsustainable" supply chains to learn about sustainability, a small number of innovative supply chains may have been left out of focus which are doing things differently and are more sustainable (Pagell \& Shevchenko, 2014). The study is also limited by some other sample characteristics. The sample was 
not random, and the large size firms had a lower representation in the sample. A bigger and random sample would add value to any such future research.

Finally, the study by its design has utilised the focal firm as the unit of analysis, and its SSCM practices and while it may be reasonable to deduce from previously tested literature that the focal firm determines the behaviour and practices in the supply chain to a great extent; but there may be cases where their impact of may not necessarily mirror SSCM practices of entire supply chain and the resulting impact on performance.

\subsection{Future Research}

There are many possible extensions of this research, depending on the scope a scholar wishes to commit to. A natural extension of the study can be an endeavor to cross-check generalizability of this research. For comparative insights into the relationships investigated here, and to increase generalizability, the research can be conducted over other geographical areas not fully covered by this research. Such a study may yield an understanding of the contextual differences that stem from the socioeconomic conditions of various geographies.

Further, there is potential for a larger number of sustainable supply chain management practices to be included in the study. It would be interesting to see whether the relationships hold true for other SSCM practices as well. Another possible direction is conducting a qualitative study, which would add further depth to the understanding of the relationships and may add newer theoretical dimensions. The richness of the interview data may lead to results that have not been considered in the literature thus far. Also, 
area-expert interviews would produce thoughts or leads related to the future direction for sustainable supply chains or views on changes in regulations or even feedback on which performance measures are perceived useful in the field (and can be converted into key performance metrics) and which ones aren't.

Regulations that are stringent may adversely affect the businesses and their performance; work in this area is of critical importance. This aspect needs further research. Within the context of transnational supply chains, the regulations may differ from country to country, and various supply chain partners may actually be chosen because of lax regulations in some countries. That may be counter to the premise that the entire supply chain works towards sustainable supply chain management practices. The changing ideology within a single supply chain based on functionality is an underexplored yet fascinating topic. This is another area that requires substantial further research.

The presented research framework also has great potential to trigger qualitative as well as quantitative research in many critical areas of sustainability, once a standard scale is developed to assess the level of sustainability of organizations within various industries. Thus, a number of potential research questions can be worked upon as extensions of this study and the resultant findings. 


\section{References}

Abbasi, M., \& Nilsson, F. (2012). Themes and challenges in making supply chains environmentally sustainable. Supply Chain Management: An International Journal, 17(5), 517-530.

Abdi, H. \& Williams, L.J. (2010). Principal component analysis. WIREs Comp Stat, 2, 433-459. Available at http://www.utdallas.edu/ herve/abdi-awPCA2010.pdf

Abukhader, S. \& Jonson, G. (2004). Logistics and the environment: is it an established subject? International Journal of Logistics: Research and Applications, 7(2), 17149.

Agarwal, R. \& Karahanna, E. (2000). Time flies when you're having fun: Cognitive absorption and beliefs about information technology usage. MIS Quarterly, 24(4), 665-694.

Agrawal, S., Singh, R.K., \& Murtaza, Q. (2015). A literature review and perspectives in reverse logistics. Resources, Conservation and Recycling, 97, 76-92.

Aguilera, R. V., Rupp, D. E., Williams, C. A., \& Ganapathi, J. (2007). Putting the S back in corporate social responsibility: A multilevel theory of social changes in organization. Academy of Management Review, 32(3), 838-863.

Aguinis, H. (2004). Regression analysis for categorical moderators. New York, NY: Guilford Press.

Ahi, P., \& Cory, S. (2013). A comparative literature analysis of definitions for green and sustainable supply chain management. Journal of Cleaner Production, 52, 329-341. 
Ahi, P., \& Searcy, C. (2015). An analysis of metrics used to measure performance in green and sustainable supply chains. Journal of Cleaner Production, 86, 360-377.

Alderfer, C. P. (1969). An empirical test of a new theory of human needs. Organizational Behavior and Human Performance, 4, 142-175.

Alexander, A., Walker, H., \& Naim, M. (2014). Decision theory in sustainable supply chain management: a literature review. Supply Chain Management: An International Journal, 19(5/6), 504-522.

Allison, P.D. (1999). Multiple regression: A primer. Thousand Oaks, CA: Pine Forge Press.

Amann, M., Roehrich, J.K., Eßig, M., \& Harland, C. (2014). Driving sustainable supply chain management in the public sector: The importance of public procurement in the European Union. Supply Chain Management, 19( 3), 351-366.

American Chamber of Commerce of Europe. (2004). European Union Environmental Guide 2004. Brussels, Belgium: American Chamber of Commerce of Europe.

Anderson, J. C., \& Gerbing, D.W. (1988). Structural Equation Modelling in Practice: A Review and Recommended Two Step Approach. Psychological Bulletin, 103(3): 411-423.

Angell, L., \& Klassen, R. (1999). Integrating environmental issues into the mainstream: an Agenda for research in operations management. Journal of Operations Management, 17, 579-598.

Armstrong, J. S., \& Overton, T.S. (1977). Estimating Nonresponse Bias in Mail Surveys. Journal of Marketing Research, 14(3), 396-402. 
Ashby, A., Leat, M., \& Hudson-Smith, M. (2012). Making connections: a review of supply chain management and sustainability literature. Supply Chain Management: An International Journal, 17(5), 497-516.

Atasu, A., Guide, V.D.R., \& Van Wassenhove, L.N. (2008). Product reuse economics in closed-loop supply chain research. Production and Operations Management, 17(5), 483-496.

Attaran, M. \& Attaran, S. (2007). Collaborative supply chain management: The most promising practice for building efficient and sustainable supply chains. Business Process Management Journal, 13(3), 390-404.

Austin, P.C., \& Steyerberg, E.W. (2015). The number of subjects per variable required in linear regression analyses. Journal of Clinical Epidemiology, 68, 627-636.

Azadi, M., Jafarian, M., Farzipoor S.R., \& Mirhedayatian, S.M. (2015). A new fuzzy DEA model for evaluation of efficiency and effectiveness of suppliers in sustainable supply chain management context. Computers \& Operations Research, $54,274-285$.

Bagozzi R. P \& Yi, Y. (1990). Assessing Method Variance in Multitrait-Multimethod Matrices: The Case of Self-Reported Affect and Perceptions at Work. Journal of AppliedPsychology, 75(5), 547-560.

Bagozzi, R., \& Yi, Y. (2012). Specification, evaluation, and interpretation of structural equation models. Journal of the Academy of Marketing Science, 40(1), 8-34. 
Bai, C., Sarkis, J., Wei, X., \& Koh, L. (2012). Evaluating ecological sustainable performance measures for supply chain management. Supply Chain Management, 17(1), 78-92.

Bai, C., Sarkis, J., \& Wei, X. (2010). Addressing key sustainable supply chain management issues using rough set methodology. Management Research Review, 33(12), 1113-1127.

Baker, G.P., \& Hall, B.J. (2004). CEO Incentives and Firm Size. Journal of Labor Economics, 22(4), 767-798.

Baldwin B. (1989). A Primer in the Use and Interpretation of Structural Equation Models. Measurement and Evaluation in Counseling and Development, 22(2), 100-112.

Bansal, P., Roth, K. (2000). Why companies go green: a model of ecological responsiveness. Academy of Management Journal, 43(4), 717-736.

Barney, J. B. (2012). Purchasing, supply chain management and sustained competitive advantage: The relevance of resource based theory. Journal of Supply Chain Management, 48(2), 3-6.

Baron, R. M., \& Kenny, D. A. (1986). The moderator-mediator variable distinction in social psychological research: Conceptual, strategic, and statistical considerations. Journal of Personality and Social Psychology, 51(6), 1173-1182.

Baron, R. M., \& Kenny, D. A. (1986). The moderator-mediator variable distinction in social psychological research: Conceptual, strategic, and statistical considerations. Journal of Personality and Social Psychology, 51(6), 1173-1182. 
Barrett, P. (2007). Structural equation modelling: adjudging model fit. Personality and Individual Differences, 42, 815-824.

Bastian, J., \& Zentes, J. (2013). Supply chain transparency as a key prerequisite for sustainable agri-food supply chain management. International Review of Retail, Distribution \& Consumer Research, 23(5), 553-570.

Baumann, H., Boons, F., \& Bragd, A. (2002). Mapping the green product development field: engineering, policy and business perspectives. Journal of Cleaner Production, 10(5), 409-425.

Benito-Osorio, D., Zúñiga-Vicente, J.Á., \& Colino, A. (2015). The link between product diversification and performance among Spanish manufacturing firms: Analyzing the role of firm size. Canadian Journal of Administrative Sciences, 32(1), 58-72.

Bentham, J. (1789) [PML]. An Introduction to the Principles of Morals and Legislation. Oxford: Clarendon Press, 1907. Cited in The History of Utilitarianism. Available at https://plato.stanford.edu/entries/utilitarianism-history/ Accessed on $5^{\text {th }}$ January, 2018.

Beske, P. (2012). Dynamic capabilities and sustainable supply chain management. International Journal of Physical Distribution \& Logistics Management, 42(4), $372-387$.

Beske, P., Land, A. \& Seuring, S. (2014). Sustainable supply chain management practices and dynamic capabilities in the food industry: A critical analysis of the literature. International Journal of Production Economics, 152, 131-143. 
Beske, P., \& Seuring, S. (2014). Putting sustainability into supply chain management. Supply Chain Management: An International Journal, 19(3), 322-331.

Beske, P., Land, A. \& Seuring, S. (2014). Sustainable supply chain management practices and dynamic capabilities in the food industry: A critical analysis of the literature. International Journal of Production Economics, 152, 131-143.

Beske-Janssen, P., Johnson, M.P., \& Schaltegger, S. (2015). 20 years of performance measurement in sustainable supply chain management - what has been achieved? Supply Chain Management: An International Journal, 20(6), 664-680. doi: 10.1108/SCM-06-2015-0216

Bhatia, N., \& Chand, M. (2014). ANP based model for the identification of select issues of Green Supply Chain Management (GrSCM). International Journal of Applied Engineering Research, 9 (4 Spec. Issue), 469-475.

Blanc, S., Ducq, Y., \& Vallespir, B. (2007). Evolution management towards interoperable supply chains using performance measurement. Computers in Industry, 58(7), 720-732.

Blome, C., \& Paulraj, A. (2013). Ethical climate and purchasing social responsibility: A benevolence focus. Journal of Business Ethics, 116(3), 567-585.

Bollen, K. A. (1989). Structural Equations with Latent Variables. New York, John Wiley $\&$ Sons.

Bolotova, Y.V. (2016). Food Manufacturing Industry in South Carolina: An Analysis of the Size, Structure, and Performance. Journal of Food Distribution Research, $47(1), 12-17$. 
Boomsma, (1987). The Robustness of Maximum Likelihood Estimation in Structural Equation Models. In Cuttance, P. \& Russell, E. (Eds.). Structural Modeling by Example: Applications in Educational, Sociological, and Behavioural Research. Cambridge University Press, 160-188.

Bostrom, M., Jonsson, A.M., Lockie, S., Mol, A.P., \& Oosterveer, P. (2014). Sustainable and responsible supply chain governance: challenges and opportunities. Journal of Cleaner Production, 107, 1-7.

Bourlakis, M., Maglaras, G., Aktas, E., Gallear, D., \& Fotopoulos, C. (2014). Firm size and sustainable performance in food supply chains: Insights from Greek SMEs. International Journal of Production Economics, 152, 112-130.

Bowen, F.E., Cousins, P.D., Lamming, R.C., \& Faruk, A.C. (2001a). The role of supply management capabilities in green supply. Production and Operations Management, 10(2), 174-189.

Bowen, F.E., Cousins, P.D., Lamming, R.C., \& Faruk, A.C. (2001b). Horses for courses: explaining the gap between the theory and practice of green supply. Greener Management International, 35, 41-60.

Bowersox, D.J., Closs, D.J., Stank, T.P., \& Keller, S.B. (2000). Integrated supply chain logistics makes a difference. Supply Chain Management Review, 4, 70-79.

Brandenburg, M., Govindan, K., Sarkis, J., \& Seuring, S. (2014). Quantitative models for sustainable supply chain management: Developments and directions. European Journal of Operational Research, 233(2), 299-312. 
Brighi, P., \& Venturelli, V. (2014). How do income diversification, firm size and capital ratio affect performance? Evidence for bank holding companies. Applied Financial Economics, 24(21), 1375-1392.

Bronn, P. S., \& Vidaver-Cohen, D. (2009). Corporate motives for social initiative: Legitimacy, sustainability, or the bottom line? Journal of Business Ethics, 87(1), 91-109.

Buckley, P.J. \& Casson, M. (1976). The Future of Multinational Enterprise, London: Macmillan Press.

Bundy, J., Vogel, R., \& Zachary, M.A. (2018). Organization-stakeholder fit: A dynamic theory of cooperation, compromise, and conflict between an organization and its stakeholders. Strategic Management Journal, 39(2), 476-501. DOI:

10.1002/smj.2736

Bush, S.R., Oosterveer, P., Bailey, M., \& Mol, A.P. (2014). Sustainability governance of chains and networks: a review and future outlook Journal of Cleaner Production, 107, 8-19.

Busse, C. (2016). Doing Well By Doing Good? The Self-Interest of Buying Firms And Sustainable Supply Chain Management. Journal of Supply Chain Management, $52(2), 28-47$.

Cagliano, R., Blackmon, K., \& Voss, C. (2001). Small Firms Under Microscope: International Differences in Production/Operations Management Practices and Performance. Integrated Manufacturing Systems, 12(7), 469-482. 
Caniato, F., Caridi, M., Crippa, L., \& Moretto, A. (2012). Environmental sustainability in fashion supply chains: An exploratory case based research. International Journal of Production Economics, 135(2), 659-670.

Carbone, V., Moatti, V., \& Wood, C.H. (2012). Diffusion of Sustainable Supply Chain Management: Toward a Conceptual Framework. International Journal, 13(4), 2639.

Carroll, A.B. (1979). A Three-Dimensional Conceptual Model of Corporate Performance. The Academy of Management Review, 4(4), 497-505.

Carter, C. R., \& Easton, P. L. (2011). Sustainable supply chain management: Evolution and future directions. International Journal of Physical Distribution and Logistics Management, 41(1), 46-62.

Carter, C.R. \& Rogers, D.S. (2008). A framework of sustainable supply chain management: moving towards new theory. International Journal of Physical Distribution \& Logistics Management, 38(5), 360-387.

Carter, C.R. (2000). Ethical issues in international buyer-supplier relationships: a dyadic examination. Journal of Operations Management, 18(2), 191-208.

Carter, C.R. (2005). Purchasing social responsibility and firm performance: the key mediating roles of organizational learning and supplier performance. International Journal of Physical Distribution \& Logistics Management, 35(3), 177-194.

Carter, C.R., \& Easton, P. L. (2011). Sustainable supply chain management: evolution and future directions. International Journal of Physical Distribution \& Logistics Management, 41(1), 46-62. 
Carter, C.R., Rogers, \& Dale S. (2008). A framework of sustainable supply chain management: moving toward new theory. International Journal of Physical Distribution \& Logistics Management, 38(5), 360-387.

Carter, C.R., Rogers, D.S., Choi, T.Y. (2015). Toward the Theory of the Supply Chain. Journal of Supply Chain Management, 51(2), 89-97.

Cascio, W. F. (1991). Applied psychology in personnel management (4th ed.). Englewood Cliffs, NJ: Prentice Hall.

Chamorro, A., Rubio, S., \& Miranda, F.J. (2009). Characteristics of research on green marketing. Business Strategy and the Environment, 18(4), 223-239.

Chan, H.K., Yin, S., \& Chan, F.T.S. (2010). Implementing just-in-time philosophy to reverse logistics systems: a review. International Journal of Production Research, 48(21), 6293-6313.

Chandy, R. \& Tellis, G. (1998). Organizing for Radical Product Innovation: The Overlooked Role of Willingness to Cannibalize. Journal of Marketing Research, $35,474-88$.

Chardine-Baumann, E., \& Botta-Genoulaz, V. (2014). A framework for sustainable performance assessment of supply chain management practices. Computers \& Industrial Engineering, 76, 138-147.

Chatha, K.A., \& Butt, I. (2015). Themes of study in manufacturing strategy literature. International Journal of Operations \& Production Management, 35(4), 604-698.

Chen, I. J., \& Paulraj, A. (2004). Towards a theory of supply chain management: The constructs and measurements. Journal of Operations Management, 22(2), 119-150. 
Chen, J.L., Shih, L.H., Yang, J.S., \& Chen, T. (2005). "Eco-Design Activities in Taiwan", Fourth International Symposium on Environmentally Conscious Design and Inverse Manufacturing. Eco Design 2005, 535-538.

Chenhall, R.H. (2003). Management control systems design within its organizational context; findings from contingency-based research and directions for the future. Accounting, Organizations and Society, 28(2/3), 127-168.

Chin, T.A., Hamid, A.B.A., Rasli, A., \& Tat, H.H. (2014). A literature analysis on the relationship between external integration, environmental uncertainty and firm performance in Malaysian SMEs. Procedia - Social and Behavioral Sciences, 130, $75-84$.

Chin, W. W., Gopal, A., \& Salisbury, W. D. (1997). Advancing the theory of adaptive structuration: The development of a scale to measure faithfulness of appropriation. Information Systems Research 8(4), 342-367.

Choi, T.M., Chiu, C.H., Govindan, K., \& Yue, X. (2014). Sustainable fashion supply chain management: the European scenario. European Management Journal, 32(5), $821-822$.

Chu, H.S., \& Song, S.J. (2004). Status and developing trends of reverse logistics. Jisuanji Jicheng Zhizao Xitong/ Computer integrated manufacturing systems, 10(1), 10-14.

Chun, Y., \& Bidanda, B. (2013). Sustainable manufacturing and the role of the international journal of production research. International Journal of Production Research, 51(23-24), 7448-7455. 
Churchill, G.A. (1979). A Paradigm for Developing Better Measures of Marketing Constructs. Journal of Marketing Research, 16 (Feb.), 64-73.

Churchill, G.A., \& Peter, J.P. (1984). Research design effects on the reliability of rating scales: a meta-analysis. J Mark Res , 21, 360-375.

Clark, D. (1999). What Drives Companies to Seek ISO 14000? Pollution Engineering, Summer, 14-15.

Cohen, W.M., Levin, R.C., \& Mowery, D.C. (1987). Firm Size and R \& D Intensity: A Re-Examination. The Journal of Industrial Economics, 35(4), 543-565.

Cooper, M. C., Lambert, D. M., \& Pagh, J. D. (1997). Supply chain management: More than a new name for logistics. International Journal of Logistics Management, $8(1), 1-14$.

Corbett, C.J. \& Klassen, R.D. (2006). Extending the Horizons: Environmental Excellence as Key to Improving Operations. Manufacturing and Service Operations Management, 8(1), 5-22.

Corbett, C.J. \& Kleindorfer, P.R. (2003). Environmental Management the Operations Management: Introduction to the Third Special Issue. Production and Operations Management, 12(3), 287-289.

Cosimato, S., \& Troisi, O. (2015). Green supply chain management. The TQM Journal, $27(2), 256-276$.

Cronbach, L.J. \& Meehl, P.E. (1955). Construct validity in psychological tests. Psychological Bulletin, 52, 281-301. 
Croxton, K. L., Garcia-Dastugue, S. J., Lambert, D. M., \& Rogers, D. S. (2001). The supply chain management processes. International Journal of Logistics Management, 12(2), 13-36.

Cucculelli, M., \& Goffi, G. (2016). Does sustainability enhance tourism destination competitiveness? Evidence from Italian Destinations of Excellence. Journal of Cleaner Production, 111(B), 370-382.

Curkovic, S., Melnyk, S.A., Handfield, R.B., \& Calantone. R. (2000). Investigating the Linkage Between Total Quality Management and Environmentally Responsible Manufacturing. IEEE Transactions on Engineering Management, 47(4), 444-464.

Dahlsrud, A. (2008). How corporate social responsibility is defined: an analysis of 37 definitions. Corporate Soc. Responsibility Environ. Manage., 15, 1-13.

Darnell, N., Handfield, R., \& Jolley, J. (2008). Environmental Management Systems and Green Supply Chain Management: Complements for Sustainability? Business Strategy and the Environment, 17(1), 30-45.

Das, D. (2017). Development and validation of a scale for measuring Sustainable Supply Chain Management practices and performance. Journal of Cleaner Production, 164, 1344-1362. DOI: 10.1016/j.jclepro.2017.07.006.

Davies, I.A., \& Crane, A. (2003). Ethical decision making in fair trade companies. Journal of Business Ethics 2003, 45(1-2), 79-92.

Davis, K. (1973). The case for and against business assumption of social responsibilities. Academy of Management Journal, 16(2), 312-322. 
de Brito, R.P., \& Berardi, P.C. (2010). Competitive Advantage In Sustainable Supply Chain Management: A Study. RAE: Revista de Administração de Empresas, 50(2), 155-169.

Dekker, R., Bloemhof, J., \& Mallidis, I. (2012). Operations Research for green logistics an overview of aspects, issues, contributions and challenges. European Journal of Operational Research, 219(3), 671-679.

Demir, E., Bektas, T., \& Laporte, G. (2014). A review of recent research on green road freight transportation. European Journal of Operational Research, 237(3), 775793.

Diabat, A., Kannan, D., \& Mathiyazhagan, K. (2014). Analysis of enablers for implementation of sustainable supply chain management - A textile case. Journal of Cleaner Production, 83, 391-403.

Dillon, W. \& Goldstein, M. (1984). Multivariate Analysis: Methods and Application. New York, NY: Wiley.

Diniz, J.D.A.S., \& Fabbe-Costes, N. (2007). Supply Chain Management and Supply Chain Orientation: key factors for sustainable development projects in developing countries? International Journal of Logistics: Research \& Applications, 10(3), 235250.

Drumwright, M.E. (1994). Socially responsible organizational buying: environmental concern as a noneconomic buying criterion. Journal of Marketing, 58(3), 1-19. 
Eduardo Ortas José M. Moneva Igor Álvarez. (2014). Sustainable supply chain and company performance. Supply Chain Management: An International Journal, 19( 3), 332-350.

Elhamma, A. (2015). The relationship between budgetary evaluation, firm size and performance. Journal of Management Development, 34(8), 973-986.

Elkington, J. (1997). Cannibals With Forks: The Triple Bottom Line of 21st Century Business. Oxford: Capstone Publishing.

Elkington, J. (1998). Partnerships from Cannibals with Forks: The Triple Bottom Line of 21st-Century Business. Environmental Quality Management, 8(1), 37-51.

Elkington, J. (2006). Governance for Sustainability. Corporate Governance: An International Review, 14(6), 522-529.

Elkington, J., \& Fennell, S. (1998). Partners for Sustainability. Greener Management International, 24(48), 48-60.

Ellram, L. M., \& Cooper, M. C. (2014). Supply chain management: It's all about the journey, not the destination. Journal of Supply Chain Management, 50(1), 8-20.

Esfahbodi, A., Zhang, Y., Watson, G., \& Zhang, T. (2017). Governance pressures and performance outcomes of sustainable supply chain management - An empirical analysis of UK manufacturing industry. Journal of Cleaner Production, 155, 66-78.

European Union (EU). (2003). Directive 2002/96/EC of the European Parliament and of the Council of 27 January 2003 on waste electrical and electronic equipment (WEEE). Official Journal L037, 13/02/2003. Brussels: European Union, 24-39. 
Fahimnia, B., Sarkis, J., \& Davarzani, H. (2015). Green supply chain management: a review and bibliometric analysis. International Journal of Production Economics, 162, 101-114.

Fernando, M., \& Almeida, S. (2012). The organizational virtuousness of strategic corporate social responsibility: A case study of the Sri Lanka family-owned enterprise MAS Holdings. European Management Journal, 30(6), 564-572.

Field, J.M. \& Sroufe, R. P. (2007). The use of recycled materials in manufacturing: implications for supply chain management and operations strategy. International Journal of Production Research, 45(18/19), 4439-4463.

Font, X., Tapper, R., Schwartz, K., \& Kornilaki, M. (2008). Sustainable supply chain management in tourism. Business Strategy and the Environment, 17(4), 260-271.

Fornell, C., \& Larcker, D.F. (1981). Evaluating Structural Equation Models with Unobservable Variables and Measurement Error. Journal of Marketing Research, $18(1), 39-50$.

Foulds, L.R., \& Luo, Y. (2006). Value-added services for sustainable third-party warehousing. International Journal of Logistics Systems and Management, 2(2), 194-216.

Freeman, R.E. (1984). Strategic Management: A Stakeholder Approach. Boston, MA: Pittman.

Fresner, J. (1998). Cleaner production as a means for effective environmental management. Journal of Cleaner Production, 6(3-4), 171-179. 
Gaussin, M., Hu, G., Abolghasem, S., Basu, S., Shankar, M.R., \& Bidanda, B. (2013). Assessing the environmental footprint of manufactured products: a survey of current literature. International Journal of Production Economics, 146(2), 515-523.

Gerbing, D. W. \& Anderson, J.C. (1985). The Effects of Sampling Error and Model Characteristics on Parameter Estimation for Maximum Likelihood Confirmatory Factor Analysis. Multivariate Behavioral Research, 20(3), 255-271.

Gladwin, T.N., Kennelly, J.J. \& Krause, T. (1995). Shifting Paradigms for Sustainable Development: Implications for Management Theory and Research. Academy of Management Review, 20(4), 874-907.

Glover, J.L., Champion, D., Daniels, K.J., \& Dainty, A.J.D. (2014). An Institutional Theory perspective on sustainable practices across the dairy supply chain. International Journal of Production Economics, 152, 102-111.

Gold, S., Hahn, R., \& Seuring, S. (2013). Sustainable supply chain management in "Base of the Pyramid" food projects-A path to triple bottom line approaches for multinationals? International Business Review, 22(5), 784-799.

Gold, S., Seuring, S., \& Beske, P. (2010) Sustainable supply chain management and inter-organizational resources: a literature review. Corporate Social Responsibility \& Environmental Management. 17(4), 230-245.

Golicic, S.L., \& Smith, C.D. (2013). A Meta-Analysis of Environmentally Sustainable Supply Chain Management Practices and Firm Performance. Journal of Supply Chain Management, 49(2), 78-95. 
Gong, Y., Zhou, J., \& Chang, S. (2013). Core Knowledge Employee Creativity and Firm Performance: The Moderating Role of Riskiness Orientation, Firm Size, and Realized Absorptive Capacity. Personnel Psychology, 66, 443-482.

Gooding, R. Z. \& Wagner III, J.A. (1985). A Meta-Analytic Review of the Relationship between Size and Performance: The Productivity and Efficiency of Organizations and Their Subunits. Administrative Science Quarterly, 30(4), 462-481.

Gopalakrishnan, K., Yusuf, Y.Y., Musa, A., Abubakar, T., \& Ambursa, H.M. (2012). Sustainable supply chain management: A case study of British Aerospace (BAe) Systems. International Journal of Production Economics, 140(1), 193-203.

Gosling, J., Jia, F., Gong, Y., \& Brown, S. (2014). The role of supply chain leadership in the learning of sustainable practice: toward an integrated framework. Journal of Cleaner Production, 137, 1458-1469.

Govindan, K., \& Cheng, T.C.E. (2015). Sustainable supply chain management: Advances in

Govindan, K., Rajendran, S., Sarkis, J., \& Murugesan, P. (2015b). Multi criteria decision making approaches for green supplier evaluation and selection: a literature review. Journal of Cleaner Production, 98, 66-83.

Govindan, K., Soleimani, H., \& Kannan, D. (2015a). Reverse logistics and closed-loop supply chain: a comprehensive review to explore the future. European Journal of Operational Research, 240(3), 603-626.

Graafland, J., \& Van De Ven, B. (2006). Strategic and moral motivation for corporate social responsibility. Journal of Corporate Citizenship, 22, 111-123. 
Granovetter, M. (1985). Economic Action and Social Structure: the Problem of Embeddedness. American Journal of Sociology, 91, 481-493.

Green, K., Morten, B., \& New, S. (1998). Green purchasing and supply policies: do they improve companies' environmental performance? Supply Chain Management: An International Journal, 3(2), 89-95.

Grosvold, J., Hoejmose , S.U., \& Roehrich, J.K. (2014). Squaring the circle: Management, measurement and performance of sustainability in supply chains. Supply Chain Management: An International Journal, 19(3), 292-305.

Group to Foster Sustainable Supply Chain Management. (2003). Business \& the Environment with ISO 14000 Updates, 14(9), 9-9.

Gualandris, J., \& Kalchschmidt, M. (2014). Customer pressure and innovativeness: Their role in sustainable supply chain management. Journal of Purchasing \& Supply Management, 20(2), 92-103.

Guide, Jr., V. D. R., Harrison, T., \& Van Wassenhove, L.N. (2003b). The Challenge of Closed-Loop Supply Chains. Interfaces, 33(6), 3-6.

Gunasekaran, A., Patel, C., \& Tirtiroglu, E. (2001). Performance measures and metrics in a supply chain environment. International Journal of Operations and Production Management, 21(1-2), 71-87.

Gupta, S., \& Palsule-Desai, O.D. (2011). Sustainable supply chain management: Review and research opportunities. IIMB Management Review, 23(4), 234-245. 
Gurtu, A., Searcy, C., Jaber, M.Y. (2015). An analysis of keywords used in the literature on green supply chain management. Management Research Review, 38(2), 166194.

Hahn, T., Figge, F., Pinkse, J., \& Preuss, L. (2010). Trade-offs in corporate sustainability: You can't have your cake and eat it. Business Strategy and the Environment, 19(4), $217-229$.

Hair, J., Black, W., Babin, B. \& Anderson R. (2010). Multivariate Data Analysis. 7. Upper Saddle River, NJ, USA: Prentice-Hall, Inc.

Hajmohammad, S., \& Vachon, S. (2016). Mitigation, Avoidance, or Acceptance? Managing Supplier Sustainability Risk. Journal Of Supply Chain Management, $52(2), 48-65$.

Handfield, R., Sroufe, R., \& Walton, S. (2012). Integrating environmental management and supply chain strategies. Business Strategy and the Environment, 14(1), 1-19.

Handfield, R., Walton, S., Sfroufe, R., \& Melnyk, S. (2002). Applying environmental criteria to supplier assessment: a study in the application of the AHP process. European Journal of Operational Research, 141, 70-87.

Harms, D., Hansen, E.G., \& Schaltegger, S. (2013). Strategies in Sustainable Supply Chain Management: An Empirical Investigation of Large German Companies. Corporate Social Responsibility \& Environmental Management, 20(4), 205-218.

Harper, D. (2010). sustainable. (n.d.). Online Etymology Dictionary. Retrieved March 12, 2010, from Dictionary.com website: http://dictionary.reference.com/browse/sustainable. 
Hart, S. (1995). A natural resource-based-view of the firm. Academy of Management Review, 20(4), 986-1014.

Hart, S. (1997). Beyond Greening: Strategies for a Sustainable World. Harvard Business Review, 75(1), 66-77.

Hart, S., \& Milstein, M. (1999). Global sustainability and the creative destruction of industries. Sloan Management Review, 41(1), 23-33.

Hassini, E., Surti, C., \& Searcy, C (2012). A literature review and a case study of sustainable supply chains with a focus on metrics. International Journal of Production Economics, 140(1), 69-82.

Hayduk, L., Cummings, G. G., Boadu, K., Pazderka-Robinson, H., \& Boulianne, S. (2007). Testing! Testing! One, two three - Testing the theory in structural equation models! Personality and Individual Differences, 42, 841-50.

Hazen, B.T. (2011). Strategic reverse logistics disposition decisions: from theory to practice. International Journal of Logistics Systems and Management, 10(3), 275292.

Hazen, B.T., Hall, D.J., \& Hanna, J.B. (2012). Reverse logistics disposition decision making. International Journal of Physical Distribution \& Logistics Management, 42(3), 244-274.

Hendry, J.R. (2006). Taking aim at business: what factors lead environmental nongovernmental organizations to target particular firms. Business and Society, 45, $47-86$. 
Hervani, A.A., Helms, M.M., \& Sarkis J. (2005). Performance measurement for green supply chain management. Benchmarking: An International Journal, 12(4), 330353.

Ho, H.P., \& Choi, T. (2012). A Five-R analysis for sustainable fashion supply chain management in Hong Kong: a case analysis. Journal of Fashion Marketing \& Management, 16(2), 161-175.

Ho, W., Xu, X., \& Dey, P.K. (2010). Multicriteria decision making approaches for supplier evaluation and selection: a literature review. European Journal of Operational Research, 202(1), 16-24.

Ho, W., Zheng, T., Yildiz, H., \& Talluri, S. (2015). Supply chain risk management: a literature review. International Journal Of Production Research, 53(16), 50315069.

Hoffman, A. J., \& Haigh, N. (2011). Positive deviance for a sustainable world: Linking sustainability and positive organizational scholarship. In K. Cameron \& G. Spreitzer (Eds.), Handbook on positive organizational scholarships (pp.953-964). Oxford, England: Oxford University Press.

Horst, T. (1972). Firm and Industry Determinants of the Decision to Invest Abroad: An Empirical Study. The Review of Economics and Statistics, 54(3), 258-266.

Houlihan, J.B. (1985). International Supply Chain Management. International Executive. 27(3), 17-18. 
Hsueh, C. (2015). A bilevel programming model for corporate social responsibility collaboration in sustainable supply chain management. Transportation Research: Part E, 73, 84-95.

Hu, L. \&, Bentler P.M. (1999). Cutoff Criteria for Fit Indexes in Covariance Structure Analysis: Conventional Criteria versus New Alternatives, Structural Equation Modeling, 6(1), 1-55.

Hwang, Y.S., Hwang, M.H. \& Dong, X. (2015). The Relationships Among Firm Size, Innovation Type, and Export Performance With Regard to Time Spans. Emerging Markets Finance \& Trade, 51, 947-962.

Igarashi, M., de Boer, L., \& Fet, A.M. (2013). What is required for greener supplier selection? A literature review and conceptual model development. Journal of Purchasing \& Supply Management, 19(4), 247-263.

Isaksson, R., Johansson, P., \& Fischer, K. (2010). Detecting supply chain innovation potential for sustainable development. Journal of Business Ethics, 97(3), 425-442.

Jaccard, J., \& Turrisi, R. (2003). Interaction effects in multiple regression (2nd ed.). Thousand Oaks, CA: Sage Publications.

Jain, V. (2012). Special issue on sustainable supply chain management and reverse logistics. International Journal of Production Research, 50(5), 1239-1242.

Jayaraman, V., Klassen, R., \& Linton, J.D. (2007). Supply chain management in a sustainable environment. Journal of Operations Management, 25(6), 1071-1074.

Jayaraman, V., Linton, J., \& Klassen, R. (2005). A Supply Chain Management in a Sustainable Environment. Journal of Operations Management, 23(1), 103-104. 
Jennings, M. M. (2013). Social responsibility and ethical considerations in the management of the supply chain. In C. Harland, G. Nassimbeni, \& E. Schneller (Eds.), The SAGE handbook of strategic supply management (pp. 331-352). Los Angeles, CA: SAGE.

Jennings, P.D. \& Zandbergen, P.A. (2005). Ecologically Sustainable Organizations: An Institutional Approach. Academy of Management Review, 20(4), 1015-1052.

Jones, T.M. (1980). Corporate social responsibility revisited, redefined. California Management Review, 22(2), 59-67.

Joreskog, K. C. \& Sorbom, D. (2001). LISREL 8 User's Reference Guide. Chicago, Scientific Software International.

Joreskog, K. G. \& Yang, F. (1996). Non-linear Structural Equation Models: The KennyJudd Model with Interaction Effects. In Marcoulides, G. A. and R. E. Schumacker (Eds.) Advanced Structural Equation Modeling: Issues and Techniques. Mahwah, NJ, Lawrence Erlbaum Associates, 57-88.

Joreskog, K. G. (1973). A General Method for Estimating a Linear Structural Equation System. In Goldberger, A. S. and O. S. Duncan (Eds.) Structural Equation Models in the Social Sciences. New York Academic Press, 85-112.

Jose, P. E. (2013). Doing statistical mediation \& moderation. New York, NY: Guilford Press.

Julia W. (2014). The Relationship Between Sustainable Supply Chain Management, Stakeholder Pressure and Corporate Sustainability Performance. Journal of Business Ethics, 119(3), 317-328. 
Kanonuhwa, M., \& Chimucheka, T. (2014). Green marketing and Purchase Behaviour of generation Y-Consumers. Mediterranean Journal of Social Sciences, 5(20), 27852788.

Kaynak, H., \& Montiel, I. (2009). The Relationship Between Sustainable Supply Chain Management And Sustainable Performance: An Integrated Framework. Academy of Management Annual Meeting Proceedings, 1-6.

Keating, B., Quazi, A., Kriz, A. \& Coltman, T. (2008). In pursuit of a sustainable supply chain: insights from Westpac Banking Corporation. Supply Chain Management: An International Journal, 13(3), 175-179.

Kemp, R. (1994). Technology and the transition to environmental sustainability. Futures, 26(10), 1023-1046.

Kenny, D.A., Kaniskan, B., \& McCoach, D.B.. (2014). The Performance of RMSEA in Models With Small Degrees of Freedom. Sociological Methods \& Research, 44(3), 486-507.

Kim, J.O. \& Mueller, C.W. (1978). Introduction to factor analysis: What it is and how to do it. Beverly Hills, CA: Sage Publications, Inc.

King, A.A. \& Lenox. M.J. (2001). Lean and Green? An Empirical Examination of the Relationship Between Lean Production and Environmental Performance. Production and Operations Management, 10(3), 244-256.

and Environmental Performance. Production and Operations Management, 10(3), 244256. 
Kjaerheim, G. (2005). Cleaner production and sustainability. Journal of Cleaner Production, 13(4), 329-339.

Kleindorfer, P.R., Singhal, K. \& Van Wassenhove, L.N. (2005). Sustainable Operations Management. Production and Operations Management, 14(4), 482-492.

Kocabasoglu, C., Prahinski, C. \& Klassen, R.D. (2007). Linking forward and reverse supply chain investments: The role of business uncertainty. Journal of Operations Management, 25, 1141-1160.

Koplin, J., Seuring, S, \& Mesterharm, M. (2007). Incorporating sustainability into supply management in the automotive industry: the case of the Volkswagen AG. Journal of Cleaner Production, 15(11-12), 1053-1062.

Krause, D.R., Scannell, T.V. \& Calantone, R.J. (2000). A structural analysis of the effectiveness of buying firms' strategies to improve supplier performances. Decision Sciences, 31(1), 33-55.

Krause, D.R., Vachon, S., \& Klassen, R.D. (2009). Special Topic Forum On Sustainable Supply Chain Management: Introduction And Reflections On The Role Of Purchasing Management. Journal of Supply Chain Management, 45(4), 18-25.

Kronborg Jensen, J. (2012). Product carbon footprint developments and gaps.

International Journal of Physical Distribution \& Logistics Management, 42(4), 338-354.

Lahiri, N. \& Narayanan, S. (2013). Vertical Integration, Innovation, and Alliance Portfolio Size: Implications for Firm Performance. Strategic Management Journal, $34,1042-1064$. 
Lambert, D.M., Cooper, M.C., \& Pagh, J.D. (1998). Supply chain management: Implementation issues and research opportunities. International Journal of Logistics Management, 9(2), 1-20.

Lamming, R.C., \& Hampson, J.P. (1996). The environment as a supply chain management issue. British Journal of Management, 7(Special Issue):45-62.

Leal-Rodríguez A.L., Eldridge, S., Roldán, J.L., Leal-Millán, A.G., \& Ortega-Gutiérrez, J. (2015). Organizational unlearning, innovation outcomes, and performance: The moderating effect of firm size. Journal of Business Research, 68(4), 803-809.

Lewis-Beck, M.S. (1980). Applied regression: An introduction. Beverly Hills, CA: Sage.

Li, D., Wang, X., Chan, H. K., \& Manzini, R. (2014b). Sustainable food supply chain management. International Journal of Production Economics, 152, 1-8.

Li, Y., Zhao, X., Shi, D., \& Li, X. (2014a). Governance of sustainable supply chains in the fast fashion industry. European Management Journal, 32(5), 823-836.

Lin, C., Choy, K.L., Ho, G.T.S., Chung, S.H., \& Lam, H.Y. (2014). Survey of green vehicle routing problem: past and future trends. Expert Systems with Applications, 41(4), 1118-1138.

Linton, J.D., Klassen, R., \& Jayaraman, V. (2007). Sustainable supply chains: An introduction. Journal of Operations Management, 25(6), 1075-1082.

Liu, S., Kasturiratne, D., Moizer, J. (2012). A hub-and-spoke model for multidimensional integration of green marketing and sustainable supply chain management. Industrial Marketing Management, 41(4), 581-588. 
Liu, X., Yang, J., Qu, S., Wang, L., Shishime, T., \& Bao, C. (2012). Sustainable Production: Practices and Determinant Factors of Green Supply Chain Management of Chinese Companies. Business Strategy \& the Environment, 21(1), 1-16.

Malhotra, N. (2004). Marketing Research, Englewood Cliffs, NJ: Pearson Education.

Malhotra, N. K. \& Dash, S. (2011). Marketing Research an Applied Orientation. London: Pearson Publishing.

Malviya, R.K., \& Kant, R. (2015). Green supply chain management (GSCM): a structured literature review and research implications. Benchmarking: An International Journal, 22(7), 1360-1394.

Mann, H., Kumar, U., Kumar, V., \& Mann, I.J.S. (2010). Drivers of Sustainable Supply Chain Management. IUP Journal of Operations Management, 9(4), 52-63.

Mann, I.J.S., Kumar, V., Kumar, U., Mann, H. (2008). Supply Chains: An Organization Theory Perspective. The International Journal of Knowledge, Culture and Change Management, 8(8), 81-94.

Markman, G. (2016). Theory Building Surrounding Sustainable Supply Chain Management: Assessing What We Know, Exploring Where To Go.. The Journal Of Supply Chain Management, 52(2), 3 - 10.

Markman, G., \& Krause, D. (2014). Special Topic Forum on Theory Building Surrounding Sustainable Supply Chain Management. Journal of Supply Chain Management, 50(4), 100-101. 
Markman, G., \& Krause, D. (2014). Special Topic Forum on Theory Building Surrounding Sustainable Supply Chain Management. Journal of Supply Chain Management, 50(3), i-ii.

Markman, G., \& Krause, D. (2014). Special Topic Forum on Theory Building Surrounding Sustainable Supply Chain Management. Journal of Supply Chain Management, 50(2), i-ii.

Maslow, A. H. (1954). Motivation and personality. New York: Harper.

Matos, S., \& Hall, J. (2007). Integrating sustainable development in the supply chain: The case of life cycle assessment in oil and gas and agricultural biotechnology. Journal of Operations Management, 25(6), 1083-1102.

McKone-Sweet, K.E. (2004). Lessons from a coffee supply chain. Supply Chain Management Review, 8, 52-59.

McWilliams, A., \& Siegel, D. S. (2001). Corporate social responsibility: A theory of the firm perspective. Academy of Management Review, 26(1), 117-127.

Meade, L., Sarkis, J., \& Presley, A. (2007). The theory and practice of Reverse Logistics. International Journal of Logistics Systems and Management, 3(1), 56-84.

Meixell, M.J., Luoma, P. (2015). Stakeholder pressure in sustainable supply chain management. International Journal of Physical Distribution \& Logistics Management, 45(1/2), 69-89.

Melewar, T.C., Gupta, S., \& Czinkota, M. (2013). Global business management for sustainability and competitiveness: The role of corporate branding, corporate identity and corporate reputation. Journal of World Business, 48(3), 285-286. 
Melo, M.T., Nickel, S., \& Saldanha-da-Gama, F. (2009). Facility location and supply chain management - a review. European Journal of Operational Research, 196(2), 401-412.

Mena, C., Humphries, A., \& Choi, T.Y. (2013). Toward a theory of multi-tier supply chain management. Journal of Supply Chain Management, 49(2), 58-77.

Mendenhall, W., Reinmuth, J.E., Robert J. Beaver, R.J. (1989). Statistics for Management and Economics. Boston: PWS-KENT Pub. Co.

Micceri, T. (1989). The Unicorn, The Normal Curve, and Other Improbable Creatures. Psychological Bulletin, 105(1), 156-166.

Miemczyk, J., Johnsen, T.E., \& Macquet, M. (2012). Sustainable purchasing and supply management: a structured literature review of definitions and measures at the dyad, chain and network levels. Supply Chain Management: An International Journal, $17(5), 478-496$.

Min, H., \& Galle, W.P. (1997). Green purchasing strategies: trends and implications. The Journal of Supply Chain Management, 33(3), 10-17.

Min, S. (2013). Supply chain management and financial performance: literature review and future directions. International Journal of Operations \& Production Management, 33(10), 1283-1317.

Mitroff. I. I. (1983). Stakeholders of the organizational mind. San Francisco: JosseyBass Publishers.

Montabon, F., Pagell, M. \& Wu, Z. (2016), Making Sustainability Sustainable. The Journal of Supply Chain Management, 52(2), 11-27. doi:10.1111/jscm.12103 
Morali, O., \& Searcy, C. (2013). A Review of Sustainable Supply Chain Management Practices in Canada. Journal of Business Ethics, 117(3), 635-658.

Morgan, C. (2004). Structure, speed and salience: Performance measurement in the supply chain. Business Process Management Journal, 10(5), 522-536

Muller, A., \& Kolk, A. (2010). Extrinsic and Intrinsic Drivers of Corporate Social Performance: Evidence from Foreign and Domestic Firms in Mexico. Journal of Management Studies, 47(1), 1-26.

Myers, N. (1997). Consumption: challenge to sustainable development. Science, 276, 5357.

Nagurney, A., \& Yu, M. (2012). Sustainable fashion supply chain management under oligopolistic competition and brand differentiation. International Journal of Production Economics, 135(2), 532-540.

Nair, A., Tingting Y. Ro, Y.K., Oke, A., Chiles, T.H., \& Su-Yol L. (2016). How Environmental Innovations Emerge And Proliferate In Supply Networks: A Complex Adaptive Systems Perspective. Journal Of Supply Chain Management, $52(2), 66-86$.

Nunnally, J.C. (1978). Psychometric theory (2nd ed.), New York: McGraw-Hill, Inc.

Nunnally, J.C., \& Bernstein, I.H. (1994). Psychometric Theory. New York: McGrawHill.

Ogundimu, E.O., Altman, D.G., \& Collins G.S. (2016). Adequate sample size for developing prediction models is not simply related to events per variable. Journal of Clinical Epidemiology, 76, 175-182. doi:10.1016/j.jclinepi.2016.02. 
Oguz, M., \& Searcy, C. (2015). A Review of Sustainable Supply Chain Management Practices in Canada. Journal of Business Ethics, 117(3), 635-658.

Ortas, E., Moneva, J.M, \& Álvarez, I. (2014). Sustainable supply chain and company performance. Supply Chain Management: An International Journal, 19(3), 332350.

Oxford (2010). Available at http://www.askoxford.com/concise oed/sustainable? view=uk . Accessed on March 12, 2010.

Pagell, M. \& Shevchenko, A. (2014). Why Research in Sustainable Supply Chain Management Should Have no Future. Journal of Supply Chain Management, 50(1), 44-55.

Pagell, M. \& Wu, Z. (2009). Building A More Complete Theory Of Sustainable Supply Chain Management Using Case Studies Of 10 Exemplars. Journal of Supply Chain Management, 45(2), 37-56.

Pagell, M., Krause, D., \& Klassen, R. (2008). Special Topic Forum on Sustainable Supply Chain Management: Theory and Practice. Journal of Supply Chain Management, 44(3), 76-76.

Pagell, M., Krause, D., \& Klassen, R. (2008). Sustainable Supply Chain Management: Theory and Practice. Journal of Supply Chain Management, 44(1), 85-85.

Pagell, M., Yang, C., Krumwiede, D.K. \& Sheu.C. (2004). Does the Competitive Environment Influence the Efficacy of Investments in Environmental Management? Journal of Supply Chain Management, 40(3), 30-39.

Paine, L. S. (2002). Value shift. New York: McGraw-Hill. 
Parmigiani, A., Klassen, R.D., \& Russo, M.V. (2011). Efficiency meets accountability: Performance implications of supply chain configuration, control, and capabilities. Journal of Operations Management, 29(3), 212-223.

Patala, S., Hamalainen, S., Jalkala, A., \& Pesonen, H.L. (2014). Towards a broader perspective on the forms of eco-industrial networks. Journal of Cleaner Production, 82, 166-178.

Paul, I.D., Bhole, G.P., \& Chaudhari, J.R. (2014). A review on green manufacturing : it's important, methodology and its application. Procedia Materials Science 6 (ICMPC), 1644-1649.

Paulraj, A. (2009).Environmental Motivations: A Classification Scheme and its Impact on Environmental Strategies and Practices. Business Strategy and the Environment, 18, 453-468.

Paulraj, A., Chen, I., \& Blome, C. (2017). Motives and Performance Outcomes of Sustainable Supply Chain Management Practices: A Multi-theoretical Perspective. Journal of Business Ethics, 145(2), 239-258. DOI: 10.1007/s10551-015-2857-0.

Pesonen, H.L. (2001). Environmental management of value chains. Greener Management International 2001, 33, 45-58.

Phillips, R., Caldwell, C.B. (2005). Value chain responsibility: a farewell to arm's length. Business and Society Review, 110, 345-370.

Ping Jr., R. A. (2003). Antecedents of Satisfaction in a Marketing Channel. Journal of Retailing. 79(4), 237-248. 
Ping Jr., R. A. (2004). On Assuring Valid Measures for Theoretical Models using Survey Data. Journal of Business Research, 57(2), 125-141.

Piplani, R., Pujawan, N., \& Ray, S. (2008). Sustainable supply chain management. International Journal of Production Economics, 111(2), 193-194.

Podsakoff, P.M., MacKenzie, S.B. \& Lee, J. (2003). Common Method Biases in Behavioral Research: A Critical Review of the Literature and Recommended Remedies. Journal of AppliedPsychology, 88(5), 879-903.

Pokharel, S., \& Mutha, A. (2009). Perspectives in reverse logistics: a review. Resources, Conservation and Recycling, 53(4), 175-182.

Porter, M. E., \& Kramer, M. T. (2006). Strategy and society: The link between competitive advantage and corporate social responsibility. Harvard Business Review, 84(12), 78-92.

Porter, M., Van der Linde, C. (1995). Green and competitive: ending the stalemate. Harvard Business Review, 73(5), 120-134.

Prahinski, C., \& Kocabasoglu, C. (2006). Empirical research opportunities in reverse supply chains. Omega, 34(6), 519-532.

Preuss, L. (2005). Rhetoric and reality of corporate greening: a view from the supply chain management function. Business Strategy and the Environment, 14(2), 123139.

Pullman, M.E., Maloni, M.J., \& Carter, C.R. (2009). Food For Thought: Social Versus Environmental Sustainability Practices And Performance Outcomes. Journal of Supply Chain Management, 45(4), 38-54. 
Rajeev, A., Pati, R.K., Padhi, S.S. \& Govindan, K. (2017). Evolution of sustainability in supply chain management: A literature review. Journal of Cleaner Production, 162, 299-314.

Rao, K.H., Raju, P.N., Reddy, G.P. \& Hussain, S.A. (2013). Public-Private Partnership and Value Addition: A Two-Pronged Approach for Sustainable Dairy Supply Chain Management. IUP Journal of Supply Chain Management, 10(1), 15-25.

Rao, P., \& Holt, D. (2005). Do green supply chains lead to competitiveness and economic performance? International Journal of Operations \& Production Management, 25(9), 898-916.

Raykov, T. (1997). Estimation of composite reliability for congeneric measures. Applied Psychological Measurement, 21(2), 173-184.

Reuter, C., Foerstl, K., Hartmann, E., \& Blome, C. (2010). Sustainable global supplier management: the role of dynamic capabilities in achieving competitive advantage. Journal of Supply Chain Management, 46, 45-63.

Richman, W. L., Kiesler, S., Weisband, S. \& Drasgow, F. (1999). A Meta-Analytic Study of Social Desirability Distortion in Computer-Administered Questionnaires, Traditional Questionnaires, and Interviews. Journal of Applied Psychology, 84(5), 754-775.

Roberts, S. (2003). Supply chain specific? Understanding the patchy success of ethical sourcing initiatives. Journal of Business Ethics, 44(2), 159-170.

Rubin, D.B. (1976). Inference and Missing Data. Biometrika, 63(3), 581-592. 
Rubio, S., Chamorro, A., \& Miranda, F.J. (2008). Characteristics of the research on reverse logistics (1995-2005). International Journal of Production Research, 46(4), 1099-1120.

Rummel, R.J. (1970) Applied factor analysis. Evanston: Northwestern University Press.

Russo, M.V. \& Fouts, P.A. (1997). A Resource-Based Perspective on Corporate Environmental Performance and Profitability. Academy of Management Journal, 40(3), 534-559.

Sabherwal, R. \& Fernandez, I. B. (2003). "An empirical study of the effect of knowledge management processes at individual, group, and organizational levels", Decision Sciences, 34(2), 225-260.

Sangle, S. (2010). Empirical Analysis of Determinants of Adoption of Proactive Environmental Strategies in India. Business Strategy and the Environment, 19, 5163.

Sarkis, J. (2003). A strategic decision framework for green supply chain management. Journal of Cleaner Production, 11(4), 397-409.

Sarkis, J., Zhu, Q., \& Lai, K. (2011). An organizational theoretic review of green supply chain management literature. International Journal of Production Economics, $130(1), 1-15$.

Schaefer, S. (1998). The Dependence of pay - Performance Sensitivity on the Size of the Firm. The review of economics and statistics, 80(3), 436-443. 
Schaltegger S., \& Burritt, R. (2014). Measuring and managing sustainability performance of supply chains: Review and sustainability supply chain management framework. Supply Chain Management: An International Journal, 19(3), 232-241.

Schwab, D.P. (1999). Research Methods for Organizational Studies. Mahwah, NJ: Lawrence Erlbaum Associates.

Schwartz, K., Tapper, R., \& Font, X. (2008). A Sustainable Supply Chain Management Framework for Tour Operators. Journal of Sustainable Tourism, 16(3), 298-314.

Sekerka, L. E., Comer, D. R., \& Godwin, L. N. (2014). Positive organizational ethics: Cultivating and sustaining moral performance. Journal of Business Ethics, 119(4), 435-444.

Setaputra, R., \& Mukhopadhyay, S.K. (2010). A framework for research in reverse logistics. International Journal of Logistics Systems and Management, 7(1), 19-55.

Seuring, S, \& Gold, S. (2012). Conducting content-analysis based literature reviews in supply chain management. Supply Chain Management: An International Journal, $17(5), 544-555$.

Seuring, S. \& Müller, M. (2007). Integrated chain management in Germany - identifying schools of thought based on a literature review. Journal of Cleaner Production, 15(7), 699-710.

Seuring, S. (2001). A Framework for Green Supply Chain Costing - Joint Cost Management in the Polyester Linings Supply Chain. Greener Management International 2001, (33), 71-80. 
Seuring, S. (2004). Industrial ecology, life cycles, supply chains - differences and interrelations. Business Strategy and the Environment,3(5), 306-319.

Seuring, S. (2004). Integrated chain management and supply chain management comparative analysis and illustrative cases. Journal of Cleaner Production, 12(810), 1059-1071.

Seuring, S. (2011). Supply chain management for sustainable products - insights from research applying mixed methodologies. Business Strategy \& the Environment, $20(7), 471-484$.

Seuring, S. (2013). A review of modeling approaches for sustainable supply chain management. Decision Support Systems, 54(4), 1513-1520.

Seuring, S., \& Muller, M. (2008a). From a literature review to a conceptual framework for sustainable supply chain management. Journal of Cleaner Production, 16(15), 1699-1710.

Seuring, S., \& Muller, M. (2008b). Core issues in sustainable supply chain management a Delphi study. Business Strategy and the Environment, 17(8), 455-466.

Seuring, S., Sarkis, J., Müller, M., \& Rao, P. (2008). Sustainability and supply chain management - An introduction to the special issue. Journal of Cleaner Production, $16(15), 1545-1551$.

Sharma, S., \& Vredenburg, H. (1998). Proactive corporate environmental strategy and the development of competitively valuable organizational capabilities. Strategic Management Journal, 19, 729-753. 
Sheriff, K.M.M., Gunasekaran, A., Nachiappan, S. (2012). Reverse logistics network design: a review on strategic perspective. International Journal of Logistics Systems and Management, 12(2), 171-194.

Shi, M., \& Yu, W. (2013). Supply chain management and financial performance: literature review and future directions. International Journal of Operations \& Production Management, 33(10), 1283-1317.

Shrivastava, P. (1995). Ecocentric management for a risk society. Academy of Management Review, 20(1), 118-137.

Sigala, M. (2008). A supply chain management approach for investigating the role of tour operators on sustainable tourism: the case of TUI. Journal of Cleaner Production, $16(15), 1589-1599$.

Sigala, M.C. (2014). Customer Involvement in Sustainable Supply Chain Management: A Research Framework and Implications in Tourism. Cornell Hospitality Quarterly, $55(1), 76-88$.

Simchi-Levi, D., Kaminsky, P. \& Simchi-Levi, E. (2003). Designing and Managing the Supply Chain - Concepts, Strategies and Case Studies, New York, NY: McGrawHill Publishing.

Simpson, D., Power, D.J., \& Samson, D. (2007). Greening the automotive supply chain: a relationship perspective. International Journal of Operations \& Production Management, 27(1), 28-48. 
Singhal, K., \& Singhal, J. (2012). Opportunities for developing the science of operations and supply-chain management. Journal Of Operations Management, 30(3), 245252. doi:10.1016/j.jom.2011.11.002

Smith, K.T., Blazovich, J.L., \& Smith, L.M. (2015). Social Media Adoption by Corporations: An Examination by Platform, Industry, Size, and Financial Performance. International Academy of Marketing Studies Journal, 19(2), 127-143.

Srivastava, S.K. (2007). Green supply-chain management: a state-of the-art literature review. International Journal of Management Reviews, 9(1), 53-80.

Starik, M. \& Rands, G.P. (1995). Weaving an Integrated Web: Multilevel and Multisystem Perspectives of Ecologically Sustainable Organizations. Academy of Management Review, 20(4), 908-935.

Statcan. (2018). Small, Medium-sized and Large Businesses in the Canadian Economy: Measuring Their Contribution to Gross Domestic Product in 2005. Retrieved from http://www.statcan.gc.ca/pub/11f0027m/2011069/part-partie1-eng.htm. Accessed on 1 January, 2018.

Stevens, J. (1996). Applied Multivariate Statistics for the Social Sciences. Hillsdale: NJ, Lawrence Erblaum Associates.

Stigler, S.M. (1977). Do Robust Estimators Work with Real Data? The Annals of Statistics, 5(6), 1055-1098.

Svensson, G. (2007). Aspects of sustainable supply chain management (SSCM): Conceptual framework and empirical example. Supply Chain Management: An International Journal, 12(4), 262-266. 
Swamidass, P.M., \& Kotha, S. (1998). Explaining manufacturing technology use, firm size and performance using a multidimensional view of technology. Journal of Operations Management, 17(1), 23-37

Swanson, D. L. (1999). Toward an integrative theory for business and society: A research strategy for corporate social performance. Academy of Management Review, 24, $506-521$.

Syahruddin, N. (2013). Sustainable Supply Chain Management: A Case Study of Indonesia's Cocoa Industry. Bulletin of Indonesian Economic Studies, 49(1), 114115.

Tabachnick, B.G. \& Fidell, L.S. (2007). Using Multivariate Statistics (5th Edition). Boston: Pearson Education.

Tachizawa, E.M., \& Wong, C.Y. (2014). Towards a theory of multi-tier sustainable supply chains: a systematic literature review. Supply Chain Management: An International Journal, 19(5/6), 643-663.

Tan, Y., Ochoa, J.J., Langston, C., \& Shen, L. (2015). An empirical study on the relationship between sustainability performance and business competitiveness of international construction contractors. Journal of Cleaner Production, 93, 273278.

Tanaka, J. S. (1987). "How Big is Big Enough?": Sample Size and Goodness of Fit in Structural Equation Models with Latent Variables. Child Development, 58(1), 134146. 
Tang, C.S., \& Zhou, S. (2012). Research advances in environmentally and socially sustainable operations. European Journal of Operational Research, 223(3), 585594.

Tao, Y., \& Yin, Z. (2014). Reverse logistics network: a literature review. Journal of Chemical and Pharmaceutical Research, 6 (7), 1916-1921.

Tate, W. L., Ellram, L. M., \& Kirchoff, J. F. (2010). Corporate social responsibility reports: A thematic analysis related to supply chain management. Journal of Supply Chain Management, 46(1), 19-44.

Taticchi, P., Tonelli, F., \& Pasqualino, R. (2013). Performance measurement of sustainable supply chains A literature review and a research agenda. International Journal of Productivity \& Performance Management, 62(8), 782-804.

Teuscher, P., Grüninger, B., \& Ferdinand, N. (2006). Risk management in sustainable supply chain management (SSCM): lessons learnt from the case of GMO-free soybeans. Corporate Social Responsibility \& Environmental Management, 13(1), $1-10$.

Touboulic, A. \& Walker, H. (2015). Theories in sustainable supply chain management: a structured literature review. International Journal of Physical Distribution \& Logistics Management, 45(1/2), 16-42.

Trochim, W.M.K (2006), Research methods knowledge base, Retrieved on January 2, 2018 from http://www.socialresearchmethods.net/kb/convdisc.php

Tseng, M.L., Lim, M., \& Wong, W.P. (2015). Sustainable supply chain management. Industrial Management \& Data Systems, 115(3), 436-461. 
Turker, D., \& Altuntas, C. (2014). Sustainable supply chain management in the fast fashion industry: An analysis of corporate reports. European Management Journal, $32(5), 837-849$.

University of Northern Iowa. (2017). SPSS Techniques Series: Statistics on Likert Scale Surveys. (available at https://it.uni.edu/kb/8040 ) (Accessed 1 November, 2017).

Upadhyay, A., Johnson, M., \& Baglieri, E. (2012, July). Antecedents and enablers in the implementation of green supply chain practices. In Proceedings: 9th International Annual EurOMA Conference/4th World P\&OM conference, Amsterdam.

Vachon, S. (2007). Green supply chain practices and the selection of environmental technologies. International Journal of Production Research, 45(18-19), 43574379.

Vachon, S., \& Klassen R.D. (2006). Extending green practices across the supply chain: the impact of upstream and downstream integration. International Journal of Operations and Production Management, 26, 795-821.

Vachon, S., \& Mao, Z. (2008). Linking supply chain strength to sustainable development: a country-level analysis. Journal of Cleaner Production, 16, 1552-1560.

van Hoof, B., \& Thiell, M. (2014). Collaboration capacity for sustainable supply chain management: small and medium-sized enterprises in Mexico. Journal of Cleaner Production, 67, 239-248.

Verhoef, P.C. \& Leeflang, P.S.H. (2009). Understanding the Marketing Department's Influence within the Firm. Journal of Marketing, 73, 14-37. 
Verma, A.S. (2014). Sustainable Supply Chain Management Practices: Selective Case Studies from Indian Hospitality Industry. International Management Review, 10(2), $13-23$.

Vermeulen, W.J.V., \& Seuring, S. (2009). Sustainability through the market - the impacts of sustainable supply chain management: introduction. Sustainable Development, 17(5), 269-273.

Vincent, J.R., \& Panayotou, T. (1997). Or distraction? Science, 276, 53-55.

Vithessonthi, C., \& Tongurai, J. (2015). The effect of firm size on the leverageperformance relationship during the financial crisis of 2007-2009. Journal of Multinational Financial Management, 29, 1-29.

Vlachos, P. A., Panagopoulos, N. G., \& Rapp, A. A. (2013). Feeling good by doing good: Employee CSR-induced attributions, job satisfaction, and the role of charismatic leadership. Journal of Business Ethics, 118(3), 577-588.

Voss, D.S. (2004). Multicollinearity. University of Kentucky. Available at http://www.uky.edu/ dsvoss/docs/multic.pdf (Accessed 1 November, 2017).

Walker, H., \& Jones, N. (2012). Sustainable supply chain management across the UK private sector. Supply Chain Management, 17(1), 15-28.

Walker, H., \& Philipp, W. (2006). Sustainable procurement: emerging issues. International Public Procurement Conference Proceedings, 559-586.

Walker, H., Di Sisto, L., \& McBain, D. (2008). Drivers and barriers to environmental supply chain management practices: lessons from the public and private sectors. Journal of Purchasing and Supply Management, 14, 69-85. 
Wang, C. L., Ahmed, P. K., \& M. Rafiq (2008). Knowledge management orientation: construct development and empirical validation. European Journal of Information Systems, 17(3), 219-235.

Wang, J., \& Dai, J. (2018). Sustainable supply chain management practices and performance. Industrial Management \& Data Systems, 118(1), 2-21. https://doi.org/10.1108/IMDS-12-2016-0540

Wang, Z., \& Sarkis, J. (2013). Investigating the relationship of sustainable supply chain management with corporate financial performance. The international journal of productivity and performance management: IJPPM, 62(8), 871-888.

Webster, S., \& Mitra, S. (2007).Competitive strategy in remanufacturing and the impact of take-back laws. Journal of Operations Management, 25(6), 1123-1140.

Weng, L.J. (2004). Impact of the Number of Response Categories and Anchor Labels on Coefficient Alpha and Test-Retest Reliability. Educational and Psychological Measurement, 64(6), 956-972.

West, S. G., Finch, J. F., \& Curran, P. J. (1995). Structural equation models with nonnormal variables: Problems and remedies. In R. H. Hoyle (Ed.), Structural equation modeling: Concepts, issues, and applications (pp. 56-75). Thousand Oaks, CA: Sage.

Winn, M., Pinkse, J., \& Illge, L. (2012). Case studies on trade-offs in corporate sustainability. Corporate Social Responsibility and Environmental Management, 19(2), 63-68. 
Winter, M., \& Knemeyer, A.M. (2013). Exploring the integration of sustainability and supply chain management: current state and opportunities for future inquiry. International Journal of Physical Distribution \& Logistics Management, 43(1), 1838.

Wittstruck, D., \& Teuteberg, F. (2012). Understanding the Success Factors of Sustainable Supply Chain Management: Empirical Evidence from the Electrics and Electronics Industry. Corporate Social Responsibility \& Environmental Management, 19(3), $141-158$.

Wolf, J. (2011). Sustainable Supply Chain Management Integration: A Qualitative Analysis of the German Manufacturing Industry. Journal of Business Ethics, 102(2), 221-235.

Wolf, J. (2014). The Relationship between Sustainable Supply Chain Management, Stakeholder Pressure and Corporate Sustainability Performance. Journal of Business Ethics, 119(3), 317-328.

Wolters, T., James, P., \& Bouman, M. (1997). Stepping-stones for integrated chain management in the firm. Business Strategy and the Environment, 6(3), 121-132.

Wong, C.Y., Wong, C.W.Y., \& Boon-itt, S. (2015). Integrating environmental management into supply chains: A systematic literature review and theoretical framework. International journal of physical distribution \& logistics management. 45(1/2), 43-68.

Wood, D.I. (1991). Corporate Social Performance Revisited. Academy of Management Review, 16(4), 691-718. 
Wu, G.C., Ding, J.H., Chen, P.S. (2012). The effects of GSCM drivers and institutional pressures on GSCM practices in Taiwan's textile and apparel industry. International Journal of Production Economics, 135(2), 618-636.

Wu, Z., \& Pagell, M. (2011). Balancing priorities: Decision-making in sustainable supply chain management. Journal of Operations Management, 29(6), 577-590.

Xu, X., \& Gursoy, D. (2015). A Conceptual Framework of Sustainable Hospitality Supply Chain Management. Journal of Hospitality Marketing \& Management, 24(3), 229-259.

Yang, H. D., Kang, H.R. \& Mason, R. M. (2008). An exploratory study on meta skills in software development teams: Antecedent cooperation skills and personality for shared mental models. European Journal of Information Systems, 17(1), 47-61.

Zailani, S., Jeyaraman, K., Vengadasan, G. \& Premkumar, R. (2012). Sustainable supply chain management (SSCM) in Malaysia: A survey. International Journal of Production Economics, 140(1), 330-340.

Zhu Q, \& Sarkis J. (2004). Relationships between operational practices and performance among early adopters of green supply chain management practices in Chinese manufacturing enterprises. Journal of Operations Management, 22, 265-289.

Zhu Q, \& Sarkis J. (2006). An inter-sectoral comparison of green supply chain management in China: Drivers and practices. Journal of Cleaner Production, 14(5), 472-486. 
Zhu, Q. \& Sarkis, J. (2007). The moderating effects of institutional pressures on emergent green supply chain practices and performance. International Journal of Production Research, 45(18-19), 4333-4355.

Zhu, Q., Sarkis, J. \& Lai, K. (2008b). Green supply chain management implications for "closing the loop". Transportation Research Part E: Logistics and Transportation Review, 44(1), 1-18.

Zhu, Q., Sarkis, J., \& Geng, Y. (2005). Green supply chain management in China: pressures, practices and performance. International Journal of Operations \& Production Management, 25(5), 449-468.

Zhu, Q., Sarkis, J., \& Lai, K. (2007). Green supply chain management: pressures, practices and performance within the Chinese automobile industry. Journal of Cleaner Production, 15, 1041-1052.

Zhu, Q., Sarkis, J., \& Lai, K. (2008a). Confirmation of a measurement model for green supply chain management practices implementation. International Journal of Production Economics, 111(2), 261-273.

Zhu, Q., Sarkis, J., \& Lai, K.H. (2007). Initiatives and outcomes of green supply chain management implementation by Chinese manufacturers. Journal of Environmental Management, 25(6), 179-189.

Zorzini, M., Hendry, L.C., Huq, F.A., \& Stevenson, M. (2015). Socially responsible sourcing: reviewing the literature and its use of theory. International Journal of Operations \& Production Management, 35(1), 60-109. 
Zsidisin, G.A., Hendrick, T.E. (1998). Purchasing's involvement in environmental issues: a multi-country perspective. Industrial Management \& Data Systems, 98(7-8), 313320. 


\section{Appendices}

\section{Appendix I Letter of Invitation to Participate in the Study}

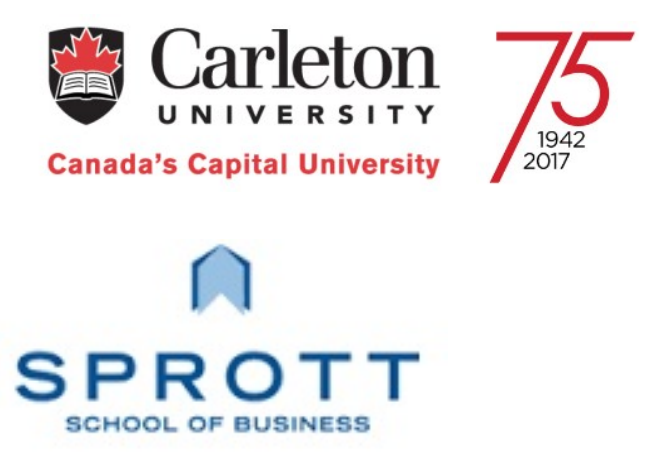

September 9, 2017

Dear Sir/Madam,

SUBJECT: Carleton University Research Study - Impact of Adoption of Sustainable Supply Chain Management Practices On a Firm's Performance

My name is Dr. I.J. Mann. I am a Ph.D. Candidate at the Sprott School of Business, Carleton University. As a former executive, I have a keen interest in sustainability issues in supply chains. Under the guidance of my Thesis Supervisor, Dr. Vinod Kumar, I am conducting research on the impact of adoption of Sustainable Supply Chain Management Practices on a Firm's Performance. This research has been reviewed by and has received clearance from the Carleton University Research Ethics Board.

The data for the study is being collected from managers who are knowledgeable of their organization's supply chain activities in firms located in Canada and/or US. If you do not deal with supply chain activities in your organisation, may I request you to kindly forward it to the manager who does so. The link for Survey is https://www.surveymonkey.com/r/XTYEZ6O .

As you are aware, sustainability and green practices are becoming key concerns of consumers and the government. Working in that direction, an increasing number of firms are adopting sustainable supply chain practices and this adoption is expected to affect the performance of the firms- including their economic, social, ecological and operating performance. 
This research should help companies better identify supply chain practices that are sustainable and can positively impact their performance.

I am writing to request your participation in the study by completing a brief SurveyMonkey® online questionnaire at: https://www.surveymonkey.com/r/XTYEZ6O (if the weblink does not take you directly to the survey, please copy and paste it into your browser). The questionnaire should take about 10 minutes to complete. Your responses will be anonymous and thus cannot be identified. Anonymity will be ensured both at the stage of data collection and also by aggregating the responses when presenting the research findings. Since your url will not be tracked, this means that you will need to complete the questionnaire in one "sitting" of ten minutes, i.e., you cannot complete it partially and go back at a later time to complete it.

There are no foreseen risks to the participants of this study. Please note that SurveyMonkey ${ }^{\circledR}$ servers on which the data will be stored are located in the U.S. and the data collected is subject to U.S. laws on privacy and security. The research findings from this study will be presented in the final $\mathrm{PhD}$ Thesis and in a series of academic papers that will be presented in academic research papers and/or at academic conferences. The data will be stored in electronic copy (in an aggregate manner) for a period of one year with only the researcher, the research supervisor and the survey company having access to it. You can withdraw from the study at any time before submission of the survey, if you wish to withdraw please do not click on the submit button.

Second, I would greatly appreciate if you could further send this email to your colleagues at the senior manager or executive levels in other firms who are knowledgeable about supply chain processes so that they may participate as well by completing the questionnaire. Your help in this regard is highly appreciated.

All information provided by you will be processed anonymously and in an aggregate manner only. It will not be identifiable and will not be attributed to your name or that of your company.

If you would like a summary of the results of this research, I would be pleased to provide it. Simply send me an email and I will send the summary as soon as the study is completed.

I will be happy to answer any questions you may have about this research. My email address is Inder.Mann@carleton.ca. Alternatively, you can contact my Thesis Supervisor, Dr. Vinod Kumar at the address given below. This study has been cleared by Carleton University Research Ethics Board (ethics clearance \#106715). If you have any ethical concerns with the study, please contact Dr. Andy Adler, Chair, Carleton University Research Ethics Board-A (by phone at 613-520-2600 ext. 2517 or via email at ethics@carleton.ca). 
Please note that we are NOT requesting any confidential or sensitive information in the questionnaire as this is a non-secure web-hosted survey. Further, as this is an anonymous survey no url or identifiers will be collected and your identity will not be known to the researcher.

Thank you for your time.

With best regards.

Dr. I. J. Mann

Ph.D Candidate

Dr. Vinod Kumar, Thesis Supervisor Sprott School of Business

Carleton University

613-520-2600 ext. 2379

Vinod.Kumar@carleton.ca 


\section{Appendix II Copy of Online Survey Consent Form}

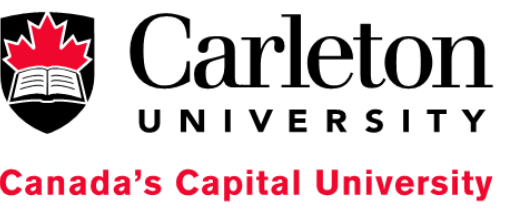

\section{Online Survey Consent Form}

Title: Impact of Adoption of Sustainable Supply Chain Management Practices On a Firm's Performance.

Date of ethics clearance: June 16, 2017.

Ethics Clearance for the Collection of Data Expires: June 30, 2018.

This is a study on the Impact of Adoption of Sustainable Supply Chain Management Practices on a Firm's Performance. As you are aware, sustainability and green practices are becoming key concerns of consumers and the government. Working in that direction, an increasing number of firms are adopting sustainable supply chain practices and this adoption is expected to affect the performance of the firms- including their economic, social, ecological and operating performance. This research should help companies better identify supply chain practices that are sustainable and can positively impact their performance.

The researcher for this study is Dr. Inder Jit Singh Mann in the Sprott School of Business at Carleton University. He is working under the supervision of Prof. Vinod Kumar in the Sprott School of Business.

This study involves one 10 minute survey that will take place online.

You have the right to end your participation in the survey at any time, for any reason, up until you hit the "submit" button. You can withdraw by exiting the survey at any time before completing it. If you withdraw from the study, all information you provided will 
be immediately destroyed. (As the survey responses are anonymous, it is not possible to withdraw after the survey is submitted.)

All research data will be collected anonymously and will be password protected. The company running the online survey is a US firm SurveyMonkey.com. The servers are located in the United States and the data collected is subject to U.S. laws on privacy and security.

The anonymous research data will be accessible by the researcher, the research supervisor and the survey company. No names or IP addresses will be linked to any of the data provided. The data will be retained for one year and will be used for Doctoral Research, for publications in academic journals, and in academic conference presentations.

If you would like a copy of the finished research project, you are invited to contact the researcher by email to request an electronic copy which will be provided to you as long as the safety of all participants will not be comprised by doing so. This request will not affect the anonymity of your responses as it is independent of anonymous survey response form submitted by you.

The ethics protocol for this project was reviewed by the Carleton University Research Ethics Board, which provided clearance to carry out the research.

\section{CUREB-A:}

If you have any ethical concerns with the study, please contact Dr. Andy Adler, Chair, Carleton University Research Ethics Board-A (by phone at 613-520-2600 ext. 2517 or via email at ethics@,carleton.ca).

Researcher contact information:

Name Dr. Inder Jit Singh Mann

Sprott School of Business

Carleton University

Email: Inder.Mann@,carleton.ca
Supervisor contact information:

Name: Prof.Vinod Kumar

Sprott School of Business

Carleton University

Tel: 613-520-2600 x 2379

Email: Vinod.Kumar@carleton.ca 
By clicking "submit", you consent to participate in the research study as described above. 


\section{Appendix III Survey Instrument Used for Research}

\section{ACADEMIC RESEARCH SURVEY}

\section{Impact of Adoption of \\ Sustainable Supply Chain Management Practices \\ On a Firm's Performance}

\section{SUMMARY OF RESEARCH FINDINGS}

If you would like a copy of the finished research project, you are invited to contact the researcher by email to request an electronic copy which will be provided to you as long as the safety of all participants will not be comprised by doing so. This request will not affect the anonymity of your responses as it is independent of anonymous survey response form submitted by you.

\section{MOTIVATIONS FOR SUSTAINABLE SUPPLY CHAIN MANAGEMENT}

\section{PRACTICES}

Please indicate the level of the following items in your organization over the past 3 years. (Please circle the number)

\section{Regulations}

$$
\begin{array}{lr}
\text { Strongly } & \text { Strongly } \\
\text { Disagree } & \text { Agree }
\end{array}
$$

1. Environmental regulation is the primary driver for all our $\begin{array}{lllllllll}1 & 2 & 3 & 4 & 5 & 6 & 7\end{array}$ environmental activities.

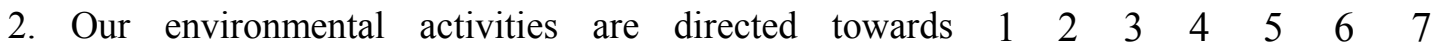
complying with institutional norms and/or regulations.

3. Preempting future environmental legislation is the main $\begin{array}{llllllll}1 & 2 & 3 & 4 & 5 & 6 & 7\end{array}$ driver for adoption of proactive environmental practices.

\section{Competitiveness}

$$
\begin{array}{lr}
\text { Strongly } & \text { Strongly } \\
\text { Disagree } & \text { Agree }
\end{array}
$$

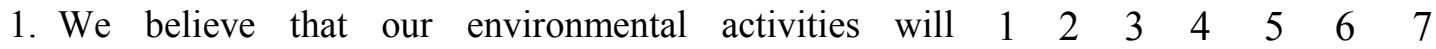
differentiate us from our competitors.

2. We believe that our ecological responsiveness will lead to $\begin{array}{llllllll}1 & 2 & 3 & 4 & 5 & 6 & 7\end{array}$ long-term profitability.

3. Protecting environment will improve long-term financial $\begin{array}{llllllll}1 & 2 & 3 & 4 & 5 & 6 & 7\end{array}$ 
performance is the main driver for adoption of proactive

environmental strategies

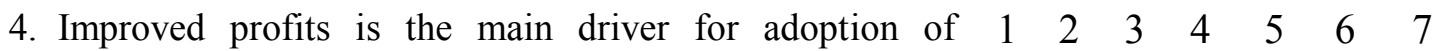
environmental practices

5. Access to overseas market is the main driver for adoption $\begin{array}{llllllll}1 & 2 & 3 & 4 & 5 & 6 & 7\end{array}$ of proactive environmental strategies

6. Improving efficiency is the main driver for adoption of $11 \quad 2 \quad \begin{array}{llllll}3 & 4 & 5 & 6 & 7\end{array}$ proactive environmental strategies.

7. Cost saving and risk reduction is the main driver for $\begin{array}{lllllllll}1 & 2 & 3 & 4 & 5 & 6 & 7\end{array}$ adoption of environmental practices.

\section{Stakeholder Pressures}

Strongly Strongly

Disagree Agree

1. Stakeholder relationship is the main driver for adoption of $\begin{array}{llllllll}1 & 2 & 3 & 4 & 5 & 6 & 7\end{array}$ proactive environmental practices.

2. Stakeholder satisfaction is the main driver for adoption of $\begin{array}{llllllll}1 & 2 & 3 & 4 & 5 & 6 & 7\end{array}$ environmental practices.

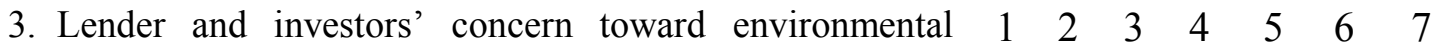
liability is the main driver for adoption of environmental practices.

Customer desire to protect environment is the main driver for adoption of environmental practices.

Non Profit Organizations/judiciary/media enquiries is the main driver for adoption of environmental practices $\begin{array}{lllllll}1 & 2 & 3 & 4 & 5 & 6 & 7\end{array}$

$\begin{array}{lllllll}1 & 2 & 3 & 4 & 5 & 6 & 7\end{array}$

\section{SUSTAINABLE SUPPLY CHAIN MANAGEMENT PRACTICES}

Please indicate the level of the following items in your organization over the past 3 years. (Please circle the number)

\section{External environmental practices}

$\begin{array}{lr}\text { Strongly } & \text { Strongly } \\ \text { Disagree } & \text { Agree }\end{array}$

1. We cooperate with our suppliers to achieve environmental $1 \begin{array}{llllllll}1 & 2 & 3 & 4 & 5 & 6 & 7\end{array}$ objectives. 


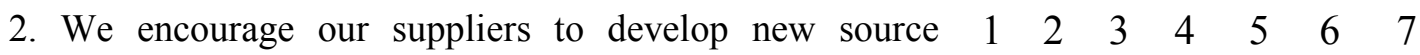
reduction strategies.

3. We cooperate with our suppliers to improve their waste $\begin{array}{llllllll}1 & 2 & 3 & 4 & 5 & 6 & 7\end{array}$ reduction initiatives.

4. We work with our suppliers for cleaner production. $\quad \begin{array}{llllllll}1 & 2 & 3 & 4 & 5 & 6 & 7\end{array}$

\section{Internal environmental practices}

$\begin{array}{lr}\text { Strongly } & \text { Strongly } \\ \text { Disagree } & \text { Agree }\end{array}$

1. We support the inventory recovery (sale) of excess $11 \begin{array}{lllllll}2 & 3 & 4 & 5 & 6 & 7\end{array}$ inventories/materials.

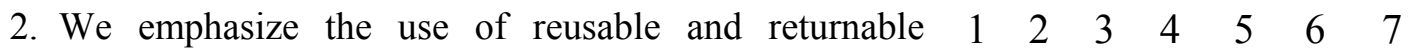
packaging for our products.

3. We constantly strive to use lesser resources in getting $1 \begin{array}{lllllll}1 & 2 & 3 & 4 & 5 & 6 & 7\end{array}$ the tasks done.

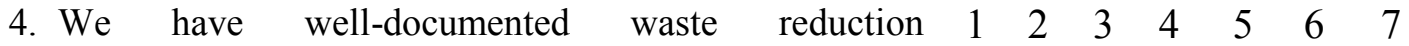
methodologies in place.

5. We eliminate physical waste from our operations.

$\begin{array}{lllllll}1 & 2 & 3 & 4 & 5 & 6 & 7\end{array}$

6. We support the sale of scrap and used materials.

$\begin{array}{lllllll}1 & 2 & 3 & 4 & 5 & 6 & 7\end{array}$

\section{Supplier Selection}

$\begin{array}{lr}\text { Strongly } & \text { Strongly } \\ \text { Disagree } & \text { Agree }\end{array}$

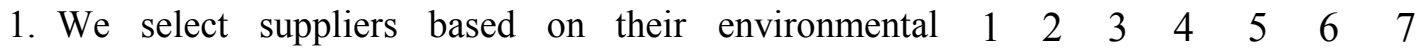
competence.

2. Suppliers are selected based on their ability to support $\begin{array}{llllllll}1 & 2 & 3 & 4 & 5 & 6 & 7\end{array}$ our environmental objectives.

3. We select suppliers based on their environmental $1122 \begin{array}{lllllll} & 2 & 4 & 4 & 5 & 6 & 7\end{array}$ performance.

We select suppliers based on their ability to develop

$\begin{array}{lllllll}1 & 2 & 3 & 4 & 5 & 6 & 7\end{array}$ environmentally friendly goods.

$\begin{array}{lllllllll}\text { Our organization has a thorough supplier environmental } & & 1 & 2 & 3 & 4 & 5 & 6 & 7\end{array}$ rating system.

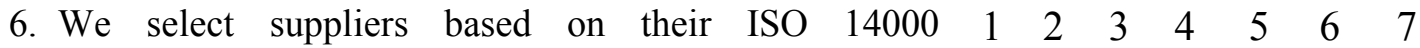
Certification. 


\section{Supplier Evaluation \& Monitoring}

$\begin{array}{rr}\text { Strongly } & \text { Strongly } \\ \text { Disagree } & \text { Agree }\end{array}$

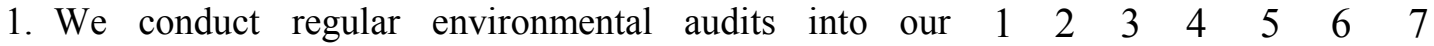
suppliers' internal operations.

2. We periodically evaluate our suppliers' environmentally $1 \begin{array}{lllllll}1 & 2 & 3 & 4 & 5 & 6 & 7\end{array}$ friendly practices.

3. We make site visits to suppliers' premises to help them $\begin{array}{llllllll}1 & 2 & 3 & 4 & 5 & 6 & 7\end{array}$ improve their eco-performance.

4. We periodically evaluate our second-tier suppliers' $1 \begin{array}{lllllll}1 & 2 & 3 & 4 & 5 & 6 & 7\end{array}$ environmentally friendly practices.

5. We ask our suppliers to commit to waste reduction goals. $\begin{array}{llllllll}1 & 2 & 3 & 4 & 5 & 6 & 7\end{array}$

6. We send environmental questionnaires to suppliers in $\begin{array}{llllllll}1 & 2 & 3 & 4 & 5 & 6 & 7\end{array}$ order to monitor their compliance.

\section{Cooperation with Customers}

$\begin{array}{rr}\text { Strongly } & \text { Strongly } \\ \text { Disagree } & \text { Agree }\end{array}$

1. We co-operate with customers for eco design.

$\begin{array}{lllllll}1 & 2 & 3 & 4 & 5 & 6 & 7\end{array}$

2. We co-operate with customers for cleaner production.

$\begin{array}{lllllll}1 & 2 & 3 & 4 & 5 & 6 & 7\end{array}$

3. We co-operate with customers for green packaging.

$\begin{array}{lllllll}1 & 2 & 3 & 4 & 5 & 6 & 7\end{array}$

4. We co-operate with customers using less energy during $\begin{array}{llllllll}1 & 2 & 3 & 4 & 5 & 6 & 7\end{array}$ product transportation.

5. We develop a mutual understanding with our customers of $\begin{array}{lllllll}1 & 2 & 3 & 4 & 5 & 6 & 7\end{array}$ responsibilities regarding environmental performance.

6. We work together with our customers to reduce the $\begin{array}{llllllll}1 & 2 & 3 & 4 & 5 & 6 & 7\end{array}$ environmental impact of our activities.

\section{Eco-Design}

$\begin{array}{rr}\text { Strongly } & \text { Strongly } \\ \text { Disagree } & \text { Agree }\end{array}$

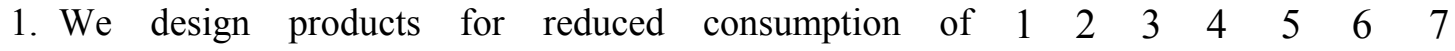
material/energy.

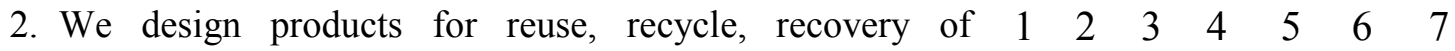
material, component parts.

$\begin{array}{lllllllll}\text { We design products to avoid or reduce use of hazardous } & & 1 & 2 & 3 & 4 & 5 & 6 & 7\end{array}$ 
products and/or their manufacturing process.

\section{Social Sustainability Practices}

$\begin{array}{lr}\text { Strongly } & \text { Strongly } \\ \text { Disagree } & \text { Agree }\end{array}$

1. Our organization frequently employs corporate codes of $\begin{array}{lllllll}1 & 2 & 3 & 4 & 5 & 6 & 7\end{array}$ conduct and other aspects of corporate social responsibility.

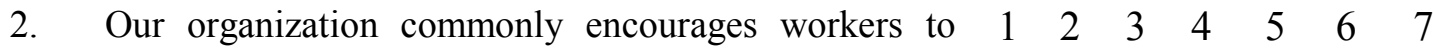
volunteer for social causes and has incentives that facilitate that involvement.

3. Our organization contributes to charitable causes.

$\begin{array}{lllllll}1 & 2 & 3 & 4 & 5 & 6 & 7\end{array}$

The general approach of our organization to human resources $\begin{array}{lllllll}1 & 2 & 3 & 4 & 5 & 6 & 7\end{array}$ is to invest heavily to attract, train and retain employees.

5. In our organization employment of women is $\left(\begin{array}{llllllll}1=\text { limited } & 1 & 2 & 3 & 4 & 5 & 6 & 7\end{array}\right.$ and usually takes place in less important jobs, $7=$ is equal to that of men)

In our organization, for similar work, wages for women are (1=significantly below those of men, $7=$ equal to those of men).

\section{PERFORMANCE}

Please indicate the level of the following items in your organization. (Please circle the number)

1. Economic Performance over the past 3 years

$\begin{array}{rr}\text { Strongly } & \text { Strongly } \\ \text { Disagree } & \text { Agree }\end{array}$

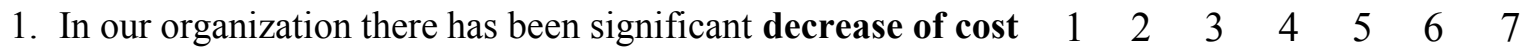
for materials purchasing over the past 3 years.

2. In our organization there has been significant decrease of cost $\quad 1 \quad \begin{array}{lllllll}2 & 3 & 4 & 5 & 6 & 7\end{array}$ for energy consumption over the past 3 years.

3. In our organization there has been significant decrease of fee $\quad \begin{array}{lllllll}1 & 2 & 3 & 4 & 5 & 6 & 7\end{array}$ for waste treatment over the past 3 years.

4. In our organization there has been significant decrease of fee $\quad \begin{array}{lllllll}1 & 2 & 3 & 4 & 5 & 6 & 7\end{array}$ for waste discharge over the past 3 years.

5. In our organization there has been significant decrease of fine $\quad 1 \quad \begin{array}{lllllll}2 & 2 & 3 & 4 & 5 & 6 & 7\end{array}$ 
for environmental accidents over the past 3 years.

2. Environmental performance over the past 3 years

$\begin{array}{rr}\text { Strongly } & \text { Strongly } \\ \text { Disagree } & \text { Agree }\end{array}$

1. In our organization there has been significant reduction of $\begin{array}{lllllll}1 & 2 & 3 & 4 & 5 & 6 & 7\end{array}$ air emission over the past 3 years.

2. In our organization there has been significant reduction of $\begin{array}{lllllll}1 & 2 & 3 & 4 & 5 & 6 & 7\end{array}$ waste water over the past 3 years.

3. In our organization there has been significant reduction of $\begin{array}{llllllll}1 & 2 & 3 & 4 & 5 & 6 & 7\end{array}$ solid wastes over the past 3 years.

4. In our organization there has been significant decrease in $\begin{array}{llllllll}1 & 2 & 3 & 4 & 5 & 6 & 7\end{array}$ consumption for hazardous/harmful/toxic materials over the past 3 years.

5. In our organization there has been significant decrease in $\begin{array}{lllllll}1 & 2 & 3 & 4 & 5 & 6 & 7\end{array}$ frequency for environmental accidents over the past 3 years.

6. There has been significant improvement $\begin{array}{lllllllll}\text { of } & \text { our } & 1 & 2 & 3 & 4 & 5 & 6 & 7\end{array}$ organization's environmental situation over the past 3 years.

3. Social Performance over the past 3 years

$$
\begin{array}{lr}
\text { Strongly } & \text { Strongly } \\
\text { Disagree } & \text { Agree }
\end{array}
$$

1. In our organization there has been significant increase in $\begin{array}{llllllll}1 & 2 & 3 & 4 & 5 & 6 & 7\end{array}$ days of vocational training over the past 3 years.

2. In our organization there has been significant increase in $\begin{array}{llllllll}1 & 2 & 3 & 4 & 5 & 6 & 7\end{array}$ philanthropy as a share of profit over the past 3 years.

3. In our organization there has been significant increase in $\begin{array}{llllllll}1 & 2 & 3 & 4 & 5 & 6 & 7\end{array}$ formalization of community relations over the past 3 years.

4. In our organization there has been significant increase in $\begin{array}{llllllll}1 & 2 & 3 & 4 & 5 & 6 & 7\end{array}$ equal opportunity employment over the past 3 years.

5. In our organization there has been significant decrease in $\begin{array}{llllllll}1 & 2 & 3 & 4 & 5 & 6 & 7\end{array}$ employee turnover over the past 3 years. 
4. Operational Performance over the past 3 years

$\begin{array}{rr}\text { Strongly } & \text { Strongly } \\ \text { Disagree } & \text { Agree }\end{array}$

1. In our organization there has been significant increase in $\begin{array}{llllllll}1 & 2 & 3 & 4 & 5 & 6 & 7\end{array}$ amount of goods delivered on time over the past 3 years.

2. In our organization there has been significant decrease in $\begin{array}{llllllll}1 & 2 & 3 & 4 & 5 & 6 & 7\end{array}$ inventory levels over the past 3 years.

3. In our organization there has been significant $1120 \begin{array}{llllll} & 2 & 4 & 5 & 6 & 7\end{array}$ improvement in capacity utilization over the past 3 years.

4. In our organization there has been significant decrease in $\begin{array}{llllllll}1 & 2 & 3 & 4 & 5 & 6 & 7\end{array}$ scrap rate over the past 3 years.

5. In our organization there has been significant increase in $\begin{array}{llllllll}1 & 2 & 3 & 4 & 5 & 6 & 7\end{array}$ products' quality over the past 3 years.

6. In our organization there has been significant increase in $\begin{array}{llllllll}1 & 2 & 3 & 4 & 5 & 6 & 7\end{array}$ product line over the past 3 years.

\section{YOUR ORGANIZATION}

1. What type of industry is your organization in?

General manufacturing $\quad \square \quad$ Food Industry

Electrical equipment, appliance, and $\square$ Chemical manufacturing component manufacturing Primary metal manufacturing $\quad \square \quad$ Fabricated metal product manufacturing Machinery manufacturing $\quad \square$ Computer and electronic product manufacturing

Transportation equipment $\square$ Other manufacturing

2. How many employees do you have in your organization? Approximately Or

3. Has your organization obtained the ISO 14000 certification?

Yes 
4. If your answer to question 3 is YES, for the last how many years has your organization maintained the

ISO 14000 certification?

Less than 3 years

3 years or more

Not applicable

5. Choose the title which most closely reflects your current position?

$\square$ Senior Manager

$\square$ Vice President

$\square$ General Manager

President

$\square$ CEO

Board of Directors Member

$\square$ Owner

$\square$ Partner

Consultant

Other (please specify)

6. In which area is your organization headquartered?

Canada

The United States

Mexico

South America

$\square$ Europe

$\square$ Oceania

$\square$ Asia

$\square$ Africa

$\square$ Other (please specify)

7. Which of the following describes the firm used in your example?

Privately owned

$\square$ Publicly owned

How many years experience do you have in the industry used in your example?

Less than 1 year $\square 1$ to less than 3 yrs. $\square 3$ to less than 5 yrs. $\square 5$ to less than 10 yrs 10 yrs. or more

WITHDRAWING FROM SURVEY: You have the right to end your participation in the survey at any time, for any reason, up until you hit the "submit" button. If you withdraw from the study, 
all information you provided will be immediately destroyed. (As the survey responses are anonymous, it is not possible to withdraw after the survey is submitted.)

CONSENT: By clicking "submit" button, I acknowledge that I consent to participate in the research study as described above.

\section{[SUBMIT]}


Appendix IV Kolmogorov-Smirnova and Shapiro-Wilk Tests of Normality

Tests of Normality

\begin{tabular}{|l|r|r|r|r|r|r|}
\hline \multirow{2}{*}{ Indicators } & \multicolumn{2}{|c|}{ Kolmogorov-Smirnova } & \multicolumn{3}{|c|}{ Shapiro-Wilk } \\
\cline { 2 - 7 } & Statistic & \multicolumn{1}{c|}{ df } & Sig. & Statistic & df & \multicolumn{1}{c|}{ Sig. } \\
\hline REG1 & .143 & 218 & .000 & .932 & 218 & .000 \\
REG2 & .162 & 218 & .000 & .914 & 218 & .000 \\
REG3 & .138 & 218 & .000 & .920 & 218 & .000 \\
COMP1 & .136 & 218 & .000 & .930 & 218 & .000 \\
COMP2 & .143 & 218 & .000 & .929 & 218 & .000 \\
COMP3 & .160 & 218 & .000 & .923 & 218 & .000 \\
COMP4 & .149 & 218 & .000 & .936 & 218 & .000 \\
COMP5 & .145 & 218 & .000 & .943 & 218 & .000 \\
COMP6 & .143 & 218 & .000 & .931 & 218 & .000 \\
COMP7 & .139 & 218 & .000 & .939 & 218 & .000 \\
PRES1 & .129 & 218 & .000 & .936 & 218 & .000 \\
PRES2 & .157 & 218 & .000 & .940 & 218 & .000 \\
PRES3 & .170 & 218 & .000 & .926 & 218 & .000 \\
PRES4 & .166 & 218 & .000 & .936 & 218 & .000 \\
PRES5 & .156 & 218 & .000 & .945 & 218 & .000 \\
EEP1 & .159 & 218 & .000 & .928 & 218 & .000 \\
EEP2 & .150 & 218 & .000 & .931 & 218 & .000 \\
EEP3 & .161 & 218 & .000 & .913 & 218 & .000 \\
EEP4 & .161 & 218 & .000 & .921 & 218 & .000 \\
IEP1 & .155 & 218 & .000 & .931 & 218 & .000 \\
IEP2 & .152 & 218 & .000 & .932 & 218 & .000 \\
IEP3 & .163 & 218 & .000 & .930 & 218 & .000 \\
IEP4 & .179 & 218 & .000 & .908 & 218 & .000 \\
IEP5 & .174 & 218 & .000 & .921 & 218 & .000 \\
IEP6 & .157 & 218 & .000 & .917 & 218 & .000 \\
SS1 & .161 & 218 & .000 & .932 & 218 & .000 \\
SS2 & .151 & 218 & .000 & .934 & 218 & .000 \\
SS3 & .162 & 218 & .000 & .931 & 218 & .000 \\
SS4 & .163 & 218 & .000 & .927 & 218 & .000 \\
SS5 & .156 & 218 & .000 & .925 & 218 & .000 \\
SS6 & .167 & 218 & .000 & .923 & 218 & .000 \\
SM1 & 218 & .000 & .930 & 218 & .000 \\
SM2 & 218 & .000 & .932 & 218 & .000 \\
SM3 & .175 & .000 & .929 & 218 & .000
\end{tabular}




\begin{tabular}{|c|c|c|c|c|c|c|}
\hline SM4 & .153 & 218 & .000 & .930 & 218 & .000 \\
\hline SM5 & .147 & 218 & .000 & .932 & 218 & .000 \\
\hline SM6 & .147 & 218 & .000 & .933 & 218 & .000 \\
\hline CC1 & .146 & 218 & .000 & .925 & 218 & .000 \\
\hline $\mathrm{CC} 2$ & .174 & 218 & .000 & .924 & 218 & .000 \\
\hline CC3 & .170 & 218 & .000 & .925 & 218 & .000 \\
\hline $\mathrm{CC} 4$ & .127 & 218 & .000 & .941 & 218 & .000 \\
\hline CC5 & .159 & 218 & .000 & .926 & 218 & .000 \\
\hline CC6 & .175 & 218 & .000 & .922 & 218 & .000 \\
\hline ED1 & .141 & 218 & .000 & .933 & 218 & .000 \\
\hline ED2 & .135 & 218 & .000 & .930 & 218 & .000 \\
\hline ED3 & .130 & 218 & .000 & .937 & 218 & .000 \\
\hline SSP1 & .144 & 218 & .000 & .928 & 218 & .000 \\
\hline SSP2 & .139 & 218 & .000 & .938 & 218 & .000 \\
\hline SSP3 & .140 & 218 & .000 & .935 & 218 & .000 \\
\hline SSP4 & .171 & 218 & .000 & .932 & 218 & .000 \\
\hline SSP5 & .198 & 218 & .000 & .925 & 218 & .000 \\
\hline SSP6 & .184 & 218 & .000 & .927 & 218 & .000 \\
\hline EP1 & .157 & 218 & .000 & .925 & 218 & .000 \\
\hline EP2 & .126 & 218 & .000 & .942 & 218 & .000 \\
\hline EP3 & .153 & 218 & .000 & .932 & 218 & .000 \\
\hline EP4 & .160 & 218 & .000 & .931 & 218 & .000 \\
\hline EP5 & .171 & 218 & .000 & .931 & 218 & .000 \\
\hline ENVP1 & .156 & 218 & .000 & .932 & 218 & .000 \\
\hline ENVP2 & .157 & 218 & .000 & .933 & 218 & .000 \\
\hline ENVP3 & .172 & 218 & .000 & .921 & 218 & .000 \\
\hline ENVP4 & .169 & 218 & .000 & .921 & 218 & .000 \\
\hline ENVP5 & .165 & 218 & .000 & .930 & 218 & .000 \\
\hline ENVP6 & .170 & 218 & .000 & .926 & 218 & .000 \\
\hline SP1 & .167 & 218 & .000 & .932 & 218 & .000 \\
\hline SP2 & .150 & 218 & .000 & .935 & 218 & .000 \\
\hline SP3 & .156 & 218 & .000 & .932 & 218 & .000 \\
\hline SP4 & .190 & 218 & .000 & .923 & 218 & .000 \\
\hline SP5 & .162 & 218 & .000 & .924 & 218 & .000 \\
\hline OP1 & .159 & 218 & .000 & .932 & 218 & .000 \\
\hline OP2 & .158 & 218 & .000 & .933 & 218 & .000 \\
\hline OP3 & .163 & 218 & .000 & .931 & 218 & .000 \\
\hline OP4 & .238 & 218 & .000 & .914 & 218 & .000 \\
\hline OP5 & .136 & 218 & .000 & .937 & 218 & .000 \\
\hline OP6 & .142 & 218 & .000 & .937 & 218 & .000 \\
\hline
\end{tabular}


Appendix V Missing Data Imputation

\begin{tabular}{|c|c|c|c|}
\hline Case No. & $\begin{array}{c}\text { Value Missing in } \\
\text { Item }\end{array}$ & $\begin{array}{c}\text { Value Substituted } \\
\text { for Missing Value }\end{array}$ & Mean of Item \\
\hline 78 & EP4 & 5 & 4.9 \\
\hline 152 & EEP3 & 5 & 5.0 \\
\hline 208 & IEP6 & 5 & 4.9 \\
\hline
\end{tabular}




\section{Appendix VI Histograms of Indicator Data}
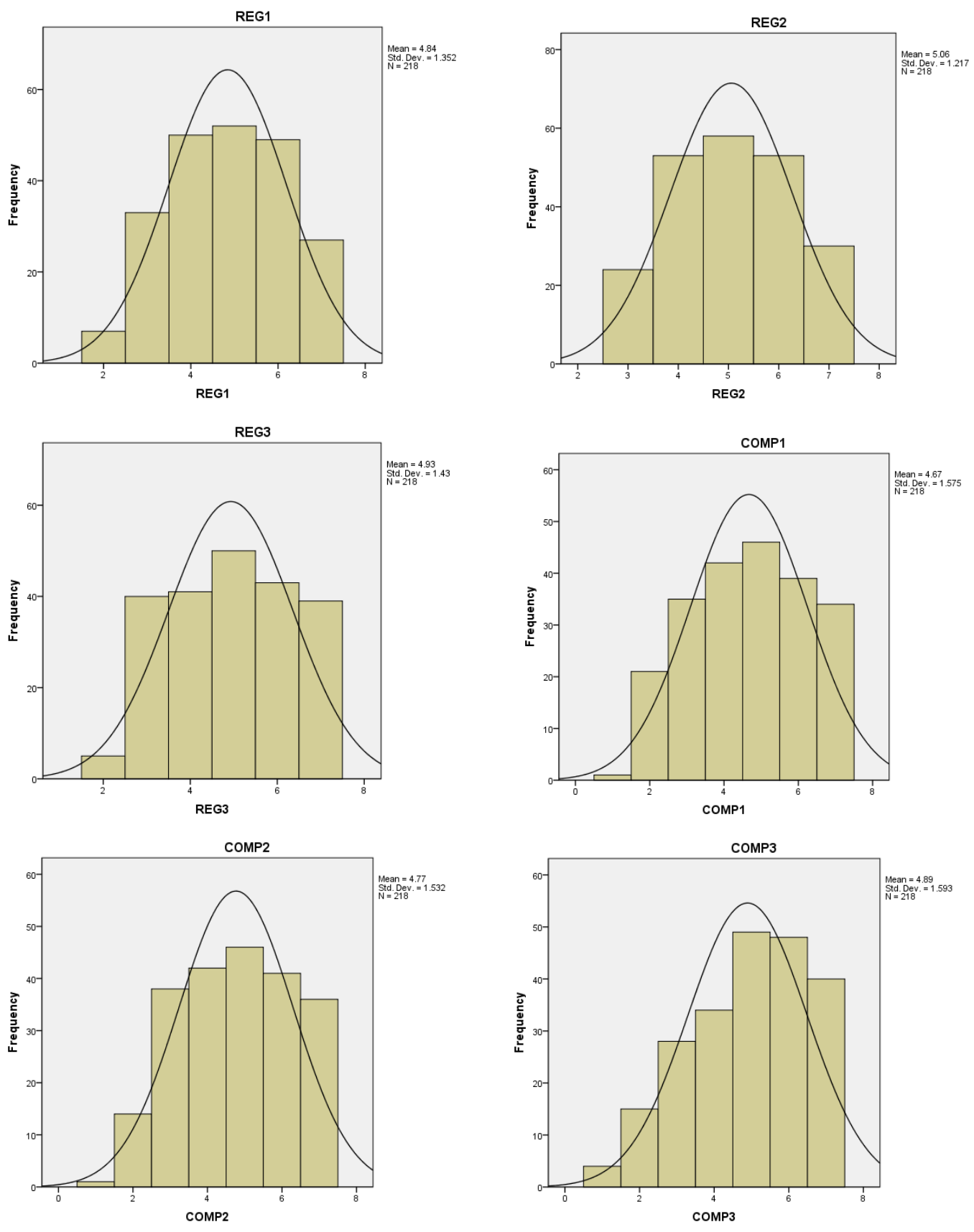

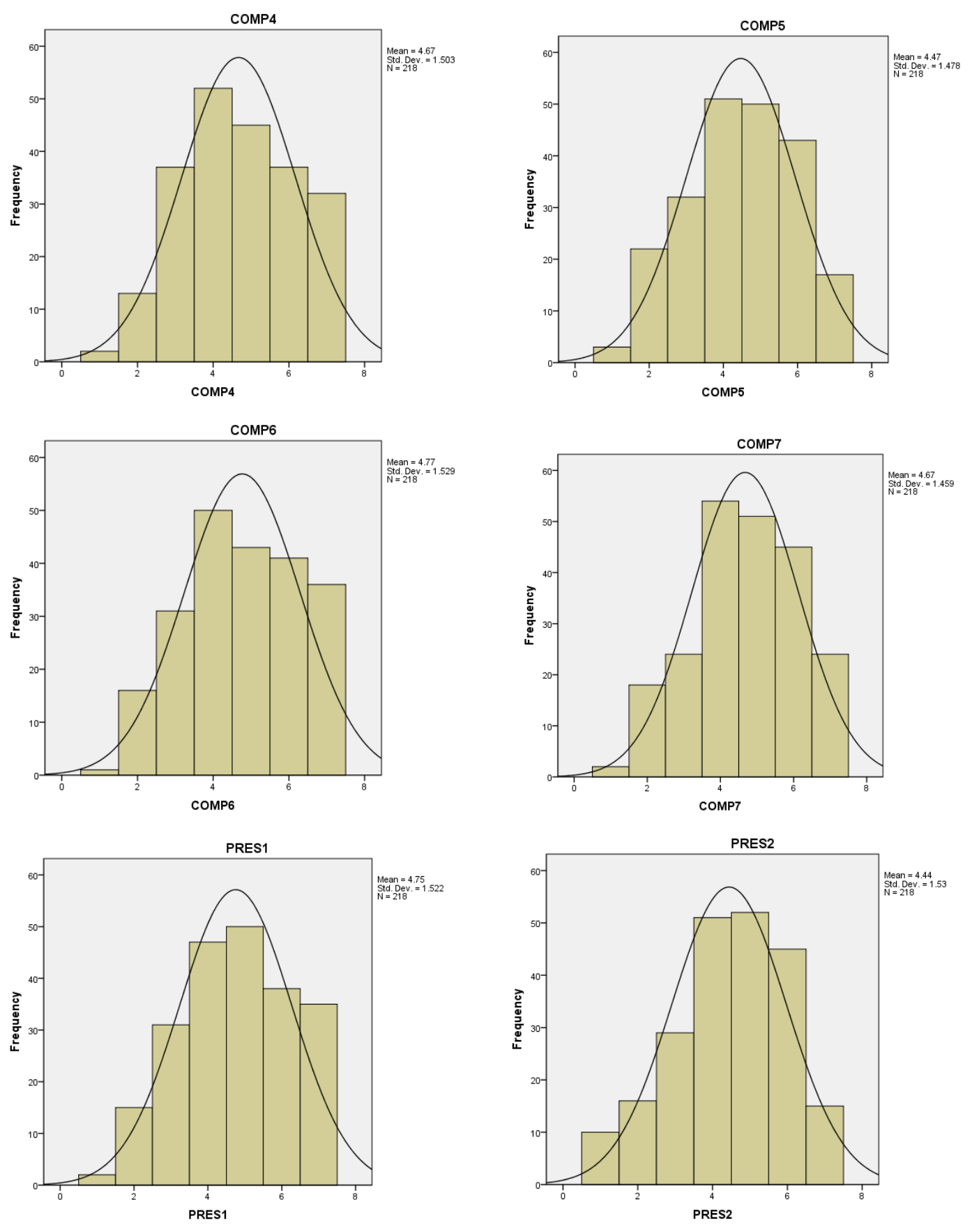

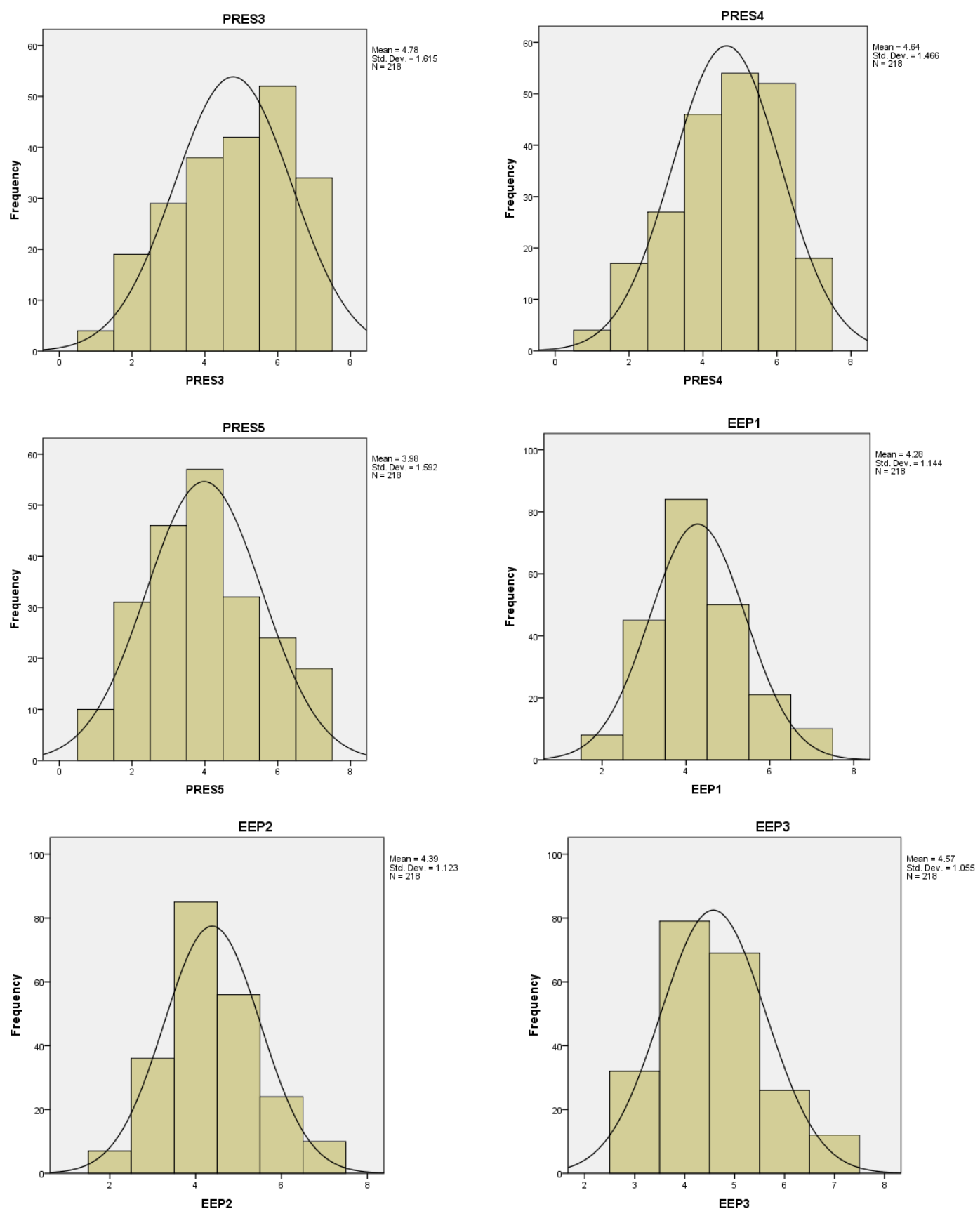

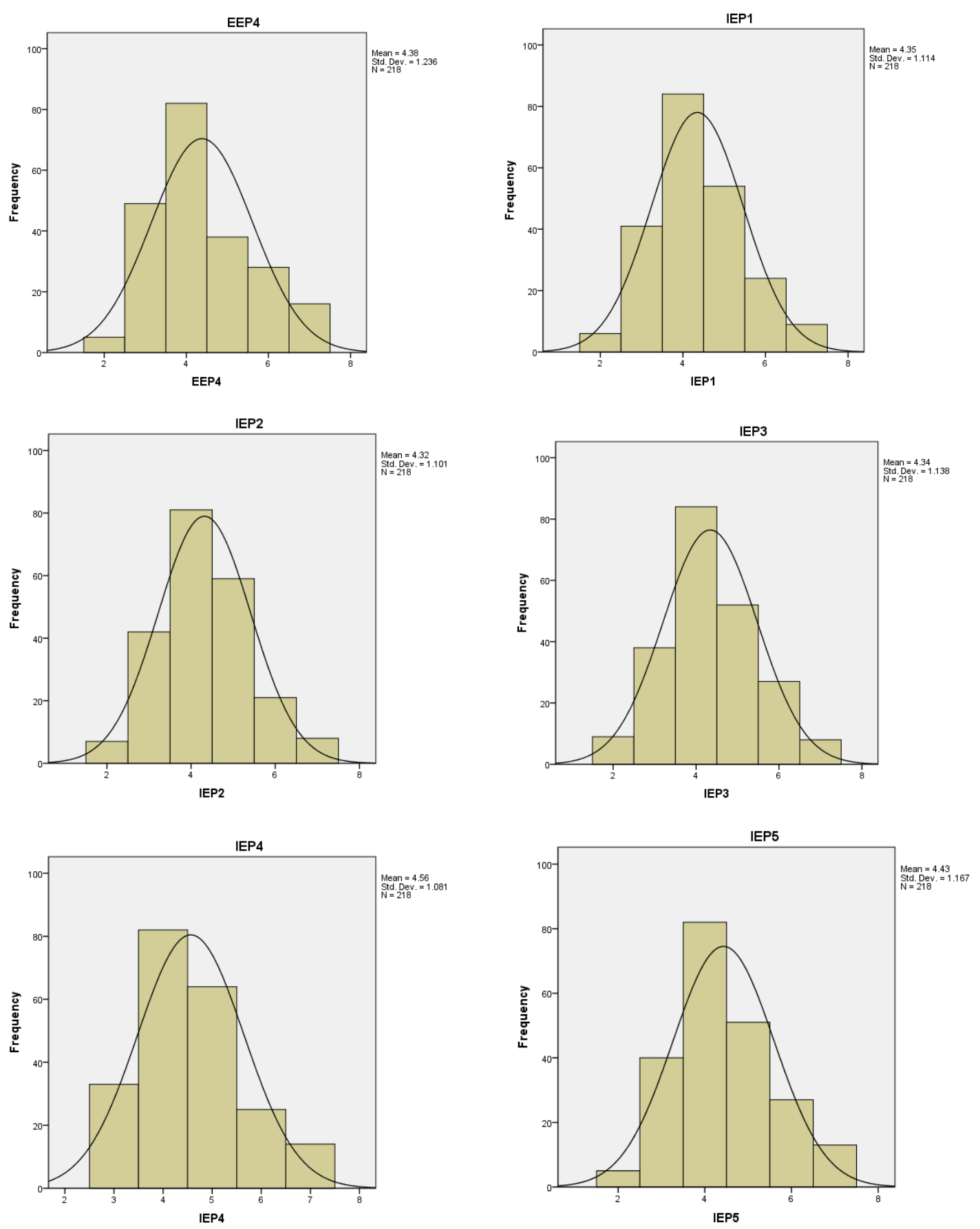

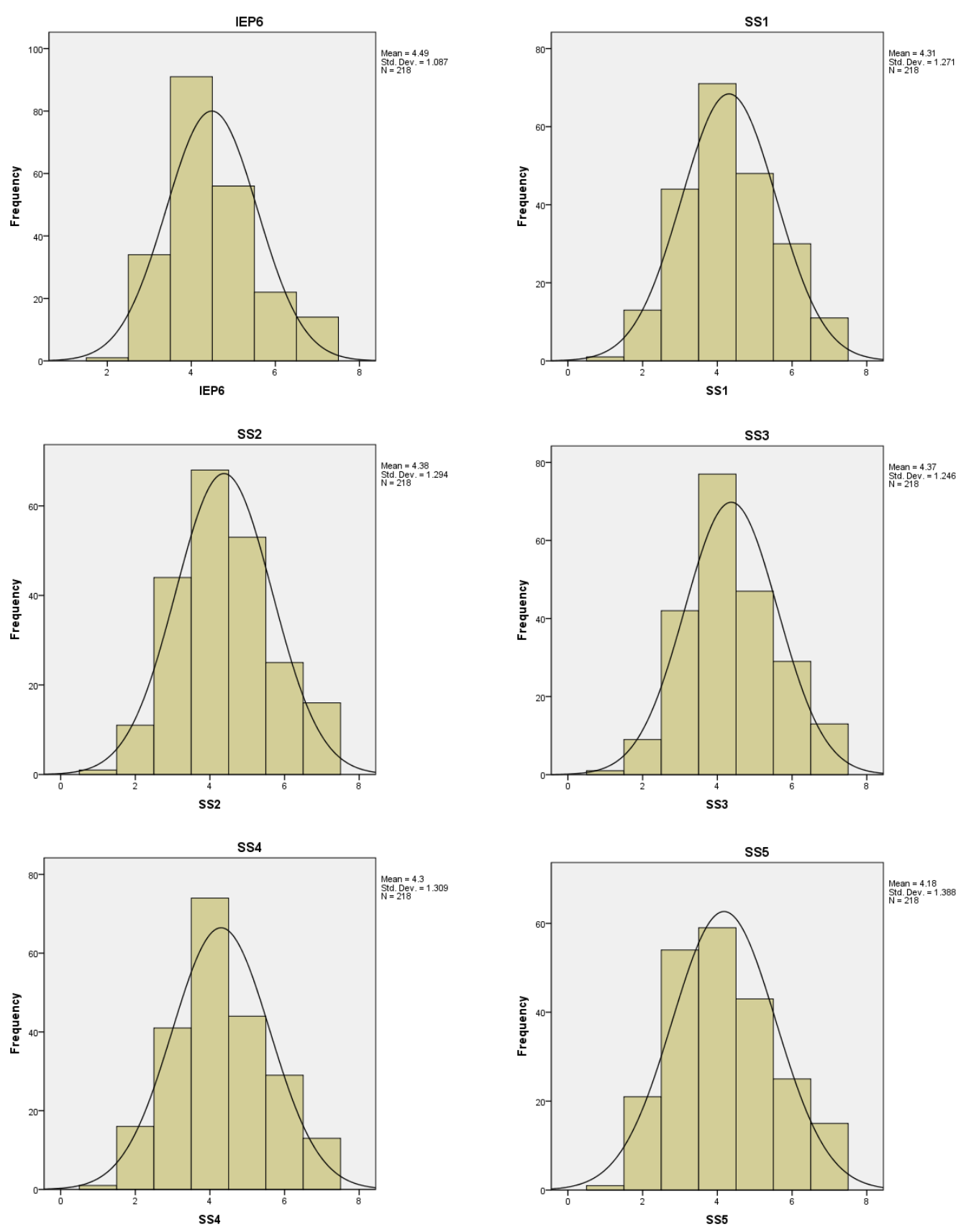

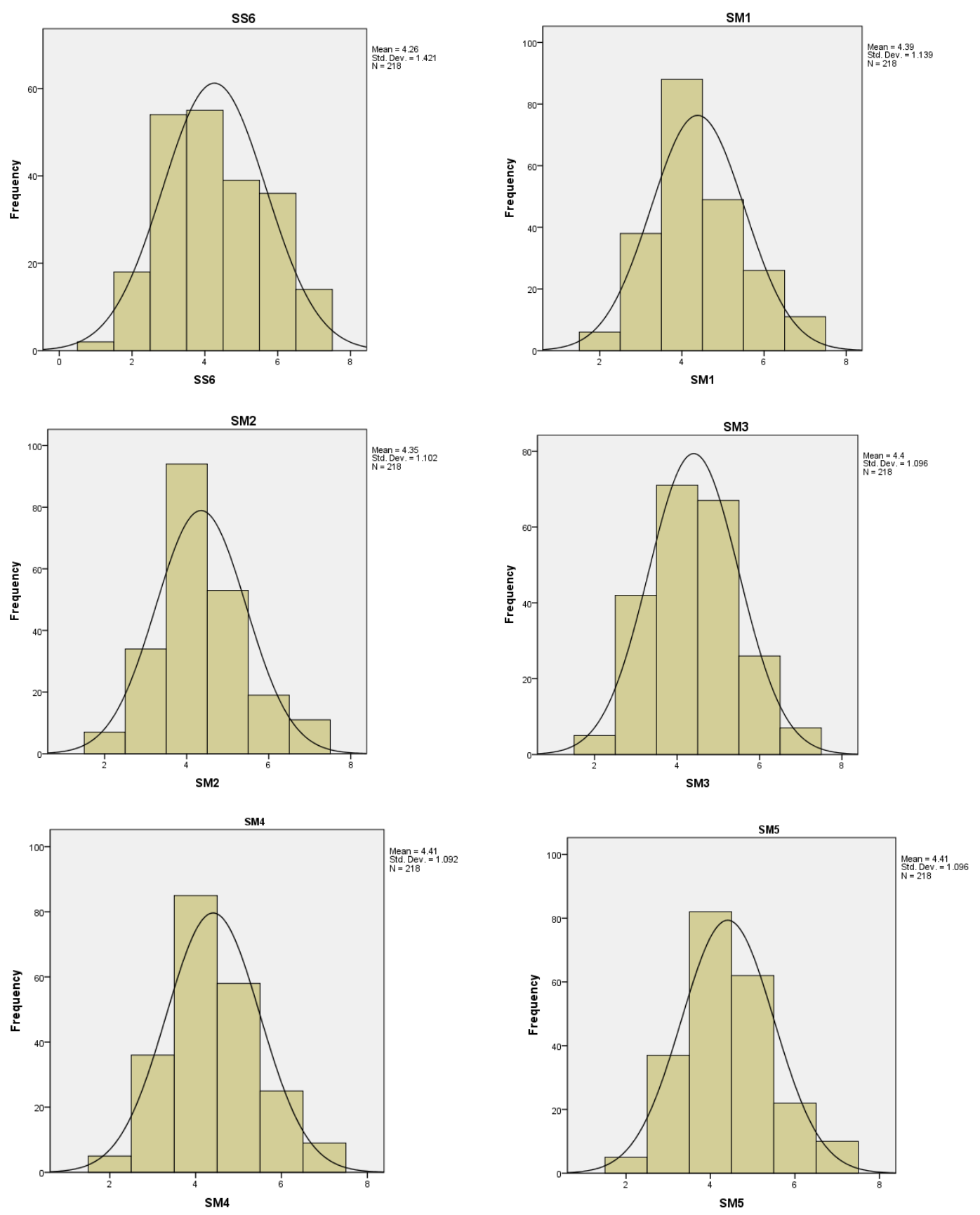

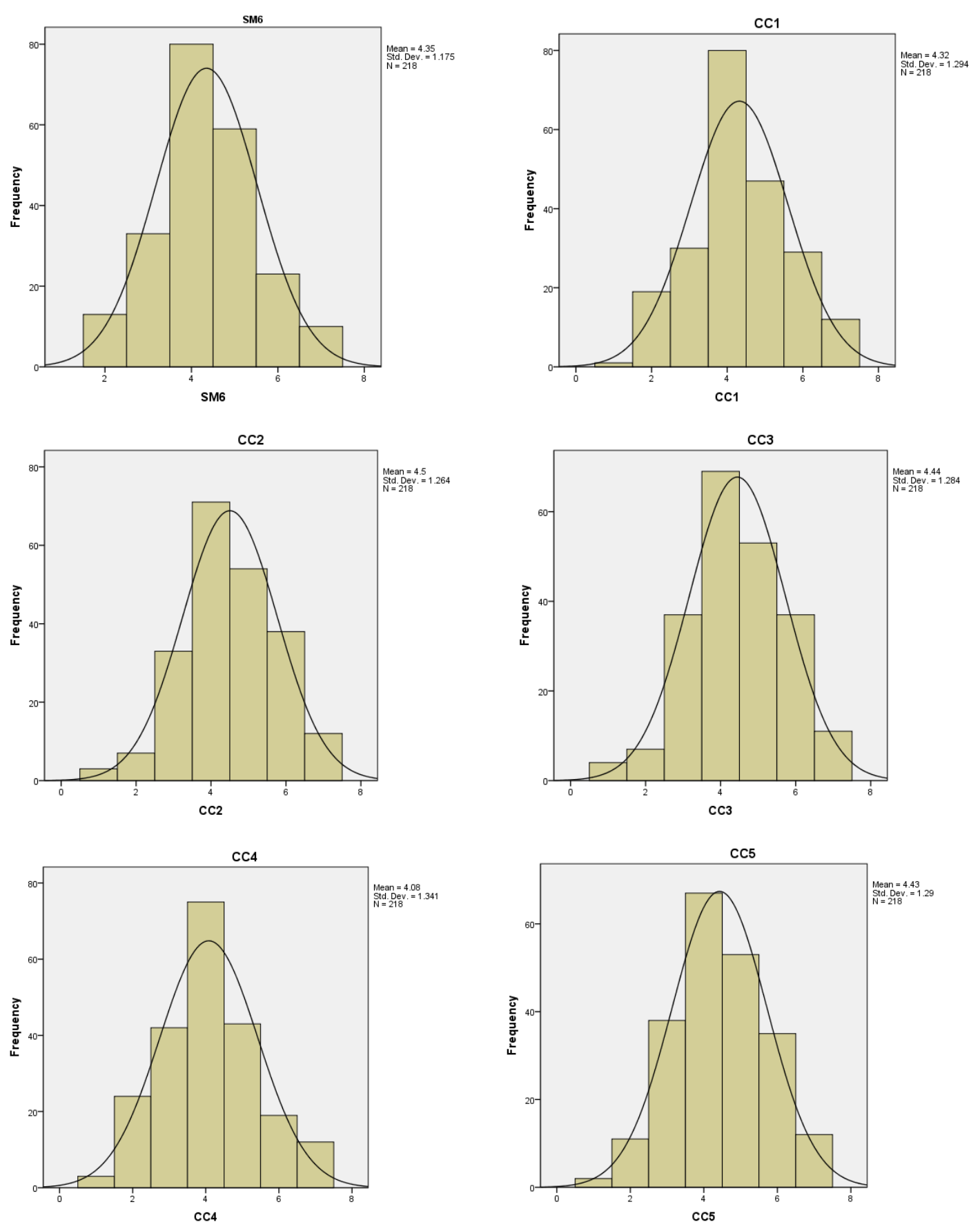

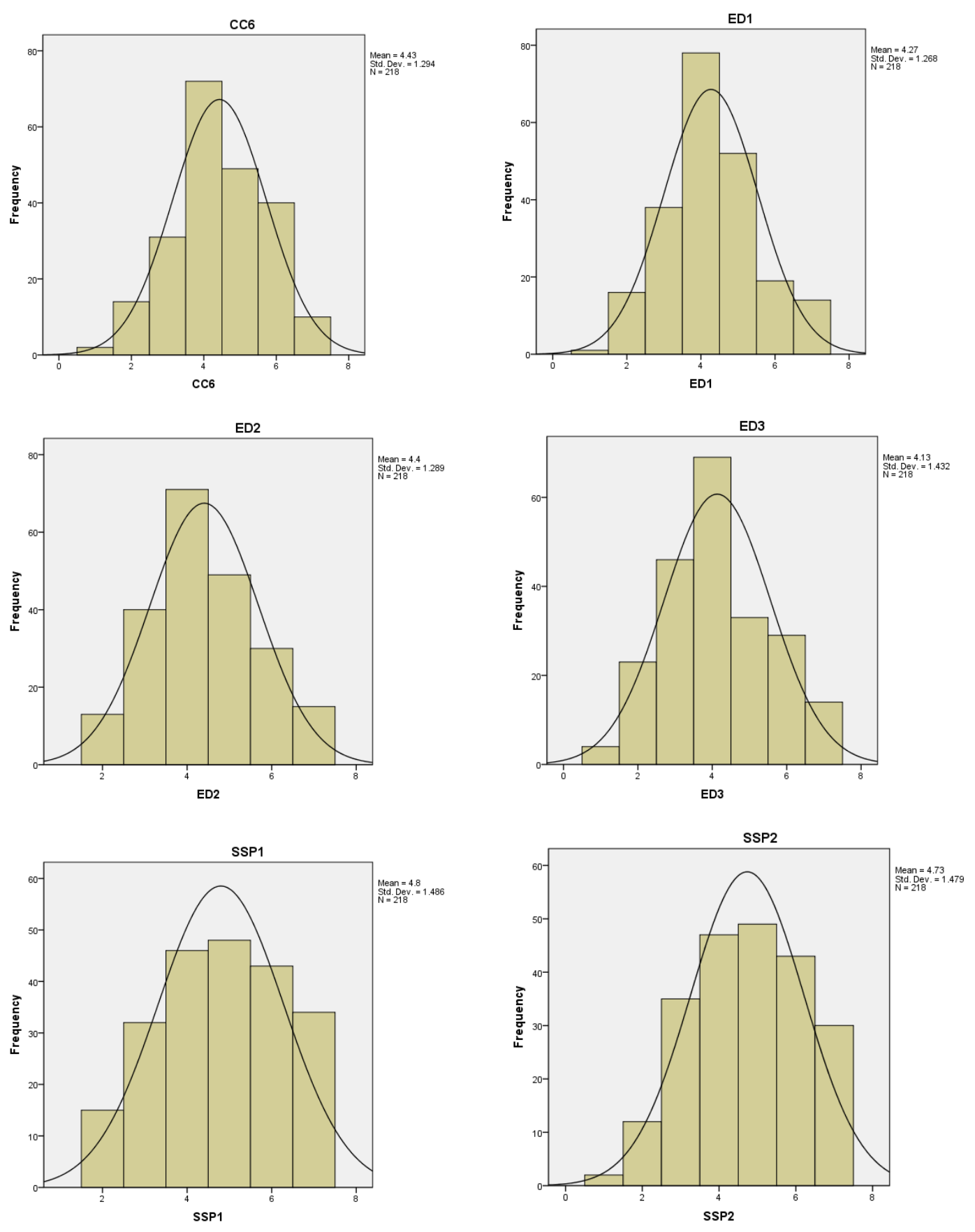

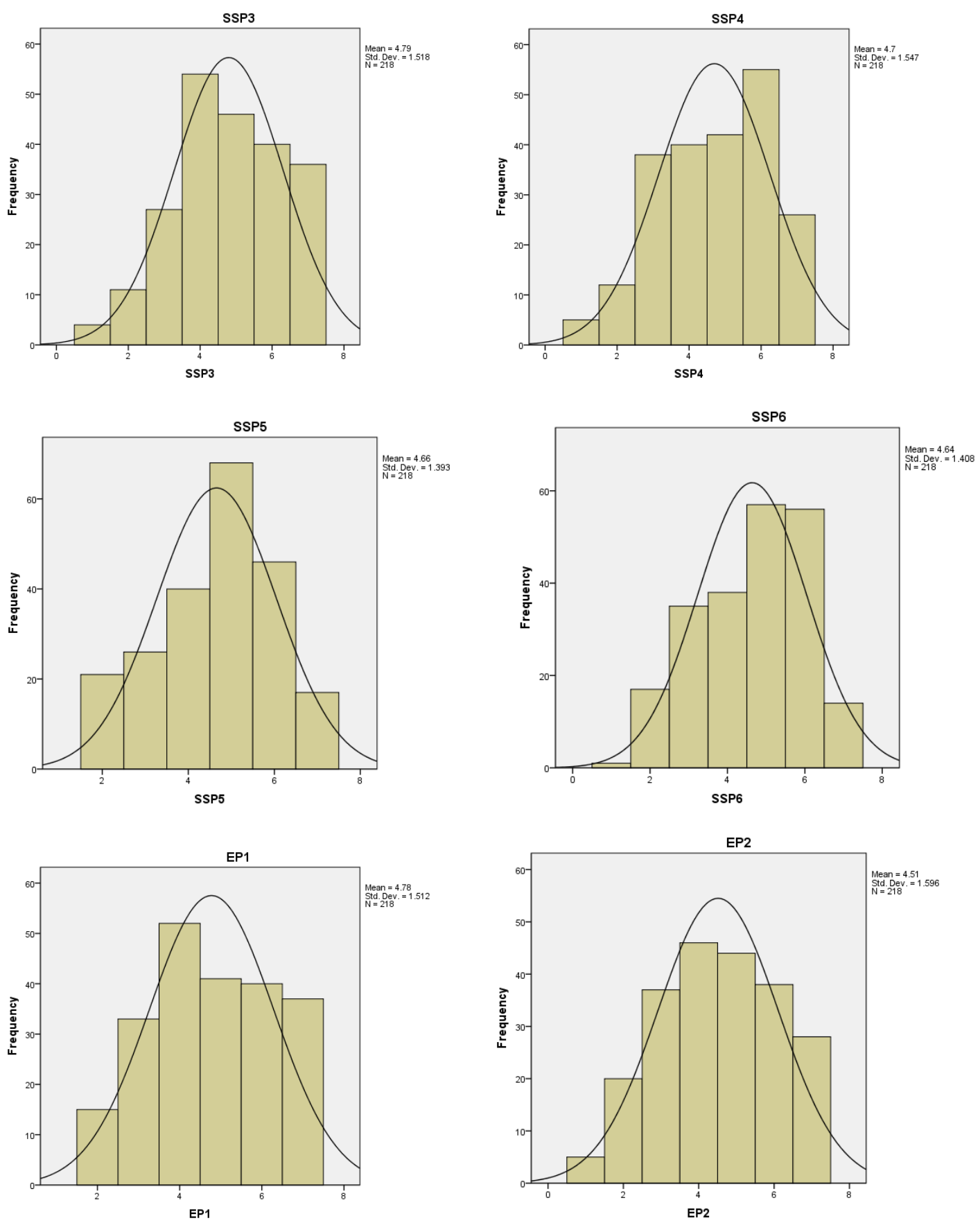

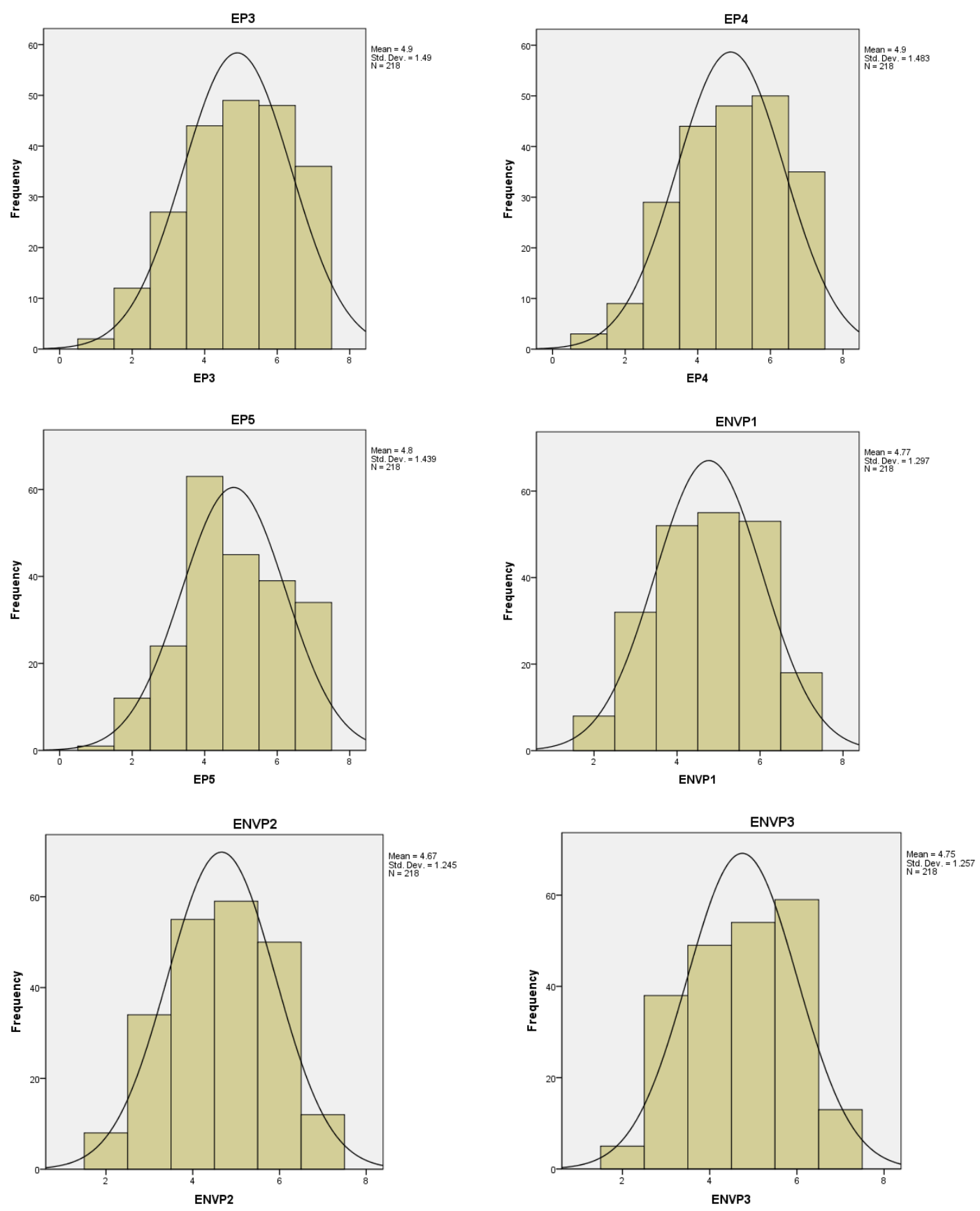

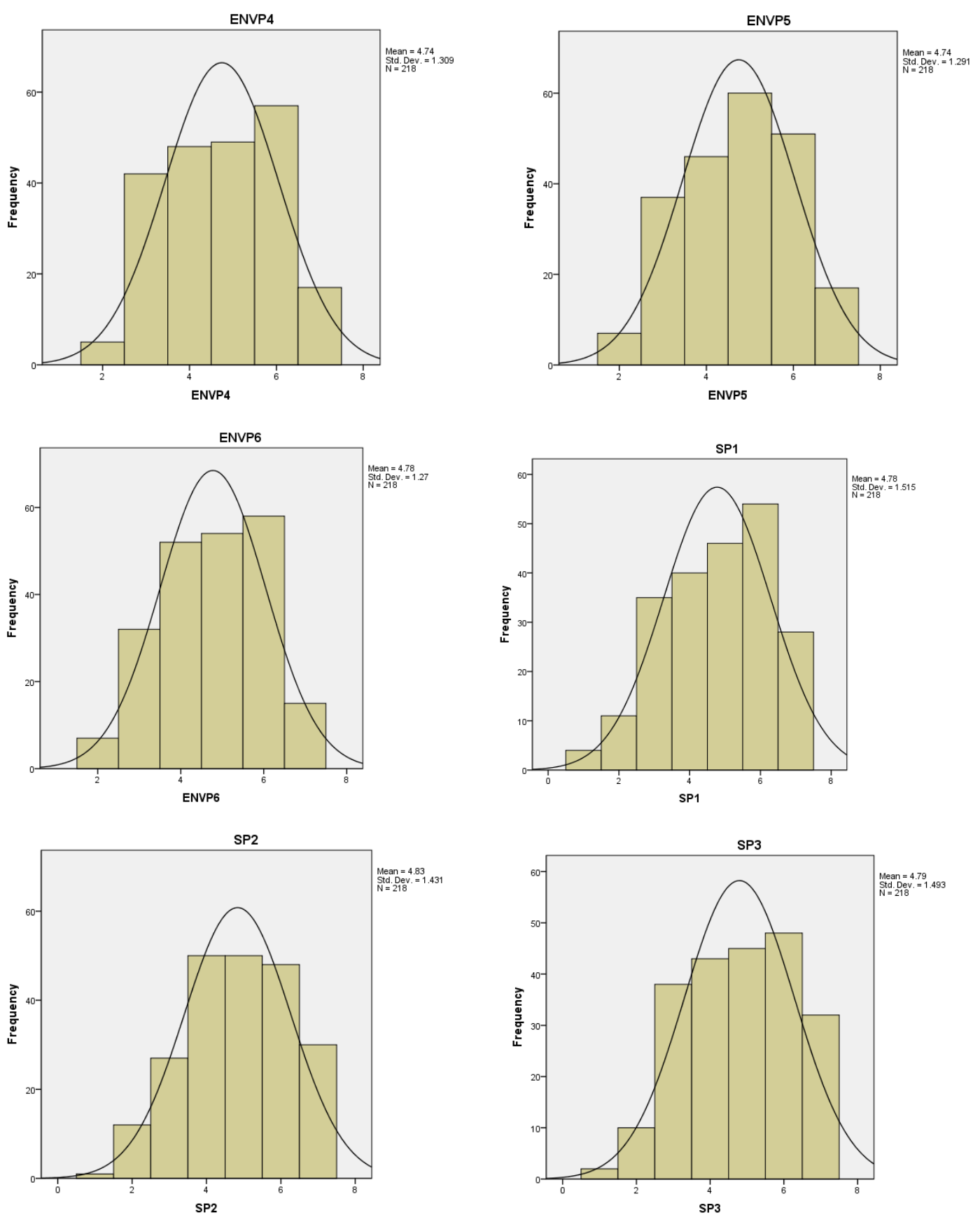

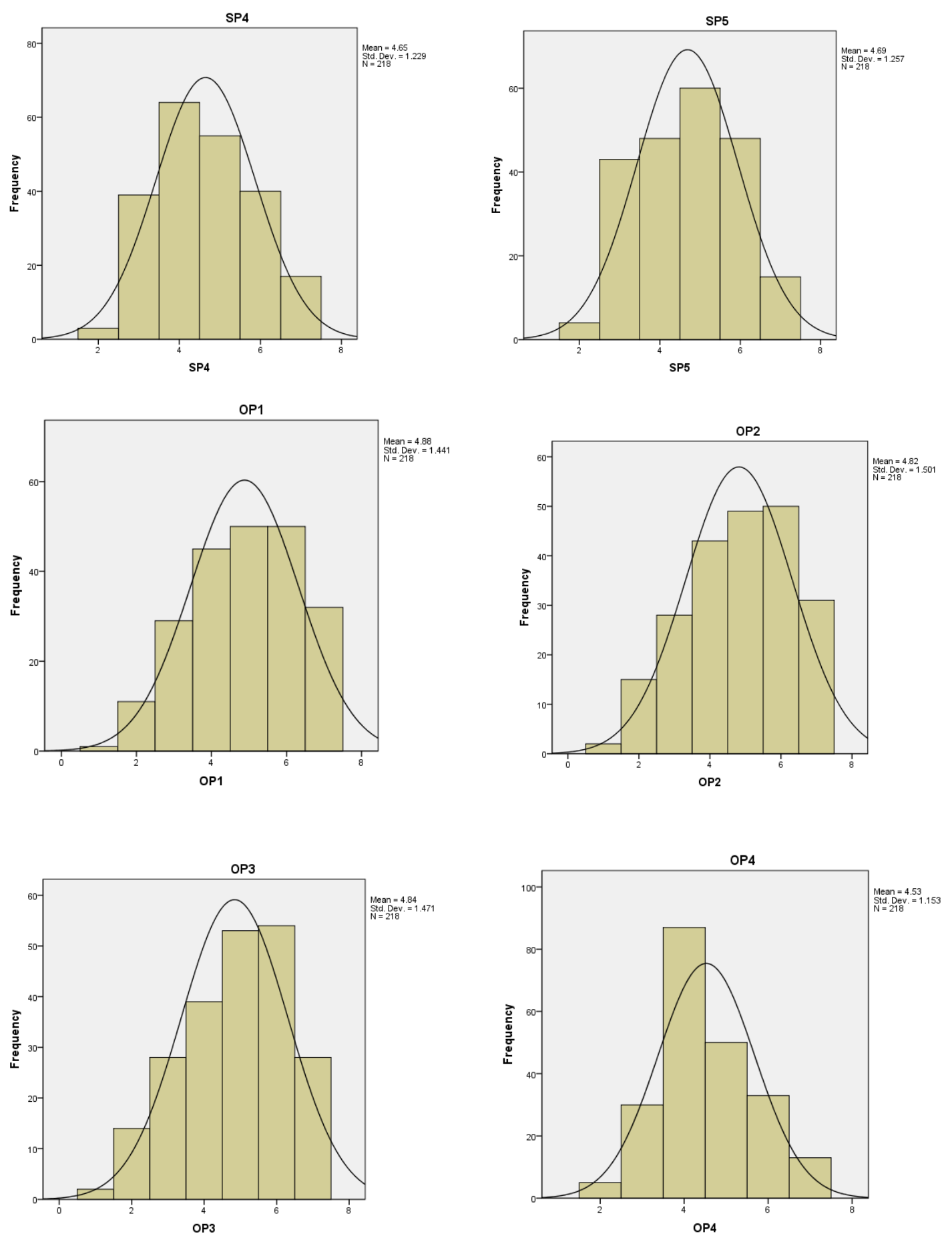

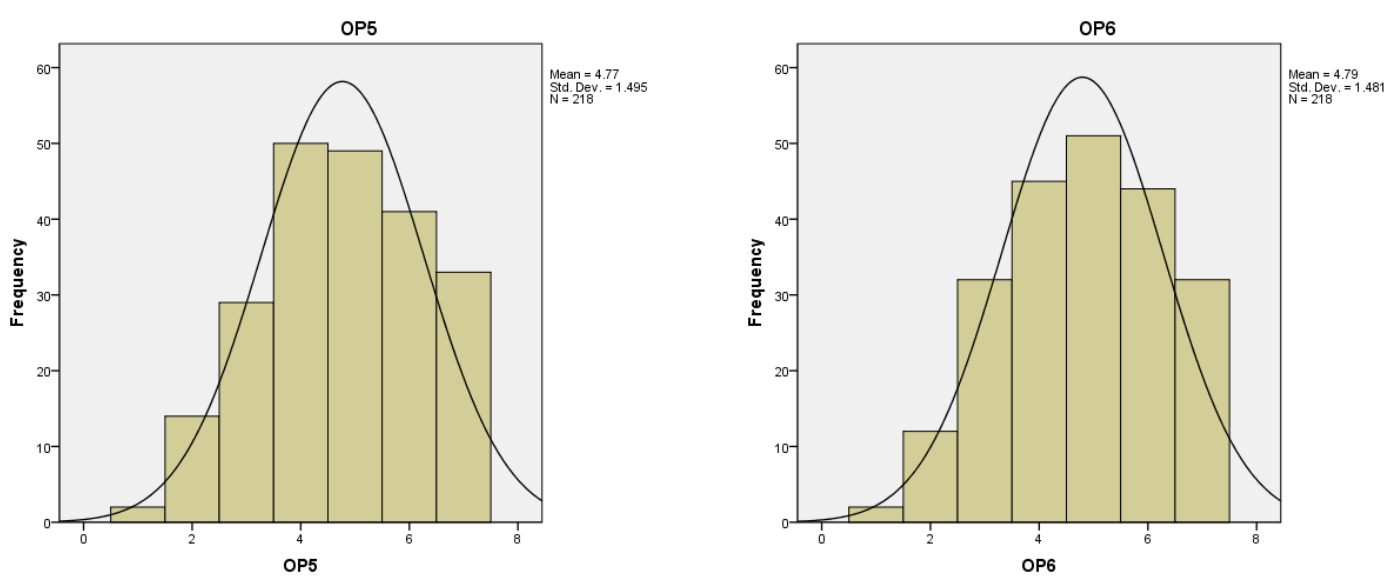


\section{Appendix VII Levene's Test for Equality of Variances and t-Test for Equality of}

Means

\begin{tabular}{|c|c|c|c|c|c|c|c|c|c|c|}
\hline \multicolumn{11}{|c|}{ Independent Samples Test } \\
\hline & & \multicolumn{2}{|c|}{$\begin{array}{c}\text { Levene's Test } \\
\text { for Equality of } \\
\text { Variances }\end{array}$} & \multicolumn{7}{|c|}{ t-test for Equality of Means } \\
\hline \multirow[b]{2}{*}{ Indicators } & \multirow[b]{2}{*}{$\begin{array}{c}\text { Assumption of Equal } \\
\text { Variances }\end{array}$} & \multirow[b]{2}{*}{$F$} & \multirow[b]{2}{*}{ Sig. } & \multirow[b]{2}{*}{$t$} & \multirow[b]{2}{*}{ df } & \multirow[b]{2}{*}{$\begin{array}{c}\text { Sig. } \\
\text { (2-tailed) }\end{array}$} & \multirow[b]{2}{*}{$\begin{array}{c}\text { Mean } \\
\text { Difference }\end{array}$} & \multirow[b]{2}{*}{$\begin{array}{l}\text { Std. Error } \\
\text { Difference }\end{array}$} & \multicolumn{2}{|c|}{$\begin{array}{l}\text { 95\% Confidence } \\
\text { Interval of the } \\
\text { Difference }\end{array}$} \\
\hline & & & & & & & & & Lower & Upper \\
\hline \multirow[t]{2}{*}{ REG1 } & Equal variances assumed & 0.466 & 0.495 & 0.354 & 216 & 0.724 & 0.064 & 0.182 & -0.294 & 0.422 \\
\hline & Equal variances not assumed & & & 0.354 & 215.776 & 0.724 & 0.064 & 0.182 & -0.294 & 0.422 \\
\hline \multirow[t]{2}{*}{ REG2 } & Equal variances assumed & 2.022 & 0.156 & -0.222 & 216 & 0.824 & -0.037 & 0.165 & -0.362 & 0.289 \\
\hline & Equal variances not assumed & & & -0.222 & 213.668 & 0.824 & -0.037 & 0.165 & -0.362 & 0.289 \\
\hline \multirow[t]{2}{*}{ REG3 } & Equal variances assumed & 1.673 & 0.197 & -1.212 & 216 & 0.227 & -0.229 & 0.189 & -0.602 & 0.143 \\
\hline & Equal variances not assumed & & & -1.212 & 215.451 & 0.227 & -0.229 & 0.189 & -0.602 & 0.144 \\
\hline \multirow[t]{2}{*}{ COMP1 } & Equal variances assumed & 0.194 & 0.66 & 0 & 216 & 1 & 0 & 0.214 & -0.421 & 0.421 \\
\hline & Equal variances not assumed & & & 0 & 215.64 & 1 & 0 & 0.214 & -0.421 & 0.421 \\
\hline COMP2 & Equal variances assumed & 0.419 & 0.518 & 0.397 & 216 & 0.692 & 0.083 & 0.208 & -0.327 & 0.492 \\
\hline & Equal variances not assumed & & & 0.397 & 215.962 & 0.692 & 0.083 & 0.208 & -0.327 & 0.492 \\
\hline COMP3 & Equal variances assumed & 0.498 & 0.481 & -0.297 & 216 & 0.767 & -0.064 & 0.216 & -0.49 & 0.362 \\
\hline & Equal variances not assumed & & & -0.297 & 214.401 & 0.767 & -0.064 & 0.216 & -0.49 & 0.362 \\
\hline COMP4 & Equal variances assumed & 0.47 & 0.494 & -0.09 & 216 & 0.928 & -0.018 & 0.204 & -0.421 & 0.384 \\
\hline & Equal variances not assumed & & & -0.09 & 214.375 & 0.928 & -0.018 & 0.204 & -0.421 & 0.384 \\
\hline COMP5 & Equal variances assumed & 0.283 & 0.595 & 0 & 216 & 1 & 0 & 0.201 & -0.396 & 0.396 \\
\hline & Equal variances not assumed & & & 0 & 215.617 & 1 & 0 & 0.201 & -0.396 & 0.396 \\
\hline COMP6 & Equal variances assumed & 0.079 & 0.78 & 0.664 & 216 & 0.508 & 0.138 & 0.207 & -0.271 & 0.546 \\
\hline & Equal variances not assumed & & & 0.664 & 215.139 & 0.508 & 0.138 & 0.207 & -0.271 & 0.546 \\
\hline COMP7 & Equal variances assumed & 0.262 & 0.609 & -0.232 & 216 & 0.817 & -0.046 & 0.198 & -0.436 & 0.344 \\
\hline & Equal variances not assumed & & & -0.232 & 215.223 & 0.817 & -0.046 & 0.198 & -0.436 & 0.345 \\
\hline PRES1 & Equal variances assumed & 0.148 & 0.701 & -0.266 & 216 & 0.79 & -0.055 & 0.207 & -0.462 & 0.352 \\
\hline & Equal variances not assumed & & & -0.266 & 215.692 & 0.79 & -0.055 & 0.207 & -0.462 & 0.352 \\
\hline PRES2 & Equal variances assumed & 0.293 & 0.589 & 0.442 & 216 & 0.659 & 0.092 & 0.208 & -0.317 & 0.501 \\
\hline & Equal variances not assumed & & & 0.442 & 215.381 & 0.659 & 0.092 & 0.208 & -0.317 & 0.501 \\
\hline PRES3 & Equal variances assumed & 0.631 & 0.428 & 0.042 & 216 & 0.967 & 0.009 & 0.219 & -0.423 & 0.441 \\
\hline & Equal variances not assumed & & & 0.042 & 215.716 & 0.967 & 0.009 & 0.219 & -0.423 & 0.441 \\
\hline PRES4 & Equal variances assumed & 0.147 & 0.702 & 0.138 & 216 & 0.89 & 0.028 & 0.199 & -0.365 & 0.42 \\
\hline & Equal variances not assumed & & & 0.138 & 215.876 & 0.89 & 0.028 & 0.199 & -0.365 & 0.42 \\
\hline PRES5 & Equal variances assumed & 0.511 & 0.476 & -0.425 & 216 & 0.672 & -0.092 & 0.216 & -0.518 & 0.334 \\
\hline & Equal variances not assumed & & & -0.425 & 215.455 & 0.672 & -0.092 & 0.216 & -0.518 & 0.334 \\
\hline EEP1 & Equal variances assumed & 1.391 & 0.24 & -0.051 & 216 & 0.959 & -0.009 & 0.179 & -0.362 & 0.344 \\
\hline & Equal variances not assumed & & & -0.051 & 214.853 & 0.959 & -0.009 & 0.179 & -0.362 & 0.344 \\
\hline EEP2 & Equal variances assumed & 0.148 & 0.701 & 0.453 & 216 & 0.651 & 0.083 & 0.182 & -0.277 & 0.442 \\
\hline & Equal variances not assumed & & & 0.453 & 215.945 & 0.651 & 0.083 & 0.182 & -0.277 & 0.442 \\
\hline EEP3 & Equal variances assumed & 1.134 & 0.288 & 0.11 & 216 & 0.913 & 0.018 & 0.167 & -0.312 & 0.348 \\
\hline & Equal variances not assumed & & & 0.11 & 215.357 & 0.913 & 0.018 & 0.167 & -0.312 & 0.348 \\
\hline EEP4 & Equal variances assumed & 1.981 & 0.161 & -1.373 & 216 & 0.171 & -0.257 & 0.187 & -0.626 & 0.112 \\
\hline & Equal variances not assumed & & & -1.373 & 215.37 & 0.171 & -0.257 & 0.187 & -0.626 & 0.112 \\
\hline IEP1 & Equal variances assumed & 0.653 & 0.42 & 0.514 & 216 & 0.608 & 0.092 & 0.178 & -0.26 & 0.444 \\
\hline & Equal variances not assumed & & & 0.514 & 215.412 & 0.608 & 0.092 & 0.178 & -0.26 & 0.444 \\
\hline IEP2 & Equal variances assumed & 1.876 & 0.172 & 0.664 & 216 & 0.508 & 0.119 & 0.18 & -0.235 & 0.473 \\
\hline & Equal variances not assumed & & & 0.664 & 215.185 & 0.508 & 0.119 & 0.18 & -0.235 & 0.473 \\
\hline IEP3 & Equal variances assumed & 1.23 & 0.269 & 0.401 & 216 & 0.689 & 0.073 & 0.183 & -0.287 & 0.434 \\
\hline & Equal variances not assumed & & & 0.401 & 215.496 & 0.689 & 0.073 & 0.183 & -0.287 & 0.434 \\
\hline IEP4 & Equal variances assumed & 3.088 & 0.08 & 0.16 & 216 & 0.873 & 0.028 & 0.172 & -0.312 & 0.367 \\
\hline & Equal variances not assumed & & & 0.16 & 213.562 & 0.873 & 0.028 & 0.172 & -0.312 & 0.367 \\
\hline IEP5 & Equal variances assumed & 0.443 & 0.506 & 0.497 & 216 & 0.62 & 0.092 & 0.185 & -0.272 & 0.455 \\
\hline & Equal variances not assumed & & & 0.497 & 215.918 & 0.62 & 0.092 & 0.185 & -0.272 & 0.455 \\
\hline IEP6 & Equal variances assumed & 5.875 & 0.016 & 0.105 & 216 & 0.917 & 0.018 & 0.175 & -0.326 & 0.363 \\
\hline & Equal variances not assumed & & & 0.105 & 210.546 & 0.917 & 0.018 & 0.175 & -0.326 & 0.363 \\
\hline
\end{tabular}




\begin{tabular}{|c|c|c|c|c|c|c|c|c|c|c|}
\hline \multicolumn{11}{|c|}{ Independent Samples Test } \\
\hline & & \multicolumn{2}{|c|}{\begin{tabular}{|c|} 
Levene's Test \\
for Equality of \\
Variances \\
\end{tabular}} & \multicolumn{7}{|c|}{ t-test for Equality of Means } \\
\hline \multirow{2}{*}{\begin{tabular}{|l} 
\\
Indicators
\end{tabular}} & \multirow[b]{2}{*}{$\begin{array}{c}\text { Assumption of Equal } \\
\text { Variances }\end{array}$} & \multirow[b]{2}{*}{$\mathbf{F}$} & \multirow[b]{2}{*}{ Sig. } & \multirow[b]{2}{*}{$\mathrm{t}$} & \multirow[b]{2}{*}{ df } & \multirow[b]{2}{*}{\begin{tabular}{|c|} 
Sig. \\
(2-tailed)
\end{tabular}} & \multirow[b]{2}{*}{$\begin{array}{c}\text { Mean } \\
\text { Difference }\end{array}$} & \multirow[b]{2}{*}{$\begin{array}{c}\text { Std. Error } \\
\text { Difference }\end{array}$} & \multicolumn{2}{|c|}{$\begin{array}{l}\text { 95\% Confidence } \\
\text { Interval of the } \\
\text { Difference }\end{array}$} \\
\hline & & & & & & & & & Lower & Upper \\
\hline \multirow[t]{2}{*}{ SS1 } & Equal variances assumed & 0.435 & 0.51 & -0.046 & 216 & 0.963 & -0.009 & 0.198 & -0.4 & 0.381 \\
\hline & Equal variances not assumed & & & -0.046 & \begin{tabular}{|l|}
215.051 \\
\end{tabular} & 0.963 & -0.009 & 0.198 & -0.4 & 0.381 \\
\hline \multirow[t]{2}{*}{ SS2 } & Equal variances assumed & 1.183 & 0.278 & -0.236 & 216 & 0.814 & -0.046 & 0.195 & -0.429 & 0.338 \\
\hline & Equal variances not assumed & & & -0.236 & 214.119 & 0.814 & -0.046 & 0.195 & -0.429 & 0.338 \\
\hline SS3 & Equal variances assumed & 0.161 & 0.689 & 0.189 & 216 & 0.851 & 0.037 & 0.194 & -0.347 & 0.42 \\
\hline & Equal variances not assumed & & & 0.189 & \begin{tabular}{|l|}
215.526 \\
\end{tabular} & 0.851 & 0.037 & 0.194 & -0.347 & 0.42 \\
\hline 554 & Equal variances assumed & 0.06 & 0.807 & 0.351 & 216 & 0.726 & 0.073 & 0.209 & -0.339 & 0.486 \\
\hline & Equal variances not assumed & & & 0.351 & 215.957 & 0.726 & 0.073 & 0.209 & -0.339 & 0.486 \\
\hline SS5 & Equal variances assumed & 0.594 & 0.442 & 0.042 & 216 & 0.966 & 0.009 & 0.216 & -0.417 & 0.435 \\
\hline & Equal variances not assumed & & & 0.042 & 214.395 & 0.966 & 0.009 & 0.216 & -0.417 & 0.435 \\
\hline SS6 & Equal variances assumed & 0.034 & 0.854 & -0.083 & 216 & 0.934 & -0.018 & 0.22 & -0.453 & 0.416 \\
\hline & Equal variances not assumed & & & -0.083 & 215.354 & 0.934 & -0.018 & 0.22 & -0.453 & 0.416 \\
\hline SE1 & Equal variances assumed & 1.755 & 0.187 & 0.51 & 216 & 0.61 & 0.092 & 0.18 & -0.263 & 0.446 \\
\hline & Equal variances not assumed & & & 0.51 & 215.305 & 0.61 & 0.092 & 0.18 & -0.263 & 0.446 \\
\hline SE2 & Equal variances assumed & 0.001 & 0.97 & 0 & 216 & 1 & 0 & 0.177 & -0.349 & 0.349 \\
\hline & Equal variances not assumed & & & 0 & \begin{tabular}{|l|}
215.994 \\
\end{tabular} & 1 & 0 & 0.177 & -0.349 & 0.349 \\
\hline SE3 & Equal variances assumed & 0.633 & 0.427 & 0.48 & 216 & 0.632 & 0.083 & 0.172 & -0.257 & 0.422 \\
\hline & Equal variances not assumed & & & 0.48 & 215.648 & 0.632 & 0.083 & 0.172 & -0.257 & 0.422 \\
\hline SE4 & Equal variances assumed & 0.26 & 0.611 & 0.206 & 216 & 0.837 & 0.037 & 0.178 & -0.314 & 0.387 \\
\hline & Equal variances not assumed & & & 0.206 & 215.988 & 0.837 & 0.037 & 0.178 & -0.314 & 0.387 \\
\hline SE5 & Equal variances assumed & 0.777 & 0.379 & 0.052 & 216 & 0.958 & 0.009 & 0.175 & -0.336 & 0.354 \\
\hline & Equal variances not assumed & & & 0.052 & \begin{tabular}{|l|}
215.876 \\
\end{tabular} & 0.958 & 0.009 & 0.175 & -0.336 & 0.354 \\
\hline SE6 & Equal variances assumed & 0.308 & 0.58 & 0.481 & 216 & 0.631 & 0.092 & 0.191 & -0.285 & 0.468 \\
\hline & Equal variances not assumed & & & 0.481 & 215.892 & 0.631 & 0.092 & 0.191 & -0.285 & 0.468 \\
\hline CC1 & Equal variances assumed & 0.637 & 0.426 & 0.129 & 216 & 0.898 & 0.028 & 0.214 & -0.394 & 0.449 \\
\hline & Equal variances not assumed & & & 0.129 & 215.856 & 0.898 & 0.028 & 0.214 & -0.394 & 0.449 \\
\hline CC2 & Equal variances assumed & 0.591 & 0.443 & -0.269 & 216 & 0.788 & -0.055 & 0.204 & -0.458 & 0.348 \\
\hline & Equal variances not assumed & & & -0.269 & 213.658 & 0.788 & -0.055 & 0.204 & -0.458 & 0.348 \\
\hline CC3 & Equal variances assumed & 0.15 & 0.699 & -0.352 & 216 & 0.725 & -0.073 & 0.209 & -0.484 & 0.338 \\
\hline & Equal variances not assumed & & & -0.352 & 214.654 & 0.725 & -0.073 & 0.209 & -0.484 & 0.338 \\
\hline CC4 & Equal variances assumed & 1.222 & 0.27 & -0.543 & 216 & 0.588 & \begin{tabular}{|c|c|c|}
-0.119 \\
\end{tabular} & 0.22 & -0.552 & 0.314 \\
\hline & Equal variances not assumed & & & -0.543 & 212.787 & 0.588 & -0.119 & 0.22 & -0.552 & 0.314 \\
\hline CC5 & Equal variances assumed & 0.176 & 0.675 & -0.486 & 216 & 0.627 & -0.101 & 0.208 & -0.51 & 0.308 \\
\hline & Equal variances not assumed & & & -0.486 & 215.62 & 0.627 & -0.101 & 0.208 & -0.51 & 0.308 \\
\hline CC6 & Equal variances assumed & 0.071 & 0.791 & -0.043 & 216 & 0.965 & -0.009 & 0.212 & -0.426 & 0.408 \\
\hline & Equal variances not assumed & & & -0.043 & 215.442 & 0.965 & -0.009 & 0.212 & -0.426 & 0.408 \\
\hline ED1 & Equal variances assumed & 0.468 & 0.495 & -0.134 & 216 & 0.894 & -0.028 & 0.206 & -0.434 & 0.379 \\
\hline & Equal variances not assumed & & & -0.134 & 215.447 & 0.894 & -0.028 & 0.206 & -0.434 & 0.379 \\
\hline ED2 & Equal variances assumed & 0.975 & 0.325 & -0.138 & 216 & 0.89 & -0.028 & 0.199 & -0.421 & 0.366 \\
\hline & Equal variances not assumed & & & -0.138 & 215.089 & 0.89 & -0.028 & 0.199 & -0.421 & 0.366 \\
\hline ED3 & Equal variances assumed & 0.198 & 0.657 & -0.789 & 216 & 0.431 & -0.174 & 0.221 & -0.61 & 0.261 \\
\hline & Equal variances not assumed & & & -0.789 & 215.788 & 0.431 & -0.174 & 0.221 & -0.61 & 0.261 \\
\hline SSP1 & Equal variances assumed & 0.011 & 0.917 & -0.364 & 216 & 0.716 & \begin{tabular}{l|l}
-0.073 \\
\end{tabular} & 0.202 & \begin{tabular}{|c|c|}
-0.471 \\
\end{tabular} & 0.324 \\
\hline & Equal variances not assumed & & & -0.364 & 215.881 & 0.716 & -0.073 & 0.202 & -0.471 & 0.324 \\
\hline SSP2 & Equal variances assumed & 0.211 & 0.646 & -1.008 & 216 & 0.315 & -0.202 & 0.2 & -0.597 & 0.193 \\
\hline & Equal variances not assumed & & & -1.008 & 215.362 & 0.315 & -0.202 & 0.2 & -0.597 & 0.193 \\
\hline SSP3 & Equal variances assumed & 0.042 & 0.838 & -0.579 & 216 & 0.563 & -0.119 & 0.206 & -0.525 & 0.287 \\
\hline & Equal variances not assumed & & & -0.579 & 215.949 & 0.563 & -0.119 & 0.206 & -0.525 & 0.287 \\
\hline SSP4 & Equal variances assumed & 0.077 & 0.782 & -0.656 & 216 & 0.513 & -0.138 & 0.21 & -0.551 & 0.276 \\
\hline & Equal variances not assumed & & & -0.656 & 215.885 & 0.513 & -0.138 & 0.21 & -0.551 & 0.276 \\
\hline SSP5 & Equal variances assumed & 0.623 & 0.431 & 0.243 & 216 & 0.809 & 0.046 & 0.189 & -0.327 & 0.419 \\
\hline & Equal variances not assumed & & & 0.243 & 215.776 & 0.809 & 0.046 & 0.189 & -0.327 & 0.419 \\
\hline SSP6 & Equal variances assumed & 0.81 & 0.369 & 0.048 & 216 & 0.962 & 0.009 & 0.191 & -0.368 & 0.386 \\
\hline & Equal variances not assumed & & & 0.048 & 215.315 & 0.962 & 0.009 & 0.191 & -0.368 & 0.386 \\
\hline
\end{tabular}




\section{Appendix VIII Skewness and Kurtosis of Collected Data}

Descriptive Statistics

\begin{tabular}{|c|c|c|c|c|c|c|c|c|c|}
\hline & $\mathbf{N}$ & Min. & Max. & Mean & $\begin{array}{c}\text { Std. } \\
\text { Deviati } \\
\text { on } \\
\end{array}$ & \multicolumn{2}{|c|}{ Skewness } & \multicolumn{2}{|c|}{ Kurtosis } \\
\hline & $\begin{array}{c}\text { Statis } \\
\text { tic } \\
\end{array}$ & $\begin{array}{c}\text { Statis } \\
\text { tic } \\
\end{array}$ & $\begin{array}{c}\text { Statis } \\
\text { tic }\end{array}$ & Statistic & Statistic & Statistic & $\begin{array}{c}\text { Std. } \\
\text { Error }\end{array}$ & Statistic & $\begin{array}{c}\text { Std. } \\
\text { Error }\end{array}$ \\
\hline REG1 & 218 & 2 & 7 & 4.84 & 1.352 & -.097 & .165 & -.865 & .328 \\
\hline REG2 & 218 & 3 & 7 & 5.06 & 1.217 & -.013 & .165 & -.957 & .328 \\
\hline REG3 & 218 & 2 & 7 & 4.93 & 1.430 & -.078 & .165 & -1.088 & .328 \\
\hline COMP1 & 218 & 1 & 7 & 4.67 & 1.575 & -.120 & .165 & -.998 & .328 \\
\hline COMP2 & 218 & 1 & 7 & 4.77 & 1.532 & -.128 & .165 & -.979 & .328 \\
\hline COMP3 & 218 & 1 & 7 & 4.89 & 1.593 & -.433 & .165 & -.677 & .328 \\
\hline COMP4 & 218 & 1 & 7 & 4.67 & 1.503 & -.055 & .165 & -.832 & .328 \\
\hline COMP5 & 218 & 1 & 7 & 4.47 & 1.478 & -.179 & .165 & -.720 & .328 \\
\hline СОМР6 & 218 & 1 & 7 & 4.77 & 1.529 & -.138 & .165 & -.918 & .328 \\
\hline COMP7 & 218 & 1 & 7 & 4.67 & 1.459 & -.246 & .165 & -.609 & .328 \\
\hline PRES1 & 218 & 1 & 7 & 4.75 & 1.522 & -.176 & .165 & -.790 & .328 \\
\hline PRES2 & 218 & 1 & 7 & 4.44 & 1.530 & -.389 & .165 & -.437 & .328 \\
\hline PRES3 & 218 & 1 & 7 & 4.78 & 1.615 & -.365 & .165 & -.819 & .328 \\
\hline PRES4 & 218 & 1 & 7 & 4.64 & 1.466 & -.389 & .165 & -.513 & .328 \\
\hline PRES5 & 218 & 1 & 7 & 3.98 & 1.592 & .203 & .165 & -.653 & .328 \\
\hline EEP1 & 218 & 2 & 7 & 4.28 & 1.144 & .422 & .165 & -.047 & .328 \\
\hline EEP2 & 218 & 2 & 7 & 4.39 & 1.123 & .319 & .165 & -.064 & .328 \\
\hline EEP3 & 218 & 3 & 7 & 4.57 & 1.055 & .447 & .165 & -.243 & .328 \\
\hline EEP4 & 218 & 2 & 7 & 4.38 & 1.236 & .528 & .165 & -.418 & .328 \\
\hline IEP1 & 218 & 2 & 7 & 4.35 & 1.114 & .366 & .165 & -.117 & .328 \\
\hline IEP2 & 218 & 2 & 7 & 4.32 & 1.101 & .307 & .165 & -.062 & .328 \\
\hline IEP3 & 218 & 2 & 7 & 4.34 & 1.138 & .251 & .165 & -.189 & .328 \\
\hline IEP4 & 218 & 3 & 7 & 4.56 & 1.081 & .518 & .165 & -.242 & .328 \\
\hline IEP5 & 218 & 2 & 7 & 4.43 & 1.167 & .405 & .165 & -.281 & .328 \\
\hline IEP6 & 218 & 2 & 7 & 4.49 & 1.087 & .611 & .165 & -.031 & .328 \\
\hline SS1 & 218 & 1 & 7 & 4.31 & 1.271 & .170 & .165 & -.411 & .328 \\
\hline SS2 & 218 & 1 & 7 & 4.38 & 1.294 & .225 & .165 & -.369 & .328 \\
\hline SS3 & 218 & 1 & 71 & 4.37 & 1.246 & .246 & .165 & -.299 & .328 \\
\hline
\end{tabular}




\begin{tabular}{|c|c|c|c|c|c|c|c|c|c|}
\hline SS4 & 218 & 1 & 7 & 4.30 & 1.309 & .193 & .165 & -.412 & .328 \\
\hline SS5 & 218 & 1 & 7 & 4.18 & 1.388 & .302 & .165 & -.585 & .328 \\
\hline SS6 & 218 & 1 & 7 & 4.26 & 1.421 & .171 & .165 & -.761 & .328 \\
\hline SE1 & 218 & 2 & 7 & 4.39 & 1.139 & .409 & .165 & -.134 & .328 \\
\hline SE2 & 218 & 2 & 7 & 4.35 & 1.102 & .442 & .165 & .239 & .328 \\
\hline SE3 & 218 & 2 & 7 & 4.40 & 1.096 & .185 & .165 & -.322 & .328 \\
\hline SE4 & 218 & 2 & 7 & 4.41 & 1.092 & .334 & .165 & -.088 & .328 \\
\hline SE5 & 218 & 2 & 7 & 4.41 & 1.096 & .342 & .165 & -.034 & .328 \\
\hline SE6 & 218 & 2 & 7 & 4.35 & 1.175 & .154 & .165 & -.103 & .328 \\
\hline CC1 & 218 & 1 & 7 & 4.32 & 1.294 & .079 & .165 & -.301 & .328 \\
\hline $\mathrm{CC2}$ & 218 & 1 & 7 & 4.50 & 1.264 & -.093 & .165 & -.143 & .328 \\
\hline CC3 & 218 & 1 & 7 & 4.44 & 1.284 & -.114 & .165 & -.137 & .328 \\
\hline CC4 & 218 & 1 & 7 & 4.08 & 1.341 & .206 & .165 & -.209 & .328 \\
\hline CC5 & 218 & 1 & 7 & 4.43 & 1.290 & -.005 & .165 & -.371 & .328 \\
\hline СС6 & 218 & 1 & 7 & 4.43 & 1.294 & -.098 & .165 & -.371 & .328 \\
\hline ED1 & 218 & 1 & 7 & 4.27 & 1.268 & .231 & .165 & -.111 & .328 \\
\hline ED2 & 218 & 2 & 7 & 4.40 & 1.289 & .215 & .165 & -.512 & .328 \\
\hline ED3 & 218 & 1 & 7 & 4.13 & 1.432 & .201 & .165 & -.504 & .328 \\
\hline SSP1 & 218 & 2 & 7 & 4.80 & 1.486 & -.142 & .165 & -.941 & .328 \\
\hline SSP2 & 218 & 1 & 7 & 4.73 & 1.479 & -.163 & .165 & -.773 & .328 \\
\hline SSP3 & 218 & 1 & 7 & 4.79 & 1.518 & -.244 & .165 & -.597 & .328 \\
\hline SSP4 & 218 & 1 & 7 & 4.70 & 1.547 & -.319 & .165 & -.738 & .328 \\
\hline SSP5 & 218 & 2 & 7 & 4.66 & 1.393 & -.326 & .165 & -.637 & .328 \\
\hline SSP6 & 218 & 1 & 7 & 4.64 & 1.408 & -.324 & .165 & -.771 & .328 \\
\hline EP1 & 218 & 2 & 7 & 4.78 & 1.512 & -.065 & .165 & -1.017 & .328 \\
\hline EP2 & 218 & 1 & 7 & 4.51 & 1.596 & -.125 & .165 & -.837 & .328 \\
\hline EP3 & 218 & 1 & 7 & 4.90 & 1.490 & -.323 & .165 & -.676 & .328 \\
\hline EP4 & 218 & 1 & 7 & 4.90 & 1.483 & -.347 & .165 & -.596 & .328 \\
\hline EP5 & 218 & 1 & 7 & 4.80 & 1.439 & -.091 & .165 & -.718 & .328 \\
\hline ENVP1 & 218 & 2 & 7 & 4.77 & 1.297 & -.145 & .165 & -.751 & .328 \\
\hline ENVP2 & 218 & 2 & 7 & 4.67 & 1.245 & -.122 & .165 & -.694 & .328 \\
\hline ENVP3 & 218 & 2 & 7 & 4.75 & 1.257 & -.145 & .165 & -.892 & .328 \\
\hline ENVP4 & 218 & 2 & 7 & 4.74 & 1.309 & -.075 & .165 & -.992 & .328 \\
\hline ENVP5 & 218 & 2 & 7 & 4.74 & 1.291 & -.133 & .165 & -.789 & .328 \\
\hline ENVP6 & 218 & 2 & 7 & 4.78 & 1.270 & -.183 & .165 & -.765 & .328 \\
\hline SP1 & 218 & 1 & 7 & 4.78 & 1.515 & -.343 & .165 & -.672 & .328 \\
\hline SP2 & 218 & 1 & 7 & 4.83 & 1.431 & -.230 & .165 & -.701 & .328 \\
\hline
\end{tabular}




\begin{tabular}{|l|l|l|l|l|l|r|r|r|r|} 
SP3 & 218 & 1 & 7 & 4.79 & 1.493 & -.195 & .165 & -.855 & .328 \\
SP4 & 218 & 2 & 7 & 4.65 & 1.229 & .190 & .165 & -.755 & .328 \\
SP5 & 218 & 2 & 7 & 4.69 & 1.257 & -.011 & .165 & -.877 & .328 \\
OP1 & 218 & 1 & 7 & 4.88 & 1.441 & -.264 & .165 & -.740 & .328 \\
OP2 & 218 & 1 & 7 & 4.82 & 1.501 & -.319 & .165 & -.711 & .328 \\
OP3 & 218 & 1 & 7 & 4.84 & 1.471 & -.386 & .165 & -.619 & .328 \\
OP4 & 218 & 2 & 7 & 4.53 & 1.153 & .324 & .165 & -.311 & .328 \\
OP5 & 218 & 1 & 7 & 4.77 & 1.495 & -.195 & .165 & -.730 & .328 \\
OP6 & 218 & 1 & 7 & 4.79 & 1.481 & -.224 & .165 & -.730 & .328 \\
Valid N & 218 & & & & & & & & \\
(listwise) & & & & & & & & &
\end{tabular}


Appendix IX AMOS Output For Structural Model

\begin{tabular}{|l|l|l|r|r|r|r|r|}
\hline \multicolumn{1}{|c|}{ DV } & & IV & $\begin{array}{r}\text { Estim } \\
\text { ate B }\end{array}$ & \multicolumn{1}{c|}{ S.E. } & \multicolumn{1}{c|}{ C.R. } & \multicolumn{1}{c|}{ P } & $\begin{array}{r}\text { Standardised } \\
\text { Beta }\end{array}$ \\
\hline ENVP & $<---$ & CC & -0.029 & 0.051 & -0.567 & 0.571 & -0.020 \\
\hline EP & $<---$ & CC & 0.618 & 0.077 & 8.012 & $* * *$ & 0.422 \\
\hline OP & $<---$ & CC & 0.261 & 0.064 & 4.070 & $* * *$ & 0.151 \\
\hline SP & $<---$ & CC & 0.025 & 0.091 & 0.271 & 0.786 & 0.014 \\
\hline CC & $<---$ & COMP & 0.388 & 0.062 & 6.240 & $* * *$ & 0.433 \\
\hline ED & $<---$ & COMP & 1.000 & & & & 0.704 \\
\hline EEP & $<---$ & COMP & 0.020 & 0.061 & 0.323 & 0.747 & 0.019 \\
\hline IEP & $<---$ & COMP & 0.080 & 0.056 & 1.434 & 0.152 & 0.075 \\
\hline SM & $<---$ & COMP & 0.154 & 0.053 & 2.908 & 0.004 & 0.146 \\
\hline SS & $<---$ & COMP & 0.653 & 0.075 & 8.699 & $* * *$ & 0.554 \\
\hline SSP & $<---$ & COMP & -0.138 & 0.049 & -2.801 & 0.005 & -0.125 \\
\hline ENVP & $<---$ & ED & -0.190 & 0.033 & -5.828 & $* * *$ & -0.214 \\
\hline EP & $<---$ & ED & 0.623 & 0.045 & 13.913 & $* * *$ & 0.674 \\
\hline OP & $<---$ & ED & 1.000 & & & & 0.915 \\
\hline SP & $<---$ & ED & -0.002 & 0.059 & -0.027 & 0.979 & -0.001 \\
\hline ENVP & $<---$ & EEP & 0.386 & 0.051 & 7.557 & $* * *$ & 0.321 \\
\hline EP & $<---$ & EEP & -0.075 & 0.058 & -1.293 & 0.196 & -0.060 \\
\hline OP & $<---$ & EEP & -0.120 & 0.061 & -1.981 & 0.048 & -0.081 \\
\hline SP & $<---$ & EEP & 0.008 & 0.088 & 0.089 & 0.929 & 0.005 \\
\hline ENVP & $<---$ & IEP & 0.408 & 0.049 & 8.242 & $* * *$ & 0.343 \\
\hline EP & $<---$ & IEP & -0.069 & 0.057 & -1.217 & 0.223 & -0.056 \\
\hline OP & $<---$ & IEP & 0.036 & 0.059 & 0.611 & 0.541 & 0.025 \\
\hline SP & $<---$ & IEP & -0.011 & 0.086 & -0.132 & 0.895 & -0.008 \\
\hline CC & $<---$ & PRES & 0.299 & 0.061 & 4.937 & $* * *$ & 0.334 \\
\hline ED & $<---$ & PRES & 0.202 & 0.095 & 2.127 & 0.033 & 0.142 \\
\hline EEP & $<---$ & PRES & 0.115 & 0.063 & 1.837 & 0.066 & 0.109 \\
\hline IEP & $<---$ & PRES & 0.142 & 0.057 & 2.475 & 0.013 & 0.133 \\
\hline SM & $<---$ & PRES & 0.176 & 0.054 & 3.224 & 0.001 & 0.166 \\
\hline SS & $<---$ & PRES & 0.191 & 0.074 & 2.595 & 0.009 & 0.162 \\
\hline SSP & $<---$ & PRES & 1.000 & & & & 0.909 \\
\hline CC & $<---$ & REG & 0.107 & 0.052 & 2.067 & 0.039 & 0.131 \\
\hline ED & $<---$ & REG & 0.303 & 0.085 & 3.567 & $* * *$ & 0.234 \\
\hline EEP & $<---$ & REG & 0.680 & 0.069 & 9.915 & $* * *$ & 0.711 \\
\hline & & & & & & & \\
\hline
\end{tabular}




\begin{tabular}{|l|l|l|r|r|r|r|r|} 
IEP & $<---$ & REG & 0.742 & 0.066 & 11.227 & $* * *$ & 0.766 \\
\hline SM & $<---$ & REG & 0.784 & 0.067 & 11.706 & $* * *$ & 0.812 \\
\hline SS & $<---$ & REG & 0.416 & 0.070 & 5.958 & $* * *$ & 0.388 \\
\hline SSP & $<---$ & REG & 0.281 & 0.047 & 6.006 & $* * *$ & 0.281 \\
\hline ENVP & $<---$ & SM & 0.494 & 0.052 & 9.473 & $* * *$ & 0.414 \\
\hline EP & $<---$ & SM & -0.096 & 0.059 & -1.628 & 0.104 & -0.077 \\
\hline OP & $<---$ & SM & -0.182 & 0.062 & -2.953 & 0.003 & -0.124 \\
\hline SP & $<---$ & SM & 0.026 & 0.089 & 0.290 & 0.771 & 0.018 \\
\hline ENVP & $<---$ & SS & 0.128 & 0.040 & 3.202 & 0.001 & 0.119 \\
\hline EP & $<---$ & SS & 0.061 & 0.046 & 1.321 & 0.187 & 0.055 \\
\hline OP & $<---$ & SS & 0.103 & 0.048 & 2.174 & 0.03 & 0.078 \\
\hline SP & $<---$ & SS & 0.018 & 0.071 & 0.250 & 0.802 & 0.014 \\
\hline ENVP & $<---$ & SSP & -0.136 & 0.039 & -3.466 & $* * *$ & -0.119 \\
\hline EP & $<---$ & SSP & -0.176 & 0.049 & -3.573 & $* * *$ & -0.147 \\
\hline OP & $<---$ & SSP & -0.211 & 0.055 & -3.831 & $* * *$ & -0.150 \\
\hline SP & $<---$ & SSP & 1.059 & 0.074 & 14.306 & $* * *$ & 0.754 \\
\hline
\end{tabular}

